
apt. Sturtevant 

THE MECHANISM

OF

MENDELIAN HEREDITY 




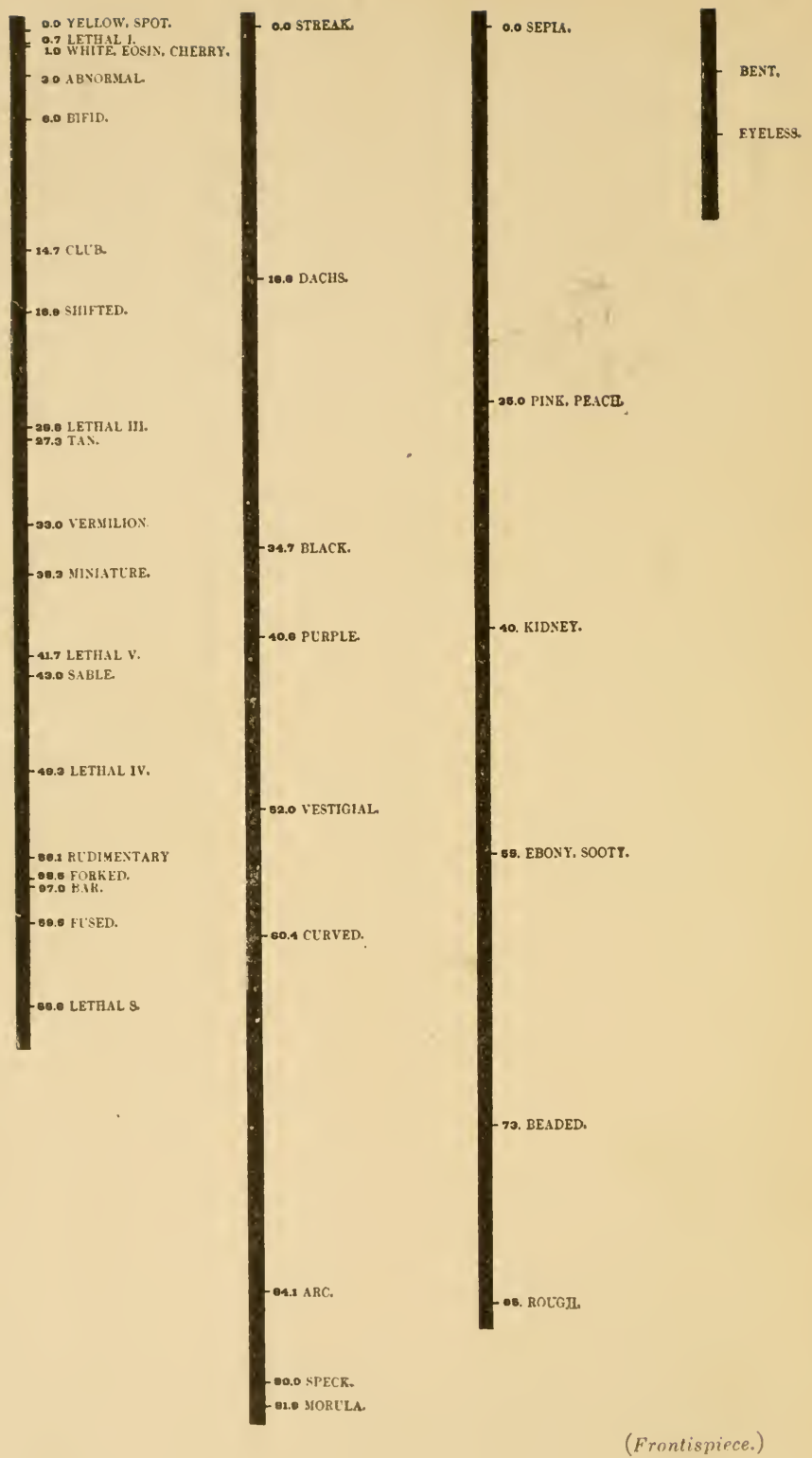

(Frontispiece.) 


\title{
THE MECHANISM
}

$\mathrm{OH}$

\section{IIENDELIAN HEREDITY}

\author{
$\mathrm{BY}$ \\ T. H. MORGAN \\ PROFESSOR OF EXPERIMENTAL ZOOLOGY \\ COLUMBIA UNIVERSITY \\ A. H. STURTEVANT \\ CUTtiNg FELLOW, COLUMBia UNIVERsity \\ H. J. MULLER \\ ASSISTANT IN ZOOLOGY, COLUMBIA UNIVERSITY \\ C. B. BRIDGES \\ FELLOW IN ZOOLOGY, COLUMBIA UNIVERSITY
}

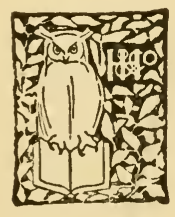

NEIV YORK

HENRY HOLT AND COMPANY 
Copyright, 1915

$\mathrm{BY}$

IIENRY HOLT AND COMPANY

THE MA PLE PKST XOKK PA 
$\tau_{0}$

EDMUND BEECHER WILSON 



\section{PREF A CE}

From ancient times heredity has been looked upon as one of the central problems of biological philosophy. It is true that this interest was largely speculative rather than empirical. But since Mendel's discovery of the fundamental law of heredity in 1865 , or rather since its re-discovery in 1900 , a curious situation has begun to develop. The students of heredity calling themselves geneticists have begun to draw away from the traditional fields of zoology and botany, and have concentrated their attention on the study of Mendel's principles and their later developments. The results of these investigators appear largely in special journals. Their terminology is often regarded by other zoologists as something barbarous, - outside the ordinary routine of their profession. The tendency is to regard genetics as a subject for specialists instead of an all-important theme of zoology and botany. No doubt this is but a passing phase; for biologists can little afford to hand over to a special group of investigators a part of their field that is and always will be of vital import. It would be as unfortunate for all biologists to remain ignorant of the modern advances in the study of heredity as it would be for the geneticists to remain unconcerned 
as to the value for their own work of many special fields of boilogical inquiry. What is fundamental in zoology and botany is not so extensive, or so intrinsically difficult, that a man equipped for his profession should not be able to compass it.

In the following pages we have attempted to separate those questions that seem to us significant from that which is special or merely technical. We have, of course, put our own interpretation on the facts, and while this may not be agreed to on all sides, yet we believe that in what is essential we have not departed from the point of view that is held by many of our co-rrorkers at the present time. Exception may perhaps be taken to the emphasis we have laid on the chromosomes as the material basis of inheritance. Whether we are right here, the futureprobably a very near future-will decide. But it should not pass unnoticed that even if the chromosome theory be denied, there is no result dealt with in the following pages that may not be treated independently of the chromosomes; for, we have made no assumption concerning heredity that cannot also be made abstractly without the chromosomes as bearers of the postulated hereditary factors. Why then, we are often asked, do you drag in the chromosomes? Our answer is that since the chromosomes furnish exactly the kind of mechanism that the Mendelian laws call for; and since there is an ever-increasing body of information that points clearly to the chromosomes as the bearers of the 
Mendelian factors, it would be folly to close one's eyes to so patent a relation. Moreover, as biologists, we are interested in heredity not primarily as a mathcmatical formulation but rather as a problem concerning the cell, the egg, and the sperm.

$$
\text { T. H. M. }
$$




\title{
CONTEN'TS
}

\author{
CHAPTER I
}

MENDELIAN SEGREGATION AND THE CHROMOSOMES

Introduction. The Groups of Linked Factors and the Chromosomes ..................... I The Inheritance of One Pair of Factors. . . . . . . . . o

The Inheritance of Two or more Pairs of Factors . . . . . . 20

\section{CHAPTER II}

\section{TYPES OF MENDELIAN HEREDITY}

Dominance and Recessiveness . . . . . . . . . . . . . 27

Manifold Effects of Single Factors . _ . . . . . . . . . . 32

Similar Effects Produced by Different Factors. . . . . . . 36

Modification of the Effects of Factors . . . . . . . . 38

I. By Environmental Influences . _ . . . . . 38

II. By Developmental Influences . . . . . . . . . 42

1II. By the Influence of Other Factors . . . . . . . . 45

IV. Conclusion . . . . . . . . . . . 46

\section{CHAPTER III}

\section{LINKAGE}

Examples Illustrating "Coupling" . . . . . . . . . . 48

Examples Illustrating "Repulsion" _. . . . . . . . . . . . 51

Examples of Different Frequencies of Crossing Over . . . . 52

The Mechanism of Crossing Over . . . . . . . . . 59

Double Crossing Over . . . . . . . . . 62

The Principle of Interference . . . . . . . . . . . . 64

The Linear Arrangement of Factors shown by Linkage Relations . 64

Linkage in Other Animals and in Plants . . . . . . . . . 70

The Reduplication Hypothesis . . . . . . . . . . . . 74 


\section{CHAPTER IV}

\section{SEX INHERITANCE}

The Drosophila or XX-XY Type . . . . . . . . . 78

The Abraxas or WZ-ZZ Type . . . . . . . . . . . . . . . . . 83

What are Sex Factors? . . . . . . . . . . . . . . . 90

\section{CHAPTER V}

\section{THE CHROMOSOMES AS BEARERS OF HEREDITARY MATERIAL}

The Evidence from Embryology . . . . . . . . . . . . . 108

The Individuality of the Chromosomes . . . . . . . . . . . . 118

The Chromosomes during the Maturation of the Germ Cells . . . 122

Crossing Over. . . . . . . . . . . . . . . . . . . 131

Cytoplasmic Inheritance . . . . . . . . . . . . . . 135

\section{CHAPTER VI}

THE CORRESPONDENCE BETWEEN THE DISTRIBUTION OF THE CHROMOSONES AND OF' THE GENETIC FACTORS

Parallelism between the Distribution of Chromosomes and of Factors 140

1. In Cases of Normal Distribution . . . . . . . . . . . 140

2. In Crosses between Species . . . . . . . . . . . 141

3. In Mutant Races . . . . . . . . . . . . . . 146

4. Tetraploid Races . . . . . . . . . . . . . 147

Identity of Distribution of the $\mathrm{X}$-chromosomes and of Sex-

linked Factors. . . . . . . . . . . . . . 148

1. In Ordinary Crosses . . . . . . . . . . . . . . 148

2. In Cases of Non-disjunction _. . . . . . . 149

\section{CHAPTER VII}

\section{MULTIPLE ALLELOMORPHS}

Definition of Multiple Allelomorphs . . . . . . . . . 155

Examples of Multiple Allelomorphs . . . . . . . . . . . 155

The Alternative Interpretations of Identical Loci and Complete

Linkage . . . . . . . . . . . . . 157 


\section{CHAPTER VIII}

MULTIPLE FACTORS

The Meaning of the term "Multiple Factors" . . . . . . . 172

Examples of Multiple Factors . . . . . . . . . . . 172

Selection and Multiple Factors . . . . . . . . . . . 195

\section{CHAPTER IX}

\section{THE FACTORIAL HYPOTHESIS}

On the Relation between Factors and Characters . . . . . . 208

1. The Organism-as-a-Whole Objection . . . . . . . . 211

2. The Invariability of the Factor and the Variability in the

Character . . . . . . . . . . 212

3. So-called Contamination of Allelomorphs . . . . . . . 214

4. Fractionation . . . . . . . . . . . 214

5. The Presence and Absence Hypothesis . . . . . . . 216

Weismann's Præformation Hypothesis and the Factorial Theory : 223

\section{APPENDIX}

Methods of Breeding Drosophila . . . . . . . . . . 229

Acknowledgments . . . . . . . . . . . 235

Bibliography . . . . . . . . . . . . 237

$\mathrm{I}_{\text {NDEX } \ldots \ldots \ldots \ldots \ldots \ldots \ldots \ldots} \ldots \ldots \ldots \ldots$ 



\section{THE MECHANISM OF MENDELIAN HEREDITY}

\section{CHAPTER I \\ MENDELIAN SEGREGATION AND THE CHROMOSOMES}

Mendel's law was announced in 1865. Its fundamental principle is very simple. The units contributed by two parents separate in the germ cells of the offspring without having had any influence on each other. For example, in a cross between yellow-seeded and green-seeded peas, one parent contributes to the offspring a unit for yellow and the other parent contributes a unit for green. These units separate in the ripening of the germ cells of the offspring so that half of the germ cells are yellow bearing and half are green bearing. This separation occurs both in the eggs and in the sperm.

Mendel did not know of any mechanism by which such a process could take place. In fact, in $186 j$ very little was known about the ripening of the germ cells. But in 1900, when Mendel's long-forgotten discovery was brought to light once more, a mechanism had been discovered that fulfils exactly the Mendelian requirements of pairing and separation.

The sperm of every species of animal or plant 
carries a definite number of bodies called chromosomes. The egg carries the same number. Consequently, when the sperm unites with the egg, the fertilized egg will contain the double number of chromosomes. For each chromosome contributed by the sperm there is a corresponding chromosome contributed by the egg, i.e., there are two chromosomes of each kind, which together constitute a pair.

When the egg divides (Fig. 1, $a-d$ ), every chromosome splits into two chromosomes, and these two daughter chromosomes then move apart, going to opposite poles of the dividing cell (Fig. 1,c). Thus each daughter cell (Fig. 1, $d$ ) receives one of the daughter chromosomes formed from each original chromosome. The same process occurs in all cell divisions, so that all the cells of the animal or plant come to contain the double set of chromosomes.

The germ cells also have at first the double set of chromosomes, but when they are ready to go through the last stages of their transformation into sperm or eggs the chromosomes unite in pairs (Fig. 1,e). Then follows a different kind of division (Fig. 1, f) at which the chromosomes do not split but the members of each pair of chromosomes separate and each member goes into one of the daughter cells (Fig. $1, g, h$ ). As a result each mature germ cell receives one or the other member of every pair of chromosomes and the number is reduced to half. Thus the behavior of the chromosomes parallels the behavior of the Mendelian units, for in the germ cells each unit derived from the father separates from the 
corresponding unit derived from the mother. These units will henceforth be spoken of as factors; the two factors of a pair are called allelomorphs of each
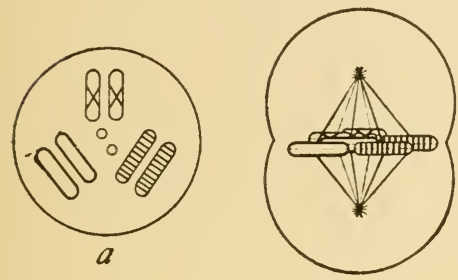

6
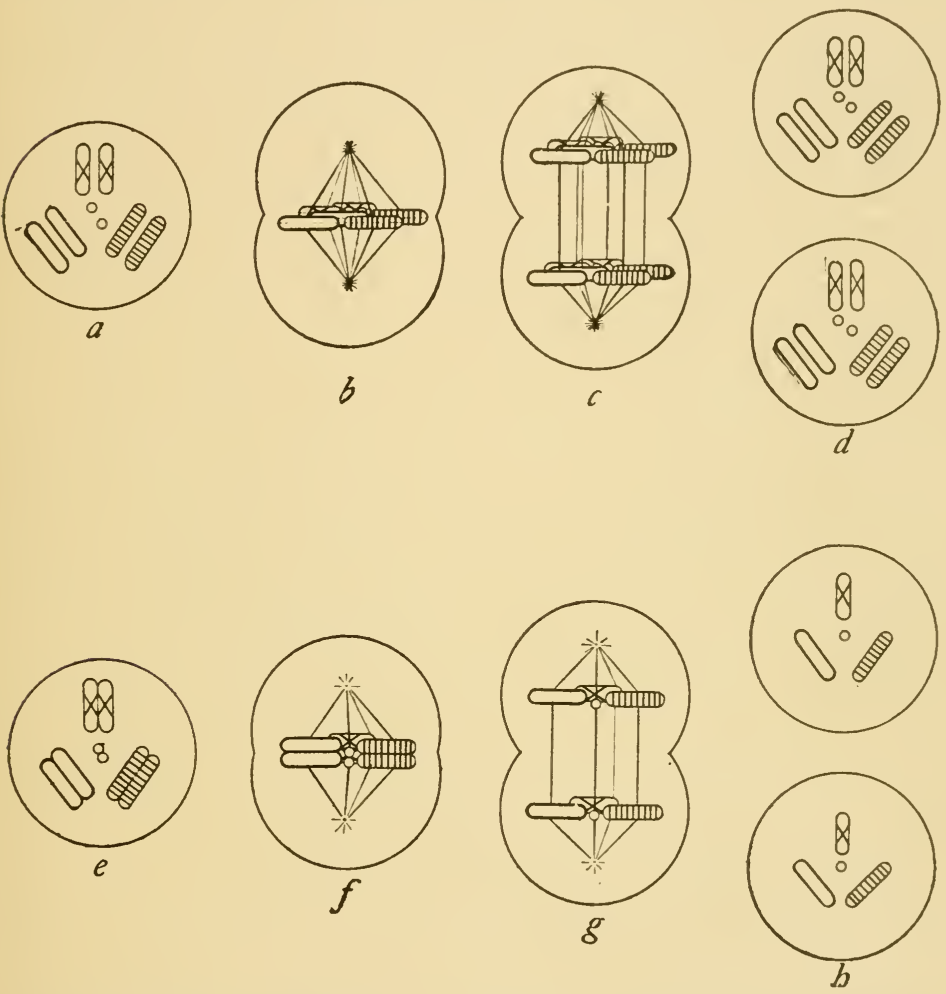

FIG. 1.-In the upper line, four stages in the division of the egg (or of a body cell) are represented. Every chromosome divides when the cell divides. In the lower line the "reduction division" of a germ cell, after the chromosomes have united in pairs, is represented. The members of each of the four pairs of chromosomes separate from each other at this division.

other. Their separation in the germ cells is called segregation.

The possibility of explaining Mendelian phenomena 
by means of the manœuvers of the chromosomes seems to have occurred to more than one person, but Sutton was the first to present the idea in the form in which we recognize it today. Moreover, he not only called attention to the fact above mentioned, that both chromosomes and hereditary factors undergo segregation, but showed that the parallelism between their methods of distribution goes even further than this. Mendel had found that when the inheritance of more than one pair of factors is followed, the different pairs of factors segregate independently of one another. Thus in a cross of a pea having both green seeds and tall stature with a pea having yellow seeds and short stature, the fact that a germ cell receives a particular member of one pair (e.g., yellow) does not determine which member of the other pair it receives; it is as likely to receive the tall as the short. Sutton pointed out that in the same way the segregation of one pair of chromosomes is probably independent of the segregation of the other pairs.

It was obvious from the beginning, however, that there was one essential requirement of the chromosome view, namely, that all the factors carried by the same chromosome should tend to remain together. Therefore, since the number of inheritable characters may be large in comparison with the number of pairs of chromosomes, we should expect actually to find not only the independent behavior of pairs, but also cases in which characters are linked together in groups in their inheritance. Even in species where a limited 
number of Mendelian units are known, we should still expect to find some of them in groups.

In 1906 Bateson and Punnett made the discovery of linkage, which they called gametic coupling. They found that when a sweet pea with factors for purple flowers and long pollen grains was crossed to a pea with factors for red flowers and round pollen grains, the two factors that came from the same parent tended to be inherited together. Here was the first case that gave the sort of result that was to be expected if factors were in chromosomes, although this relation was not pointed out at the time. In the same year, however, Lock called attention to the possible relation between the chromosome hypothesis and linkage.

In other groups a few cases of coupling became known, but nowhere had the evidence been sufficiently ample or sufficiently studied to show how frequently coupling occurs. Since 1910, however, in the fruit fly, Drosophila ampelophila, a large number of new characters have appeared by mutation, and so rapidly does the animal reproduce that in a relatively short time the inheritance of more than a hundred characters has been studied. It became evident very soon that these characters are inherited in groups. There is one great group of characters that are sex linked. There are two other groups of characters slightly greater in number. Finally a character appeared that did not belong to any of the other groups, and a year later still another character appeared that was linked to the last one but was independent of all the 
other groups. Hence there are four groups of characters in Drosophila. A partial list of these groups is given in the following table:

\section{Group I}

Abnormal

Bar

Bifid

Bow

Cherry

Chrome

Cleft

Club

Depressed

Dotted

Eosin

Facet

Forked

Furrowed

Fused

Green

Jaunty I

Lemon

Lethal 1

Lethal 1a

Lethal 2

Lethal 3

Lethal 3a

Lethal 4

Lethal 5

Lethal 6

Lethal 7

Lethal B

Lethal Sa

Lethal Sb

Lethal Sc

Miniature

Noteh

Reduplicated

Ruby

Rudimentary

Sable

Shifted

Short

Skee

Spoon

Spot

Tan

Truncate intens.

Vermilion

White

Yellow

\section{Group II}

Antlered

Apterous

Arc

Balloon

Black

Blistered

Comma

Confluent

Cream II

Curved

Dachs

Extra vein

Fringed

Jaunty

Limited

Little crossover

Morula

Olive

Plexus

Purple

Speck

Strap

Streak

Tip

Trefoil

Truncate

Vestigial

$\begin{array}{ll}\text { Group III } & \text { Group IV } \\ \text { Band } & \text { Bent } \\ \text { Beaded } & \text { Eyeless }\end{array}$

Cream III

Deformed

Dwarf

Ebony

Giant

Kidney

Low crossover

Maroon

Peach

Pink

Rough

Safranin

Sepia

Sooty

Spineless

Spread

Truncate intens.

Trident

White head

White ocelli 
The four pairs of chromosomes of the female of Drosophila are shown in Fig. 2 (to the left). There are three pairs of large chromosomes and one pair of small chromosomes. One of the four is the pair of sex chromosomes ( $\mathrm{X}$ chromosomes). In the male, Fig. 2 (to the right), there are likewise three pairs of large chromosomes and a smaller pair. The two sex chromosomes in the male are here represented as differ-

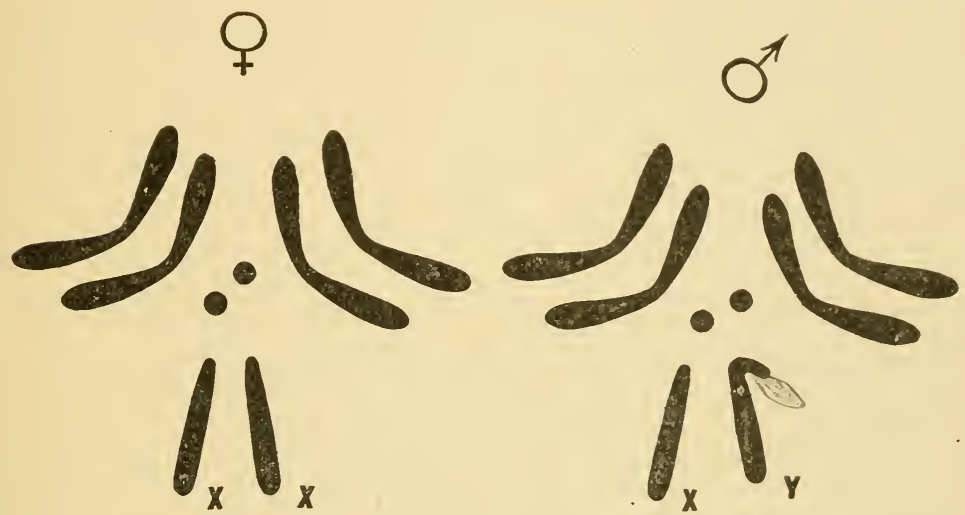

F1G. 2.-Diagram of female and of male group (duplex) of chromosomes of Drosophila ampelophila showing the four pairs of chromosomes. The hook on the Y chromosome is a convention. The members of each pair are usually found together, as here.

ing from each other in shape. In the diagrams the $\mathrm{Y}$ chromosome is represented as hook shaped, but this is intended only as a convention. It is true that in the case of non-disjunction where the $I$ chromosome has been transferred to the female it has this hook shape, but as yet it has not been possible to identify the $\mathrm{Y}$ chromosome as hook shaped in the male. Stevens' work had seemed to show 
that the $\mathrm{X}$ chromosome is attached to another chromosome and that there is no $\mathrm{Y}$ chromosome. In the earlier papers on Drosophila this relation of the chromosomes was assumed to be correct and the female was represented as $\mathrm{XX}$ and the male as $\mathrm{XO}$.

In Drosophila, then, there is a numerical correspondence between the number of hereditary groups and the number of the chromosomes. Moreover, the size relations of the groups and of the chromosomes correspond. The method of inheritance of the factors carried by these chromosomes will now be considered more in detail.

\section{The Inheritance of one Pair of Factors}

The inheritance of a single pair of characters may be illustrated by the following examples from Drosophila, one from each of the four groups.

The mutant stock called vestigial is so characterized because it has only small vestiges of the wings. If a fly with vestigial wings is mated to the wild type with long wings (Fig. $3, \mathrm{P}_{1}$ ), the offspring will have long wings (Fig. $3, \mathrm{~F}_{1}$ ). If these hybrid flies of the first generation (the first filial generation, or $\mathrm{F}_{1}$ ) are mated to each other, their offspring (or $\mathrm{F}_{2}$ ) will be of two sorts: some will have long wings and others will have vestigial wings. There will be three times as many flies with long wings as flies with vestigial wings. This is the Mendelian ratio of $3: 1$ that appears when a single pair of characters is involved. 

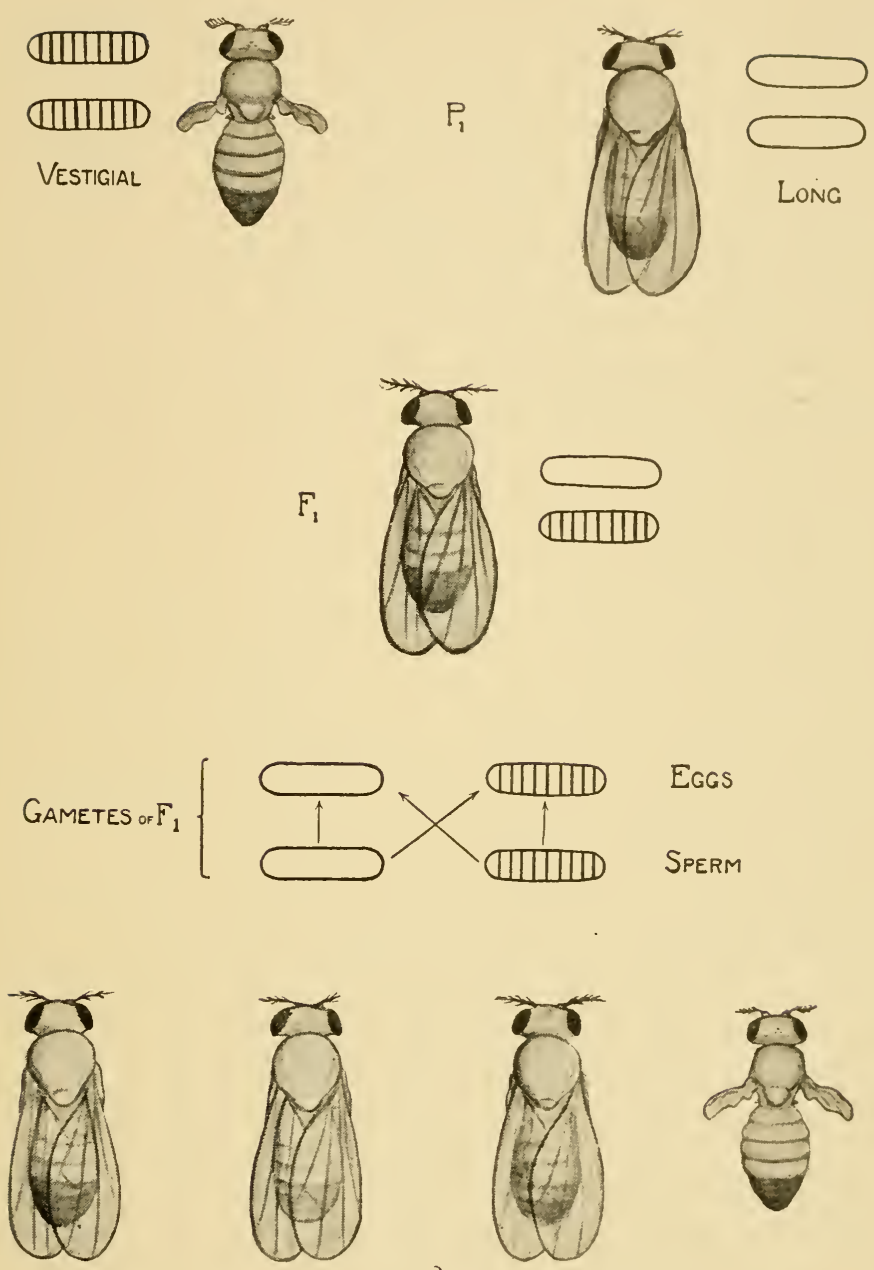

$\mathrm{F}_{2}$
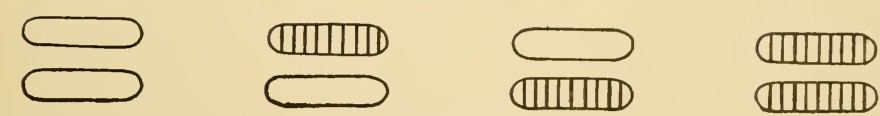

FIG. 3.-Vestigial winged by long winged (wild type) fly. The second chromosome that carries the recessive factor for vestigial is cross-barred, the corresponding chromosome of the normal is plain. 
If the factors for vestigial wings are carried by a pair of chromosomes (the cross-barred chromosomes in Fig. 1) then at the ripening of the germ cells (eggs and sperm) such a pair of chromosomes will come together (Fig. 1,e) and then separate (Fig. 1,g); so that each germ cell (Fig. $1, h$ ) will have one such chromosome and not the other.

If such a sperm cell fertilizes an egg of the wild fly that contains a similar group of chromosomes, ex-

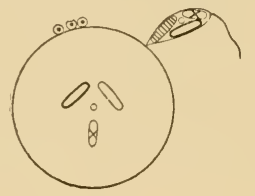

A

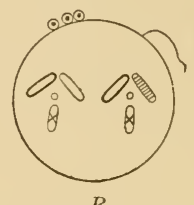

$B$

FIG. 4.-Diagram to illustrate the fertilization of an egg by a sperm $A$. One chromosome in the egg differs from the corresponding (homologous) chromosome in the sperm. The fertilized egg (zygote) with the double (duplex) number of chromosomes in $B$.

cept that the corresponding chromosome carries the factor for long wings (Fig. 4, $A$ ), the result will be to produce a fertilized egg (Fig. $4, B$ ) in which one member of the pair of chromosomes in question comes from the mother and carries the factor for long, and the other comes from the father and carries the factor for vestigial wing. Since this egg with both factors present produces a fly with long wings, the vestigial character is said to be recessive to the long; or conversely the long is said to be dominant to the vestigial character.

When the eggs and the sperm of hybrid flies of this origin come to maturity, the homologous chromo- 
somes conjugate in pairs, as shown diagrammatically in Fig. 5, $b$. The chromosomes then separate (Fig. 5, $c$ and $d$ ) at the time of division of the cell, and one of the resulting daughter cells gets the chromosome bearing the vestigial, and the other daughter cell gets the homologous chromosome, bearing the long factor. Hence, there will be two kinds of eggs in the female and two kinds of spermatozoa in the male. When two such hybrid flies mate with each other, any
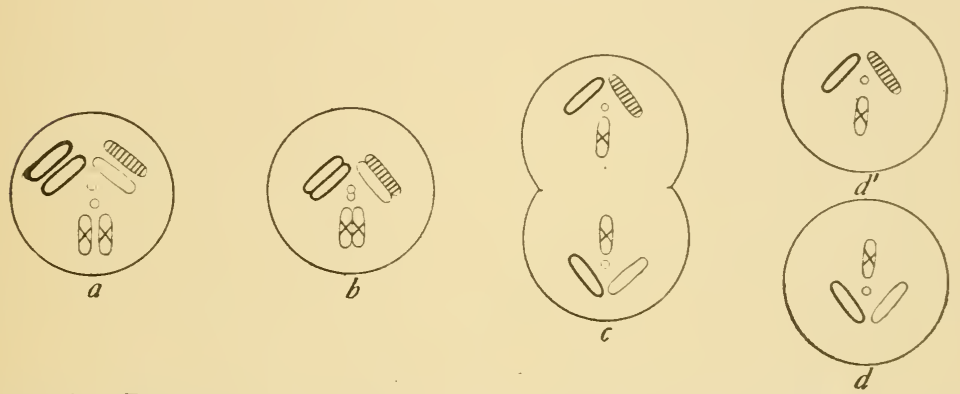

FIG. 5.-Diagram to illustrate in a heterozygous individual the conjugation and segregation of the chromosomes eluring "reduction."

sperm may meet and fertilize any egg. The possible combinations that result, and the frequency with which they occur, are shown in the next diagram (Fig. 6).

As shown in this diagram, a spermatozoon bearing the factor for long wings fertilizing an egg bearing the same factor produces a fly pure for long wings; a spermatozoon bearing the factor for long wings fertilizing an egg bearing the factor for vestigial wings produces a hybrid fly that has long wings. Hence we say the long dominates the vestigial character. 
Similarly, a spermatozoon bearing the factor for vestigial wings fertilizing an egg bearing the factor for long wings produces a hybrid with long wings; a spermatozoon bearing the factor for vestigial wings

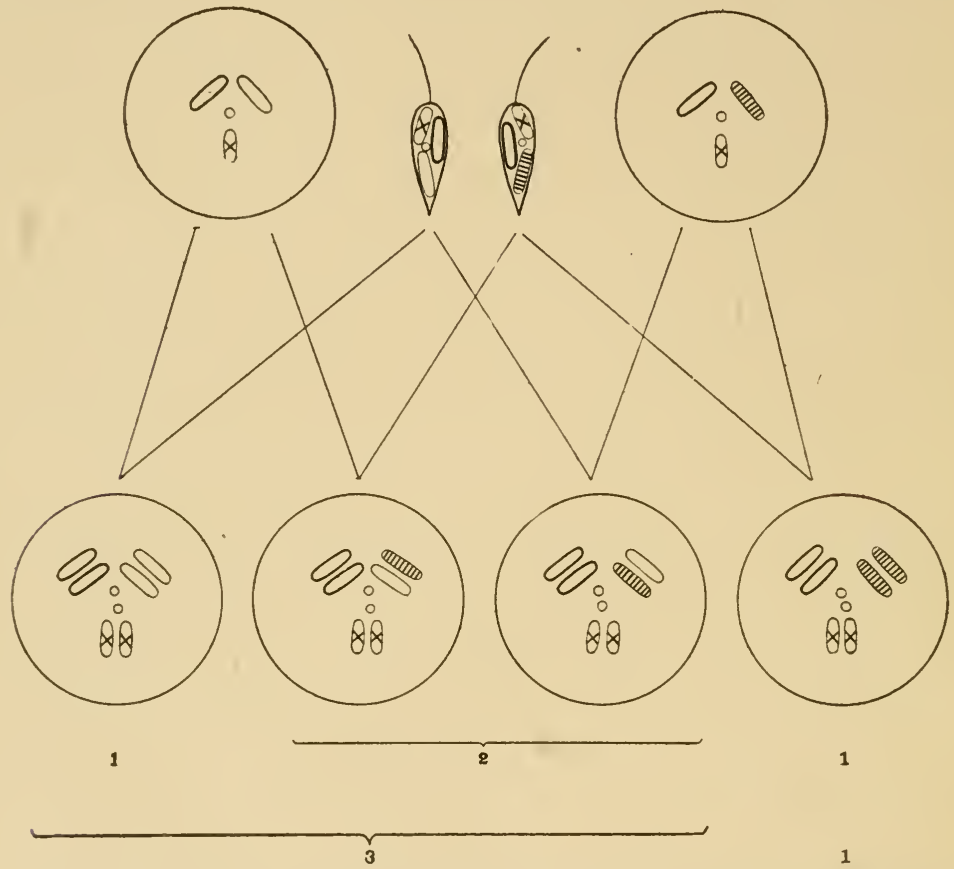

FIG. 6.-Diagram to illustrate how by the random meeting of two kinds of sperm and two kinds of eggs the typical $3: 1$ ratio results.

fertilizing an egg bearing the factor for vestigial wings produces a fly pure for vestigial wings.

Since the sperm and the eggs meet at random there should be 1 pure long, to 2 heterozygous long, to 1 vestigial; or putting together all flies with long wings, 3 long to 1 vestigial. Three to one is the character- 
istic Mendelian ratio when one pair of characters is involved.

In another mutant stock, ebony, the body and wings are very dark in contrast to the wild fly whose color is "gray." Gray is used to designate the color of the wild fly, whose wings are gray, but whose body is yellowish with black bands on the abdomen. If ebony is crossed to gray the offspring $\left(\mathrm{F}_{1}\right)$ are gray but are somewhat darker than the ordinary wild flies. When these hybrids are inbred they give $\left(\mathrm{F}_{2}\right) 1$ gray, to 2 intermediates, to 1 ebony. The group of intermediates in the second generation $\left(\mathrm{F}_{2}\right)$ can not be separated accurately from the pure gray type. If they are counted as gray, the result is three grays to one ebony.

Since ebony and gray assort independently of long and vestigial, as will be shown later, the factor for ebony must be supposed to be carried by a chromosome of a different pair from the one that carries vestigial. Since this chromosome behaves in the same way as does the one that bears the vestigial factor, the scheme used for vestigial will apply here also.

Another mutant stock is characterized by small eyes, and since in the extreme form it may lack one or both eyes entirely (Fig. 7), the name "eyeless" has been given to this mutànt. When this stock is bred to wild flies the offspring have normal eyes. These inbred give three normal to one eyeless fly. As shown in the table on page 6, this character belongs in still another, the fourth, group, and its 
mode of inheritance is explicable on the supposition that it lies in the fourth pair of chromosomes.

For an adequate understanding of the inheritance
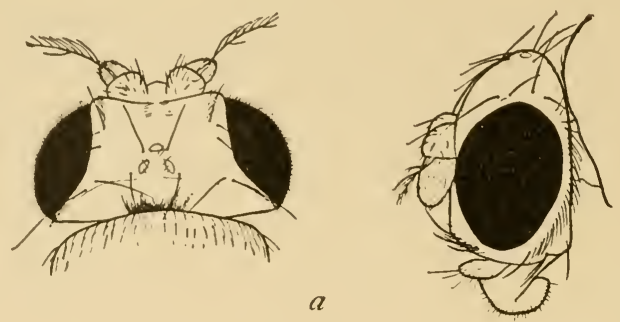

$a^{\prime}$
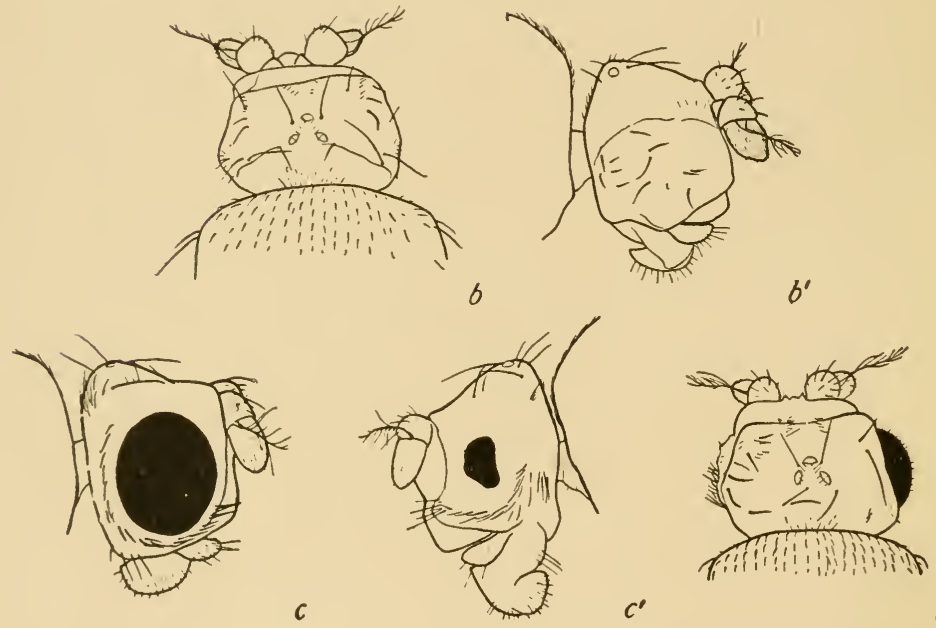

Fig. 7.-Normal eyes of Drosophila $a, a^{\prime}$. Eyeless $b-d ; b, b^{\prime}$ top and side view of head of fly without eyes; $c, c^{\prime}$ right and left eyes of another fly; $d$, small eye on right side, none on left.

of factors in the first group it will be necessary to consider the distribution of the sex chromosomes (Fig. 8). In the female of Drosophila there are two $\mathrm{X}$ chromosomes (XX). After the conjugation and 
separation of the $\mathrm{X}$ chromosomes in the female there is one $\mathrm{X}$ chromosome left in each egg. In the male there is one $\mathrm{X}$ chromosome and another chromosome, its mate, called the $\mathrm{Y}$ chromosome. Hence in the male there are two classes of spermatozoa: one containing $\mathrm{X}$, the other $\mathrm{Y}$. If a $\mathrm{Y}$-bearing spermatozoon should

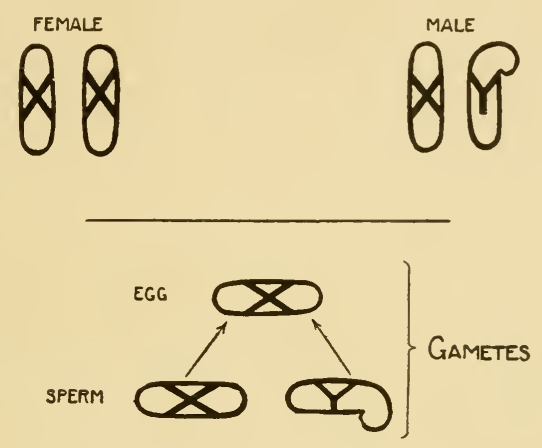

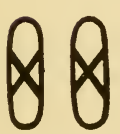

FEMALE

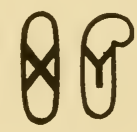

MALE

FIG. 8.-Diagram to show the history of the sex chromosomes from one generation to the next.

fertilize an egg the result will be an XY individual, or male. It is evident that the $\mathrm{Y}$ chromosome is found only in the males, while an $\mathrm{X}$ chromosome passes not only from female to female, but also from female to male and from male to female.

As will be shown now, certain factors follow the distribution of the $\mathrm{X}$ chromosomes and are there- 
fore supposed to be contained in them. These factors are said to be sex linked.

The inheritance of white eyes may serve as an illustration for the entire group of sex linked characters. If a white-eyed male is bred to a red-eyed female (wild type) (Fig. 9), the sons and daughters $\left(\mathrm{F}_{1}\right)$ have red eyes. If these are inbred the offspring $\left(\mathrm{F}_{2}\right)$ are three reds to one white, but the white-eyed flies are all males. If we trace the history of the sex chromosomes we can see how this happens.

In the red-eyed mother, each egg contains an $\mathrm{X}$ chromosome bearing a factor for red eyes. In the white-eyed father, half of the spermatozoa contain an $\mathrm{X}$ chromosome which carries a factor for white eyes, while the other half contain a Y chromosomewhich carries no factors (Fig. 9). Any egg fertilized by an $\mathrm{X}$-bearing spermatozoon of the white-eyed father will produce a female that has one red-producing $\mathrm{X}$ chromosome and one white-producing $\mathrm{X}$ chromosome (Fig. 9). Her eyes are red, because red dominates white. Any egg fertilized by a Y-bearing spermatozoon of the white-eyed father will produce a son (Fig. 9) that has red eyes, because his $\mathrm{X}$ chromosome brings in the red factor from the mother, while the $\mathrm{Y}$ chromosome does not bring in any dominant factor. At the ripening of the germ cells in the $F_{1}$ female the number of chromosomes is reduced to half. There result two kinds of eggs, half with the red-bearing and half with the white-bearing $\mathrm{X}$ (Fig. 9). Similarly in the male there will be two classes of sperm, half with the red-bearing $\mathrm{X}$ chromosome, 


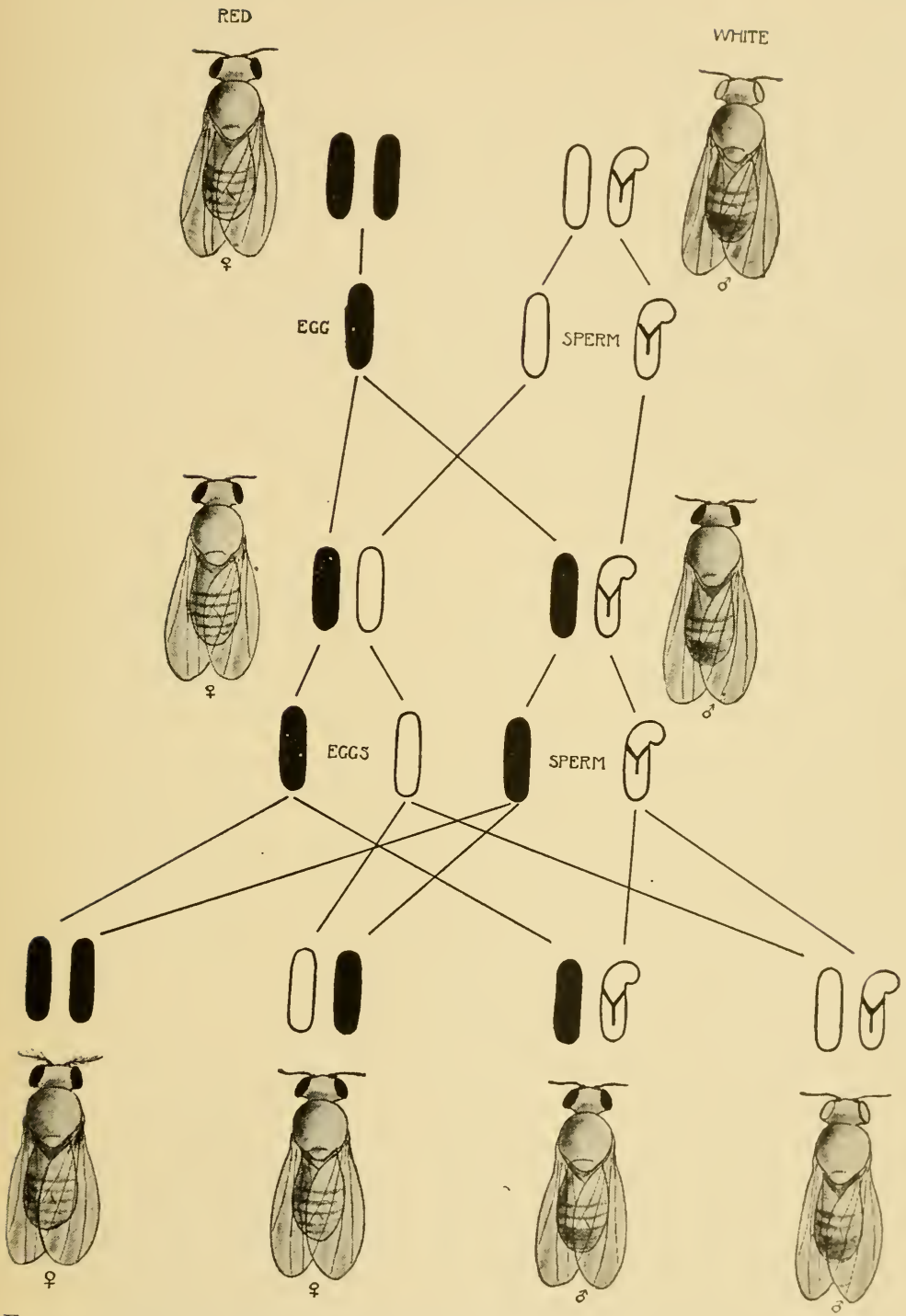

FIG. 9.-Red-eyed female by white-eyed male (D. ampelophila). This is the reciprocal of the cross shown in Fig. 10. 
half with the indifferent $\mathrm{Y}$ chromosome. Random meeting of eggs and sperm will give the result shown in the lower line of the diagram. There will be a $3: 1$ ratio, as in other Mendelian crosses, but the white individuals in $\mathrm{F}_{2}$ will be males. The factor for red in the $\mathrm{F}_{1}$ male will always stay in the $\mathrm{X}$ chromosome, so that all the female-producing spermatozoa will carry red, and consequently all $\mathrm{F}_{2}$ females will be red. The males will have red eyes if they receive the redbearing chromosome from their mother and white eyes if they receive the white-bearing chromosome from their mother.

The reciprocal cross is made by mating a whiteeyed female to a red-eyed male (Fig. 10). The daughters will have red eyes and the sons white eyes. If these are inbred their offspring will be red and white in equal numbers, and not the usual three reds to one white. The explanation of this new ratio is at once apparent as soon as the history of the sex chromosomes is studied.

The two X chromosomes in the white-eyed mother carry the factor for white eyes. After ripening, each egg carries one white-bearing $\mathrm{X}$ chromosome. The single $\mathrm{X}$ chromosome of the female-producing spermatozoon of the red-eyed father carries the factor for red eyes; the male-producing spermatozoa carry the $Y$ chromosome which, as stated above, is indifferent. Any egg fertilized by a spermatozoon containing the red-bearing $\mathrm{X}$ chromosome will produce a red daughter, because red dominates white. Conversely, any egg fertilized by the Y-bearing male-producing sper- 


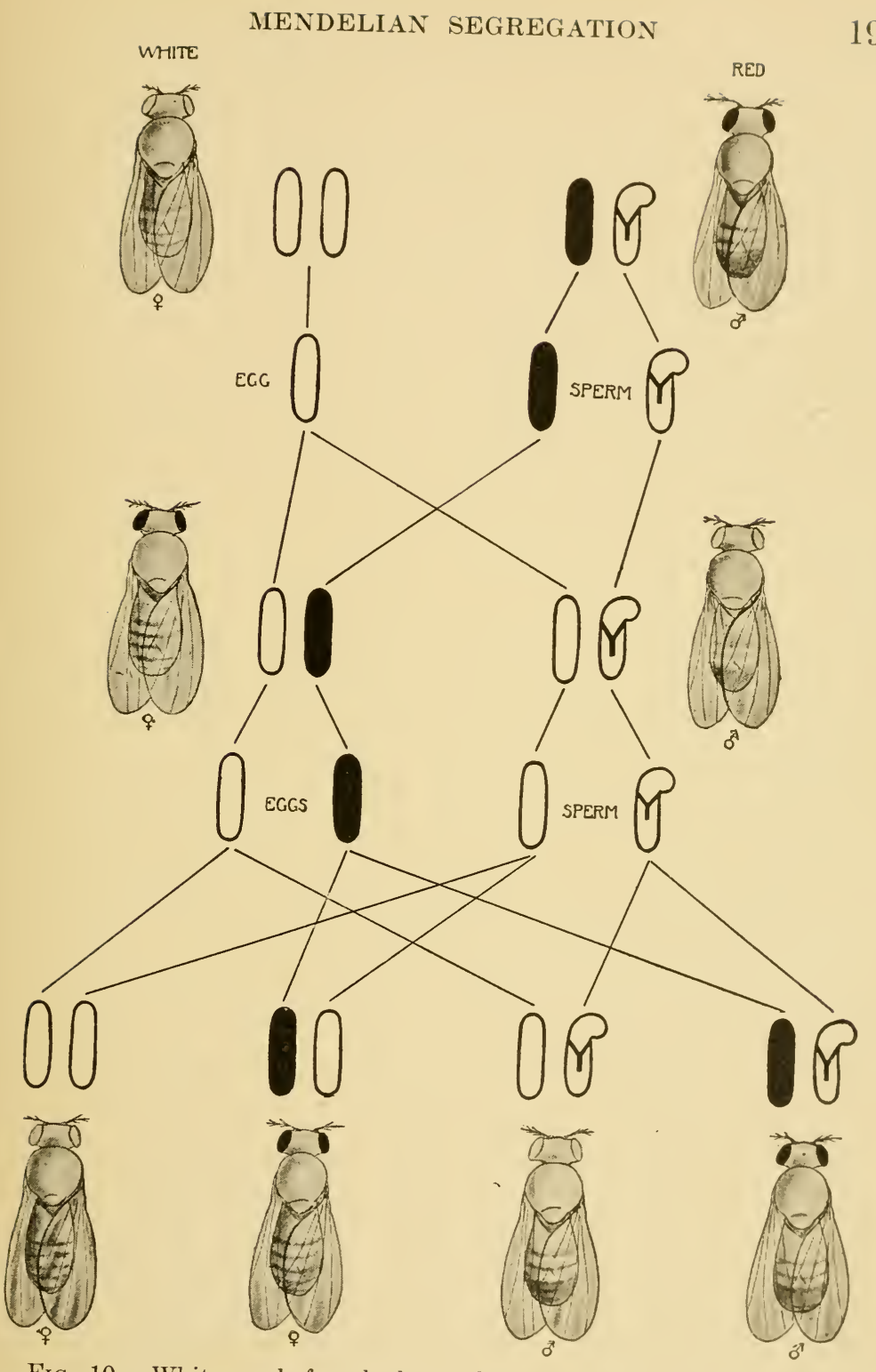

Frg. 10.-White-eyed female by red-eyed male (D. ampelophila). The factors for these characters are carried by the $\mathrm{X}$ chromosomes, the factor for red by the black $\mathrm{X}$, and the factor for the white by the plain $\mathrm{X}$. The history of the chromosomes is shown in the middle of the diagram. 
matozoon will produce a white-eyed son, because the only $\mathrm{X}$ chromosome that the son contains is derived from his mother, both of whose $\mathrm{X}$ chromosomes carry a white-producing factor.

When these red-eyed daughters and white-eyed sons are inbred the possible combinations are shown in the lower line of the diagram (Fig. 10).

There will be two kinds of eggs, one containing a redbearing, the other a white-bearing, $\mathrm{X}$ chromosome. The female-producing spermatozoa will contain a white-bearing $\mathrm{X}$ chromosome; the male-producing spermatozoa will contain a $\mathrm{Y}$ chromosome. A redbearing egg fertilized by a female-producing spermatozoon will produce a red-eyed female; a whitebearing egg fertilized by a female-producing spermatozoon will produce a white-eyed female. A red-bearing egg fertilized by a male-producing spermatozoon will produce a red-eyed male; a white-bearing egg fertilized by a male-producing spermatozoon will produce a white-eyed male. The resulting ratio is 1 red to 1 white, in both sexes.

The distribution of the chromosomes explains how in one cross the Mendelian ratio of $3: 1$ obtains, and also how in the reciprocal cross there is a $1: 1$ ratio.

The Inheritance of Two or More Independent PAIRS OF FACTORS

The application of the chromosome hypothesis to crosses between races that differ in two pairs of factors is illustrated by the following example (Fig. 
11). If a vestigial gray fly is mated to a long-winged ebony fly, all the offspring $\left(F_{1}\right)$ will have long wings and gray (or slightly darker) body color. If these hybrids $\left(F_{1}\right)$ are inbred, offspring $\left(F_{2}\right)$ will be produced in the ratios:

9 Flies with long wings and gray body color.

3 Flies with vestigial wings and gray body color.

3 Flies with long wings and ebony body color.

1 Fly with vestigial wings and ebony body color.

In the diagram (Fig. 11) two pairs of chromosomes, the second and the third pairs, are represented by the following conventions: The cross-barred chromosomes, each of which carries a factor for vestigial, are the second pair. The third pair, that contains the factors for ebony, is represented as black. The third pair of chromosomes in the vestigial fly is "normal" in respect to ebony. Correspondingly the second pair of chromosomes in the ebony fly is "normal" in respect to vestigial.

Each germ cell of the vestigial-gray parent will contain one chromosome with the factor for vestigial and one for gray, and each germ cell of the longwinged ebony parent will contain one chromosome with the factor for long and one for ebony. The hybrid (Fig. 11) will contain, therefore, a pair of chromosomes, one of which carries vestigial, the other long; and will also contain another pair, one of which carries ebony, the other gray.

In the maturation of the germ cells of the hybrid, the members of each pair separate from each other as shown in Fig. 11 in the gametogenesis of $F_{1}$. 

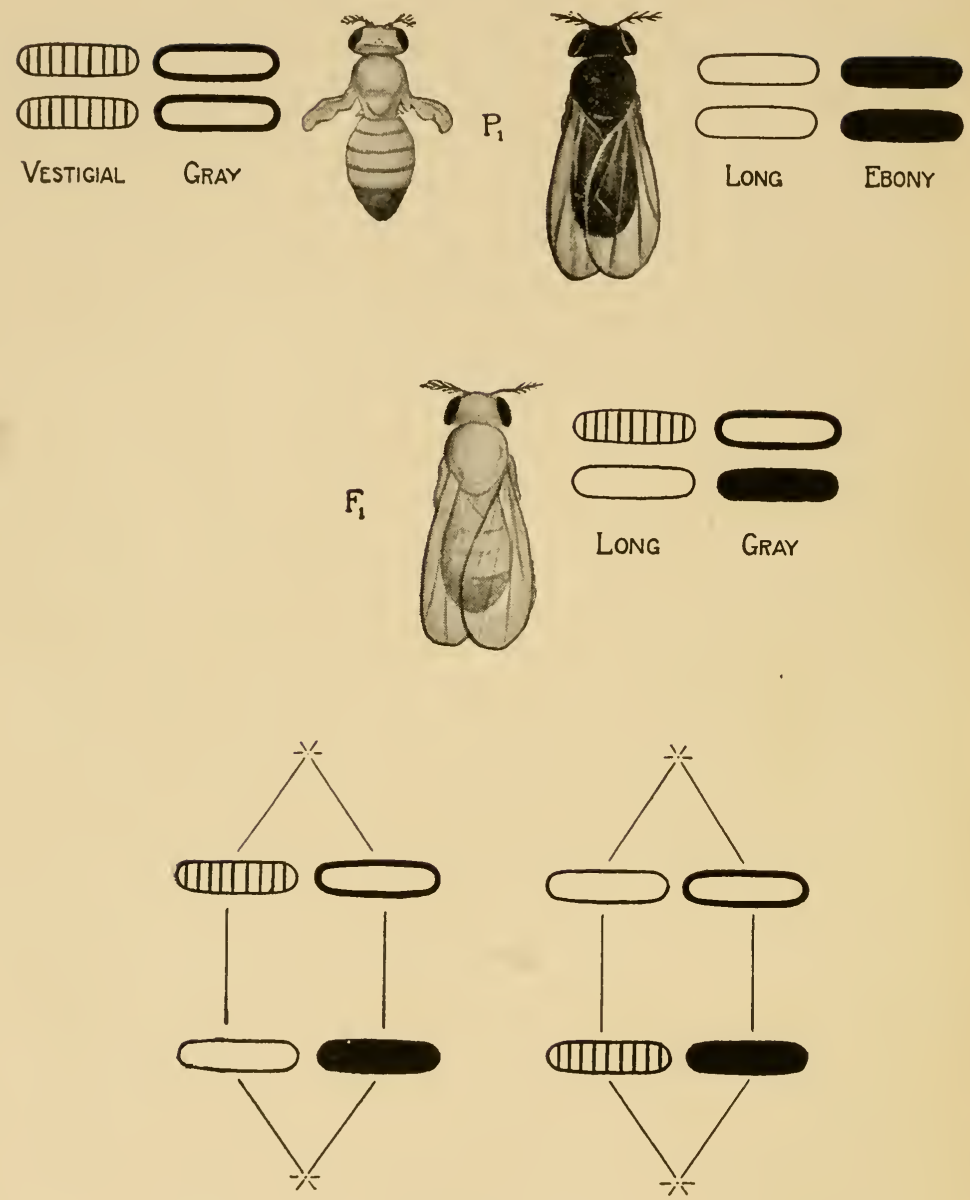

\section{Gametogenesis of $F_{1}$}

FIG. 11.-Vestigial gray by long ebony fly, to illustrate the inheritance of two pairs of characters. The factor for vestigial is carried by the second, the factor for ebony by the third chromosome pair. In the lower part of the figure the two modes of separation, of the two pairs of chromosomes involved here, are represented. Four kinds of gametes result. These four kinds combine at random in fertilization, so that 16 classes are procluced in $\mathrm{F}_{2}$, as shown in the next figure. 
The two pairs of chromosomes "assort" on the spindle in either one of the two ways shown in the diagram; resulting in four and only four kinds of gametes.

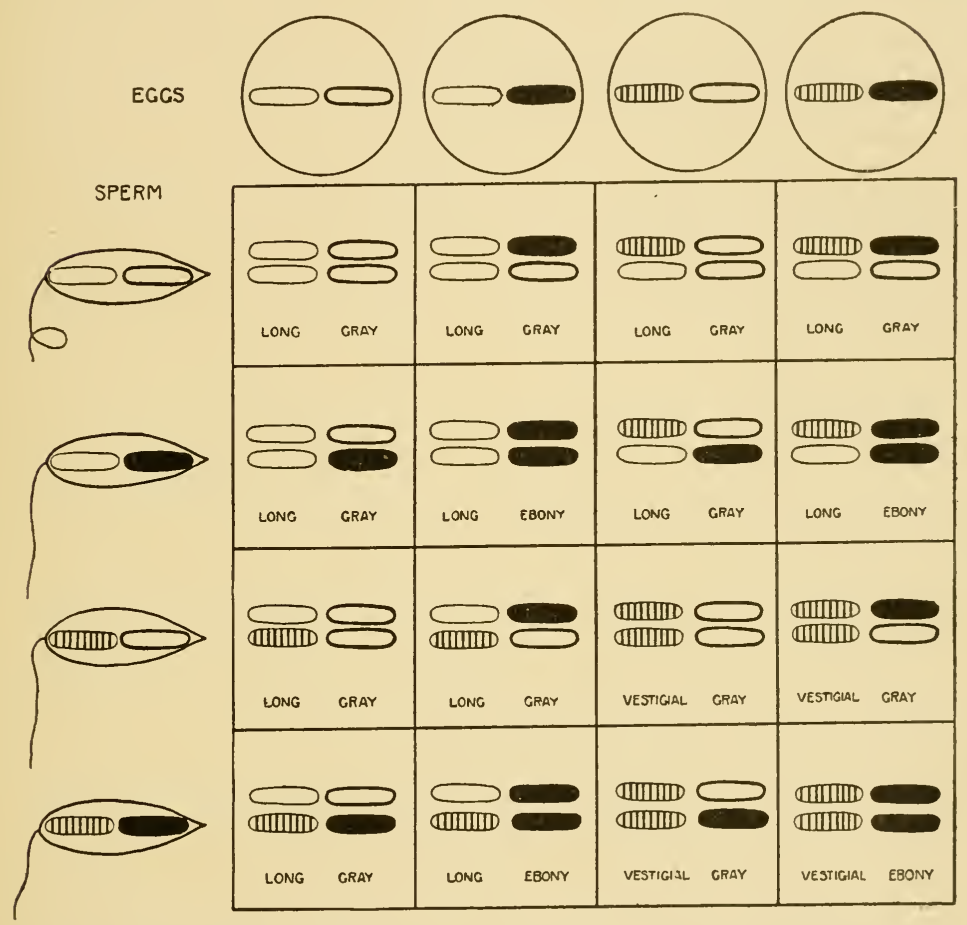

FIG. 12.-Diagram to show the 16 possible kinds of permutations of the four kinds of gametes of Fig. 11. Along the top line are four kinds of eggs; along the left side are four kinds of sperm; in the squares are the combinations formed by the meeting of each kind of egg with each kind of sperm, giving 9 long gray; 3 long ebony; 3 vestigial gray; 1 vestigial ebony.

The process just described takes place both in the male and in the female. Consequently there will be four kinds of eggs and four kinds of spermatozoa. 
Chance meeting between these will give the results shown in the next diagram (Fig. 12).

In the table (Fig. 12) the four kinds of eggs are represented at the head of the four vertical columns, and the four kinds of spermatozoa at the left of each horizontal row. In the squares the combination of each kind of sperm with each kind of egg is represented, giving the ratio of 9 long gray: 3 vestigial gray: 3 long ebony: 1 vestigial ebony.

The $\mathrm{F}_{2}$ expectation may, of course, be derived more directly as follows: There will be 3 long to 1 vestigial. These longs will be both gray and ebony in the ratio again of 3 to 1 ; hence 9 long gray to 3 long ebony. Correspondingly, the vestigials will be both gray and ebony, in the ratio of 3 to 1 ; hence 3 vestigial gray to 1 vestigial ebony. The result is the same as before.

If one of two independent pairs of characters is sex linked, the same scheme holds in those cases where the recessive sex linked character enters through the grandfather, but the ratio is different when the recessive sex linked character enters through the grandmother (viz., $3: 3: 1: 1$ ), as is to be expected from the mode of inheritance of white eyes taken alone $;^{1}$ and here, too, the result conforms fully to the chromosome scheme.

Three factors can be worked out by means of the

${ }^{1}$ For example, taking white and red alone the ratio of the $\mathrm{F}_{2}$ is $1: 1$. But among the reds the ratio of gray to ebony will be $3: 1$ and among the whites will be $3: 1$. Hence the result 3 red gray, 1 red ebony, 3 white gray, 1 white ebony. 
chromosomes as readily as one or two. It will not be necessary to give the full analysis, for it will be easily understood from the scheme already given. If a fly with vestigial wings is crossed to an ebony, eyeless fly three pairs of factors are involved that lie in different chromosomes. The $\mathrm{F}_{1}$ flies are normal, for there is in the hybrid a normal mate for each of the three recessive factors. The possible recombinations are shown in the next diagram, Fig. 13. There
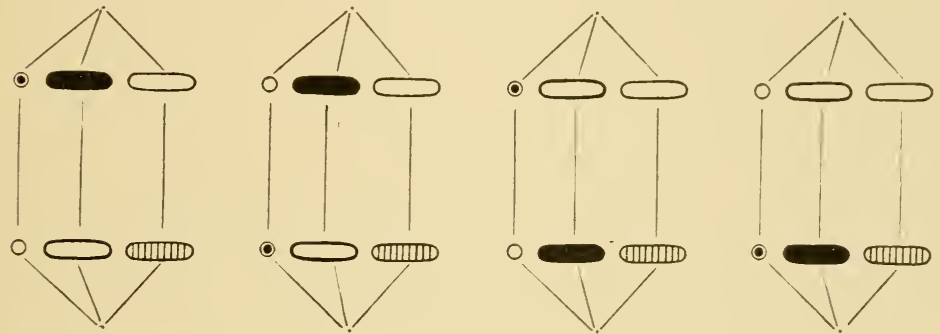

FIG. 13.-Diagram to show the segregation of the three pairs of chromosomes. Eight combinations are possible, giving 8 kinds of germ cells, with 64 possible re-combinations.

are four different positions for the chromosome pairs on the spindle, leading to eight kinds of germ cells. By chance meetings of the eight kinds of sperm with the eight kinds of eggs there will result 8 types as follows:

27 Long, gray, normal eye (wild type).

9 Vestigial, gray, normal eye.

9 Long, ebony, normal eye.

9 Long, gray, eyeless.

3 Vestigial, ebony, normal eye.

3 Vestigial, gray, eyeless.

3 Long, ebony, eyeless.

1 Vestigial, ebony, eyeless. 
The same manner of treatment will work for more than three pairs of chromosomes; the number of kinds of germ cells increases in geometrical ratio. In most animals and plants the number of chromosomes is higher than in Drosophila, and the number of pairs of factors that may show independent assortment is, in consequence, increased. In the snail, Helix hortensis, the half number of the chromosomes is given as 22 ; in the potato beetle 18 ; in man, probably, 24; in the mouse 20 ; in cotton 28; in the fouro'clock 16; in the garden pea 7 ; in corn 20 ; in the evening primrose 7 ; in the nightshade 36 ; in tobacco 24 ; in the tomato 12 ; in wheat 8 . If 20 pairs of chromosomes are present there will be over one million possible kinds of germ cells in the $F_{1}$ hybrid. The number of combinations that two such sets of germ cells may produce through fertilization is enormously greater. From this point of view we can understand the absence of identical individuals in such mixed types as the human race. The chance of identity is still further decreased since in addition there may be very large numbers of factors within each chromosome. 


\section{TYPES OF MENDELIAN HEREDITY}

Experience has shown that Mendelian inheritance applies to all sorts of characters, structural, physiological, pathological, and psychological; to characters peculiar to the egg, to the young, and even to old age; to length of life; to fundamental taxonomic characters as well as to "superficial" characters; and to characters intimately concerned in maintaining the life of the individual, as well as to characters which apparently do not influence survival. Some of these different types and their mode of inheritance will be briefly described, but since the general principles involved are more important than the kind of character that is affected, the results will be treated under general headings.

\section{Dominance and Recessiveness}

The four-o'clock (Mirabilis jalapa) has a white and a red-flowered variety. If these are crossed the hybrid is pink in color. The pink hybrid inbred (selffertilized in this case) gives in the next generation $\left(\mathrm{F}_{2}\right)$ one red, to two pink, to one white (Fig. 14). Owing to the intermediate color of the hybrid (or heterozygote) it is impossible to say that either color dominates the other. The factor for red and 
the factor for white both affect the plant in which they occur. In this and in similar cases the $\mathrm{F}_{2}$ ratio of $1: 2: 1$ is obtained, because it is possible to distinguish the pure red and the pure white from the heterozygous plants.

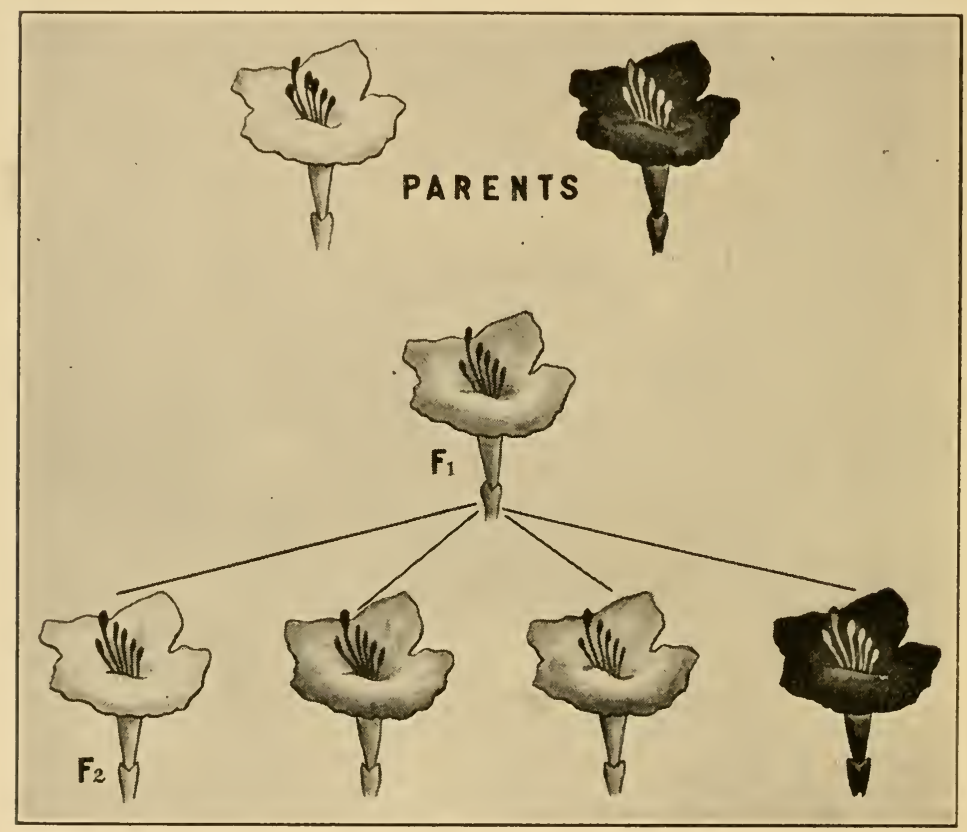

FIg. 14.-Diagram to illustrate the cross between a red and a white flowered Mirabilis jalapa ( 4 o'clock), which produces a pink, intermediate heterozygote.

The Andalusian fowl is a similar case. When certain races of black are bred to certain races or kinds of "white" the hybrid is slate "blue" in color. These blue birds, called Andalusians, when inbred, give one black to two blue to one white. Blue is 
the heterozygous condition; it is not possible to produce a pure breeding race of Andalusians, for the combination that produced an Andalusian falls apart in the germ cells of the Andalusian birds. The bird is blue because the pigment is not spread evenly over the feather but is restricted to small but black specks.
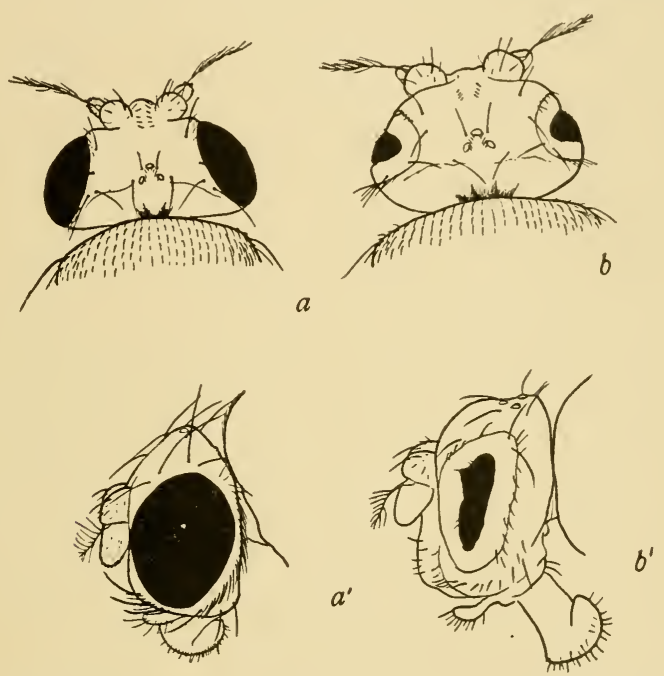

Fig. 15.- Normal $\left(a, a^{\prime}\right)$ and bar eye $\left(b, b^{\prime}\right)$ of Drosophila; shown in side view, and as seen from above.

The Andalusian blue is a mosaic of black and white, and not at all a dilute black.

A good example of an intermediate hybrid is found when the mutant fly with bar eye (Fig. 15) is bred to a wild fly. The daughters have bar eyes that are not as narrow as those of the pure bar stock. The range of variation is great, however, for some of the hybrids have eyes that are nearly as round as the normal, and 
in others the eye is nearly as narrow a bar as that of pure stock. In the male, which has one factor for bar eye, the eye is as narrow as in the pure (i.e., homozygous) female with two factors. The intermediate condition in the female which is hybrid (heterozygous) for this factor is hence not explained by the lesser effect of the single factor, but is probably due to the competing influence of the other allelomorph. Of course it might be contended that since in the male there is a different chromosome complex (XABCD YABCD) from that in the female (XABCD$\mathrm{XABCD}$ ) it is this difference in other factors that causes the heterozygous female to have a wider eye than the male; but this argument is rendered improbable here, when we recall that in only one out of many cases of sex linked inheritance, in which the heterozygous female is intermediate, is the male different from the homozygous female.

In other cases the influence of one of the parents of the cross may be so slight as to escape detection on ordinary observation, and may require special measurements for demonstration. When flies with miniature wings (Fig. 16) are mated to wild flies, the daughters have long wings, which Lutz has shown to be a little shorter in proportion to the length of the legs than are the wings of wild females; but the difference is so slight that it could not have been detected without biometrical methods.

Finally, we must consider the class of cases in which complete dominance has been described. All the cases given by Mendel in peas were supposed 
to fall under this heading: yellow dominates green, round dominates wrinkled, etc.

Whether a character is completely dominant or not appears to be a matter of no special significance. In fact the failure of many characters to show complete dominance raises a doubt as to whether there is such
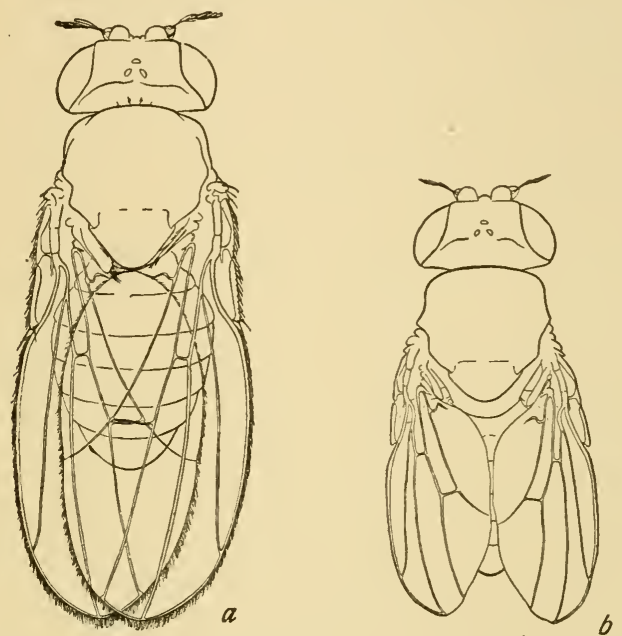

FIG. 16.- $a$, Long wing (wild type) of Drosophila; $b$, miniature wing. ( $a$ and $b$ are not drawn to scale.)

a condition as complete dominance. Some cases approach so nearly to that condition that special tests may be required to show that the hybrid is affected by the recessive factor. For instance, in flies the factor for white eyes seems to produce no effect when white is bred to red. The $\mathrm{F}_{1}$ reds are indistinguishable from pure reds. But by weakening the red by adding recessive factors other than white, the influence of white can be demonstrated, as Mor- 
gan and Bridges have shown. Therefore although the effect of the white factor can not be detected in the single combination with red, it is reasonable to suppose that some effect is really present. Similarly, conditions were found in which the effect of heterozygosis for eosin, vermilion, or pink could be demonstrated. While the question is one of only subsidiary importance, yet in the separation of classes it is often useful to be able to distinguish the pure from the hybrid form; but whether this can or can not be done in any given case does not affect the fundamental principle of segregation which is the essential feature of Mendel's discovery.

\section{Manifold Effects of Single Factors}

It is customary to speak of a particular character as the product of a single factor, as though the factor affected only a particular color, or structure, or part of the organism. But everyone familiar at first hand with Mendelian inheritance knows that the so-called unit character is only the most obvious or most significant product of the postulated factor. Most students of Mendelian heredity will freely grant that the effects of a factor may be far-reaching and manifold. A few examples may make this plain.

In Drosophila there is a mutant stock called "club," in which the wing pads fail to unfold (Fig. 17) in about 20 per cent. of the flies. In the majority of club flies the wings expand fully, and are like those of the wild fly. Owing to this fact, that not all the 
flies even in a pure stock of club show this character, it was difficult to study the inheritance of the supposed factor that sometimes inhibits the unfolding of the wing pads. Nevertheless, it was possible even with this handicap to show that the character depended on a sex linked recessive factor. Later
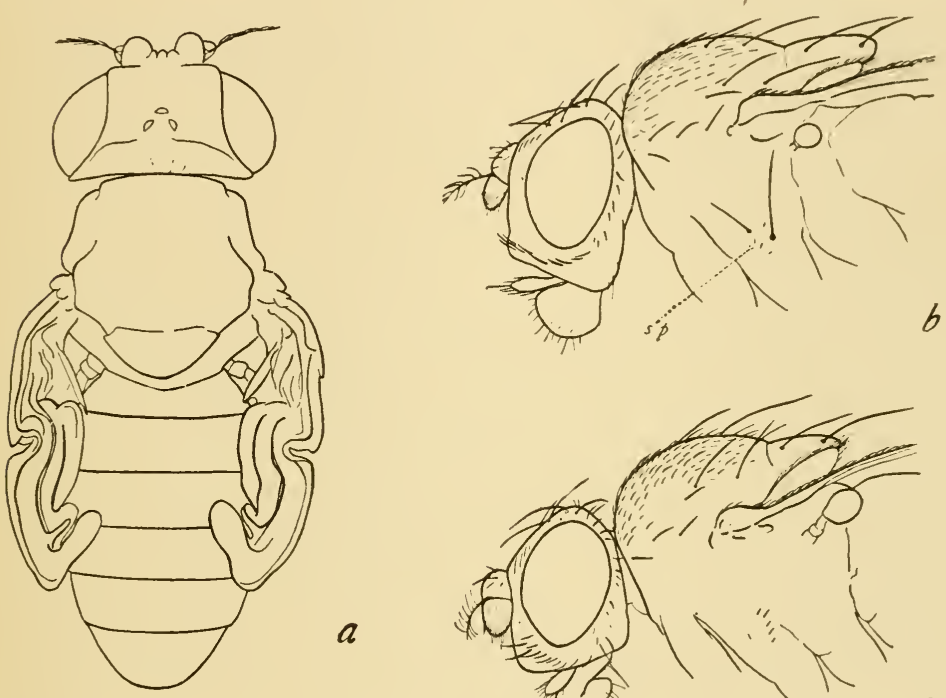

$a$

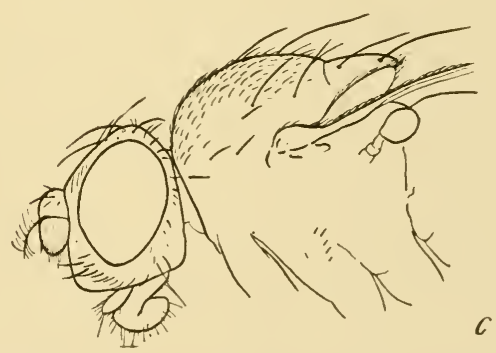

FIg. 17.-Club wing (to left). The absence of the spines on the side of the thorax in "club" is shown in $c$, and the normal condition is shown in $b$.

the discovery was made that a particular pair of spines always present on the side of the thorax of the wild flies, is absent from the club flies, irrespective of whether the wings do or do not unfold (Fig. 17,c). This constant feature of the mutant made its study quite simple. Another pair of spines, those upon the 
rear margin of the scutellum, point constantly in an abnormal direction in club stock. The head of club flies is often flattened, the eyes are smaller, and the thorax and abdomen are somewhat distorted. Here we have an example of a single germinal difference, the factor for club, producing several distinct effects,
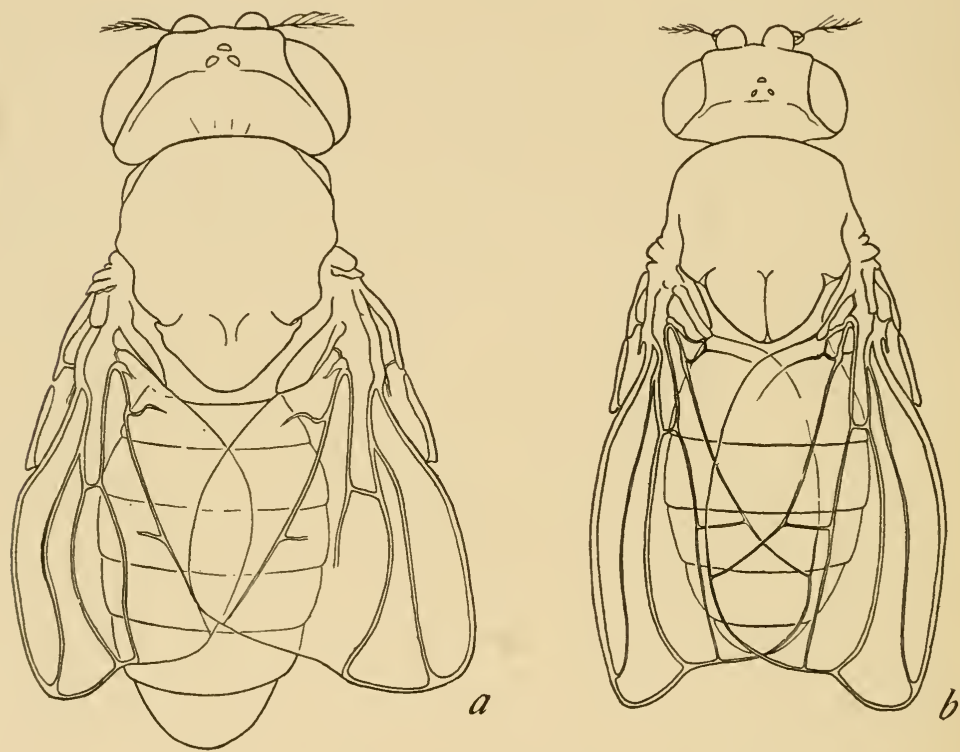

FI( . 18.- Rudimentary wing (to left), and truncate wing (to right).

some of which are constant features of the stock, while others are occasional or variable.

Another and similar example is found in the rudimentary winged flies (Fig. 18, a). The wing is usually shorter than the abdomen, but may be longer and even approach the normal wing in length and shape. The 
last pair of legs are often thicker and shorter. If many larvæ are present, or the food conditions poor, the larvæ of rudimentary flies can not stand the competition and die off, and in consequence the rudimentary class is smaller than expected. The males are fertile, but the females are almost entirely sterile, although rarely one of them may lay a few eggs and some of these hatch. The infertility is probably due to absence or rareness of mature eggs in the ovaries. There are also other effects than these four mentioned, all of which are produced by the same factor, and, no doubt, were our knowledge complete, we should find in all mutants many differences in addition to the ones picked out for study and called "unit characters." DeVries' definition of mutation entirely covers this relation; in fact, it even goes further and implies that a single difference may affect the entire organization. Perhaps this does occur, but practically the number of differences that can be observed between a wild and a mutant stock derived from it, is limited. The attack that is sometimes made on the unit character hypothesis fails in its intention the moment it is understood that a single factor (difference) has generally not one but many effects. Most workers in Mendelian heredity are fully conversant with these facts. This attack on the unit character conception is usually made by those not familiar with the actual situation and who take the expression unit character too literally. It may be conceded that the expression has at times been abused even by some of Mendel's followers. 
Similar Effects Produced by Different Factors

There are many cases in which characters that are superficially alike are the product of different factors. White color that characterizes so many domesticated races of plants and animals is a case in point. There are two pure breeding races of white flowered sweet peas. When crossed, they produce colored flowers. When the $\mathrm{F}_{1}$ offspring are inbred the $\mathrm{F}_{2}$ generation consists of 9 reds to 7 whites. This $9: 7$ ratio is a special case of the $9: 3: 3: 1$, in which the last three classes are superficially alike. The explanation here is that there are two kinds of recessive whites that have originated independently. On the chromosome hypothesis one white is due to mutation in one chromosome and the other white to mutation in another chromosome. When the races are crossed, each race supplies that chromosome which contains the normal factor of the white of the other race. In the $\mathrm{F}_{2}$ generation any plant that contains at least one of the normal chromosomes of both pairs will not be white. There will be nine such cases. Any plant that contains both of the white-producing chromosomes of either pair will be white. There will be seven such cases.

There are also two pure races of white fowls that, when crossed, give colored birds. Each white behaves as a recessive to color. For instance, the white silky crossed to a white dorking gives colored birds. These inbred give 9 colored to 7 white birds. 
There is a third kind of white race of poultry, namely, white Leghorn, in which white is dominant. Crossed to colored birds the offspring are white (with often a few colored feathers, which indicates that dominance is not complete).

In the silkworm also a dominant white and a recessive white factor have been found. The genetic results are comparable in all respects to those in the fowl.

There are also cases of blacks or melanic types, that have different factorial bases. There are three black races of Drosophila-called sable, black, and ebony-that belong respectively to the first, second, and third groups. These are much alike, but close scrutiny reveals slight differences. Any two crossed together give gray $\mathrm{F}_{1}$ flies.

There are three pink eye colors in Drosophila, one whose locus is in the third chromosome (pink), and two sex linked eye colors which are so similar that no certain difference between them can be observed.

Not only pigment but also structural characters may parallel each other in a remarkable manner. For example, in Drosophila the mutant stocks "bow" (sex linked) and "arc" (II chromosome) have wings that curve evenly downward over the abdomen. There are also two kinds of flies whose wings turn up sharply near the ends. These stocks are "jaunty" (second chromosome) and "jaunty I," which is sex linked. Two types, called "fringed"'(II chromosome) and "spread" (III chromosome), are characterized by thin textured wings held out nearly at right 
angles to the body. In the case of rudimentary and truncate (Fig. 18) the wings are so similar that without breeding tests one of them might easily be taken for the other. Finally, "facet" and "rough" both have the ommatidia of the eye disarranged very much in the same way.

Modification of the Effects of Factors

\section{By Environmental Influences}

It is a commonplace that the environment is essential for the development of any trait, and that traits may differ according to the environment in which they develop. In most cases different genetic types produce different results in any ordinary environment. The environment, being common to the two, may therefore in such cases be ignored, or rather taken for granted. There are other cases, however, in which a particular genetic type appears different from another one only in a special environment. Where this environment is not the normal one, its discovery is an essential element of the experiment.

One of the best cases is that given by Baur. The red primrose (Primula sinensis rubra) reared at a temperature of $30^{\circ}-35^{\circ} \mathrm{C}$. (with moisture and shade) has pure white flowers, but the same plants reared at $15^{\circ}-20^{\circ}$ have red flowers. If the white-bearing plants are brought into a cooler place, the flowers that are already in bloom remain white, but those that develop later in the cooler temperature are red. There 
is another race of primula (Primula sinensis alba) that always has white flowers, even at $20^{\circ}$. Strictly speaking, we should say, not as we generally do for brevity's sake, that the difference between the two races is that one has white, the other red flowers, but we should say rather that $\mathrm{P}$. rubra reacts at $20^{\circ}$ by producing red, at $30^{\circ}$ by forming white flowers; $\mathrm{P}$. alba, on the other hand, reacts both at $20^{\circ}$ and at $30^{\circ}$ by producing white flowers. The constant difference between these races is not in their color, but in the possibility of producing specific colors at certain temperatures.

This is the point of view, of course, that must also be taken for cases in which differences exist in all the usual environments; for, here also, it is the different possibilities of reaction that are inherited. Brevity warrants us in speaking of particular characters as inherited, rather than the specific possibility of reaction that gave these characters; but no one need be misled by the shorter expression.

Two similar cases of the influence of the environment have been found in Drosophila. There is a mutant stock known as abnormal abdomen in which the normal black bands of the abdomen are broken and irregular or even entirely absent (Fig. 19). In flies reared on moist food the abnormality is extreme; but even in the same culture the flies that continue to hatch become less and less abnormal as the culture becomes more dry and the food scarce, until finally the flies that emerge later can notbe told from normal flies. If the culture is kept well fed the change does 
not occur, but if the flies are reared on dry food they are normal from the beginning. The character is a sex linked dominant, as shown by the following crosses. When an abnormal male is bred to a normal (wild) female, the daughters are abnormal (if the
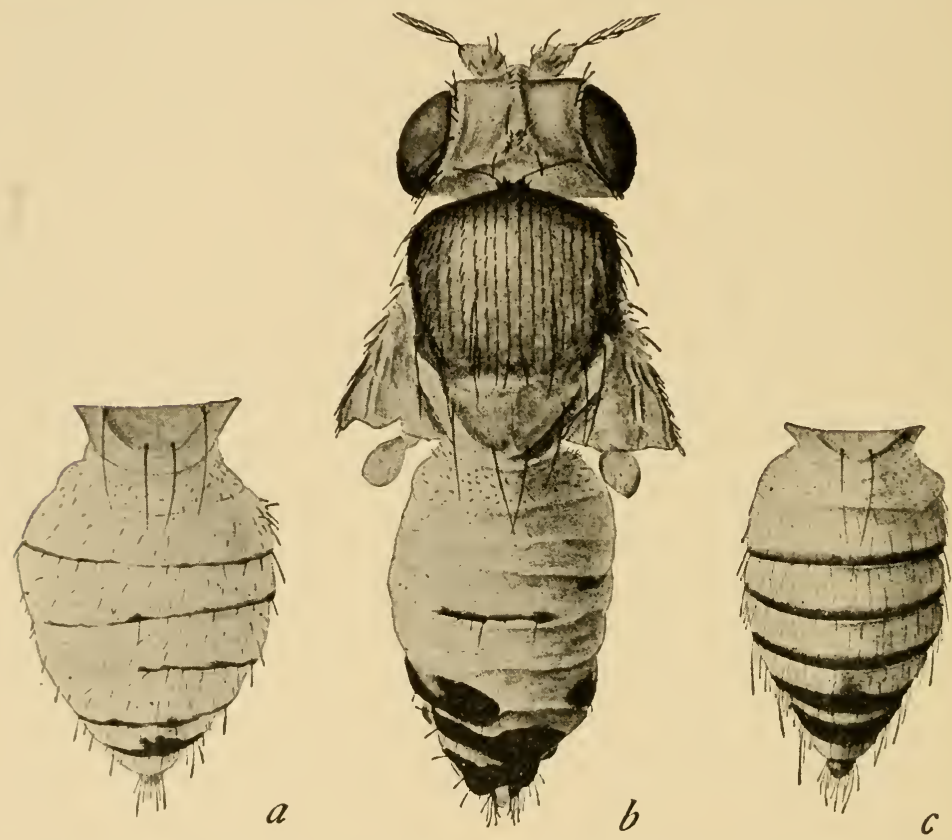

FIG. 19.-Mutant type called Abnormal Abdomen of Drosophila ampelophila (the wings have been cut off); $a$ is female; $b$, male; $c$, female that approaches the normal type.

food is moist), but all the sons are normal. If the medium is dry, however, both the daughters and the sons alike are normal. But these normal $\mathrm{F}_{1}$ daughters will produce the expected abnormal offspring if the conditions are suitable, and these offspring are just as 
abnormal as though the female had herself been abnormal. The reciprocal cross, viz., abnormal females by normal males, givesabnormal sons and daughters, if the food is suitable, but normal if the food is dry, etc. In both cases the $\mathrm{F}_{2}$ gives the expectation for a sex-linked dominant factor if the medium is suited to bring out the abnormal character, and the result is entirely obscured if the food is dry. Here, at will, we can demonstrate a regular Mendelian ratio by control of the environment, and conversely, we can conceal completely what is taking place by substituting another environment. That the same genetic process is going on in both cases can be demonstrated by suitable tests.

A case similar in principle occurs in a mutant stock of Drosophila that produces supernumerary legs. This stock was observed in winter to produce a considerable percentage of flies with supernumerary legs, but few or none in summer, especially in warm weather. Miss Hoge, who has studied this stock, finds that when the flies are kept in an ice chest at a temperature about $10^{\circ} \mathrm{C}$. a high percentage of flies with supernumerary legs occurs. Sometimes several legs or parts of a leg are doubled, or the doubling may occur twice in the same leg. The general rule that Bateson pointed out for duplicated legs in other insects appears to hold here, viz., the adjacent parts are mirror images of each other.

In the cold the duplicate leg gives a regular Mendelian result; but at normal temperature the duplication is a rare event and its mode of inheritance 
obscured. In a hot climate there would be no evidence that such a factor was being regularly transmitted. But if the type moved into a cold region it would show duplication in many of the legs.

\section{By Developmental Influences}

"Age," too, is in a sense an environmental condition, which influences the development of characters. Thus a white flower may change to purple as the plant gets older, or the flaxen hair of a child may turn to brown when he becomes a man. But, as in the case of other "environmental" conditions, age may not have the same effect on individuals with different factors; in this way it comes about that animals or plants which differ by certain factors may show a difference in character only at certain ages, or may not show the same difference at all ages. In Drosophila, flies with the factor for pink eyes are easily distinguishable from those with the factor for purple eyes, when the flies are young, but as they grow older, the eyes of both races assume a dark purplish shade, and become practically indistinguishable from each other. Conversely, old flies with the factor for black are usually easy to separate from those having the normal "gray" factor, but the newly hatched flies, in which the black pigment is not yet fully developed, are separated with greater difficulty.

These cases in which a factor-difference has a visible effect only at a certain age are in no fundamental respect different from cases like that of the Drosophila 
with reduplicated legs, where a factor difference has a visible effect only under special external circumstances.

A number of cases of Mendelian inheritance are known in which only the larvæ, and not the adults, are affected. Tower has described crosses in which the beetle Leptinotarsa signaticollis was crossed with L. undecimlineata (Fig. 20, $A, B$ ). In the first stage $(C)$, the larvæ of these two beetles are exactly alike, but in the second stage, the larvæ of L. undecimlineata are white and the larvæ of L. signaticollis are yellow; and in the third stage the undecimlineata larvæ are still white without stripes, while the others have well-developed tergal stripes $(B)$. When these species are crossed under certain external conditions the $F_{1}$ larvæ are yellow and, later, striped. The beetles that come from them are intermediate. Inbred, these beetles give three larvæ of the yellow type to one of the white type.

There is extensive evidence from cytology, experimental embryology, and regeneration, to show that all the different cells of the body receive the same hereditary factors. We must suppose, then, that the Mendelian factors are not sorted out, each to its appropriate cell, so that factors for color go only to pigment cells, factors for wing-shape to cells of the wings, etc., but that differentiation is due to the cumulative effect of regional differences in the egg and embryo, reacting with a complex factorial background that is the same in every cell. These regional peculiarities of different parts of the egg and embryo, may, 
like the age of the individual, also be considered as influences external to the hereditary factors which affect the development of characters. And not only
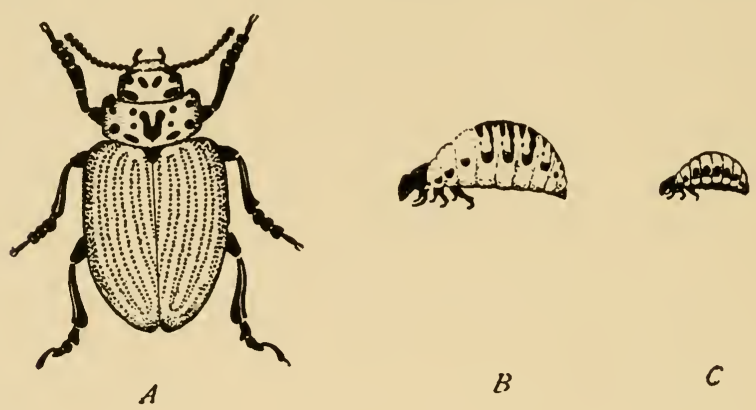

$B$

c
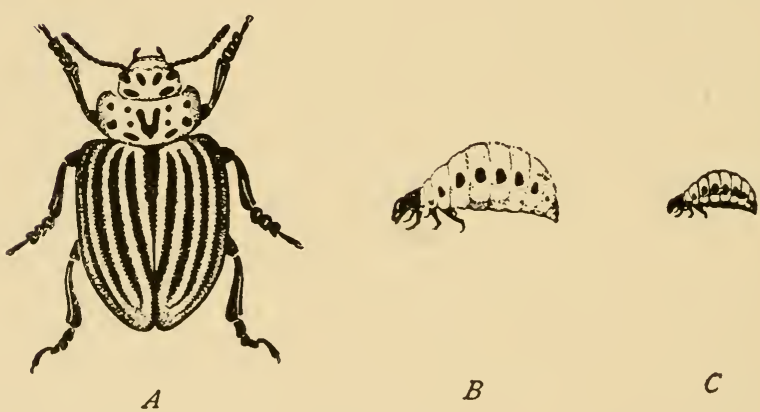

$B$

C

FIG. 20.-Leptinotarsa signaticollis (above), and L. undecimlineata (below), with their full grown $(B)$ and second stage $(C)$ larvæ to the right of each. (After Tower.)

do regional peculiarities influence characters, but special regions are usually required for a given factor difference to manifest itself, just as certain temperatures or ages may be necessary. Thus when we 
speak of factors for eyes or for legs, we really mean factor-differences which can produce effects only in the eye, the leg, or other regions of the body. In other cases the expression of a factor-difference may not be limited to one region but may produce a different effect in different regions; for example, a gray white-bellied mouse, which differs from the yellow mouse by only a single factor, is lighter than yellow on the under side, but darker on the upper side.

\section{By the Influence of Other Factors}

Analogous also is the fact that certain factordifferences produce a visible effect only when they are in company with a particular complex of other hereditary factors. Thus, a fly with the factors for vermilion eyes can not be distinguished from one with the factors for pink eyes if both contain, in addition, the factors for white eyes, for the factors for white allow no other color to develop. Again, it is obvious that without the factors necessary for the development of a given character, no factors merely determining special modifications of that character can have any effect. In other cases, the effect of a given factor may not be entirely suppressed, but greatly changed, if certain other factors in the hereditary complex are changed. Thus, in flies which already have the factor for vermilion eyes, the factor for purple eyes produces an eye still lighter than vermilion, but in flies containing the normal allelomorph of the factor for vermilion, the factor for purple pro- 
duces an eye decidedly darker than normal. Such cases of interaction of factors, in which the effect of one factor is altered by the action of another factor, are very numerous.

\section{Conclusion}

It would have been indeed strange if Mendelian factor-differences had not been found that require special conditions-environmental, developmental, or factorial-in order to produce a given effect, or any effect at all. For Mendelian factors may cause or influence all sorts of characters-that is, any or all kinds of developmental or physiological reactions; and many of these reactions are known to be affected by age, temperature, region of the body, and so forth. The facts given above are in no possible sense subversive to Mendelian principles. On the contrary they illustrate to great advantage the previously given interpretation of all hereditary charactersnamely, that every character is the realized result of the reaction of hereditary factors with each other and with their environment. Failure to understand this viewpoint has led to some futile criticism by the opponents of the modern Mendelian interpretation in terms of unit factors. This criticism is as pointless as it would be to criticize the atomic theory on the ground that oxygen does not, under all conditions, and in all its compounds, give rise to substances with the same properties.

The validity of the unit factor conception rests 
upon the fact that whenever (as often happens) all other conditions, external and internal, that modify characters remain constant, clear-cut ratios are obtained which can be explained only as due to segregation, in definite ways, of particular hereditary factors that perpetuate themselves unchanged from generation to generation. The validity of the factorial hypothesis may also be proved under circumstances not so well controlled, however. In cases where, on the factorial hypothesis, a certain factor is expected to be present in an individual, then, even if the individual fails to develop the character commonly taken as indicative of the factor, the actual presence of the factor may be demonstrated by breeding tests. For if, in subsequent generations, circumstances - genetic or environmental-are provided, like those in which the character previously appeared, it will again show itself. Flies of the race with abnormal abdomen, if raised in a dry bottle; appear perfectly normal, but the presence within them of the factor for abnormal may be demonstrated by rearing their offspring in a wet bottle. Again, the factor for pink eyes may be carried by a race with white eyes, and although pink does not show in the whiteeyed race, its presence there may then be demonstrated by crosses of these flies with flies that are not white. Cases like these could be multiplied over and over again. 


\section{CHAPTER III}

\section{LINKAGE}

If two factors lie in the same member of a chromosome pair we should expect them always to be found together in successive generations of a cross unless an interchange can take place between such a chromosome and the homologous chromosome derived from the other parent.

Whenever the two factors remain together in the same chromosome there will be formed equal numbers of gametes containing the two factors and of gametes containing the normal allelomorphs of the two factors. But if pieces of homologous chromosomes are interchanged, then some of the gametes will contain one of the factors in question, and an equal number will contain the other factor. The process of interchange between chromosomes is called crossing over; the tendency of factors to stay together is called linkage.

An example may make clearer this process of crossing over. The factor for black body color and that for vestigial wings both lie in the second pair of chromosomes. If a black vestigial fly is crossed to a wild fly (gray, long wings) (Fig. 21) the offspring are gray with long wings. These $\mathrm{F}_{1}$ flies have one chromosome containing both the factor for black and the factor for vestigial, and a homologous chromosome 
with the normal allelomorphs of these factors. After maturation one or the other of these chromosomes

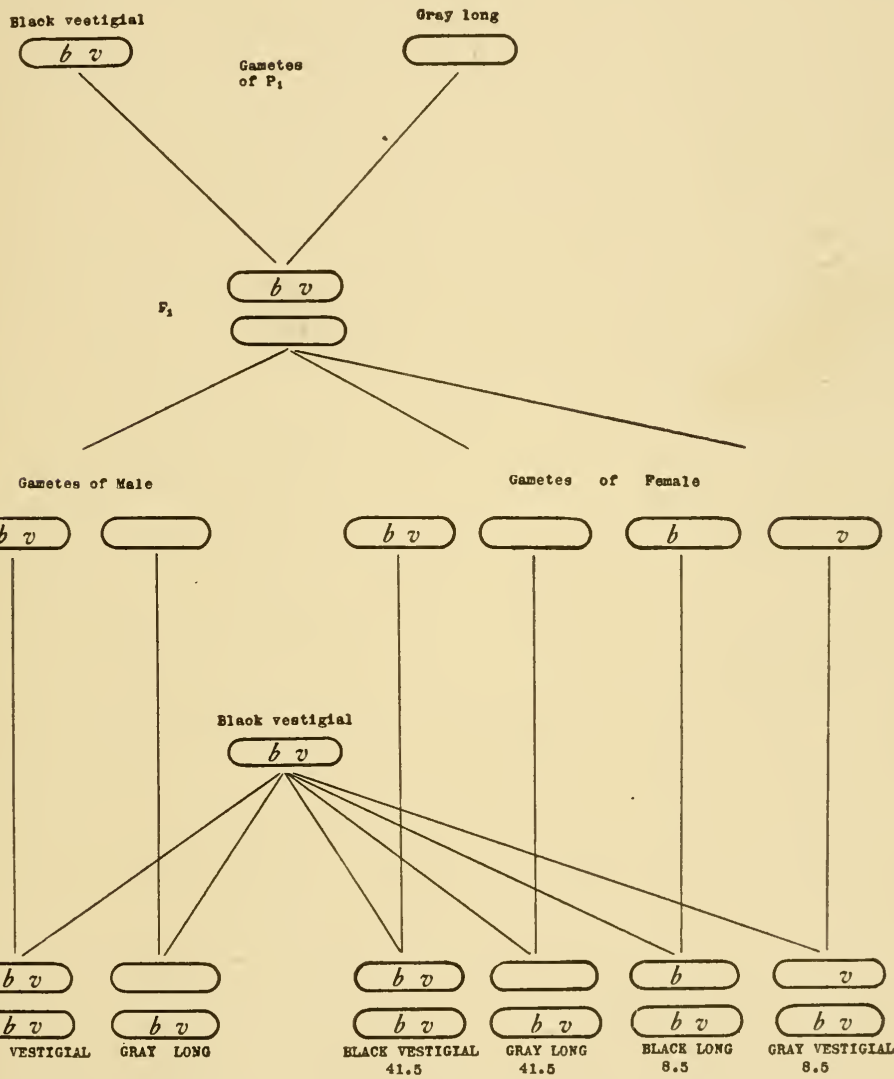

FIG. 21.-Diagram to illustrate non-crossing over in the male and crossing over in the female in a cross between black vestigial by gray long (coupling experiment). The $\mathrm{F}_{1}$ male was backcrossed to black vestigial females with the results shown to the left; and the $\mathrm{F}_{1}$ female was backcrossed to black vestigial males, with the results shown to the right.

will be left in each egg and each sperm. The gametes will consequently contain the same combinations of 
factors as were present in $\mathrm{P}_{1}$ unless an interchange has taken place between the two chromosomes. The best way to find out whether such an interchange has taken place is to mate the $\mathrm{F}_{1}$ males and females to the double recessive type, black vestigial, because black and vestigial being recessive factors will not obscure the factors that are carried by the gametes of the $\mathrm{F}_{1}$ to be tested. When the $\mathrm{F}_{1}$ male is backcrossed to a black vestigial female, Fig. 21 (to the left), only two classes of offspring are produced. Half of the flies are black vestigial and half are gray, long. This must mean that there has been no crossing over in the hybrid $\mathrm{F}_{1}$ male; for he produces only two kinds of gametes and these are of the kind that combined to produce him. In other words, the chromosomes received from his parents have remained intact.

If we test the $\mathrm{F}_{1}$ female in the same way, Fig. 21 (to the right), the result is different. When such a female is bred to the double recessive male, black vestigial, four kinds of offspring result, as follows:

Non-crossovers

Crossovers

Black, vestigial Gray, long 41.5 per cent. 41.5 per cent.

83 per cent.

17 per cent.

Of these four classes the first two correspond to the combinations which the $\mathrm{F}_{1}$ received from its parents, namely, black vestigial and gray long; the other two are classes that would be expected if crossing over had 
taken place between black and vestigial in the pair of homologous chromosomes. The numerical results

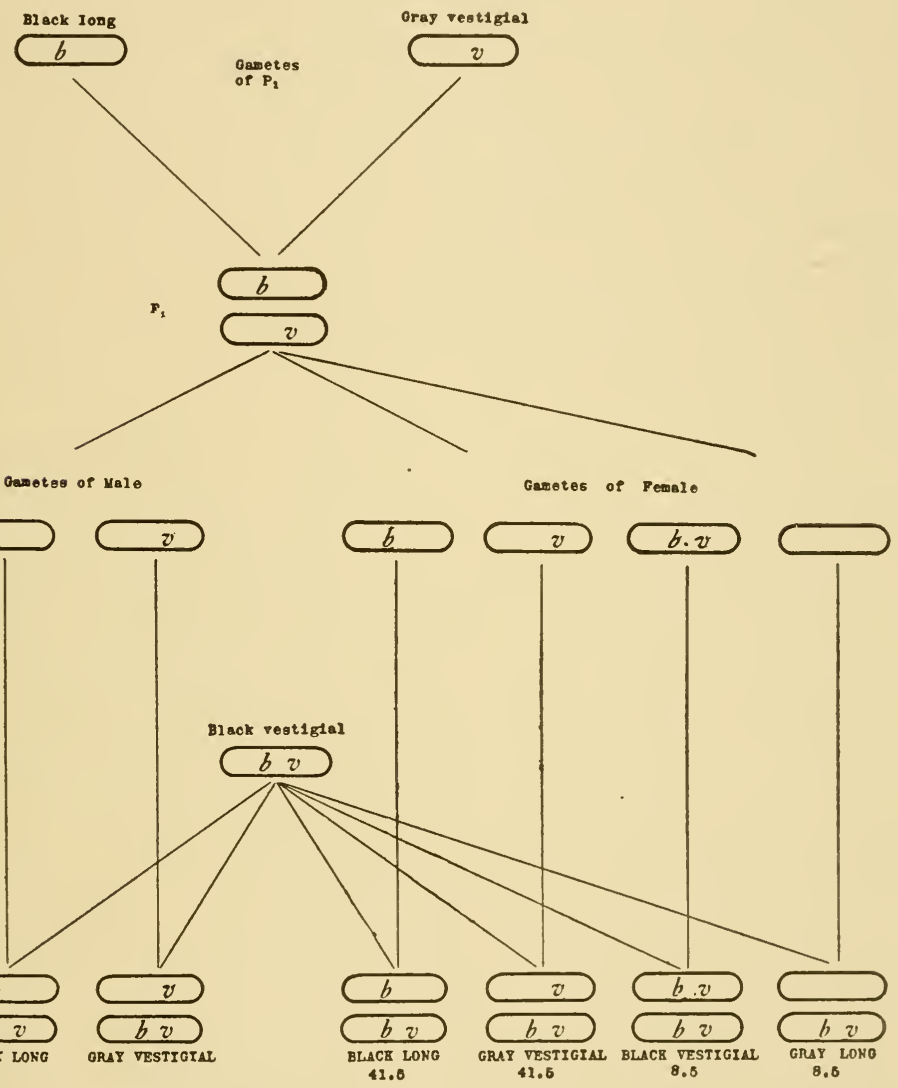

FIG. 22.-Diagram, like that of Fig. 21, to illustrate non-crossing over in the male and erossing over in the female when gray vestigial is mated to gray long (repulsion experiment). The percentage of crossovers here is the same as in Fig. 21 showing that the same percentage results irrespective of how the factors enter.

show that this crossing over takes place in about 17 per cent. of cases. In other words, the chances are 
about five to one that the combination that went in holds together.

It is also instructive to repeat the cross in such a way that the two mutant factors, black and vestigial, enter from different sides, i.e., one parent contributes black and the other vestigial. As shown in the next diagram (Fig. 22), each parent carries in its chromosome one mutant factor and the normal allelomorph of the other.

If the $F_{1}$ males are backcrossed to black vestigial females only two classes result, viz., black long and gray vestigial, Fig. 22 (to the left). These are the combinations that entered; hence no crossing over has taken place in the $F_{1}$ males. We see that here the linkage is not due to some affinity between the factors black and vestigial, per se, for in this cross they always enter different gametes as surely as they stayed together before. The reason for this difference in result is that in this cross they came from different parents and must have been in opposite chromosomes, whereas in the previous cross they were in the same chromosome.

If we test the $\mathrm{F}_{1}$ females by mating to black vestigial males, four classes result, viz.,

Non-crossovers

Crossovers

Black, long Gray, restigial Black, vestigial Gray, long 41.5 per cent. 41.5 per cent. 8.5 per cent. 8.5 per cent.

83 per cent.

17 per cent.

Crossing over has taken place in the $F_{1}$ females, and the numerical results show that this happens in 
17 per cent. of cases. Here too we see that now the factors tend to separate, whereas in the case of the other $F_{1}$ female they tended to stay together, since they lay in the same chromosome. In the present case, when the chromosomes interchange, the factors are brought together, and so the crossover classes are just the opposite in the two cases, as also are the non-crossover classes. Yet there is the same amount of crossing over shown in both crosses, so that the frequency of the double recessives and double dominants in the first cross is exactly equal to the frequency of the single recessive and single dominants in the last cross. Which classes shall have the high frequency and which the low does not depend on the nature of the factors themselves, therefore, but on which ones come from the same parent, i.e., lay in the same chromosome at first, and which lay in opposite chromosomes. The amount of crossing over is seen to be independent of the way in which the factors enter an individual. Hence it is fair to infer that the process is not peculiar in any way to hybrids, but takes place in the same way and to the same extent in gametogenesis in pure homozygous stocks. This is also indicated by the fact, later to be discussed, that when several different allelomorphs of a factor may occur, all give the same per cent. of crossing over with other factors.

Many other combinations, involving a large number of different characters in the second group, have been studied and give consistent results. There is never any crossing over in the male; and, in the fe- 
male, the amount of crossing over is different for different factor combinations but, for any given combination, it is not altered by the way in which the factors entered the cross, and is, ordinarily, ${ }^{1}$ constant.

Tests like the preceding ones for the second group have been carried out for the third group, and give the same kind of results. There is crossing over in the female and no crossing over in the male.

At present only two members of the fourth group are known, and the phenomena of linkage have not yet been studied in detail, but it is probable that there is no crossing over in one sex.

In the first group (sex linked characters), a very large amount of data has been collected. Here again there is abundant evidence to show that crossing over takes place in the female, but not in the male. The curious fact also comes to light that no mutations have been discovered in the $\mathrm{Y}$ chromosome, nor does it contain any factors dominant to any known mutant or normal factors in its mate, the $\mathrm{X}$ chromosome. Since the linkage of a considerable number of factors in the $\mathrm{X}$ chromosome has been studied in detail the evidence from this source best serves to illustrate cases where the linkage is strong, where it is moderate, and where it is weak.

The body color called yellow and the eye color white have been used in many experiments. If a yellow white female is mated to a wild male (gray red) (Fig. 23), the daughters are gray with red eyes (like the fathers), but the sons are yellow white like

${ }^{1}$ Subjert to certain variations which will be noted later. 

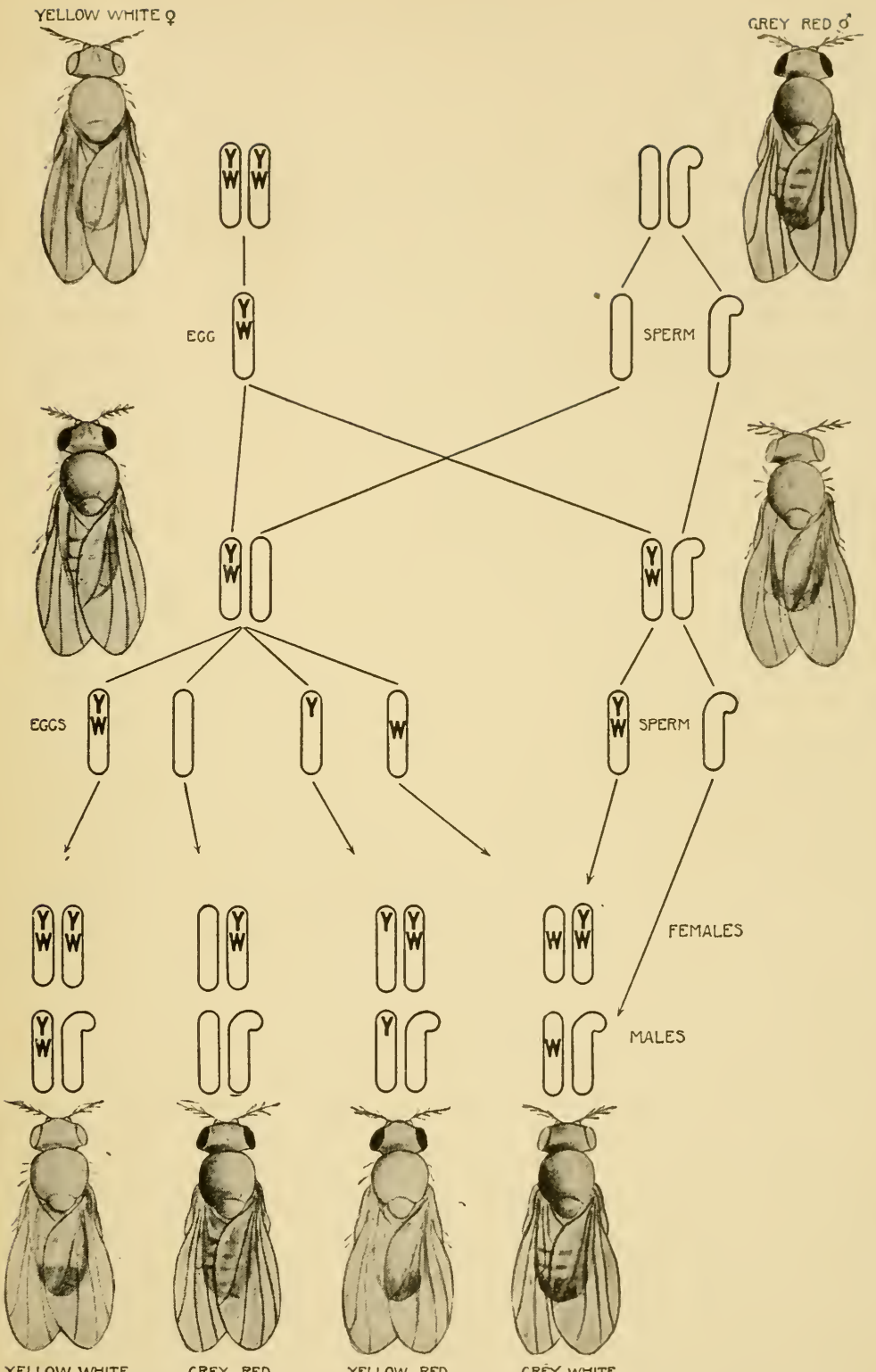

YELLOW WHITE

GREY RED

YELLOW RED

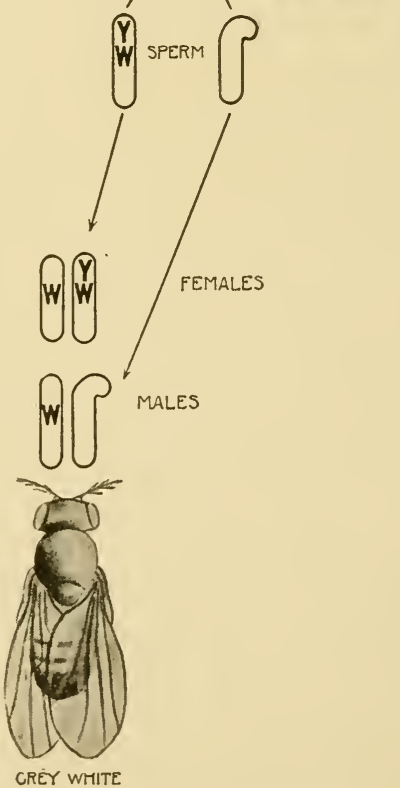

FIg. 23.-Diagram illustrating the inheritance of two pairs of sex linked characters, viz., yellow white and gray red. In $\mathrm{F}_{2}$ the males and the females give the same classes. 
the mother. The explanation of this result is obvious; for the son gets his single $\mathrm{X}$ chromosome from his mother, and should therefore have the characters that go with this chromosome. His $\mathrm{Y}$ chromosome, derived from the father, does not influence the result at all. The daughters, however, get one $\mathrm{X}$ chromosome from the mother (yellow white) and the other from the father (gray red). The factors for gray and red dominating give gray red daughters.

The composition of these $\mathrm{F}_{1}$ females can be tested by breeding to the double recessive male (yellow white) since this does not carry any dominant factors which will obscure what factors are received by the $\mathrm{F}_{2}$ females from their mothers. But the $\mathrm{F}_{1}$ males are themselves yellow white, so that the $\mathrm{F}_{1}$ females may be mated to their brothers. In fact, the outcome is the same, whether a yellow white male from stock or a yellow white $F_{1}$ brother is bred to the $F_{1}$ female. The $\mathrm{F}_{2}$ offspring of such crosses give the following classes and ratios:

Non-crossovers

Crossovers

Yellow white Gray red Yellow red Gray whe 49.5 per cent. 49.5 per cent. 0.5 per cent. 0.5 per cent.

99 per cent.

1 per cent.

This $\mathrm{F}_{2}$ result reveals the kinds of eggs produced by the $F_{1}$ female (since a double recessive father was used). Crossing over takes place between yellow and white in only 1 per cent. of cases.

There is no way of testing linkage in the $\mathrm{F}_{1}$ male, which is like a homozygous individual so far as the re- 
sult is concerned, as his $\mathrm{Y}$ chromosome does not contain any factors dominant to yellow and white, even though it came from the gray red male.

The reciprocal cross also offers certain points of interest. When a gray red female is mated to a yellow white male both sons and daughters are gray red. The daughters get a gray red chromosome from the mother and these factors dominate the factors derived from the father. The sons $\left(\mathrm{F}_{1}\right)$ get their single $\mathrm{X}$ chromosome from their mother and show her colors (gray and red).

If these gray red $\mathrm{F}_{1}$ females are back crossed to a yellow white male they give the same numerical result that this test gave in the reciprocal cross, viz., four classes of offspring with 1 per cent. of crossing over.

The $F_{1}$ males behave in all crosses exactly as do wild males, which is to be expected, since their single $\mathrm{X}$ chromosome is derived from the wild type mother.

It will not be necessary to consider in detail the same cross when the two factors enter from different parents; they will now keep apart exactly to the same degree that they kept together before. This is illustrated for the backcross as follows:

Non-crossovers

Crossovers

Yellow red Gray white Yellow white Gray red 49.5 per cent. 49.5 per cent. 0.5 per cent. 0.5 per cent.

99 per cent.

1 per cent.

As pointed out in the discussion of the black vestigial cross, this fact is very important, for it serves to 
show in a most striking way that in the previous experiment with yellow and white, these factors hold together so strongly from generation to generation, not because of any innate relation between these characters, but simply because they started together in the same chromosome.

In the case of yellow and white just given the linkage between the two factors is very strong in the sense just defined, that is, they tend in a high degree to preserve whichever combination they have. Other factors show a different strength of linkage. For example, if a female with white eyes and miniature wings is bred to a wild male, and then the $\mathrm{F}_{1}$ females (red, long) are backcrossed to white miniature males they will give the following classes of offspring.

Non-crossovers

White miniature Red long 33.5 per cent. 33.5 per cent.

67 per cent.
Crossovers

White long Red miniature 16.5 per cent. 16.5 per cent.

33 per cent.

The two large classes, white miniature and red long, correspond to the combinations that entered. The two smaller classes are the crossover combinations. Crossing over, therefore, takes place in 33 per cent. of cases.

Another combination gives a still greater amount of crossing over : the linkage may be said to be weaker. If a white eyed female is bred to a bar male (bar is a dominant mutation), and if the $F_{1}$ females (red bar eyed) are bred to the double recessive (white round eyed) sons, the following classes appear: 
Non-crossovers

White round

28 per cent.
Red bar 28 per cent.

56 per cent.

Crossovers

White bar

Red round

22 per cent.

22 per cent.

44 per cent.

Here a large amount of crossing over appears, about 44 per cent. In fact, so freely do the factors interchange that without sufficiently large and accurate numbers the linkage might entirely escape detection.

\section{The Mechanism of Crossing Over}

If it be admitted that the Mendelian factors are carried by chromosomes it can not be denied that interchange between homologous chromosomes must occur, for sex linked factors cross over from each other, and yet are known to be in the same pair of chromosomes, since they all follow the $\mathrm{X}$ chromosome in its distribution. The evidence allows for no other interpretation. But why should crossing over take place so rarely between certain factors and so often between others? We can make use here of certain information in regard to the chromosomes that gives a very simple answer to the question. In the early germ cells, before the maturation period begins, the chromosomes appear to be scattered in the nuclei, and the homologous chromosomes in many cases show no tendeney to lie together, although in some animals, e.g. in many flies, the members of a pair are often found side by side. In this early period the germ cells divide as do other cells and thereby increase in numbers. But at the termination of this 
period, the homologous chromosomes unite in pairs. There has been much controversy as to how this union takes place, but in some cases at least, the uniting chromosomes twist around each other as they come together. This is illustrated to the left in Fig. 24. As a consequence, parts of one chromo-

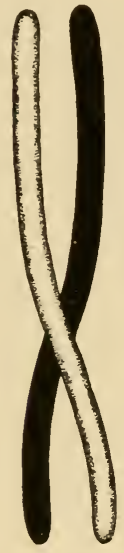

A

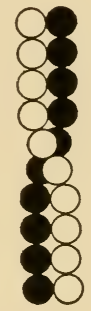

$B$

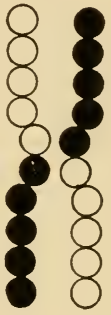

$C$

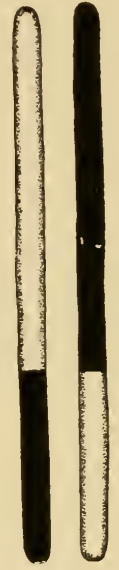

$D$

Fig. 24.-Diagram to represent crossing over. At the level where the black and the white rod cross in $A$, they fuse and unite as shown in $D$. The details of the crossing over are shown in $B$ and $C$.

some will come to lie now on one, now on the other side of the mate. If when the twisted chromosomes separate, the parts on the same side go to the same pole the end result will be that shown to the right in Fig. 24. Each chromosome has interchanged a part with its mate. This process has been called crossing over. It is, of course, also possible that the twisted chromosomes do not break and reunite where 
they cross, and if they do not then when they begin to separate they simply pull apart irrespective of the side on which they lie. When this occurs each chromosome remains intact and no crossing over takes place.

Later some of the evidence on which the above statements rest will be examined more critically. For the present it need only be pointed out that such a crossing over of parts of the chromosomes would supply the necessary mechanism to account for interchange. The chance that such a process of crossing over will occur between any two given points on the chromosome should obviously be greater, the greater the distance between those points. If then the Mendelian factors lie along the chromosomes, the amount of crossing over between any two of them will depend on their distance apart. Should two points lie near together a crossover will only rarely occur between them; if they lie further apart the chance of such a crossover taking place at some point between them will be greater. From this point of view the percentage of crossing over is an expression of the "distance" of the factors from each other.

In this way the diagram shown in the frontispiece has been constructed. Not only can all the facts of linkage so far studied be explained on this basis, but, as will now be shown, certain further results can be predicted. This is illustrated in what may be called a three-point experiment, i.e., an experiment in which three pairs of factors are involved. 
The three factors already studied, namely, white, miniature, and bar, furnish an excellent illustration. If we represent the percentages of crossing over as relative distances along the chromosome the three points will lie as shown in Fig. 25.

If crossing over takes place between white and miniature and between miniature and bar, then it
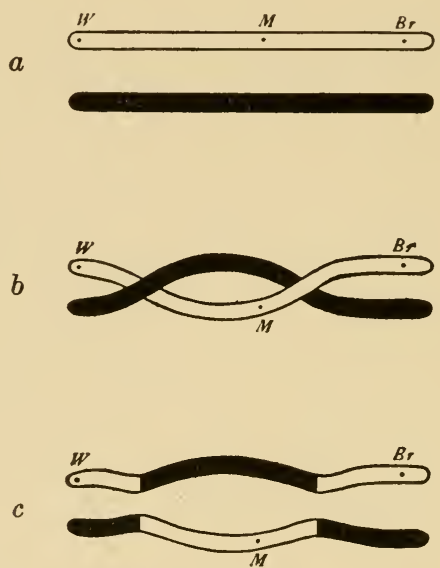

Fig. 25.-Diagram to illustrate double crossing over. The white and the black rods (a) twist and cross at two points. Where they cross they are represented as uniting (shown in $c$ ). That an interchange of pieces has taken place between $W$ and $B r$ is demonstrated by the factor $M$ having gone over to the other chromosome.

might be expected sometimes to take place in both regions at once, as shown in Fig. 25, $b$. The result here would be to produce two chromosomes like those shown in the lower figure. The combinations of factors which these two chromosomes resulting from double crossing over would contain, are white long bar and red miniature round. Since these two classes 
of gametes are actually produced, the results of the experiment fulfil the theoretical expectation.

There is a corollary of importance to this conclusion. When a cross is made that involves only white and bar, the double crossing over, that can be detected only when an intermediate point is followed, must still be supposed to take place. Whenever it does take place white bar flies and red round flies result. These will be added to the non-crossover classes since they have the same external characteristics. Consequently, the non-crossover classes will be increased and the crossover classes decreased. In fact, the sum of the two crossover percentages 33 and 22 (55) is much greater than the apparent amount (44) of crossing over when only white and bar are involved. Here then we have an explanation of why long distances taken as a whole give too little crossing over, as compared with the same distances taken section by section. The lowered percentage is an actual mathematical necessity owing to the occurrence of double crossing over.

In the case of double crossing over the two points of crossing over can not be near together unless the chromosomes are tightly twisted. Consequently, when crossing over occurs at any point the region on each side should be protected from further crossing over. That this actually happens may now be demonstrated. For example, from vermilion to sable is 10 units, and from sable to bar is 14 units more (as seen in the frontispiece). If crossing over occurs between vermilion and sable the region between 
sable and bar should be somewhat protected from crossing over. The usual amount of crossing over between sable and bar is 14 per cent., but in those cases in which crossing over between vermilion and sable occurs, this value becomes reduced to somewhat less than 4 per cent. In this same fashion a region just to the left of sable is protected, but this protection decreases with the distance from the vermilion sable region. The fact that one crossing over makes less likely another crossing over in a nearby region, or in a sense interferes with a second crossing over nearby, is called interference. As has been shown, interference decreases with increase of distance. ${ }^{1}$

In the construction of the chromosome maps shown in the frontispiece the distance taken as a unit is that within which 1 per cent. of crossing over will occur. Thus, yellow and white are placed one unit apart, since there is 1 per cent. of crossing over between yellow and white. White and bifid give 5 per cent. of crossing over, hence they are placed five units apart; and since yellow and bifid give 6 per cent., bifid must be on the other side of white from yellow. In a similar way the relative positions of the other factors have been plotted, the position of any factor on the map being determined, as far as possible, by

${ }^{1}$ If it should be found that crossing over takes place at a stage when the chromosomes actually are tightly twisted, there is no evident mechanism which would tend to prevent crossing over from taking place at two points near together, unless in this case we should suppose that crossing over results from a breaking of the threads at some point due to the strain of very tight twisting, and that a break at one point relieves the strain in the vicinity, thus tending to prevent another crossing over nearby. 
the per cent. of crossing over between it and the factor nearest to it. In general, it may be said that the number of units of distance on the map between any two factors (A and $\mathrm{C}$ ), will equal the per cent. of crossing over that will actually be observed between them in an experiment involving these two pairs of factors, even although their distance on the map may not have been obtained directly from their linkage with each other, their positions having, instead, been determined by their linkage with other factors. On account of double crossing over, however, this would not be expected to hold for very long distances; and, as has been explained, we do actually find that, if long distances are involved, the distance between $\mathrm{A}$ and $\mathrm{C}$ determined as on the map, by adding the intermediate distances $\mathrm{A}-\mathrm{B}$ and $\mathrm{B}-\mathrm{C}$, is longer than the distance $\mathrm{AC}$ as directly determined in an experiment involving only these two pairs of factors. It nevertheless remains true that, given the distance between any two factors on the map, the per cent. of crossing over between them can always be calculated from this distance (since the amount of discrepancy due to double crossing over also depends on the distance); this shows that the amount of crossing over between them is an expression of their position in a linear series. This striking fact, that the mathematical relations between the various linkage values conforms to a linear series, is a strong argument that the factors are actually arranged in line in the chromosomes. If the relations between the various linkage values were not determined by some linear relation of the 
factors but were of a random sort, these relations could not be calculated from a linear map.

As a concrete illustration of the way in which a group of factors behaves as a linear series, attention may be called to the manner of distribution of the factors among the germ cells of a female heterozygous for a large number of factors in the same pair of chromosomes. Let us write the factors derived from one parent, i.e., those in one of the chromosomes, on one line (see formula p. 67), in the order which they have on the map (see frontispiece), and the allelomorphic factors derived from the other parent, i.e., those in the homologous chromosome, in corresponding positions on the line below. Then in such a case the mature eggs contain either all of the factors represented on one line and none of those on the other, or they contain all of the factors present in one section of the line, and all of the factors present in the remaining section of the other line. In other words, the factors obviously stick together in sections according to their position in the linear series. When double crossing over occurs the line is broken in two places, but even here whole sections remain intact.

The above facts may be illustrated by an actual case. The first formula shows the composition of a hybrid female which has received from her mother the mutant factors: yellow, white, abnormal, bifid, vermilion, miniature, sable, rudimentary, and forked, and from her father the normal allelomorphs of these factors, together with the dominant mutant factor, bar. 


$$
\left\{\begin{array}{cccccccccc}
y & w & a & b_{i} & v & m & s & r & f & b^{\prime} \\
Y Y & W & A & B_{i} & V & M & S & R & F & B^{\prime}
\end{array}\right\}
$$

A number of females of this type have been made up by Muller. The next formula shows the kinds of eggs that were produced by one of these females and the numbers of each kind that were produced.

\section{Non-crossovers:}

$$
\begin{aligned}
& \text { y w a b } b_{i} \quad \text { v m s } r \text { f } b^{\prime}-6 \text {. } \\
& \mathrm{YWAB} \text { B M S R F B'-8. }
\end{aligned}
$$

Single crossovers:

$$
\begin{aligned}
& \mathrm{YW} \text { a } b_{\mathrm{i}} \quad \mathrm{v} \mathrm{m} \text { s } \mathrm{r} f \mathrm{~b}^{\prime}-2 \text {. } \\
& \mathrm{Y} W \mathrm{~A} \mathrm{~B}_{\mathrm{i}} \quad \mathrm{v} \mathrm{m} \text { s } \mathrm{r} f \mathrm{~b}^{\prime}-2 \text {. } \\
& \text { y w a bi } b_{i} \text { M R R B } B^{\prime}-2 \text {. } \\
& \mathrm{Y} W \mathrm{~A} \mathrm{~B}_{\mathrm{i}} \quad \mathrm{Vm} \mathrm{s} \quad \mathrm{r} f \mathrm{~b}^{\prime}-1 \text {. } \\
& \mathrm{YWA} \mathrm{B} \text { VM S } \mathrm{r} f \mathrm{~b}^{\prime}-1 \text {. } \\
& \text { y w a bi v m s R F } B^{\prime}-1 \text {. }
\end{aligned}
$$

Double crossover:

y w a b $b_{i} \quad$ M S R F b $b^{\prime}-1$.

Counts of over 600 offspring from females of the same type have given similar results. The characteristic method of interchange here demonstrated may perhaps be better realized by contrasting the combinations just given with the following, which illustrate types of eggs found not to be produced by such females.

$$
\begin{array}{lllllll}
\text { y W a } & B_{i} & V m & \text { s } & \text { f } & B^{\prime} \\
Y W a & b_{i} & \text { Vm s } & R f & B^{\prime}
\end{array}
$$

It is not supposed, however, that the per cent. of 
crossing over represents precisely the distance between the factors, for it may be that crossing over is more likely to take place in one region of the chromosome than in another. In that case the distances between factors in this region calculated from the amount of crossing over between them, would be relatively greater than the actual distance. It is supposed, however, that at least the order of the factors in the diagram represents their real order. Sturtevant has found definite factors which alter the amount of crossing over in the chromosomes, and these factors actually do affect the amount of crossing over differently in the different regions. A map of the chromosomes based upon the per cent. of crossing over when these factors are present would show different relative distances between the loci than those calculated from the normal linkage values. It is to be noted, however, that even in these diagrams, the order of the factors remains unchanged. One of the factors lies in the second chromosome and lowers the amount of crossing over in certain regions of this chromosome; the other lies in the third and apparently affects only this chromosome, and chiefly the end of this chromosome in which it itself is located. Bridges has found that the percentage of crossing over in the second chromosome is also lowered with increase in the age of the female, and it may be that other influences as well may affect the amount of crossing over. This variation in crossing over is in no way prejudicial to the conception of crossing over above outlined. Variation in the amount of crossing over has 
also been found in other forms than Drosophila, but in these cases the determining conditions and their effect on the various linkage values have not as yet been discovered.

\section{Linkage in Other Animals and in Plants}

Since the discovery in 1906 of linkage in sweet peas many cases have been found in animals and in plants. In sweet peas themselves two groups of linked factors are now known, one containing three pairs of factors and the other three or possibly four. In garden peas there are two pairs of linked factors and two other cases that are doubtful; in the primrose there is a group of five pairs of linked factors; in the snapdragon there is a group of three pairs; in stocks there is a group of three or probably four pairs. In animals, linkage, aside from sex linkage, has been discovered in only one form besides Drosophila, viz., the silkworm, in which Tanaka has found that several linked factors are present, i.e., four allelomorphs in one locus linked to two allelomorphs in another locus. There are, it is true, several other cases in which the evidence leads one to suspect that linkage occurs, but these are too uncertain at present to be included in the list. In all the above cases the linkage is "partial," that is, a certain amount of crossing over takes place, at least in one sex.

There are a number of cases of sex linkage, which, being only a special case of linkage, undoubtedly belong in the same category, but the amount of cross- 
ing over between the sex factor and the various sex linked factors can not be calculated, since in the sex that is heterozygous for the sex factor no crossing over has been observed. Sex linkage has been found

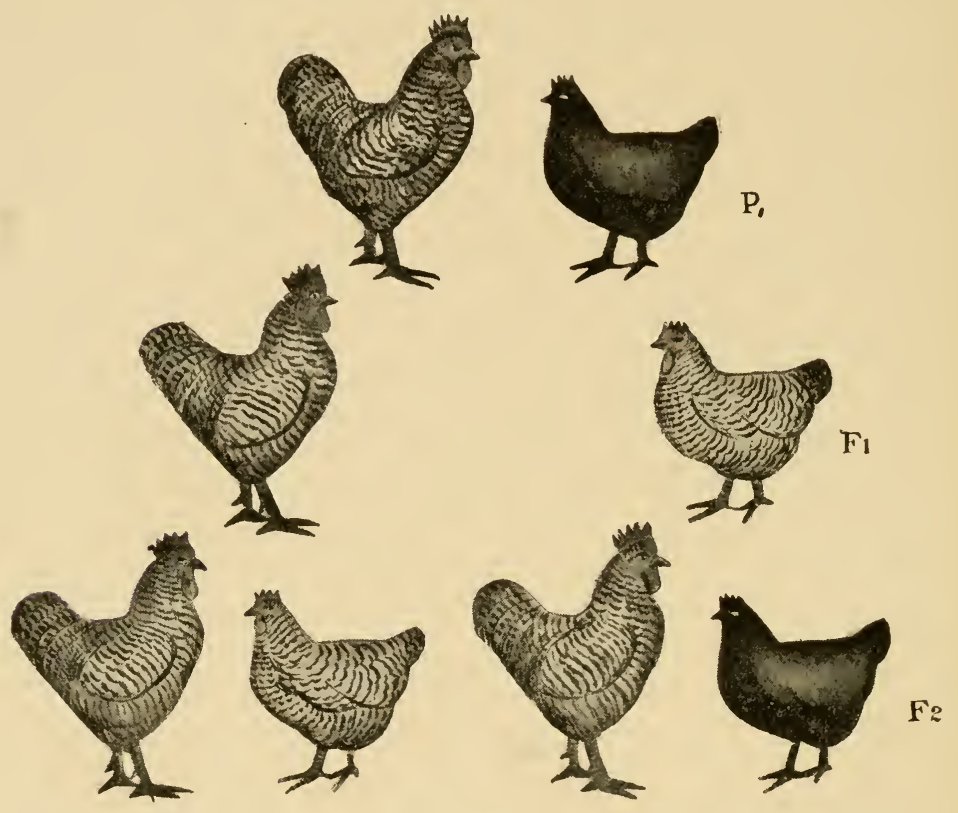

Fig. 26.-Black Langshan female by Barred Plymouth Rock male. Compare with Fig. 30 (similar cross in Abraxas) for scheme of inheritance, which is the same in both. Substitute Black for lacticolor and Bar for grossulariata.

in the moths Abraxas (Figs. 30 and 31) and Lymantria, in the fowl (Figs. 26, 27, 28, 29) (six factors), canary, pigeon, Drosophila (Figs. 9 and 10), fish, cat, man, and the plant Lychnis. In all, somewhat more than fifteen species show linkage.

This number appears small in comparison with the 
large number of species in which Mendelian inheritance has been discovered; but there are several reasons why more cases have not been recorded. In the first place, the number of chromosomes is generally large compared with the number of characters that

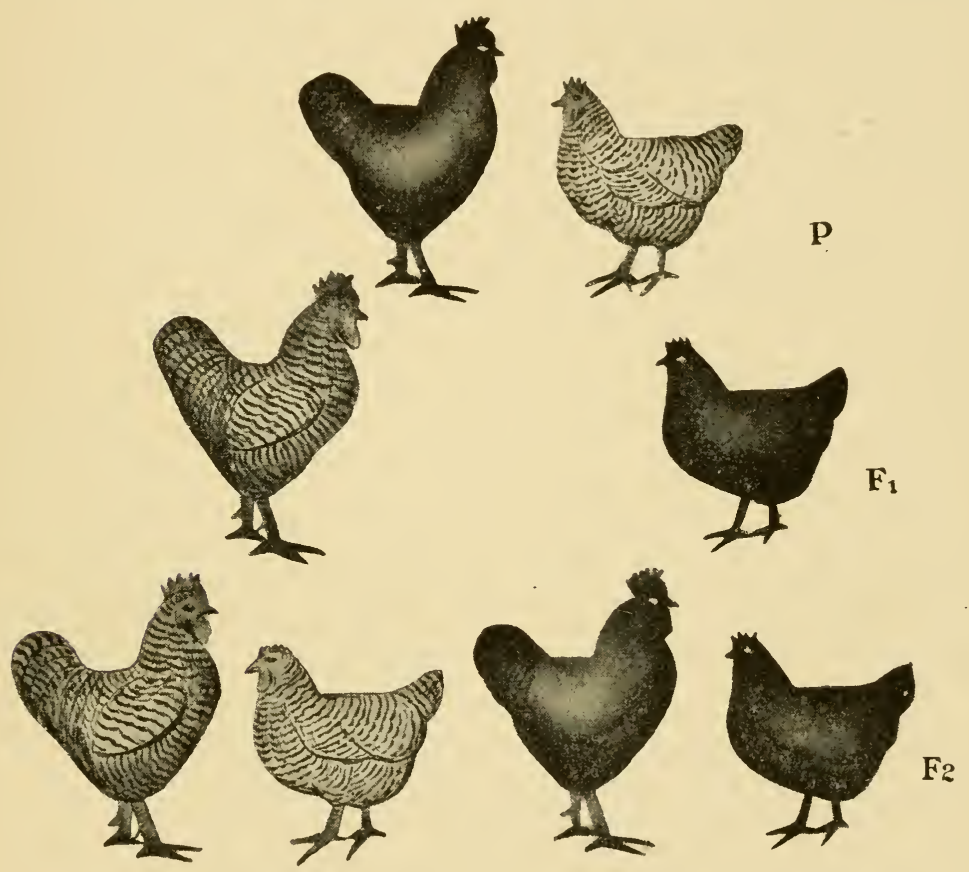

Fig. 27.-Barred Plymouth Rock female by Langshan male. Compare similar cross in Abraxas for scheme of inheritance.

have been studied in such a way that linkage would be noticed. Thus, there is little chance of finding two factors lying in the same chromosome. Secondly, unless this linkage is close, it might easily escape detection, especially when the number of off- 
spring recorded is small. In such cases the data are usually fitted to the nearest "Mendelian" ratio even
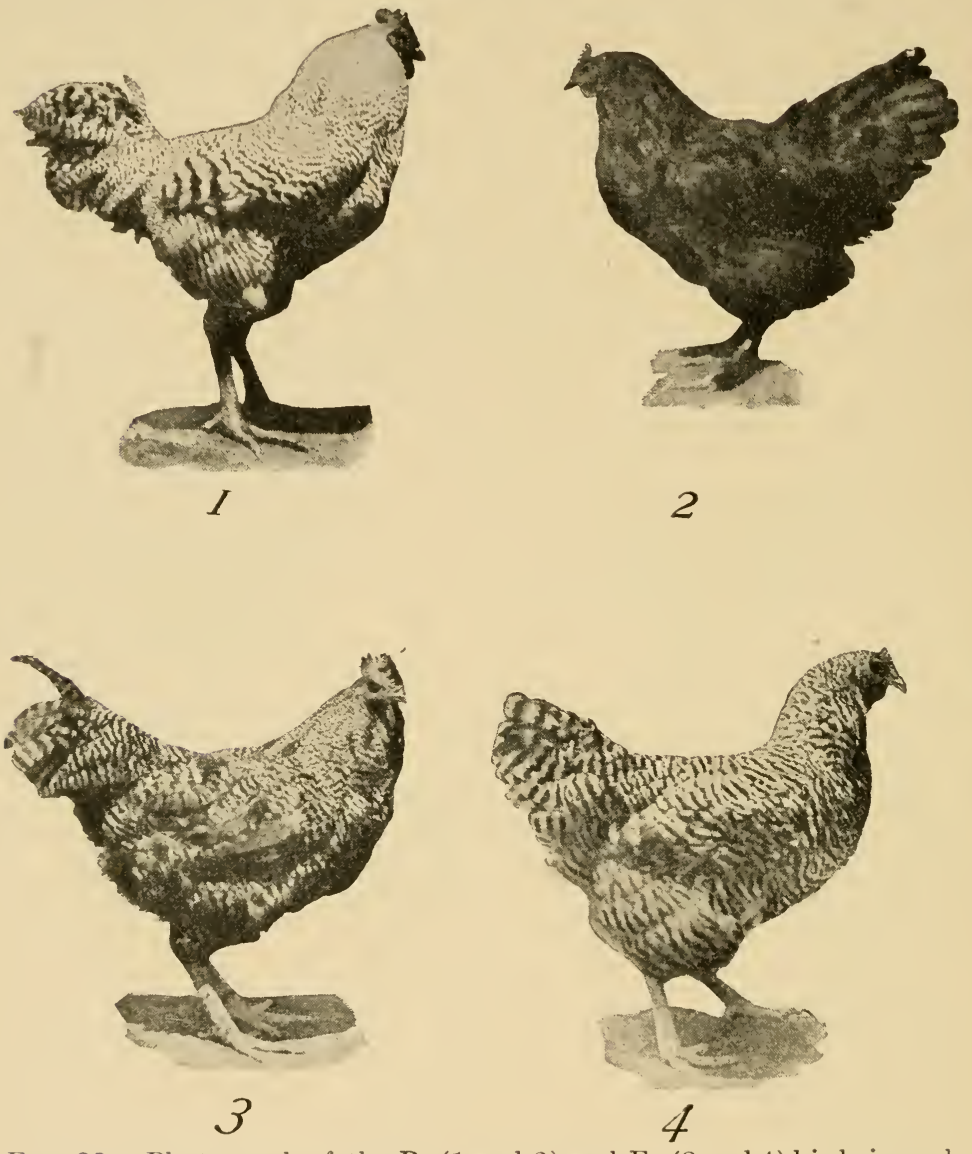

FIG. 28.-Photograph of the $P_{1}(1$ and 2$)$ and $F_{1}(3$ and 4$)$ birds in such a cross as that of Fig. 26.

though discrepancies are apparent. Even in species where a number of different characters have been studied these are often recorded in separate tables, 
which excludes the possibility of detecting any linkage that is present, for obviously linkage cannot
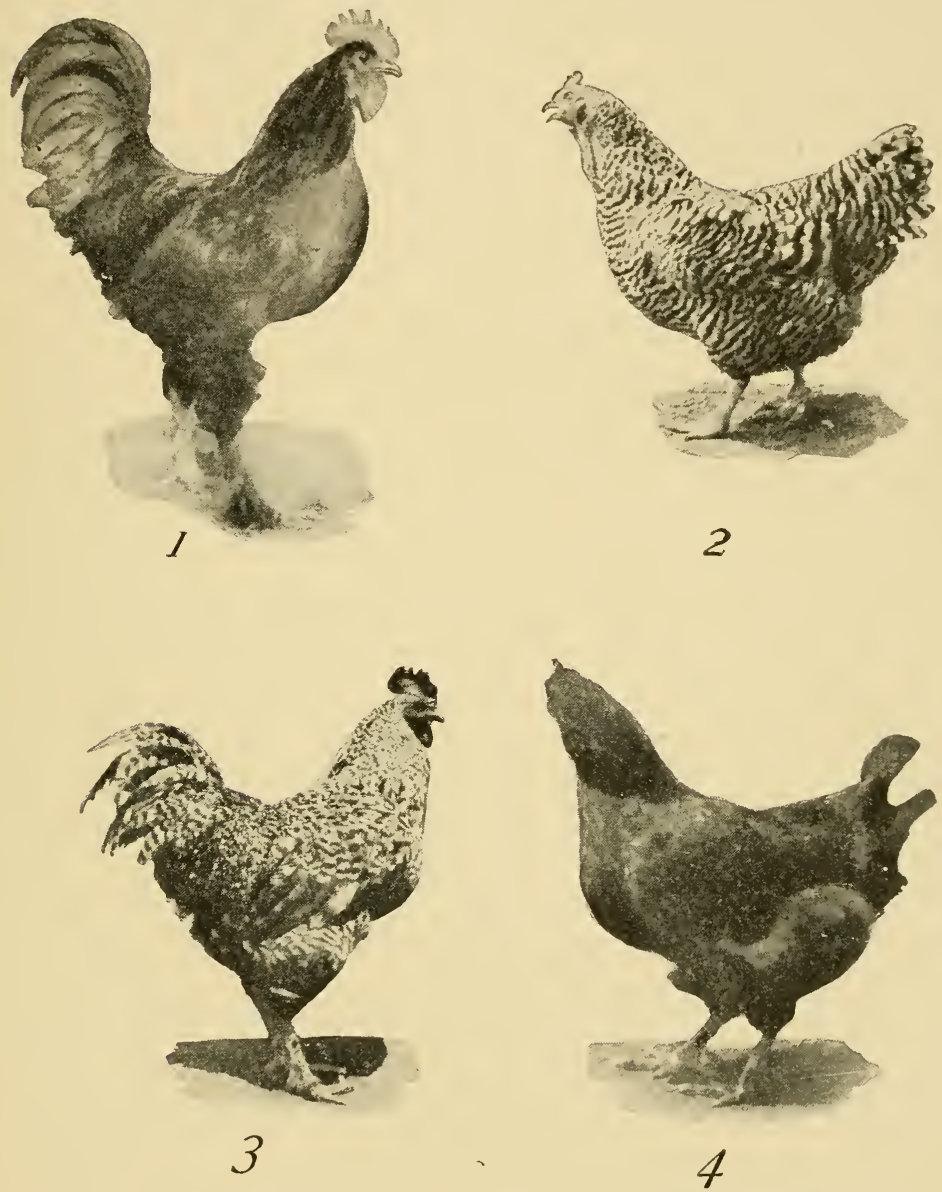

FIG. 29.-Photograph of $\mathrm{P}_{1}(1$ and 2$)$ and $\mathrm{F}_{1}(3$ and 4$)$ birds in such a cross as that of Fig. 30 . The $\mathrm{P}_{1}$ male is a standard figure.

be seen unless at least two pairs of factors are studied at the same time. The steady increase in the number 
of cases of linkage that is occurring at the present time, when the importance of detecting them has become apparent, and the methods for studying them have been worked out, appears to presage the realization of linkage as a general phenomenon. Its occurrence in such widely separated types is also a sign that it is a constant accompaniment of Mendelian inheritance.

\section{The Reduplication Hypothesis}

Linkage has been interpreted by Bateson and his co-workers on a basis entirely different from that adopted in this book. These investigators do not connect Mendelian factors with the chromosomes in any way, and do not suppose that segregation occurs at the reduction division. In a case of linkage between two pairs of factors, $\mathrm{Aa}$ and $\mathrm{Bb}$, the doubly heterozygous individual will have the formula $\mathrm{ABab}$. Bateson supposes that in such an individual segregation takes place before the reduction divisionperhaps in early cleavage stages, perhaps after the formation of the gonads. Two cell divisions are required for this segregation. In the first, $A$ and $a$ do not divide, but one goes to each daughter cell, i.e., they segregate. $\mathrm{B}$ and $\mathrm{b}$, however, both divide, and each daughter cell receives both $\mathrm{B}$ and $\mathrm{b}$. The resulting cells then have the formulæ, $\mathrm{ABb}$ and $\mathrm{aBb}$, respectively. In other words, $\mathrm{A}$ and a have segregated, but $\mathrm{B}$ and $\mathrm{b}$ have not. At the next division $\mathrm{B}$ and $\mathrm{b}$ segregate, giving four cells, with the combina- 
tions $\mathrm{AB}, \mathrm{Ab}, \mathrm{aB}$, and $\mathrm{ab}$, respectively. These cells then proceed to divide, the number of divisions not being the same for each, which results in the production of more of some kinds of cells than of others. But this multiplication must be assumed to be a symmetrical process, since the observed number of $\mathrm{AB}$ gametes equals the number of $\mathrm{ab}$, and similarly $\mathrm{Ab}$ equals $\mathrm{aB}$. The whole process just described is known as "reduplication." The term is applied to the same cases as those included under the name of linkage.

When three pairs of factors are involved in the same "reduplication series" Bateson supposed at one time that they are segregated at three successive cell divisions, after which the eight resulting cells divide at unequal rates. Later Trow suggested for such a case that perhaps only two segregating divisions occur at first, producing the cells $\mathrm{ABCc}, \mathrm{AbCc}, \mathrm{aBCc}$, and abCc, which may then multiply so as to give the proper proportions for the $\mathrm{A}$ and $\mathrm{B}$ combinations. After this there occurs in every cell a division which segregates $\mathrm{C}$ and $\mathrm{c}$. The resulting cells then divide again so as to produce the observed relations between the $\mathrm{C}$ pair and the other factors.

The nature of the factors themselves in the different lines of cells resulting from segregation can not be supposed to determine the difference in the number of times that these lines divide, because if an individual has received $A B$ from one parent and $a b$ from the other, the lines of cells reduplicate in a way just opposite to that in an individual which received $\mathrm{Ab}$ 
from one parent and $a B$ from the other. In one individual the line $\mathrm{AB}$ divides a certain number of times more than $\mathrm{aB}$, whereas in the other $\mathrm{aB}$ divides just that many times more than $A B$. In other words, the number of times a line of cells divides must be assumed to be determined in some way by whether or not, in its formation, certain factors separated that had established a relation with each other by being present together in the egg or sperm from which the individual came. To explain this, Bateson and Punnett have suggested that at the time of fertilization there is established in the egg a "polarity" which determines the planes of the segregating divisions. But it seems impossible to imagine how this or any other mechanism could bring about the above result. On attempting to follow out in concrete detail the events which must be assumed to occur in any case of reduplication, we find that, if the above stated relation is to hold, then, on "polarity" or any other hypothesis, the assumption of the most in tricate and improbable relations and processes is forced upon us.

This interpretation of linkage was originally based largely upon the supposed fact that the "gametic ratios" (ratio of parental combinations to new or crossover combinations in the gametes) fell into the series $1: 1: 1: 1,3: 1: 1: 3,7: 1: 1: 7,15: 1: 1: 15,31: 1: 1$. 31 , etc. The supposed connection between this series and reduplication is too involved to explain here, and gametic ratios which do not fall into it are now definitely known. In fact, it seems probable that 
ratios which do fall into it are no more frequent than would be expected from a chance distribution.

Another assumption upon which the reduplication hypothesis is based is the old idea of somatic (prereductional) segregation. This hypothesis, once advocated by Roux and Weismann as an explanation of differentiation, is opposed by a large body of experimental evidence from the fields of regeneration and experimental embryology, and has been given up by practically all students of developmental mechanics, including Roux himself.

At first it was doubted whether more than two pairs of factors could show reduplication in the same organism, but when it was experimentally proven that two pairs were not the limit, the scheme was extended. When gametic ratios not falling into the $3,7,15$, series were found, the theory was modified to permit other ratios. When it was found that the result depended upon the way in which the factors entered the cross, the "polarity" hypothesis was added. Some further extension will be necessary to account for the phenomenon of "interference" discussed above. 


\section{CHAPTER IV}

\section{SEX INHERITANCE}

There are two types of sex inheritance known in those species in which separated sexes exist. In one type, which may be called the Drosophila type (XX$\mathrm{XY}$ type, or, for short, the XY type), the female is homozygous for a sex factor, the male heterozygous; in the other, the Abraxas type (the WZ-ZZ type, or, for short, the WZ type) the female is heterozygous for a sex factor, the male homozygous. Since in both cases the heterozygous individuals must always mate with the homozygous ones there should result in each succeeding generation equal numbers of heterozygous and homozygous individuals, and so the bisexual condition is perpetuated as follows:

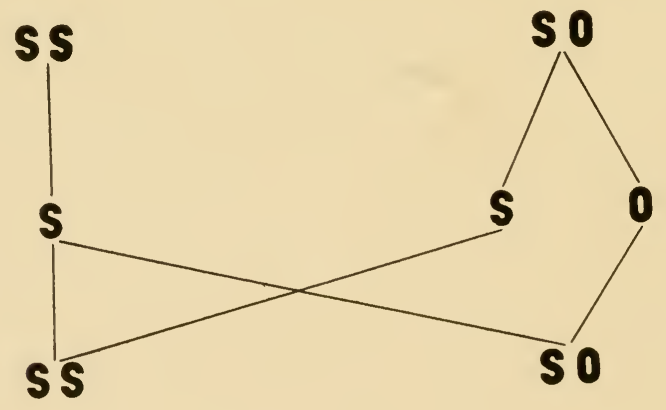

The genetic evidence so far gained has placed in the Drosophila type the following animal forms: Dro- 
sophila, man, cat; and the plants, Lychnis and Bryonia. The cytological evidence refers to the same type the insect groups of bugs, flies, beetles, grasshoppers; the spiders, certain worms (Ascaris), echinoderms, amphibia and mammals (including man). The genetic evidence has placed in the Abraxas type several moths and butterflies, and several birds; viz., chickens, ducks, and canaries. ${ }^{1}$ Favorable cytological evidence has been found only in the case of a few moths.

In many cases of the Drosophila type, in which the history of the sex chromosomes has been worked out cytologically, it has been found that in the male there is a pair of chromosomes, the two members of which are different in size or shape. These are the "sex chromosomes" and are designated as $\mathrm{X}$ and $\mathrm{Y}$. In many species of the Drosophila type the $\mathrm{Y}$ is slightly smaller than the $\mathrm{X}$, and in the various other species of this type all gradations in the relative size of the $\mathrm{Y}$ are found, between this condition and the condition where $\mathrm{Y}$ is completely absent. In some related species, on the other hand, the chromosomes which obviously correspond to $\mathrm{X}$ and $\mathrm{Y}$ are alike in appearance. It is not, after all, the size difference usually visible in the male, between $\mathrm{X}$ and $\mathrm{Y}$, which gives these two chromosomes their significance in sex determination, but rather a difference in the factors they contain. The size difference is an incidental concomitant, or, as it were, a token or label that is

\footnotetext{
${ }^{1}$ Richardson's work on strawberries suggests that this plant may come under the Abraxas type
} 
not present in all species. In all these cases the female contains two $\mathrm{X}$ chromosomes, the $\mathrm{Y}$ chromosome being confined to the male line.

This type of sex determination represents all eggs as alike-each containing one $\mathrm{X}$ (after the polar bodies have been extruded), but the sperm is of two kinds, one containing the $\mathrm{X}$ and the other $\mathrm{Y}$, or merely no $\mathrm{X}$. The scheme is as follows:

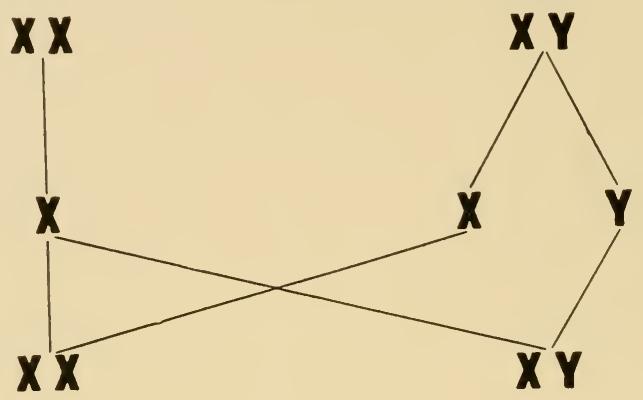

It will be seen that all the spermatozoa carrying $\mathrm{X}$ produce females, while all those carrying $\mathrm{Y}$ or no $\mathrm{X}$ produce males.

The Y chromosome, when present, descends from father to son. It might seem, therefore, that if the $Y$ carried a sex factor for maleness the scheme would work out as well as if a sex factor were carried by the $\mathrm{X}$ chromosome. But in several cases there is no $\mathrm{Y}$ in the male, and in certain cases to be described later, due to non-disjunction, there are females that have a formula XXY and yet their sex is not affected in any way on account of the presence of the supernumerary $\mathrm{Y}$. It follows that sex is not determined by the presence or absence of the $\mathrm{Y}$ chromosome but by the 
number of the $\mathrm{X}$ chromosomes that are present. In the cases that follow, where sex determination of the Drosophila type was discovered by a study of sex linked inheritance, as well as in the above cases, where the mechanism was discovered through cytological observations, proof that the male is heterozygous for a Mendelian factor for sex is derived from the fact that he gives rise to two kinds of spermatozoa-male producing and female producing-in equal numbers. We know this in the cases worked out cytologically because here the spermatozoa carrying $\mathrm{X}$ must all produce females, while the other half must produce males; and we know it, in the cases worked out genetically, because here only half the spermatozoa from a male with a dominant sex linked character carry the dominant factor, and these all produce females, while the rest produce males. The female must contain the same Mendelian sex factor as is present in the female-producing spermatozoa of the male; but the female must be homozygous for this factor, since any egg, if fertilized by a male-producing spermatozoon, contributes this factor to the resulting male.

Although the only way in which the results of sex linked inheritance of the Drosophila type differ from non-sex linked cases is the one above stated, namely, that a dominant male transmits his dominant sex linked factor only to his daughters, nevertheless it may be well at this point to recall specifically what ratios are produced in consequence, in the various types of crosses.

Examples of sex linked inheritance in Drosophila 
have already been given; that of white eyes is typical of all the rest. The main facts may be restated here. If a white eyed male is bred to a red eyed female the offspring are red eyed (Fig. 9). If these are inbred all of the $\mathrm{F}_{2}$ daughters are red eyed, but half of the sons are white eyed and half red eyed. In a word, the grandfather transmits his characters visibly to half of his grandsons but to none of his granddaughters.

In the reciprocal cross (Fig. 10), a white eyed female bred to a red eyed male produces the crisscross result of red eyed daughters and white eyed sons. These give white and red eyed males and females in equal numbers. On the assumption that the factor for white eyes is carried by the sex chromosomes the inheritance of white eyes can be readily understood. It will be observed that a female transmits to each of her sons one of her $\mathrm{X}$ chromosomes with all the factors contained in it. Her sons will show all of these sex linked characters whether they be dominant or recessive since they receive no other $\mathrm{X}$ to dominate those characters and the $\mathrm{Y}$ contains no dominant factor. For example, if a stock be made up pure for yellow body color, white eyes, abnormal abdomen, bifid wings, sable body color, forked spines and bar eyes, and if a female of this stock be bred to a wild male, all of her sons will be yellow, white, abnormal, bifid, sable, forked and bar. The daughters, however, will receive not only this chromosome from their mother, but will also receive a chromosome from the wild male (their father) con- 
taining the normal allelomorphs of all these factors. In the case of all the factor-pairs, except abnormal and bar, the normal allelomorph dominates. Therefore, the females will appear normal for all characters except abnormal and bar, which are dominant.

In the cat, Doncaster has discovered a sex linked factor affecting the coat color. In man several characters, such as color blindness, hæmophilia, and others less certainly identified have been found to follow the same scheme.

A comparison of sex linkage in Abraxas with that in Drosophila shows that the mode of inheritance of sex linked characters is identical in these two cases, but the sex relations are exactly reversed. In the Abraxas type sex linked inheritance takes place in accord with the plan that the female is heterozygous in sex production. If the chromosome that carries this sex differentiator is called $\mathrm{Z}$, and its mate in the female $\mathrm{W}$, the formula for the male would be $\mathrm{ZZ}$ and that for the female WZ. The scheme follows:

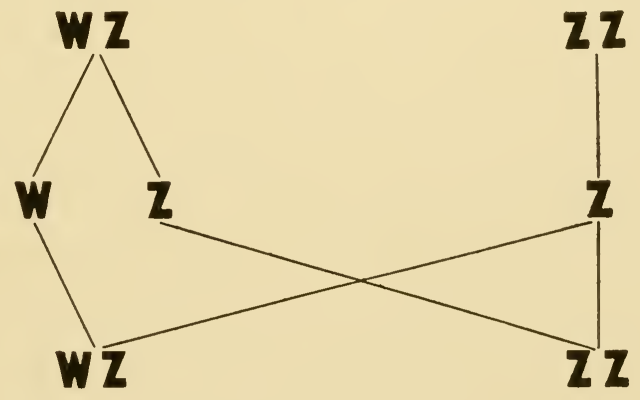

Inheritance in Abraxas is illustrated in the following diagrams (Figs. 30 and 31), in which the common 
wild type A. grossulariata is crossed to the rare mutant type A. lacticolor.

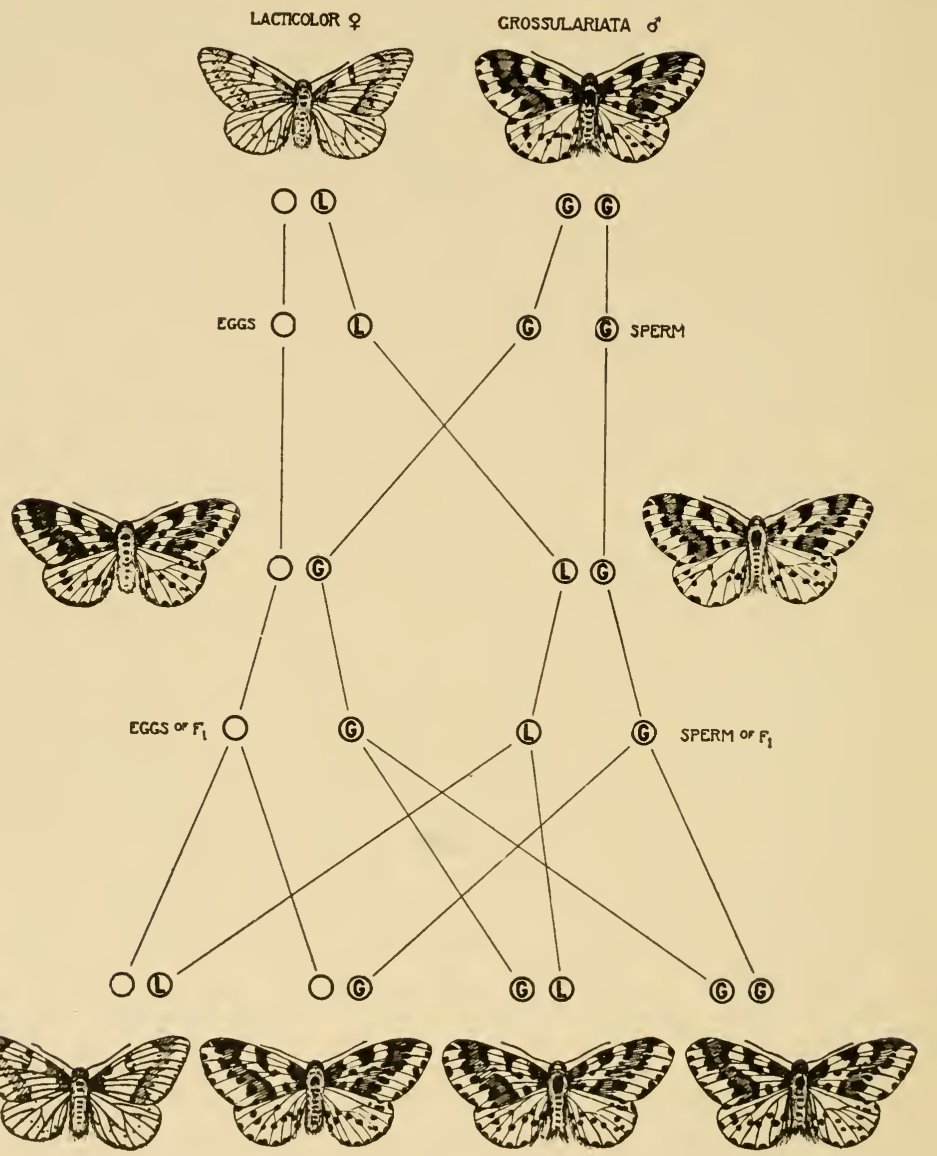

Fig. 30.-Abraxas lacticolor female by A. grossulariata male. The sex chromosomes are represented by the circles in the center of the diagram, and the letters contained in them stand for the factors that each carries. The $\mathrm{W}$ chromosome, confined to the female line, is represented without either G or L; for it, like the Y chromosome in Drosophila, carries no sex linked factors. 
In the first cross (Fig. 30), where the lacticolor female is mated to the grossulariata male, the off-
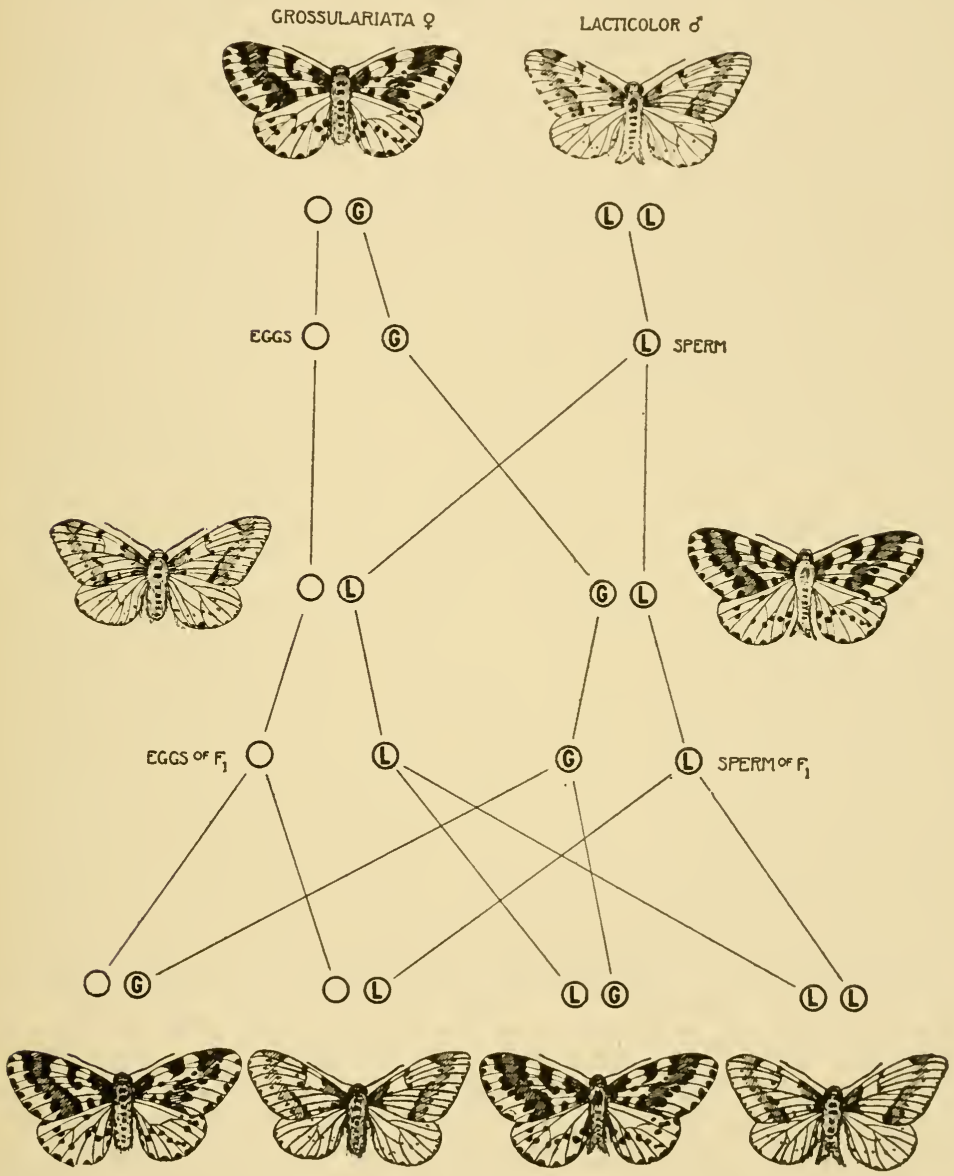

Fig. 3I.-Abraxas grossulariata female by A. lacticolor male. The reciprocal cross of the one shown in Fig. 30.

spring are all of the grossulariata type. When these are inbred they give $\left(\mathrm{F}_{2}\right)$ three grossulariata to one 
lacticolor, but the lacticolors are females only. The lacticolor grandmother has transmitted her peculiarity visibly to half of her granddaughters, but to none of her grandsons.

In the reciprocal cross (Fig. 31) of lacticolor male by grossulariata female, the daughters are like their father (lacticolor), and the sons are like their mother (grossulariata). This is so-called criss-cross inheritance. When the hybrids $\left(\mathrm{F}_{1}\right)$ are inbred, they give lacticolor males and females and grossulariata males and females in equal numbers.

Sex linked inheritance, as shown by the foregoing results, becomes intelligible if the factor for lacticolor is carried by the chromosome $\mathrm{Z}$. Its occurrence in $\mathrm{Z}$ is indicated here by writing an $\mathrm{L}$ inside the circle which represents that chromosome, while the allelomorphic character carried by the $\mathrm{Z}$ of the grossulariata individual is indicated by writing $G$ in the circle. The $\mathrm{W}$ chromosome is indicated by the blank circle. The two cases then work out as shown in the diagrams.

The preceding analysis shows that the genetic evidence calls for a mechanism in which the female is heterozygous for. sex, since those of her eggs which carry the factor for grossulariata all develop into females, the others into males. In the case of Abraxas there was for some years no positive cytological evidence in support of this view. Fortunately, the cytological side is now in a much better position owing to the work of Doncaster and Seiler.

Doncaster examined Abraxas cytologically, and 
found that both the female and the male have 56 chromosomes, with no obviously unequal pair.

Normally in Abraxas the sex ratio is about 1 to 1. In one exceptional line this equality of sexes was not the rule. In this strain Doncaster found many females which gave only daughters, and not a single son. Other females of this line gave many daughters but also a few sons, while still others gave practically a normal 1 to 1 ratio.

When Doncaster examined this line cytologically, he found that although the males were normal, with 56 chromosomes, the females were aberrant, having only 55 chromosomes.

In the maturation of the eggs of such a 55 chromosome female, the odd chromosome went to one pole, so that one polar plate had 27 and the other 28 chromosomes. Doncaster found further that the odd chromosome went more often to the polar body than to the egg. The many eggs that eliminate the odd chromosome become after fertilization individuals with 55 chromosomes, that is, females-while the few that retain it become 56 chromosome individuals - that is, males. The preponderance of the females is thus accounted for. Such females having 55 chromosomes would belong to the $\mathrm{OZ}$ type.

In normal strains there is a $\mathrm{W}$ chromosome present, but since this $\mathrm{W}$ chromosome may be absent without effect upon the sex of the individual, as shown above, it must be regarded as functionless in determining sex, and in this sense it corresponds to the $\mathrm{Y}$ of Drosophila. This evidence proves that there is 
present in Abraxas that cytological basis which the evidence from sex linkage demands, namely, a condition the converse of that known in other groups of insects.

The evidence that Seiler has obtained relates to the wild strains of the moth Phragmatobia fuliginosa. The reduced number of chromosomes in the polar plate of the egg is 28 (Fig. 32, a). The large dyad formed by synapsis of the sex chromosomes $\mathrm{Z}$ and $\mathrm{W}$ is shown in the middle of the group. At the first polar division all the chromosomes separate from their mates, the ordinary chromosomes (autosomes) as well as the sex chromosomes. But as $\mathrm{W}$ separates from $Z$, it breaks into two parts which we may call large $\mathrm{W}$ and small $\mathrm{w}$ (Fig. $32, b, c$ ). As a result there are 29 chromosomes at one pole (the pole that contains $W$ and $w$ ) and 28 chromosomes at the other pole (the pole containing $\mathrm{Z}$ ). It is a matter of chance which group goes into the polar body and which remains in the egg. Consequently there are two kinds of eggs, $\mathrm{Ww}$ and $\mathrm{Z}$.

In the male there are 56 chromosomes, which give the reduced number 28. The two large Z's can be made out in Fig. 32, $d$. These meet, when the reduced number 28 is formed, and then separate, one going to each pole (Fig. 32, h). Each spermatozoon contains, therefore, one $\mathrm{Z}$ chromosome.

FIG. 32.-Phragmatobıa fuliginosa. $a$, equatorial plate of first polar body of egg; $b$ and $c$, daughter plates of the first polar spindle; $d$, equatorial plate of spermatogonium; $e$, equatorial plate of first spermatocyte; $f$ and $g$, equatorial plates of second spermatocyte; $h$, anaphase stage of first maturation; $i$ and $j$, equatorial plates of somatic cells with 56 (in $i$ ), and 61 chromosomes (in $j$ ). (After Seiler.) 
SEX INHERITANCE

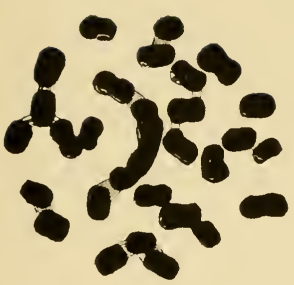

$a$

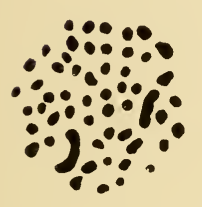

d
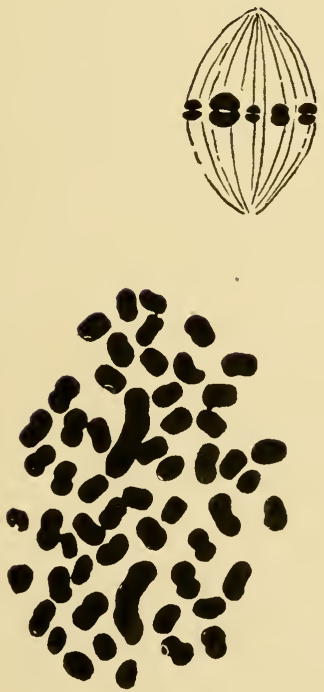

$g$

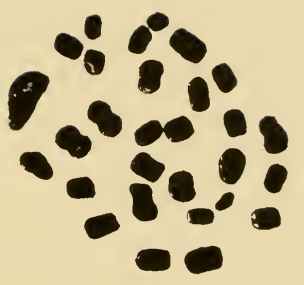

$b$
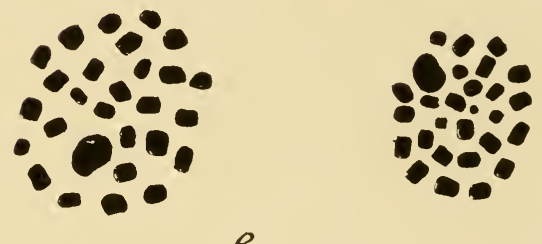

e

$f$

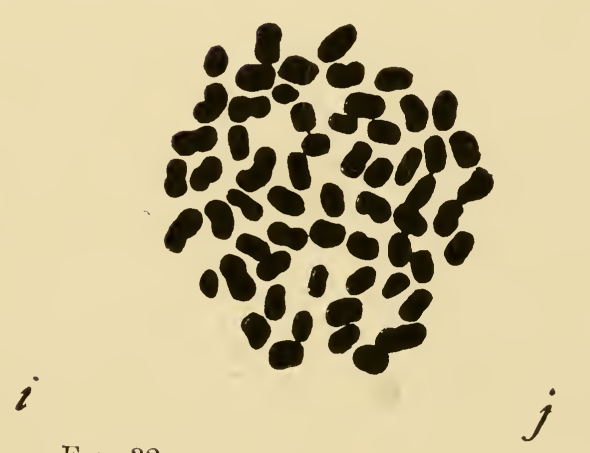

FIG. 32 .

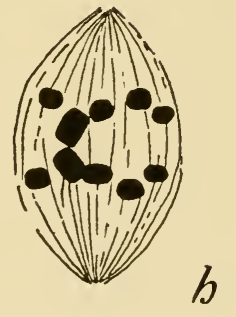


Any sperm fertilizing an egg containing $\mathrm{Ww}$ produces a female. The male embryos should contain therefore 56 chromosomes, the female 57. Counts of chromosomes in embryos show that while some contain 56, others contain $58, \cdot 61$ and 62 . Seiler suggests that the $\mathrm{Z}$ element is also compound and sometimes separates into four components in the somatic cells. Aside from this peculiarity his results indicate that the male is monogametic and the female digametic in accordance with the WZ-ZZ scheme.

In other Lepidoptera, examined by Stevens, by Doncaster, by Dederer and by Seiler, the males and females have the same chromosome configuration. In other words, if a $\mathrm{WZ}$ pair is present in the female the members are of the same size, or so nearly of the same size that they cannot be distinguished. It will be recalled that in a few other insects, believed for other reasons to belong to the Drosophila type, the $\mathrm{X}$ and the $\mathrm{Y}$ chromosomes are of the same size. The failure to find two sizes of sex chromosomes in moths is, therefore, not an argument against the view that the female is heterozygous for a sex factor. On the contrary, it is to be considered only a fortunate circumstance that this difference in a sex factor is sometimes associated with a size difference in no way directly depending on the sex factor itself.

\section{What aRe Sex Factors}

The inheritance of sex is explained by the assumption that one difference distinguishes the male from 
the female; the difference is a single or a double amount of the so-called sex factor. The chromosomes are the carriers of these sex factors. The symbols used here, viz., XX-XY and WZ-ZZ, are intended primarily for the chromosomes, but also for the sex factors.

These formulæ for the Drosophila type and for the Abraxas type raise the question as to whether the postulated sex factors are identical in the two cases. The employment of different letters for the two types suggests, of course, that the sex factors may be different. And it is true that the two sets of letters are used to avoid an apparent paradox that appears if we use only $\mathrm{X}$ and $\mathrm{Y}$ in both cases. If this is done, $\mathrm{XY}$ on one scheme represents the male and on the other scheme the female. Nevertheless, for the present the employment of different letters need not necessarily mean that different. factors for sex are present in the two great classes, for these reverse results may be due to the action of the same factor-difference in a different setting. For example, acid may be the color differentiator in a setting of a certain solution containing it and litmus (with one drop of acid the color being blue, with two drops red), but in a setting containing Congo red the same differentiator may produce just the opposite effects (one drop red, two drops blue). On the other hand, it is conceivable that the setting (litmus and acid) may remain the same and yet a reverse result be produced by having a different differentiator -alkali instead of acid. 
Since genetics has at present nothing to offer that will decide the question as to whether another set of sex differentiators is present, or whether the same differentiators with a different setting are involved in these two cases, discussion is quite certain to be futile.

It may seem inconsistent to use the name of the chromosome as the symbol for the sex factor when dealing with the inheritance of sex, while in all other cases a factor representing a point in the chromosome is used to designate the special character under consideration. No doubt with this idea in mind, several writers have followed the practice of indicating the sex factor by a significant letter, such as $\mathrm{F}$ for femaleness and $\mathrm{M}$ for maleness. As the use of such letters often involves a question of interpretation, a brief consideration may be given to this matter. In the discussion that follows reference is made always to the Drosophila type, but exactly the same arguments apply to the Abraxas type.

1. It has been suggested, for example, that a factor for the male be added to the formulæ so that maleness may not appear simply as the absence of one factor for femaleness. Thus, in such formulæ as FMFM ( $q$ ) and FMM ( 8 ) the factor for maleness is added to indicate that when a single amount of $\mathrm{F}$ is present the male factors produce the male. But since M's are distributed everywhere, the formula is little more than a concession to male vanity, for $M$ is not here a differentiator. Moreover, the use of the letters MM is here unjustifiable because there is no ground 
for supposing that maleness is due to one pair of factors. It must be due to a complex of many factors all of which are present in both sexes.

2. Since there is evidence to show in some cases that there is no sex factor in the $\mathrm{Y}$ chromosome, the factor or factors carried by $\mathrm{X}$ can have no mate in this sex, hence the allelomorph or allelomorphs must be 0 . If one chooses to represent this zero by a small letter, by $\mathrm{f}$ or $\mathrm{m}$ for instance, there is no inconsistency in doing so, for there is in this instance the cytological observation to justify its use. It is, however, misleading to represent this 0 by $\mathrm{M}$ as has sometimes been done.

3. There is at present no evidence to show that there is only one factor for sex carried by each sex chromosome, however probable this may seem from other relations, for it has not been possible to determine the linkage relation of the sex factor or factors to other factors in the sex chromosome, because crossing over of like factors in the homozygous sex would lead to no visible effect, and in the heterozygous sex no crossing over takes place.

4. If in the formulæ $\mathrm{FF}(q)$ and $\mathrm{FO}(\delta)$ the letter $\mathrm{F}$ is interpreted as a factor for femaleness, the formula must not be construed as meaning that $\mathrm{F}$ may not also be a factor for maleness. For, as a matter of fact, one $\mathrm{F}$ factor may be essential to the production of the male. Therefore, until we get more definite information as to the existence of a single or of several factors for sex, and as to whether they are the same factors in the two types, and what the rela- 
tion of $\mathrm{F}$ and $\mathrm{M}$ may be in hermaphroditic types, it is less inconsistent to use the symbols for the sex chromosomes as the symbols for the sex factors also, if it is at the same time recognized that the whole chromosome is not involved in determining sex.

The same factors that determine whether eggs or sperm develop in an individual must also be responsible for the development of many characters that go along with the male or the female condition, in other words those characters that are different in the two sexes (sex limited). Sex factors of whatever kind, however, must like all factors be supposed to produce their effects in conjunction with the rest of the cell, with other factors, or with anything else there, for it must always be remembered that the sex factor is only one of many factors that are at work. Hence for the realization of any particular character that is associated with a particular sex there are probably many factors that cooperate. If the latter change, the character in question may also change, while the sex factor remains the same. The character may, in this case, be said to be dependent not only on the sex factor, but also on another differentiator that can only realize itself conjointly with the sex factor. Thus while the accessory sexual organs, as well as the secondary sexual characters and all other sex-limited characters, may be modified by special differentiators that are not present in the sex chromosomes, yet the sex factor also produces an effect on their development which is different according to whether the sex factor exists in single or double amount. In 
the case of some other characters, however, it is conceivable that the sex factors co-operate in their production, and yet have the same effect whether present in single or double amount. Such characters would not be sex limited.

As in the case of sex limited characters, so in the case of sex itself there must be many factors in the fertilized egg that are as essential to the development of sex as are the sex factors themselves, but as they are distributed to all individuals alike, they are not thought of as differentiators, but as forming the chemical background on which the single or the double amount of the sex factor gives its result. It is quite conceivable that one or more of these other factors might so change that the sex differentiators would become inoperative or even change so that these other factors themselves become the differentiators that determine sex.

The environment - the outer world-is also one of the components that enters into the development of every individual. A specific environment is one of the conditions of development. Why then, it may be asked, may not the environment turn the scale and determine sex? As a general proposition this must be acceded to at once-it is entirely a matter of proof. If there is an internal mechanism to determine sex in a normal environment it is quite conceivable that it might be supplanted in a new world. It is a question of evidence as to how often, if ever, this occurs. It is furthermore quite conceivable that some animals have no internal mechanism to regulate 
sex but depend on a difference in their medium. If such an environment can be discovered it would be sex determining in the same sense in which the term is here employed when the sex differentiators are hereditary factors.

Sex determination in the Gephyrean worm Bonellia is a case in point. The female is a large oval worm with a long proboscis. The male is very small and degenerate and lives as a parasite on the proboscis of the female. The development has recently been studied by Baltzer. He finds that if the young Bonellia embryos are put into an aquarium in which old females are present, they settle down on the proboscis of the female and degenerate into males. If, on the contrary, the young embryos are kept by themselves they pass through an indifferent stage but later differentiate into female worms. Whether a male or a female develops from an egg depends here on whether at a certain stage the embryo comes under the influence of the proboscis of a female or fails to do so. Some secretion from the proboscis may be the differentiator in such a case. It is clear that here it is environment that determines the sex of the individual. The evidence suggests that the male organs develop first in the presence of a certain secretion from the proboscis of the female which also serves to arrest the animals in this stage. If, however, the animal fails to meet with these conditions, it usually ceases for a time to develop and fails to produce the male organs. Later it starts once more to go forward and develops the 
female organs which are characteristic of this sex. Baltzer found, however, that only 90 per cent. of these free embryos became females; the remaining 10 per cent. developed into hermaphrodites. He speaks of Bonellia as a protandric hermaphrodite in which one or the other sort of reproductive organs may be suppressed by the environment, but this is only another way of describing the results.

There are several groups in which a change from parthenogenesis to sexual reproduction takes place in response to changes in the environment. The best known cases are the rotifer (Hydatina senta), some of the daphnians (Moina and Simocephalus) and certain insects (aphids). Hydatina gives the clearest evidence (Fig. 33). It has been shown by Whitney and by A. F. Shull that if this rotifer is fed on a colorless flagellate and kept in water from old cultures it can be kept indefinitely reproducing by parthenogenesis, i.e., by eggs that are not fertilized. If taken out of these solutions and put into spring water, a certain percentage of the females will give rise to daughters whose eggs may be fertilized. These daughters behave therefore as sexual females. But if they are not impregnated their eggs remain viable and develop parthenogenetically into males. If in addition to being transferred to spring water the females are fed with a green flagellate, Dunaliella, then, as Whitney has shown, almost all of their daughters ( 80 per cent.) are changed into the sexual form, i.e., a form producing eggs capable of being fertilized (or if not fertilized, developing into males). 
An environmental change determines whether parthenogenesis or sexual reproduction takes place. The environment may equally well be said to de-

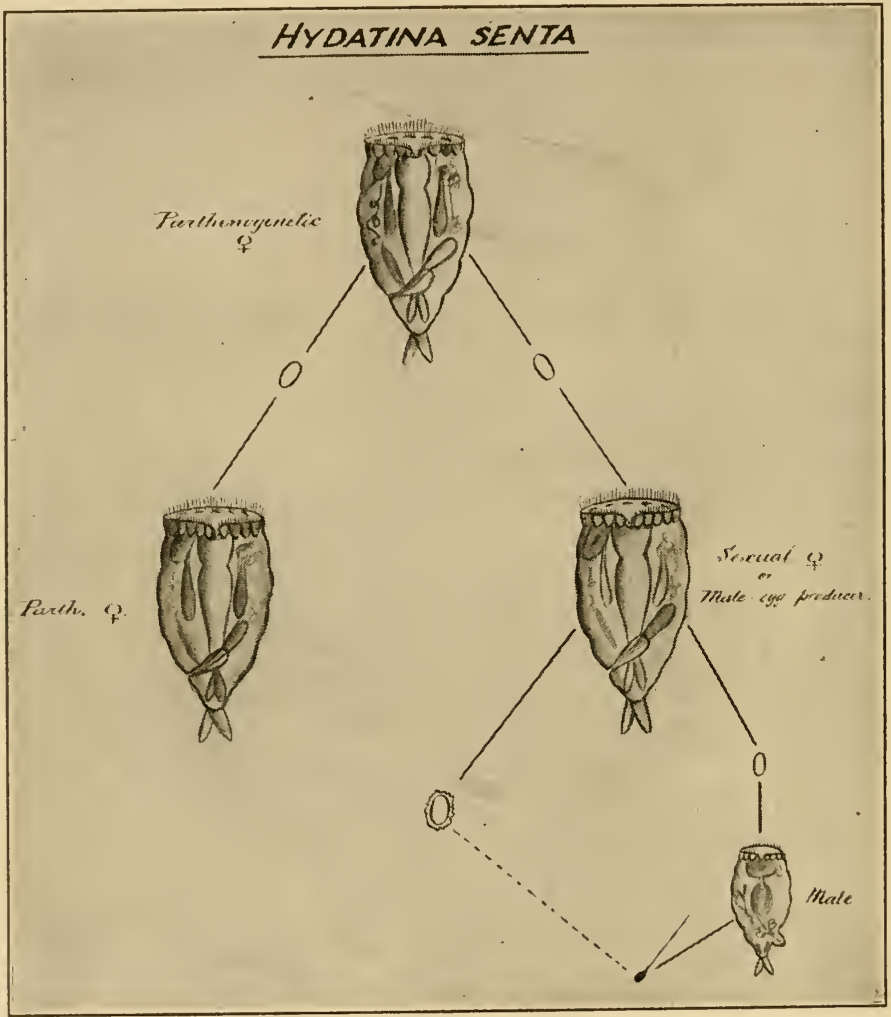

Fig. 33.-Diagram to illustrate the life cycle of Hydatina senta. The environment determines whether the parthenogenetic individual (at the top) gives rise to a female like herself, or to one that if fertilized at an early age produces a sexual egg, but if not fertilized produces small eggs from which males develop parthenogenetically.

termine whether an egg becomes a parthenogenetic female-producing female or a male-producing female. 
But another difference is necessary to determine whether an egg of the latter individual develops into a male or into a female, namely, the entrance of a spermatozoon into the egg before it has completed its growth.

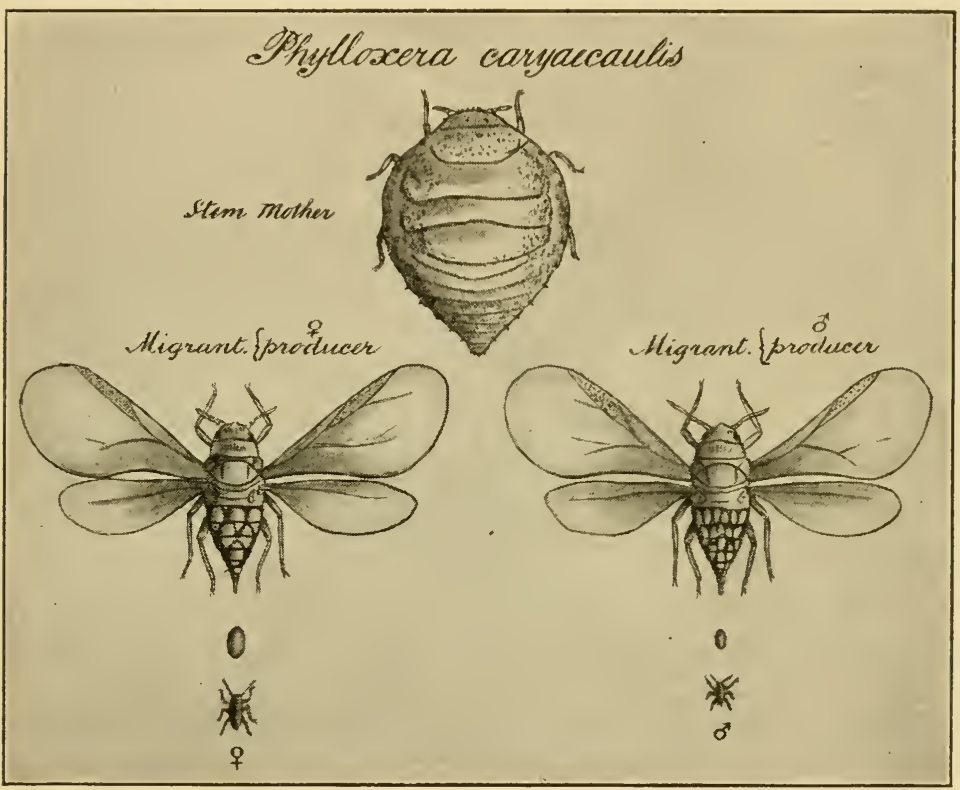

FIG. 34.-Diagram to illustrate the life cycle of Phylloxera caryæcaulis.

In the phylloxerans of the hickories the fertilized egg gives rise to a female called the stem mother (Fig. 34). She emerges from the egg in the early spring and attaches herself by means of her proboscis to a leaf, causing it to produce a gall that envelops her. Within the gall she lays her eggs. These hatch, and produce the winged or migrant generation 
(Fig. 34). In one species, P. caryæcaulis, all the migrants in one gall are alike in that they produce the same kind of egg, i.e., in some galls all the migrants contain large eggs (that produce sexual females), while in other galls all of the migrants contain smaller eggs (that develop into males).

The sexual female lays one egg, that is fertilized, from which the stem mother emerges the following spring. The males give rise only to female-producing sperm, each spermatozoon containing two sex chromosomes. The other class of sperm degenerates. Hence we can understand why it is that all fertilized eggs produce females only.

The chromosomal cycle undergoes the series of changes shown in Fig. 35. In P. caryæcaulis there are eight chromosomes, including four sex chromosomes $(\mathrm{XxXx})$. Since the history of the sex chromosomes alone furnishes certain information that makes clear some of the changes in the life cycle, the other chromosomes may be disregarded for the present.

Starting at the bottom of the diagram it will be seen that the sexual egg after extruding the two polar bodies contains two sex chromosomes indicated by $\mathrm{X}$ and $\mathrm{x}$. Two kinds of males are indicated in the diagram, one containing $\mathrm{Xx}$ the other $\mathrm{Xx}^{\prime}$, and as a consequence there will be two kinds of female-producing sperm, one kind for each male, namely, $\mathrm{Xx}$ and $\mathrm{Xx}^{\prime}$. If the former fertilizes the sexual egg, the resulting stem mother will be $\mathrm{XxXx}$, if the latter, the stem mother will be $\mathrm{XxXx}^{\prime}$. These two kinds of stem mothers are indicated at the top of the diagram. 
One of them, XxXx, produces eggs which, after extruding one polar body, give rise to the migrants bearing large eggs; from the latter eggs, in turn, come

I"GENERATION

$\mathbf{X}_{\mathbf{x}} \mathbf{X}_{\mathbf{x}}$

STEM MOTER - FCMLE. FRODUCNG LINE

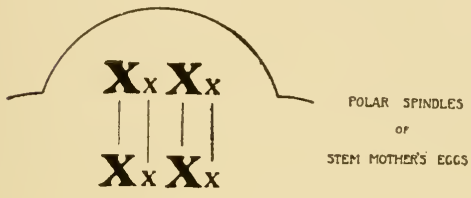

$\mathbf{X}_{\mathbf{x}} \mathbf{X}_{\mathbf{x}^{\prime}}$

STEY MOTHER - MALE'PRODUCNG LIEE

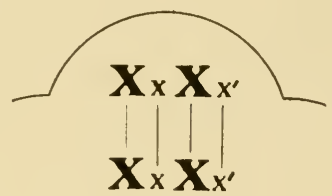

$2^{\text {ND }}$ GENERATION

$\mathbf{X}_{\mathbf{x}} \mathbf{X}_{\mathbf{x}}$

MIGRANT - FEMALE PRODUCER

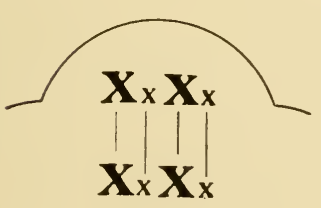

FEMALE ECG
$\mathbf{X}_{\mathbf{x}} \mathbf{X}_{\mathbf{x}^{\prime}}$

MIGRANT.- MALE PRODUCER

$\mathbf{X} \mathbf{X}_{x x^{\prime}}$

POLAR SPINDLES

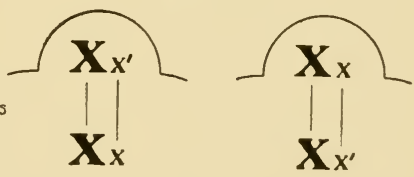

MaLe EGGS

$3^{\text {No }}$ CENERATION

$\mathbf{X}_{x} \mathbf{X}_{x}$

FEMALE

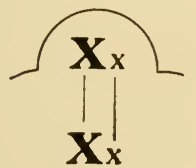

SEXUAL EGG
POLAR SPINDLE
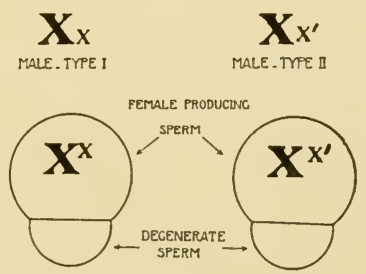

Fig. 35.-Diagram to illustrate the chromosomal cycle of Phylloxera caryæcaulis. 
the sexual females. The other stem mother $\mathrm{XxXx}^{\prime}$, produces eggs, which, after extruding one polar body, give rise to the migrants bearing small eggs. Prior to the time when these small eggs are about to give off their single polar body, the two large $\mathrm{X}$ 's conjugate and the two small x's conjugate, and when the polar body is given off one large and one small $\mathrm{X}$ pass out, and one large and one small $\mathrm{X}$ remain in the egg. In other words there is at this time a reduction in the number of sex chromosomes, and, as a consequence, a male is produced. Now as the diagram shows, $\mathrm{Xx}$ may remain in the egg and $\mathrm{Xx}^{\prime}$ pass out; or, in other eggs, $\mathrm{Xx}^{\prime}$ may remain in the egg and $\mathrm{Xx}$ may pass out. There will be, in consequence, two kinds of males, one $\mathrm{Xx}$, the other $\mathrm{Xx}^{\prime}$, and as stated, two kinds of female producing sperm $\mathrm{Xx}$ and $\mathrm{Xx}^{\prime}$.

Thus the life cycle is brought back to the starting point. It may be added that so far as the chromosomes other than the $\mathrm{X}$ chromosomes are concerned there is no synapsis and no reduction to the haploid number in either line until the maturation divisions of the third or sexual generation occur. The life cycle of this species illustrates three points:

First.-That all of the sperm are female producing, because the male-producing class of sperm degenerates, as has been shown by direct observation.

Second.-That the parthenogenetic females can produce males through the elimination of two chromosomes. The female contains four sex chromosomes and the male two. The elimination of the 
two chromosomes in the polar body of the maleproducing egg has been directly demonstrated.

Third.-In this species the somewhat unusual relation of one stem mother giving rise to the line that culminates in the sexual eggs, and of another stem mother giving rise to the line that culminates in the males, can be explained on the assumption that one pair of the sex chromosomes is heterozygous in some factor indicated in the diagram by priming one of the x's. This explanation is in part theoretical, although it is based on the actual observation of two kinds of males that differ in respect to the behavior of one of the smaller x's.

In other species of phylloxerans, and in many aphids, one stem mother may produce both lines, i.e., some of her offspring may ultimately give rise to sexual females and others to males. In such cases, as is illustrated in the next diagram (Fig. 36), there is but one kind of stem mother, and the four sex chromosomes (there are only two sex chromosomes in the aphids) are alike. Here some environmental influence must determine that in certain eggs conjugation of two pairs of chromosomes takes place. Such eggs give rise to males. In other eggs where this does not take place the sexual female will be produced.

In both $\mathrm{P}$. caryæcaulis and in P. fallax, and also in the other forms referred to above, the difference between the behavior of the chromosomes in the stem mother and in the male-producing migrant is dependent on environmental influences. On the 
other hand, the difference between the eggs contained in the male-producing and in the female-producing migrants, and between the behavior of the chro-

\section{$\mathbf{X X X X}$ \\ STEM MOTHER}

I GENERATION

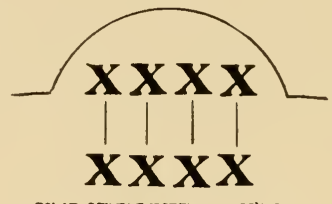

POLAR SPINDLE O STEM-MOTMER'S EGG

2® GENERATION

\section{$\mathbf{X X X X}$}

MICRANT.-FEMALE PRODUCER

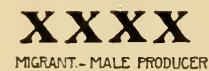

\section{$\mathbf{X X} \quad \mathbf{X X}$}

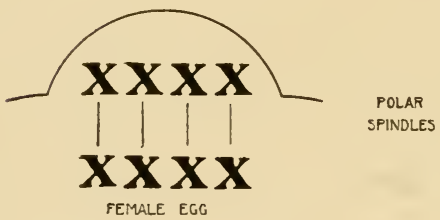

3 - GENERATION

$\mathbf{X X} \mathbf{X X}$

FEMALE

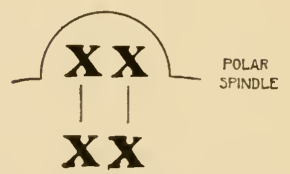

$\mathbf{X X}$

Male

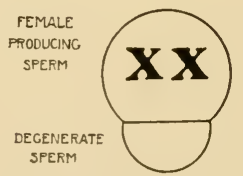

FiG. 36.-Diagram to illustrate the chromosomal cycle of Phylloxera fallax. 
mosomes in these eggs, depends in P. caryæcaulis on an initial chromosomal difference between the types of migrants, but in P. fallax on some environmental influence. The difference between the two kinds of sexual individuals, i.e., sex itself, is determined in both cases by the distribution of the chromosomes, however that distribution may itself be conditioned.

It is scarcely necessary to speak of other cases, in which, although an internal mechanism is known to exist for producing equal numbers of males and females, yet more individuals of one or the other sex may actually appear. For instance, it has been shown repeatedly in Drosophila that when a sex linked lethal factor is present in the sex chromosome, any male that contains this lethal $\mathrm{X}$ chromosome will perish. The females, on the other hand, will live, because they contain in addition another $\mathrm{X}$ chromosome, having the dominant normal allelomorph of the lethal factor. These lethal factors may be factors that cause abnormalities in organs essential to the life of the individuals and destroy the individual in this sense. The changed ratios do not at all affect the theory that there exists in Drosophila an internal sex-determining mechanism, although were the cases not actually worked out, the abnormal ratios might have seemed to disprove the theory of the sex chromosomes.

We can imagine other ways in which even in the presence of a regulating sex mechanism the actual ratio of males to females might be changed from equality to some other ratio. For instance, since the 
female-producing spermatozoa contain one more chromosome and are larger in consequence, as Zeleny and Faust have shown, such sperm might travel up the oviduct with less speed than the male-producing sperm. Hence the sex ratios would be affected in favor of the males. Furthermore, secretions in the oviduct might act differently on the two kinds of sperm, the age of the sperm might affect one kind more than the other, etc. Such effects would be expected to bring about deviations from the normal ratios, but effects of these kinds can not fairly be brought forward to disprove the hypothesis that the $\mathrm{X}$-bearing spermatozoa give rise to females and the no-X-bearing (or $\mathrm{Y}$ ) spermatozoa give rise to males. It has even been suggested that external conditions might so weaken or strengthen the $\mathrm{X}$ chromosome that an X-bearing spermatozoon might produce a male or that a no X-bearing sperm might produce a female. If such effects can be produced they would act, no doubt, in the way postulated. But there is a large amount of evidence showing that factors are not ordinarily altered by environmental influences. Nevertheless there is no conflict here with the sex chromosome mechanism, only another one is imagined to have the power to overthrow it. No adherent of the chromosome theory would deny the theoretical possibility that at times external conditions may at least overcome the usual effect of the sex factor if not the sex factor itself, but the burden of proof for such supposed reversal of the normal result lies with those who maintain it. Proof, if it were forthcom- 
ing, that the machinery of sex determination may be upset is not an argument against the sex chromosome theory. It is not a refutation of the factorial hypothesis of sex determination, for in such a case there would only be a substitution of an environmental factor for a genetic one. Opponents and advocates of the chromosome theory of sex determination have often failed to realize that "factor for sex" is not used in an absolute sense, but as the best known or most usual factor-difference among any number of possible theoretical ones; and in consequence the identification of sex as a character with the factor for sex determination has led to needless confusion. If the factor for sex were identified with sex itself, i.e., if it alone would produce sex, there would be of course only one form of sex determination possible. But, as no one maintains such an interpretation of sex determination, this view can not be properly advanced as an argument against the sex chromosome theory. 


\section{CHAPTER V}

\section{THE CHROMOSOMES AS BEARERS OF HEREDITARY MATERIAL}

The evidence in favor of the view that the chromosomes are the bearers of hereditary factors comes from several sources and has continually grown stronger, while a number of alleged facts, that seemed opposed to this evidence, have either been disproven, or else their value has been seriously questioned. We propose now to examine in some detail the observations and experiments that bear on the chromosome theory of heredity.

\section{The Evidence from Embryology}

Relating to the Influence of the Chromosomes on Development

It has been argued that since the sperm transmits equally with the egg, and since only the sperm head, consisting of the nucleus, enters the egg, inheritance is only through the nucleus. But it must be admitted that around the entering sperm nucleus there may be a thin enveloping protoplasm, which, however scanty, might suffice to transmit certain cytoplasmic factors. Moreover, while the tail of the sperm appears in some cases to be left outside the 108 
egg, in other cases it appears to enter and to be absorbed.

Behind the head of the spermatozoon, and at the base of the tail, there is a middle piece which contains a derivative of the old centriole or division center. Since the centrosome carried by the sperm has been found in some forms to give rise to the new centrosomes that occupy the poles of the first cleavage spindle of the egg, it may appear that a paternal contribution can come about in this way. It is true that the continuity of the centrosome of the sperm with that of the dividing egg has been disputed in some forms; but it is difficult to prove that the sperm centrosome is lost, even though it may disappear owing to loss of staining power.

The nucleus contains a sap which is probably of cytoplasmic origin. The presence of this sap may again be appealed to by those who do not accept the chromosomes as the bearers of heredity, as a weak link in the evidence. It is true that the nuclear sap appears to be squeezed out of the nucleus of the sperm head, leaving a compact and apparently solid mass of chromatin, yet its complete elimination can not be proved. Hence, while those who favor chromosomal transmission find in the facts of normal fertilization strong indications favorable to that view, yet it is also true that those who are inclined to dispute this view find several loopholes in the argument of their opponents.

The importance of the nucleus in heredity has further been shown by experiments of Bierens de 
Haans, Herbst, and Boveri on giant eggs of sea urchins fertilized by sperm of another species. The hybrid larvæ produced when normal eggs of one species are fertilized by sperm of the other species are intermediate in character between the two parental types of larvæ; while those from giant eggs of the same species fertilized by sperm of the other, also intermediate, incline more to the maternal side. The nucleus of the giant egg is double the size of that of the normal egg and according to Bierens de Haans the chromosomes are also double in number. Consequently, the amount of maternal chromatin should be double that introduced by the sperm, and might produce a corresponding influence on the hybrid character. But since in these giant eggs the cytoplasm is also doubled, it is not evident that the results are due to the chromosomes rather than to the cytoplasm. By means of the following ingenious comparison Boveri has shown that the results must be ascribed to the chromosomes rather than to cytoplasm. Normal eggs were broken into fragments, the nucleated pieces were fertilized with the sperm of the other species, and those fragments of half the volume of the normal egg were isolated. As is known, such fragments develop into whole larvæ, whose nuclei will have the usual chromatin content. The egg cytoplasm is, however, reduced to half. Nevertheless the larvæ did not incline to the paternal side, although these larvæ, like all larvæ from fragments, were often simpler than the normal. Hence since a relative decrease in the amount of 
cytoplasm does not here affect the character of the larvæ, it is rational to suppose that an increase such as is present in the giant eggs likewise produces no such effects as observed in the larvæ. At the same time, normal eggs were cross fertilized and in the two-cell stage the blastomeres were separated. The contributions by the two parents were relatively the same as in the normal egg. These larvæ were like those from egg fragments, and serve as a control of those larvæ in so far as they bear on the question of how far size alone may affect the result. Moreover, in them, the relation of the chromosomes to the cytoplasm is the same as in the normal egg (whether the sperm does or does not bring in cytoplasm). Hence, since the amount of cytoplasm is shown to have no influence on the character of these larvæ, there is no reason for supposing that it had any influence in the case of the giant eggs.

Boveri's studies upon dispermic fertilization of the egg of the sea urchin bear directly upon the question at issue. He found that when two sperm simultaneously enter the same egg, each brings in a centrosome, so that a tetra- or tri-polar spindle is formed for the first division, as shown in Fig. 37. Instead of a double set of chromosomes, as in normal fertilization, there are three sets. At the first division, the chromosomes are irregularly distributed upon the multipolar spindles. In consequence, some cells may get one of each kind of chromosome, while other cells may get less than a full complement (Fig. 38). These dispermic eggs almost always give 
rise to abnormal embryos, as several observers have recorded. The result can best be attributed to the irregular distribution of qualitatively different chromosomes; only those embryos in which each cell has a full complement developing normally.

Boveri's evidence went still further, for he separated the first cleavage cells of these dispermic eggs
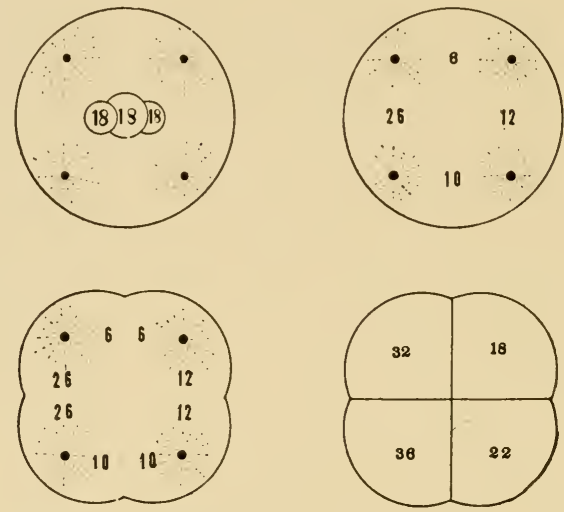

Fig. 37.-Dispermic fertilization of egg of sea urchin. The four centrosomes cause an unequal distribution of the fifty-four chromosomes, leading at the first division to four cells which contain different numbers of chromosomes.

and followed their history. Some of them gave rise to perfect dwarf larvæ. The number of normal embryos was small, but was that expected on the chance distribution of the chromosomes, for we should expect to find in a few cases an isolated cell that contained a full complement of chromosomes and from such a cell a normal embryo would be formed. The abnormality in development of the rest of the isolated cells was not due to any harmful 
effect caused by isolation, for it had been shown by Driesch and others that when the first two cells of a sea-urchin egg that has been normally fertilized are separated, each forms a perfect embryo. Such cells, although containing only half the cytoplasm, contain
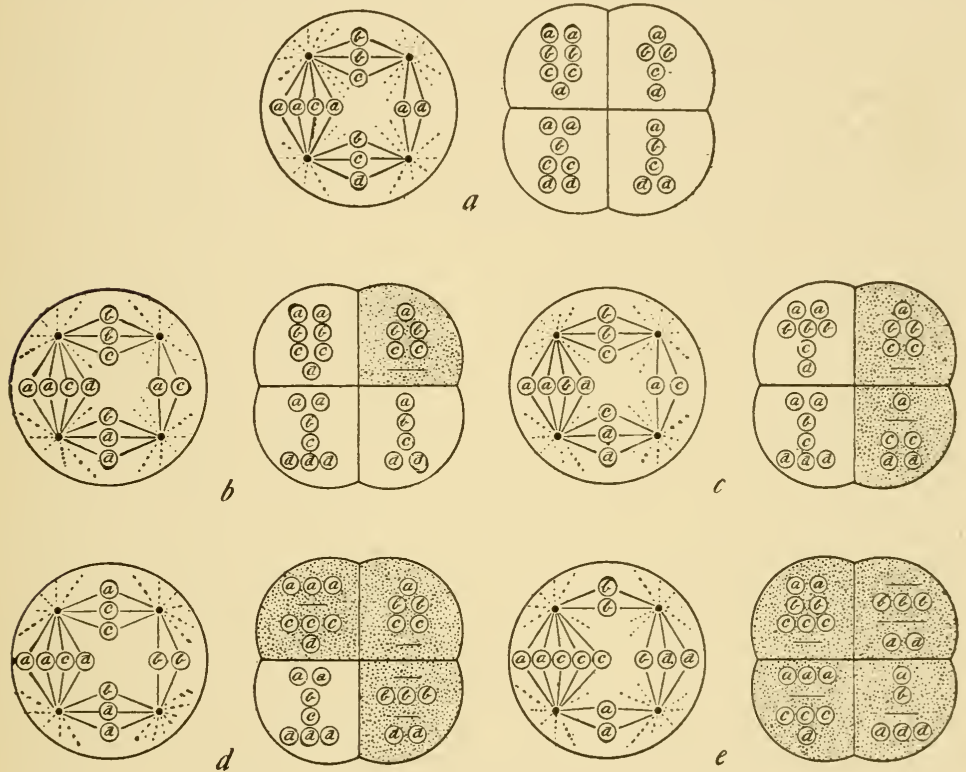

FIG. 38.-Diagram to show five combinations of chromosomes resulting from the first division of dispermic eggs, in which either each cell gets one complete set of chromosomes, $a$; or three cells get a full set, $b$; or two cells, $c$; or one cell, $d$; or none of the four cells, $e$, get a full set. (After Boveri.)

a full set of chromosomes. The difference, therefore, between these cells and isolated cells from dispermic eggs would seem to be due mainly to their different chromosomal contents.

Further evidence in favor of the chromosomal hypothesis is found in certain cases of hybrids between 
species of sea urchins. The best analyzed cases are those that Baltzer has worked out. Crosses were made between four species of sea urchins; one such cross will serve as an example (Fig. 39). The eggs of Sphærechinus were fertilized by the sperm of Strongylocentrotus. The division of the chromosomes proceeded in normal manner. The pluteus

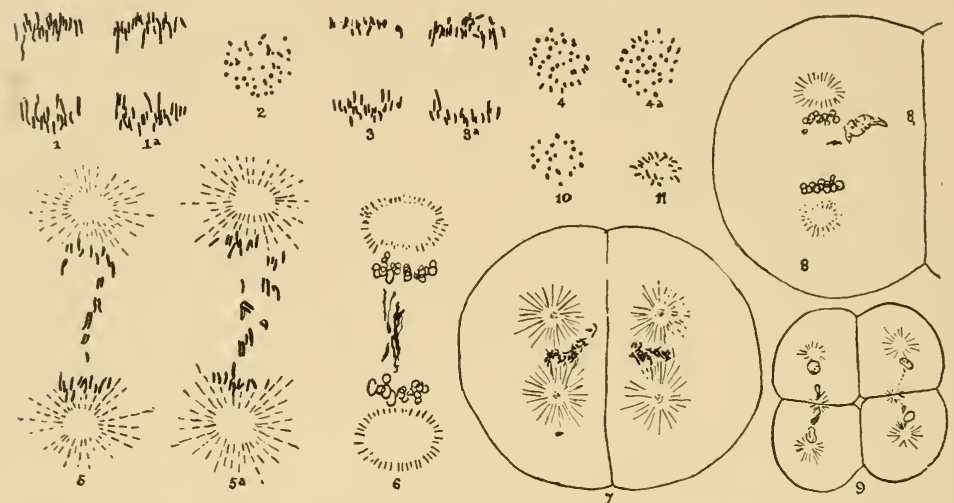

FIG. 39.-1 and $1 a$, chromosomes in the first normal cleavage spindle of Sphærechinus; 2, equatorial plate of two-cell stage of same; 3 and $3 a$, spindles of two-cell stage of egg of hybrid of Sphærechinus by Strongylocentrotus; 4 and $4 a$, same, equatorial plates; 5 and $5 a$, hybrid of Strongylocentrotus by Sphærechinus cleavage spindle in telophase; 6 , next stage of last; 7, same, two-cell stage; 8 , same, later; 9 , same, four-cell stage; 10 , same, equatorial plate in two-cell stage ( 22 chromosomes); 11 , same, from later stage, 24 chromosomes. (After Baltzer.)

that developed was intermediate in character; or at least showed peculiarities both of the maternal and of the paternal types. The reciprocal cross was made by fertilizing the eggs of Strongylocentrotus with the sperm of Sphærechinus. At the first cleavage of the egg some of the chromosomes divide normally, while other chromosomes remain inactive and finally be- 
come scattered in the region between the others that have retreated toward the poles. When the division is completed the belated chromosomes are found to be excluded from the daughter nuclei. They appear irregular in shape and show signs of degeneration. At the next division of the egg they may still be found, but they are lost later, and seem to take no part in the development. The difference between this and the other cross seems directly caused by the differences observed in the behavior of the chromosomes.

A count of the chromosomes in the hybrid embryos shows about twenty-one chromosomes. The maternal nucleus contained eighteen. It appears that only three of the paternal chromosomes have taken a regular part in the development-fifteen of them must have degenerated in the way described above. The hybrid embryos that developed were of ten abnormal; the few that developed as far as plutei were apparently entirely maternal in character. Since the reciprocal cross proves that the maternal characters are not dominant, the most reasonable interpretation is that, although the foreign sperm had started the development, it had produced little or no effect on the character of the larvæ, and this absence of effect would seem most probably to be due to the elimination of most of the paternal chromosomes. It might possibly be maintained that the same kind of effect produced by the egg of Strongylocentrotus on the chromosomes of Sphærechinus is likewise produced on the protoplasm introduced by the sperm. But there is here, in contrast to the case for the chromosomes, 
no evidence of any abnormal cytoplasmic behavior which could account for the observed abnormal effect.

Tennent also has found that when the sea urchin Toxopneustes (\%) is crossed to Hipponoë ( $\left.\sigma^{7}\right)$ no loss of chromatin occurs, and the larvæ are predominantly paternal, but in the reciprocal cross (Hipponoë $\rightarrow$ by Toxopneustes $\sigma^{7}$ ) some of the chromatin is eliminated and the larvæ are more like the maternal type.

Some experiments by Herbst also have an important bearing on the question. The eggs of Sphærechinus were put into sea water to which a little valerianic acid had been added. This is one of the recognized methods of starting parthenogenetic development. After five minutes the eggs were taken out and put into pure sea water to which sperm of Strongylocentrotus was added. The sperm fertilized a few of the eggs. The eggs had already begun to undergo some of the changes that lead to development. The belated sperm failed to keep pace with the division so that the paternal chromosomes did not reach the poles of the egg before the egg chromosomes reformed their nuclei (Fig. 40). In consequence, the paternal chromosomes formed a nucleus of their own that came to lie in one of the cells formed by the division of the egg. As a result one cell had a maternal nucleus and the other had a double, paternal and maternal, nucleus. In later development the paternal nucleus became incorporated with the maternal nucleus of its cell. Embryos were found later, in the cultures, that were on one side maternal 
and on the other side hybrid in character and probably came from such half-fertilized eggs. It will be recalled that Baltzer has shown that when the cross is made in this direction both paternal and

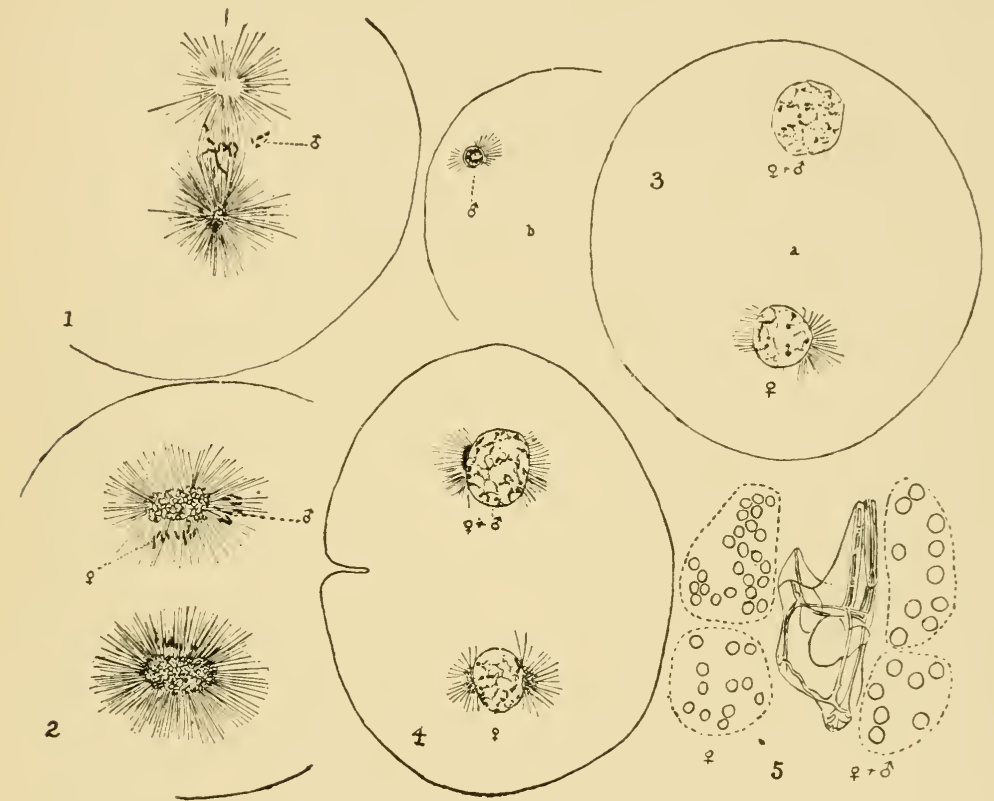

FIG. 40.-1, The chromosomes of the egg lie in the equator of the spindle, the chromosomes of the sperm at one side; 2, a later stage showing all of the paternal chromosomes lying at one side passing to one pole; 3 (to the right), later stage; the conditions are the same; there is also a supernumerary sperm in the egg (shown to the left, in another section); 4 , same condition as last; 5 , pluteus larva that is purely maternal on one side, and hybrid on the other. (After Herbst.)

maternal chromosomes behave normally at each division. The conclusion follows with much plausibility that the absence of paternal characters on one side is due to the absence of paternal chromosomes on that side. 


\section{The Individuality of the Chromosomes}

The view that the chromosomes are persistent as individual structures in the cell has steadily gained ground during the last twenty years. The process of karyokinetic or mitotic division by means of which at each cell division the halves derived from a lengthwise split of each chromosome are carried to opposite poles, so that a genetic continuity is maintained between corresponding chromosomes (and parts of chromosomes) in mother and daughter cells, has been found to be almost universal in both plants and animals. It is true that several instances have been described in which the nucleus simply pinches into two parts, and there can be little doubt that such cases occur; but no one has been able to show in a convincing way that cells which have once divided in this manner ever return to the regular process of karyokinetic division. Case after case of amitosis that has been described for the germ cells has been either disproven, or found to rest on faulty observation, or else to relate to cells like those of the egg coats that take no part in the germinal stream.

There are several observations that lead to the view, at present generally accepted, that the chromosomes retain their individuality from one cell division to the next. These may now be given.

During the resting stage the chromosomes spin out in such a way that they appear to form a continuous network in the nucleus. They can not be identified individually during this period. When the chromo- 
somes again become visible, preparatory to the next division, it has been found by Boveri in Ascaris, which is particularly well suited for the study of this point, that in sister cells the configuration of the groups of chromosomes is the same (Fig. 41). The similarity of the sister cells would be expected had the chromosomes retained during the resting stage the same shape and size and relative location that they had at the end of the last division. On no other
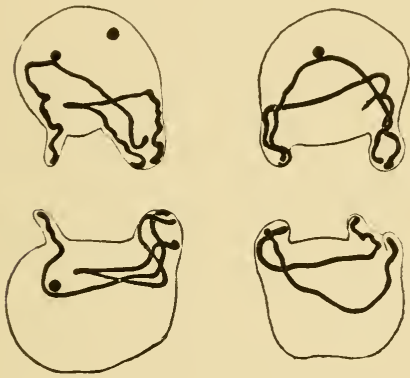

a

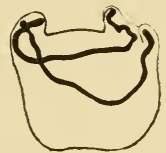

b
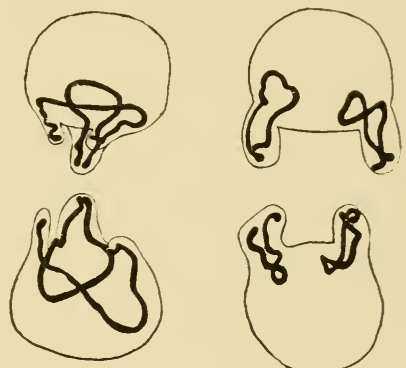

$c$

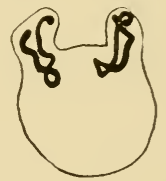

d

Fig. 41.-Four pairs of sister cells of Ascaris, in which the chromosomes are reappearing. Note the similarity of arrangement in the cells of each pair. (After Boveri.)

view can we so readily understand the similarities between the sister cells; for, in other cells of these same embryos that are not sister cells, a great variety of arrangements is found, and no two arrangements are so nearly alike as are those that are found in cells that have separated from each other at the last division. In a few instances certain observers believe that they have even been able to distinguish the separate chromosomes throughout the whole 
resting period of the cells, but this must be received with some caution. In many animals and in some plants the chromosomes are of very different sizes and shapes, and many, or even all of them, can be identified at each division. It is found that these size relations hold throughout all divisions of the cells. While this evidence appears at first sight to show that the chromosomes are structures that perpetuate themselves, preserving their identity, yet it might be maintained, in fact it has been maintained, that each species has its own peculiar protoplasm from which chromosomes of a particular kind and number are, as it were, crystallized out anew before each cell division. This point of view can not, however, be reconciled with the evidence that follows. In Metapodius, Wilson has found that individuals may differ in the particular chromosome that he calls the $\mathrm{m}$ chromosome. While the normal individuals have a pair of $\mathrm{m}$ chromosomes, one individual had three m's; but all of the cells of any given individual have the same number. These chromosomes furnish strong support of the continuity of the chromosomes; for, in whatever number they enter the individual during fertilization, they retain that number throughout all the subsequent generations of cells. The same is true, of course, for the sex chromosomes.

Corroborative proof is found in certain hybrids, where the evidence is even more significant, because in such cases the chromosomes introduced by the male are, as it were, in a foreign medium. For example, Moenkhaus first pointed out that when 
the fish Fundulus is crossed to another fish, Menidia, the two kinds of chromosomes present in the fertilized egg can readily be distinguished in later divisions. Similar observations have been made for many other crosses (Fig. 42) by Morris, G. and P. Hertwig, Federley, Doncaster, Rosenberg, etc. Despite the fact that the paternal chromosomes are in a foreign
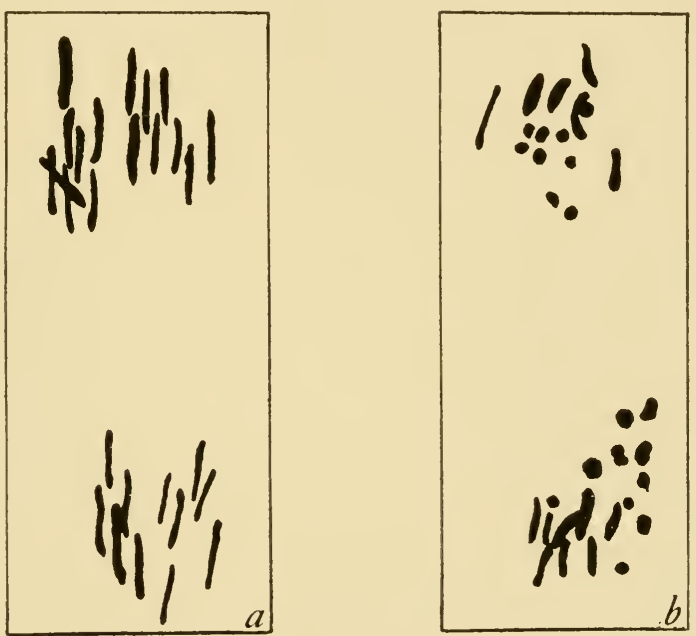

FIg. 42.- $a$, Telophase, division of an embryonic cell of Fundulus; $b$, telophase, division of an embryonic cell of egg of Fundulus fertilized by sperm of Ctenolabrus. (After Morris.)

medium they retain their characteristic size, form, and number. The embryos from these eggs are abnormal, and often die, not because chromosomes are eliminated but because the combination does not work out successfully. On the other hand, in hybrid embryos (studied by Herbst, Baltzer, and Tennent), in which paternal chromosomes are eliminated, they 
seem never to re-appear subsequently, while those not eliminated always re-appear at the next cell division. Other cases of the same sort are known.

In general it may be said that even an abnormal set of chromosomes, once established in a cell, tends to persist through all succeeding cell generations. This evidence indicates that the chromosomes are not mere products of the rest of the cell but are selfperpetuating structures.

\section{The Chromosomes during the Maturation of} the Germ Cells

On the most essential point concerning the maturation of the egg and sperm there is no dispute: the observed number of chromosomes is reduced to half. It is generally agreed that this lowering of the number is due to the union of similar chromosomes in pairs, each chromosome derived from the father conjugating with the homologous chromosome derived from the mother. In cases where different chromosomes can be distinguished by their shape or size relations, the relations of these pairs correspond exactly to what they should be if like chromosomes conjugated.

When we come to consider how this union of chromosomes is brought about, there is much divergence of opinion, for the evidence is fragmentary or contradictory on almost every point. The reason for this uncertainty is clear: the stages at which the reduction in the number of the chromosomes takes place are extraordinarily difficult to interpret, be- 
cause at this time the chromosomes are in the form of what seems to be a dense tangle of long threads. When this stage has been passed through, and the chromosomes are distinguishable again, the pairing has been completed. For any information that is worth while we have to rely on the best material available. It may be disputed which material is the best, but it will be generally conceded that a few types have shown themselves superior to others. The account of maturation that is here followed confines itself to two types - one for the male and the other for the female. These are selected cases, it is true, but they are those that give, in the opinion of the writers, two of the most complete accounts of these stages. The selection is admittedly not without bias, for these types can be most advantageously utilized to illustrate how crossing over can take place between the members of homologous pairs of chromosomes.

The salamander, Batracoseps attenuatus, has furnished some of the best material for the study of the ripening of the germ cells of the male. The account that follows is taken from Janssens' elaborate and detailed study of the spermatogenesis of Batracoseps.

At the end of the multiplication period (spermatogonial divisions) the nucleus appears as shown in Fig. 43, a. It then passes into a condition resembling a resting stage, $b$. Later the chromosomes begin to emerge in the form of long thin threads as shown in $c, d, e$. In the last figure (the leptotene stage) the ends of the thin threads are directed toward one pole 
where some of the ends can be seen to be arranged in pairs. As they unite in pairs these thin threads often have the appearance of twisting tightly around
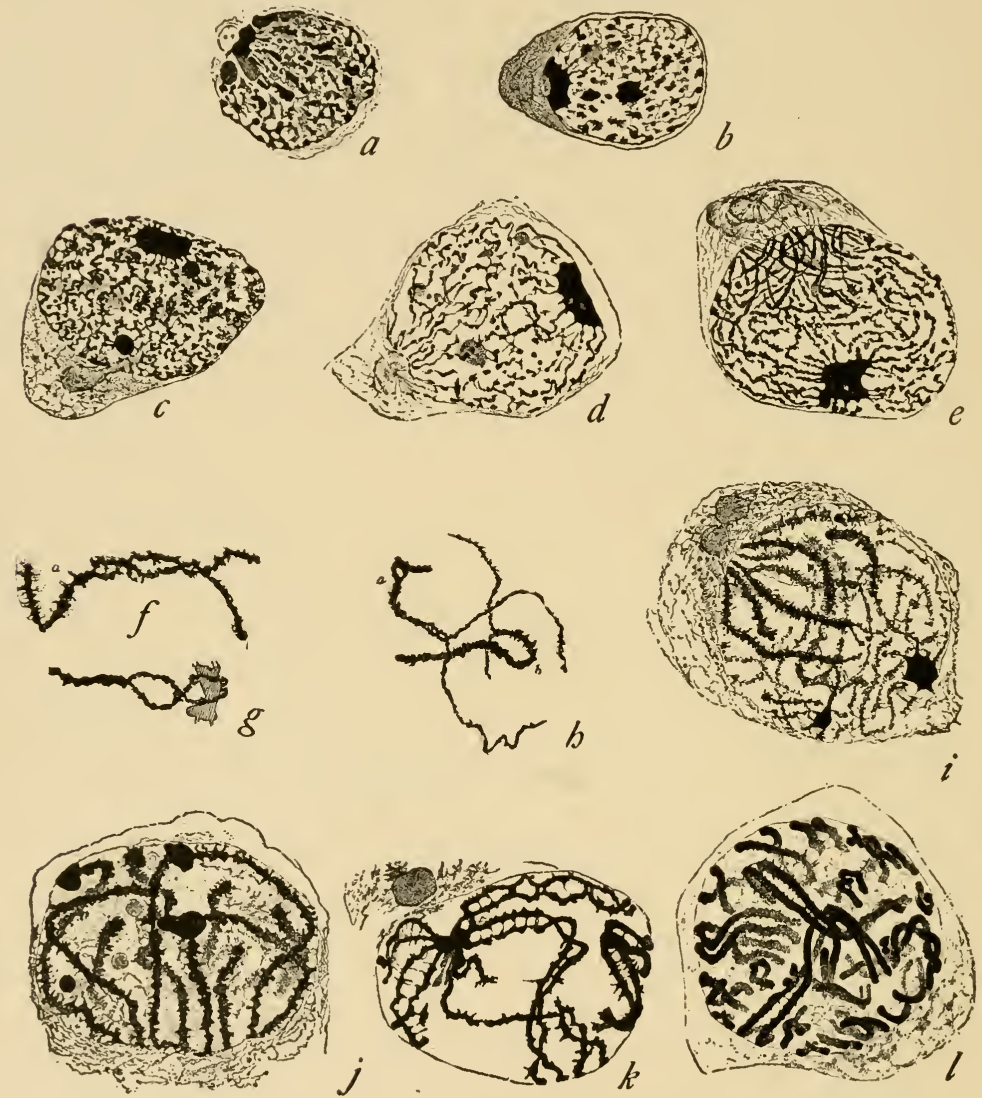

FIG. 43.-Spermatogenesis of Batracoseps attenuatus. $a$, late telophase of spermatogonial division; $b$, resting stage after the last spermatogonial division; $c$, appearance of the spireme; $d$ and $e$, later stage of last (bouquet grele); $f, g, h$, twisting of leptotene threads around each other (amphitene stage); $i$, amphitene stage (entire cell); $j$, pachytene stage (bouquet pachytene); $k$, longitudinal splitting of threads (strepsinema stage); $l$, shortening and thickening of the chromosomes. (After Janssens.) 
each other, beginning at the end where they first approached each other. The details of the union of the threads are further shown in $f, g, h$. As they unite they contract until they are in the form of a thicker thread, as seen in $i$, where the process of fusion has progressed as far as the middle of the nucleus. Later, $j$, the threads become fused throughout their length (pachytene stage). Still later the thick threads begin to show a longitudinal split (diplotene stage), and cross connections, uniting the halves of the threads, appear in different places. The threads thicken until finally a stage is reached like that shown in $k$, which, by further contraction, reaches the condition shown in $l$, a stage preparatory to the first maturation division. The threads of each pair, in all the stages of the latter part of the diplotene stage, are much twisted around each other; they are now so thick that they show the twisted condition very plainly.

The egg undergoes a series of changes during its maturation which parallels those of the sperm, and which leads also to the reduction in the number of the chromosomes to half of the full number. The eggs of a shark (Pristiurus melanostomus) have been described by Maréchal as passing through the following stages. At the end of the period of multiplication the eggs pass into à resting stage (Fig. 44, a) in which the chromatin appears as a delicate reticulum. A later stage is shown in $b, c$, when the separate thin threads begin to make their appearance, and take parallel courses, $d$ (leptotene stage). These 

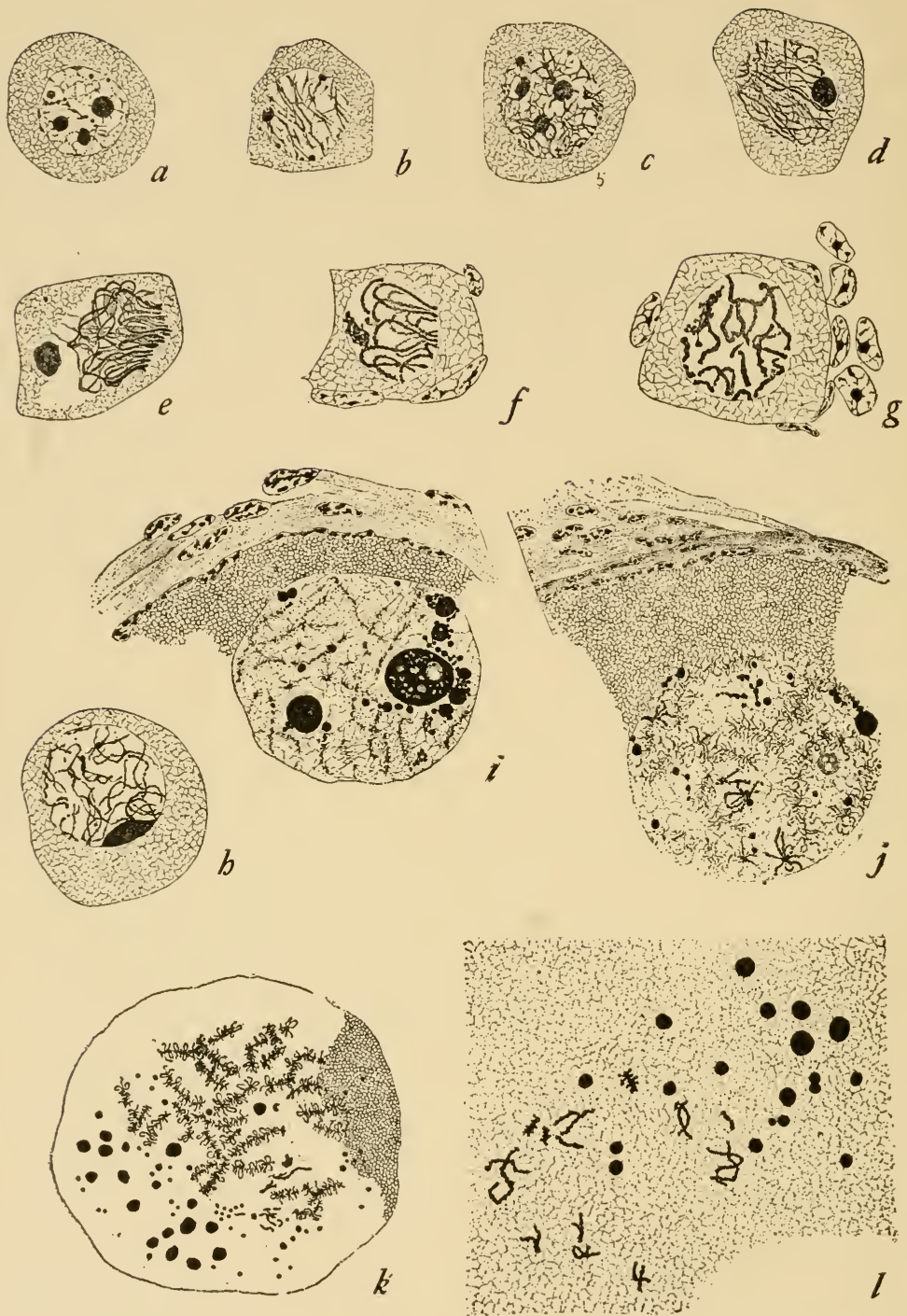

FIG. 44.-The growth, synapsis, and reduction stages in the egg of Pristiurus melanostomus. (After Maréchal.) 
thin threads next assume the form of loops with their free ends pointing toward one pole, $e$ (bouquet stage, also called the period of synapsis). At their free ends the threads soon appear to meet in pairs, $d$ and $e$. Each pair, by the apparent fusion of its threads, leads to the formation of a thick thread in the form of a loop, $f$. Further condensation and separation of the threads leads to the condition shown in $g$. The thick double threads next show a lengthwise split, the halves being often twisted around each other (diplotene stage) $h$. The pairs of threads now begin again to become longer and to occupy more of the interior of the nucleus as seen in $i$. The eggs have grown larger meanwhile and the yolk appears. As the nucleus grows still larger, keeping pace with the growth of the cell, the chromosomes begin to lose their staining capacity. Despite the difficulty of tracing the chromosomes throughout the remaining period, Maréchal has succeeded in following them, step by step. His drawings of the chromosomes give the impression of the existence of a central core or filament remaining, as shown in Fig. $44 i, j, k$. Delicate loops and threads are attached to this core and may be traced out into the region of each side of the chromosome. During these stages deeply staining balls of material, the nucleoli, appear in the nucleus. Finally the chromatin threads begin to condense again and once more take the stain; the chromosomes are found lying in pairs often twisted around each other as before, as seen in $l$. They pass in this condition on to the first 
polar spindle, which develops in the egg as the nuclear membrane breaks down.

At the time when the double chromosomes of the sperm and the egg are about to pass onto the first

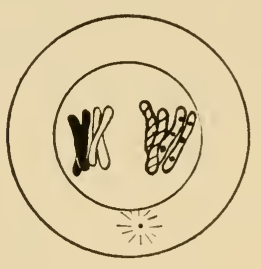

$\boldsymbol{a}$
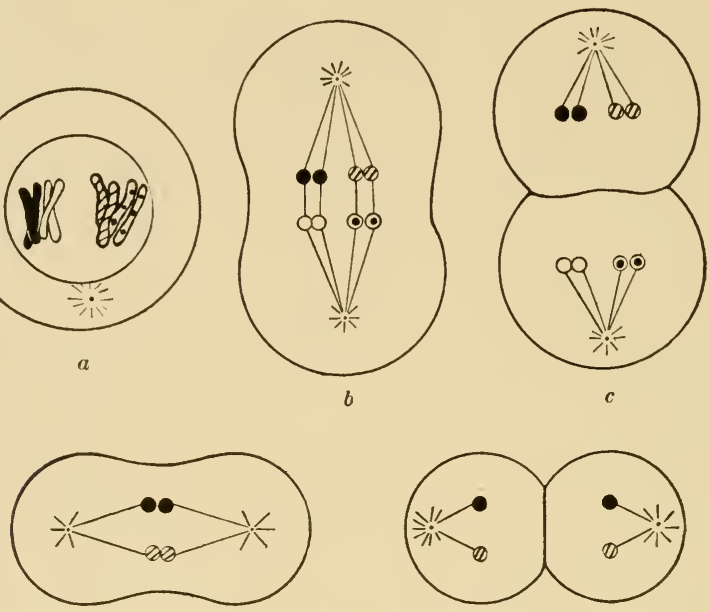

$d$
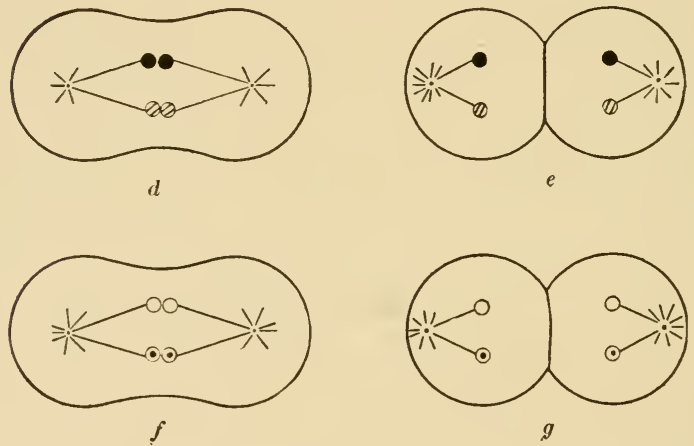

FIG. 45.-Diagram to illustrate the two reduction divisions of spermatogonial cells. $a$, first spermatocyte with two tetrads; $b$ and $c$, division of last; $d$ and $f$, division of two cells of $c$; $e$ and $g$, completion of second division.

maturation spindle each half of the double chromosome splits lengthwise so that four parallel strands are present (Figs. 45 and 46); such a group of strands is known as a tetrad. It is usually held, although there 
is some dissent, that the first longitudinal split that appears in the thick thread (pachytene stage) lies between the two chromosomes that had previously come together, such a separation of the members of a pair of chromosomes being known as a reductional split. The second lengthwise split is supposed to separate like halves of the same chromosomes. It is called an equational split.

These two splits are in preparation for the two maturation divisions that usually take place in rapid succession, without an intervening resting stage. It is customary therefore to look upon the second lengthwise split as a precocious split in the chromosomes preparatory to the second division. If the reduction in the number of the chromosomes to half of the original number were the sole object of the reduction divisions, one division would suffice to separate the two chromosomes of a pair that had united and it is not apparent why there should be a second division at all.

The two maturation divisions with tetrad formation are typically illustrated in the changes that take place in the spermatogenesis and oögenesis of Ascaris, the thread worm of the horse, as worked out by van Beneden, Brauer, O. Hertwig and others. In one variety four chromosomes occur which become reduced to two; hence there are only two tetrads present (Fig. 45, a). At the first division two halves of each thread move to one pole and two to the other as in $b$ and $c$. At the second division the separation of the two remaining threads takes place, 
$d$ and $f$. At the end of the process there are two chromosomes remaining in each of the four cells, $e$ and $g$. Each cell becomes a spermatozoon. Here as in most cases there is nothing to show whether the first division is reductional and the second equational, or the reverse. There is much divergence of opinion on this point for different species. The end

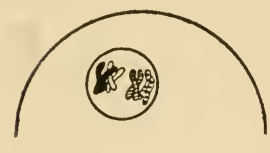

$a$

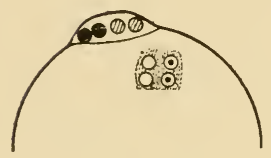

d

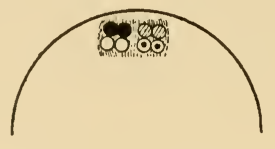

b

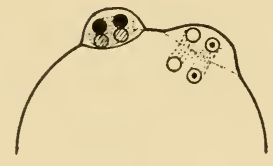

$e$

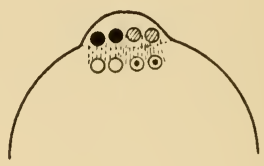

$c$

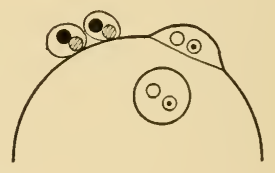

$f$

FIG. 46.-Diagram to show the extrusion of the two polar bodies. Two tetrads are represented in $a$. The two succeeding divisions $b-c$, $d-e$, show the separation of the members of the tetrads with the result that one of each kind is left in the egg.

result, however, is the same so far as the genetic problem is concerned, the sequence being ordinarily a matter of no significance.

In the egg (Fig. 46) the process is identical with that in the sperm, except that one of the two cells formed is much smaller than the other. The small cell is the polar body. At the first division the nucleus 
sends out half of its chromatin into the first polar body (Fig. 46, c). Without a resting stage a new spindle is formed around the chromosomes in the egg and a second polar body is thrown off, as in $e$. The first polar body may also divide. The three polar bodies and the egg, $f$, are comparable to the four spermatozoa. All four spermatozoa are functional, but only one product of the two divisions of the egg is functional. Unless the tetrad is specifically oriented upon the polar spindle of the egg the chance is equally good that any one of the four threads that make up the tetrad will be the one that remains in the egg.

\section{Crossing Over}

If the preceding account of the maturation of the egg and of the sperm were accepted as covering the entire behavior of the chromosomes during this period, there would be no possibility for an interchange between the members of a pair. But there are several stages in the ripening of the germ cells when an interchange between homologous chromosomes might possibly take place. For instance, when the thin threads are coming together (Fig. 43, e, $f, g, h$ ) several observers have described them as twisting around each other (synaptic twisting) as represented in these figures. If where the threads cross a part of one thread becomes continuous with the remainder of the other thread (Fig. 24) an interchange of pieces will have been accomplished. If, as shown in Fig. $24, B$, the chromosomes are represented as a linear 
series of beads (chromomeres), then, when the conjugating chromosomes twist around each other, whole sections of one chain will come to lie, now on one side, now on the other side, in the double chromosome. If, when the two series of beads come to separate from each other, all of the segments that lie on the same side tend to go to one pole, and all of those on the opposite side to the other pole, each series must, in order to separate, break apart between the beads at the crossing point. Moreover, since the essential part of the process is that homologous beads go to opposite poles it follows that the break between the beads of two chains must always be at identical levels. It is not necessary to assume that crossing over takes place at every node, but only that it may sometimes take place. In fact, our work on Drosophila shows for the sex chromosome in the female that crossing over takes place in only about half of the cells, and double crossing over is a rather rare event.

There is a later stage also at which crossing over might be supposed to take place. After the thin threads have conjugated to form the thick threads, and these have shortened and split lengthwise, four strands are present (Fig. 47). If two of the strands fuse at the crossing place (the pieces of one strand uniting endwise with the pieces of the other) crossing over is brought about. It is this type in particular that Janssens named chiasmatype. In support of this method of crossing over are Janssens' observations on Batracoseps, where he concludes from the 
method by which the strands are found joined at the time when they draw apart, that cross union of the threads must have previously taken place.

If crossing over be supposed to take place between two single threads (Fig. 24) all four gametes that ultimately result from such a cell will be crossover gametes. On the other hand, if crossing over takes

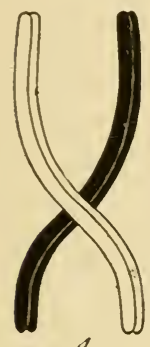

$A$

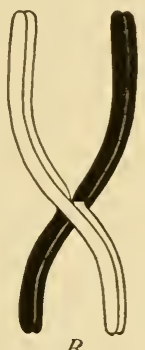

$B$

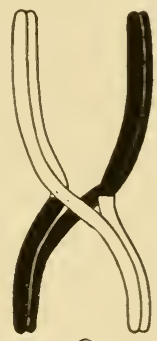

C

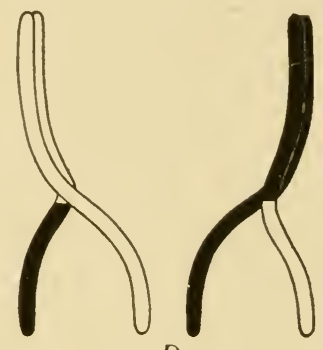

D

FIG. 47.-Four stages in crossing over, according to the "typical" chiasma type of Janssens. The white rod and the black rod are each split lengthwise; crossing over takes place only between two of the four strands.

place by means of the chiasmatype (Fig. 47) only two of the resulting four cells will be crossover gametes, the other two being non-crossover gametes. ${ }^{1}$

Looked at from the point of view of the total output, there would be no way in which to tell whether one or the other of the above processes has taken place; although the formation of a given number of crossover gametes involves only half as many participating cells in the case of the single thread type as in the case of the double thread type.

${ }^{1}$ If, after the thick threads have split, crossing over involving both strands of each chromosome should take place, instead of only one strand as in the chiasmatype, sensu strictu, the four gametes that result would be crossover gametes. 
At present it seems better not to attempt to commit the theory of crossing over to one rather than to another of these stages; for, whether the process occurs at the leptotene thread stage as suggested above, or, as Janssens believes, at a later stage (strepsinema), the genetic result is the same. What we wish to point out is that in the phases through which the chromosomes pass at the maturation stages there is given an opportunity for an interchange of parts. The genetic evidence shows very clearly that interchanges do take place, as is best illustrated in the case of the sex chromosomes, whose history can be traced with some assurance from one generation to the next.

What we wish especially to insist upon and emphasize is that the evidence from linkage in Drosophila has shown beyond any doubt that crossing over is not a process that involves only a particular factor in relation to its allelomorph. Our work has shown positively that there is a tendency for large sections of the chromosomes to interchange whenever crossing over occurs.

Another idea that is likely to suggest itself in this connection has also been disproven by the evidence from Drosophila. It might be supposed that at a resting stage the chromosomes go to pieces and the fragments come together again before the next division period. Linkage might then mean the likelihood of fragments remaining intact, etc. But if the chromosomes broke up completely into their constituent elements at each resting period then 
there is no explanation as to why the factors in a group remain together in sections as explained on page 66 . If it is supposed that the chromosomes break only once or twice, and that linkage represents the holding together of the pieces, then one is forced to assume that the breaking up is the same in both members of a pair, yet entirely inconstant in different cells; for otherwise the reunion of the fragments would lead to duplication or loss of whole sections of the chromosomes, and all order would soon be lost. A large amount of data relating to sex linked characters has shown that the sex chromosomes must remain intact as often as they break apart, and even when they break apart this takes place, as a rule, at only one place.

\section{Cytoplasmic Inheritance}

The interpretation of Mendelian inheritance on a chromosomal basis by no means excludes the possibility that there may be other forms of inheritance depending on other cell materials. Although the cytoplasm is essential for the development of the organism, and is transmitted by the egg to each new generation, its materials do not perpetuate themselves unchanged as do the chromosomes, and are therefore really not hereditary. There are, however, certain bodies carried by the protoplasm, such as plastids (possibly also chondriosomes), which like the chromatin are able to grow and divide, and hence might have the power to perpetuate themselves unchanged 
indefinitely. Such bodies might not only produce passive products, like starch or pigment, but even active enzymes, which, interacting with other products of development, might determine the characteristics of the race.

Structures like the shell and the yolk of eggs are purely maternal in origin, but since they do not have the power of growth and division, they are not able to perpetuate themselves indefinitely, nevertheless they may determine certain characteristics of the embryo, and to this extent may appear to influence the hereditary characters of the generation to which the embryo belongs. For instance, the females of certain races of silkworm moths have white eggs, because the shell is white. If such eggs are fertilized by sperm of another race, that has eggs with a dominant green colored shell, the shells are nevertheless white. Conversely when the green eggs of a female moth of the green egg race are fertilized by the sperm of a male of a white egg race, the color remains green. When the moths develop from either of these two kinds of hybrid eggs, one white, one green, they lay only green eggs, because in the hybrid the factor for green dominates and determines the color of the shell that is produced in the new eggs. These green eggs give rise to moths, three of which lay eggs that are green to one that lays eggs that are white, showing that here there is only the ordinary case of Mendelian inheritance, which is obscured, however, when the characters of the young embryo are considered, because, as has been shown, these 
characters are due to peculiarities of the eggs before they are laid.

The serosa on the other hand is a cellular membrane that develops around the embryo and produces pigment. The pigment seen through the shell gives the embryo a definite color, which in the hybrid embryo is characteristic of the maternal race. Since the serosa pigment is not present in the egg, but develops after fertilization the inheritance here appears to be determined by the character of the egg and not by the sperm. But the genetic history of this character of the embryo is apparently the same as that of the color of the shell or of the yolk. It can, therefore, be interpreted in the same way. There must, then, be present in the egg some substance that is at first uncolored, and later this substance when carried into the serosa produces pigment, presumably by interacting with something else there. In the next generation, however, the influence of the father comes to light when the $\mathrm{F}_{2}$ embryo produces its serosa material; for now the nucleus of the $\mathrm{P}_{1}$ male has had opportunity to determine what this material may be, and should the paternal factor be the dominant one it determines the kind of material that the eggs will contain and hence the color of the serosa of this new generation.

A case of cytoplasmic inheritance has been described by Correns in the four-o'clock, Mirabilis jalapa. There is a race whose leaves are checkered with green and white, but some branches may have leaves entirely green, other branches may have only 
white leaves. If the flowers of the green branches are self-fertilized, the young plants are green. If the flowers of the white branches are self-fertilized, the offspring have white leaves and these plants perish for want of chlorophyll. From the checkered branches the offspring may be green, or checkered, or white.

When a cross is made between the flowers borne by branches that are unlike, the inheritance is purely maternal. For example, if the pistil of a white branch is fertilized with pollen from a pure green plant, only white leaved offspring are produced. The reciprocal cross, the pistil from a green branch fertilized with pollen from a white branch, gives only green offspring, and these remain green through all subsequent generations.

Correns points out that these results can be interpreted if the whitening is due to a sort of disease that is carried by the cytoplasm. The egg cytoplasm carries over the disease to the next generation. As the pollen does not bring in any cytoplasm the disease is not transmitted through the male side.

Baur points out that in several other plants in which varieties with leaves marked with white exist, as in Melandrium, Antirrhinum, etc., the inheritance is strictly Mendelian, for the $F_{1}$ generation is green and the $\mathrm{F}_{2}$ generation is made up of three greens to one marked with white. In these cases the color may depend on a chromosomal factor. But there is a case in Pelargonium that Baur thinks can not be explained in either of the foregoing ways. Here 
again there are mosaic branches, white branches, and also green brancheș. Flowers on green branches crossed with flowers on white branches give mosaic plants, irrespective of which way the cross is made. A self-fertilized flower from a green branch gives rise to a plant with purely green leaves. If a flower from a checkered branch is self-fertilized it produces a checkered plant. If a flower from a white branch is self-fertilized it gives rise to a white plant.

Baur suggests tentatively, the following hypothesis to explain the case of Pelargonium. The green color of this plant, like that of all flowering plants, is due to chlorophyll grains and these grains multiply, supplying all the cells in generations that subsequently arise with their quota of grains. In the white parts these grains are defective in the sense that they fail to produce the green color, but retain their power of multiplying. If now it is assumed that the pollen as well as the egg may transmit some chlorophyll grains the results can be explained. For, in the division of the cells that contain both green (normal) and white (abnormal) grains there will arise at times an unequal distribution of the grains, and in extreme cases two kinds of branches may arise, one with green and the other with white grains. The hypothesis calls for transmission through the cytoplasm of the pollen as well as through that of the egg cell. Baur states that until this fact can be established the interpretation must be uncertain. 


\section{CHAPTER VI}

THE CORRESPONDENCE BETWEEN THE DISTRIBUTION OF THE CHROMOSOMES AND OF THE GENETIC FACTORS

Attention has been called to the fact that paired factors are distributed in the same way as are homologous chromosomes, and that factors which are assorted independently are distributed in the same way as non-homologous chromosomes. In proof of the latter point there is Wilson's evidence for a Metapodius with three homologous m-chromosomes. It was found that the extra $m$ goes to the gamete that receives $\mathrm{X}$ as often as to the other gamete. Miss Carothers describes a somewhat similar case in certain grasshoppers, in which the distribution of a pair of unequal chromosomes is independent of the distribution of the $\mathrm{X}$ chromosome. Not only are the pairs of factors assorted independently, as are the chromosomes, but in Drosophila, where the number of independently assorting groups of factors has been determined, it has been found that the number is identical with the number of chromosome pairs. Moreover, even the relative sizes of the groups-both as determined by the number of factors they contain and by the frequency of crossing over within them-are the same 
as those of the chromosomes. Finally, the distribution of the factors within any one group is what the chromosome hypothesis calls for. For the frequencies of separation (or combination) between the different factors of a group are in a linear relation to each other, and the relation is even specifically of such a type (involving interference) as would be expected to occur if the separations between the factors resulted from the crossing over between two twisted chromosomes which the cytological evidence indicates may occur.

Even in cases where the chromosomes are not distributed in the usual way it is found that the factors have the same unusual method of distribution. For example, in moths there are some cases of extraordinary interest because the chromosomes can be traced to and through the ripening period of the eggs of the hybrid. Certain species of the moth Pygæra that have different numbers of chromosomes were crossed by Federley. The full number (calculated) and the reduced number of chromosomes in the different species are as follows:

$\begin{array}{lcc} & \text { Diploid } & \text { Haploid } \\ \text { P. anachoreta } & 60 & 30 \\ \text { P. curtula } & 58 & 29 \\ \text { P. pigra } & 46 & 23\end{array}$

In the hybrids, the full number is the sum of the two haploid sets that went in from the parents. This shows that the chromosomes preserve their individuality through many successive cell divisions in a 
foreign cytoplasm. In the maturation a few of the chromosomes seem at times to unite in pairs, but most of them fail to do so, so that while the number of the chromosomes at the first maturation division is slightly less than the full number it is much more than half of that number. Different types of hybrids behave slightly differently in respect to the extent to which union in pairs takes place. The failure to unite indicates that in normal maturation homologous chromosomes mate with each other, for here there are few or no chromosomes that are strictly homologous and yet there is just as much opportunity as in normal maturation for nonhomologous chromosomes from the same parent to unite.

When the first spermatocyte division takes place in the hybrid, all the unmated chromosomes divide, but the few chromosomes that are mated presumably separate. Consequently each of the daughter cells has the double number of chromosomes (a set from each parent species), except for the few chromosomes that had been united in pairs. At the second maturation division the chromosomes again divide, so that the spermatozoa too should receive nearly the double number of chromosomes, one set from one species, the other set from the other species.

If, then, the factors are contained in the chromosomes, we should expect that, except for any factors in the few chromosomes that mate and separate, the hybrid would transmit to all its offspring the same 
factors, since every spermatozoon receives, with the above exceptions, all the chromosomes (paternal and maternal) that the hybrid contains. On crossing the hybrid to either parent, it is found that the offspring actually are very much alike, i.e., have all received practically the same factors - a striking contrast to the result usually obtained in "backcrosses." In respect to just one character (a larval marking), however, the above relation does not hold, but ordinary Mendelian results are obtained, and this in turn corresponds with the fact that a few chromosomes do undergo segregation. In regard to the other characters, not only are the offspring like each other, but they resemble the hybrid more than either of the pure species, corresponding with the fact that they contain complete sets of chromosomes from both types. But they do not look just like the $F_{1}$ hybrid, and correspondingly one set of chromosomes is in the diploid, the other in the haploid number. This is because they receive a set of one species from both parents, but a set of the other species only from the hybrid parent. Federley also shows that when maturation takes place in this triploid individual one set of chromosomes does not undergo mating, but the others-presumably those in the two identical sets-do pair with each other, so that the total number is reduced to one bivalent set, and one single set.' If the paired chromosomes separate and the unpaired ones divide, as occurs in the $\mathrm{F}_{1}$ hybrid, the double number of chromosomes, a set of each species, will again be found in the sperm, as was the case in the first hybrid. In other 
words there is expected no return to either parent type, but the hybrid when backcrossed always continues to produce hybrids. Moreover, there is no apparent weakening or other influence exerted by the egg on the foreign chromosomes even in successive generations. The breeding results of Standfuss, who backcrossed other moths for several generations, show exactly this phenomenon-the same type of hybrid constantly produced in every generation.

A similar behavior of the chromosomes has been recently described by Doncaster in a cross between other species of moths, and is illustrated in the following figures. The full number of chromosomes in the moth Biston hirtaria is shown in Fig. 48, $a$. There are 28 in all, of which four are small. Another species, Biston zonaria, has something over a hundred very small chromosomes (Fig. 48, $b$ ). The reduced number of chromosomes of the former species is 13 (one large one being coupled with a small one), of the latter 56. The chromosome group of the hybrid (zonaria $\circ$ by hirtaria $o^{\circ}$ ) is shown in Fig. $48, c$. The exact number of chromosomes is difficult to count, but there are 14 large ones and about 56 small ones. In this hybrid a stage is passed through that resembles the synapsis stage. When the chromosomes emerge from this stage (Fig. 48, $c^{\prime}$ ), almost the full number are found present, although Doncaster thinks that a few of them have united in pairs; for as shown in the figure there are now 12 or 13 large and 50 or 51 small chromosomes. These are a few less than the full number present before synapsis. In this case, how- 

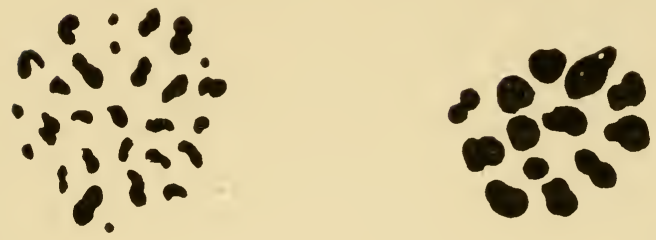

$a$

$a^{\prime}$
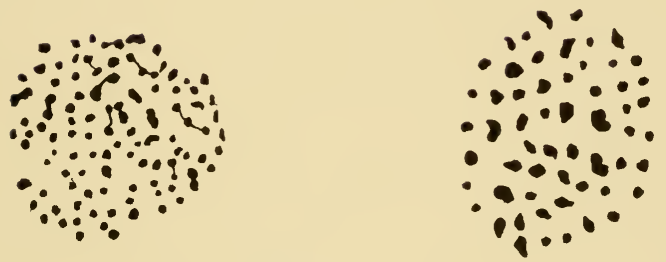

$\delta$
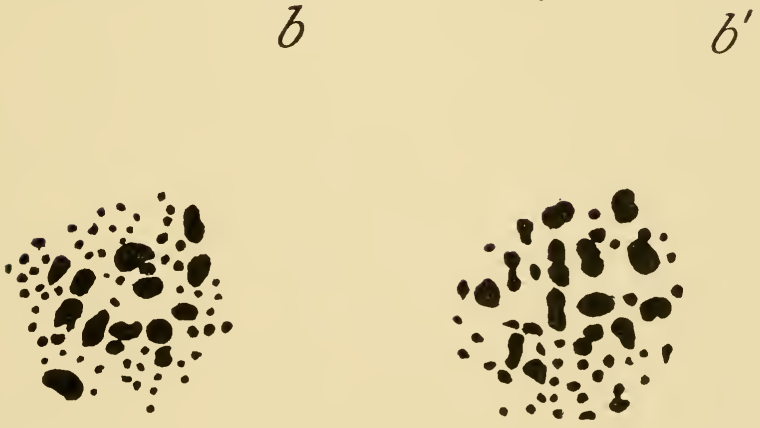

C

$C^{\prime}$

FIG. 48.-Biston hirtaria; $a$, spermatogonial chromosomes; $a^{\prime}$, primary spermatocyte chromosomes (reduced number). Biston zonaria; $b$, spermatogonial chromosomes; $b^{\prime}$, primary spermatocytes (reduced number). Hybrid, out of zonaria female by hirtaria male; $c$, spermatogonial chromosomes; $c^{\prime}$, primary spermatocytes. (After Harrison and Doncaster.) 
ever, no data concerning the genetic behavior of the hybrids have been reported.

Another instance of parallelism between unusual chromosome phenomena and genetic results is that found in Enothera lata and semilata by Lutz, Gates and Thomas. The normal chromosome number in Enothera lamarckiana is 14 , but the race called lata always has 15 chromosomes, i.e., one kind of chromosome exists in the triploid number. This is true even of lata plants which originated independently of the ordinary stock, in widely different races of Enothera. The same results apply to semilata, which appears to be a variety of lata. Lata and semilata occasionally arise "spontaneously" from lamarckiana, in a small per cent. of the offspring of any one individual, and the explanation for this may be found in the fact that occasionally, in the gametogenesis of lamarckiana, two mated chromosomes, instead of separating, pass to the same pole (non-disjunction) so that the offspring would have three chromosomes of this type and contain 15 chromosomes in all. The behavior of the extra chromosome in the lata individuals is also of interest, for it is found that in gametogenesis, when the mated chromosomes separate, the extra chromosome does not divide regularly as do unpaired chromosomes in moths, but tends to pass to one pole. This would result in half the gametes containing it and transmitting the lata condition and the other half being normal. Very often, however, the chromosome lags on the spindle and so fails to be included in the nucleus of either daughter 
cell, or it may even be torn apart, as if by spindle fibers from opposite poles. Consequently less than half of the gametes (at least the sperm, for gametogenesis was not studied in the female organs) receive the extra chromosome. The proportion varies greatly in different individuals. This conforms with the genetic result that lata individuals, crossed to lamarckiana, give varying proportions of lata offspring but never produce offspring more than half of which are lata.

In Primula, a striking case of correspondence between abnormal genetic and chromosome phenomena has been found, that appears strongly in favor of the chromosome hypothesis, although the discoverer, Gregory, has hesitated to draw this conclusion. Two giant races of the primula (P. sinensis), were found to have twice the number of chromosomes characteristic of other domesticated races. The breeding experiments with these plants show that they also have a double set of factors as compared with the same factors in ordinary primulas. While in ordinary plants each chromosome is double and, therefore, each factor is represented twice, for instance by $\mathrm{A}$ and $\mathrm{A}$, in the giants there are four like chromosomes, hence four factors AAAA. If the giant race contains some factors already mutated, such as $\mathrm{A}^{1}$, the giant might contain one, two, three, or four of the mutant factors $\mathrm{A}^{1}$. Such plants would be $\mathrm{AAAA}^{1}$ or $\mathrm{AAA}^{1} \mathrm{~A}^{1}$ or $\mathrm{AA}^{1} \mathrm{~A}^{1} \mathrm{~A}^{1}$ or $\mathrm{A}^{1} \mathrm{~A}^{1} \mathrm{~A}^{1} \mathrm{~A}^{1}$. As stated above, the breeding work shows that there is a quadruple set of factors, but the evidence is as yet insufficient to de- 
cide whether a mutant factor $\mathrm{A}^{1}$ has as its mate (always pairs at maturation with) a special one of the remaining A's or may become the mate of any one of the three. On the chromosome hypothesis we should expect, on the whole, the latter to be true. Whichever of these views becomes established the parallel between the double set of chromosomes and the double set of factors is the important fact. Gregory admits this, but adds the caution: "Yet on the other hand the tetraploid number of chromosomes may be nothing more than an index of the quadruple nature of the cell as a whole."

In the preceding cases it has been shown that the factors and the chromosomes have the same method of distribution. In the case of sex and sex linked factors it can even be shown that they have the same distribution as the sex chromosomes. This identity of distribution holds not only for $\mathrm{F}_{2}$ results and $\mathrm{F}_{3}$ tests, but for all kinds of backcrosses as well. The relation holds, moreover, for all known sex linked factors, of which in Drosophila there are more than forty cases, and for all combinations of sex linked factors. Not to interpret this evidence to mean that the factors are contained in and carried by the chromosomes is to reject a mechanistic basis known to exist in the cell. Nothing is gained if, in order to avoid the obvious connection between the inheritance of the character and the transmission of the chromosome, we assume that something else in the cell, a portion of the cytoplasm, perhaps, also follows the distribution of the sex chromosomes. Such a postu- 
late only adds an unknown and improbable assumption and leaves the situation less clear than before.

The advantage of the chromosomal interpretation as applied to the sex chromosomes is nowhere better illustrated than in the history of a process called non-disjunction, which was discovered by Bridges. Furthermore this case, supported on the one hand by extensive and definite experimental breeding and on the other hand by cytological investigation, offers the most direct evidence yet obtained concerning the relations of particular characters and particular chromosomes, for in this case an abnormal distribution of the sex chromosomes goes hand in hand with an identical abnormal distribution of all sex linked factors. It was found that females from a certain strain of white-eyed flies gave, on out-crossing, about 5 per cent. of unexpected classes. For instance, one of the white females crossed to a red-eyed male (wild type) produced not only red-eyed daughters and white-eyed sons, as expected, but also a few white-eyed daughters and a corresponding number of red-eyed sons. The approximate percentage in which these classes appeared is as follows:

$\begin{array}{llrl}\text { Red } \% & \text { White } \sigma^{x} & \text { White } \% & \text { Red }{ }^{x} \\ 47.5 \% & 47.5 \% & 2.5 \% & 2.5 \%\end{array}$

In general, therefore, there were 95 per cent. of expected forms and 5 per cent. of offspring that were apparently inconsistent with expectation on the chromosome theory. Closer inspection of these 
results showed that the exceptions could be explained, if, occasionally, the two $\mathrm{X}$ chromosomes failed to disjoin in the reduction division, both passing out of some of the eggs of the white-eyed mother into the polar body, or, conversely, both remaining in the egg. If the two white-bearing $\mathrm{X}$ 's should remain in the egg then such an egg fertilized by a Y sperm would give rise to a white-eyed daughter. Likewise the no- $\mathrm{X}$ egg fertilized by the $\mathrm{X}$ sperm of a red-eyed male would give a red-eyed son. The white daughters would, as just shown, contain two X's and one $\mathrm{Y}$ chromosome, unlike ordinary daughters, which contain two X's only. Since in these females there are three sex chromosomes instead of a pair, at the reduction division two must pass into one cell and one into the other. This division might take place in four ways: $\frac{\mathrm{XY}}{\mathrm{X}}, \frac{\mathrm{X}}{\mathrm{XY}}, \frac{\mathrm{Y}}{\mathrm{XX}}$ and $\frac{\mathrm{XX}}{\mathrm{Y}}$ (representing the egg below and the polar body above in each case). The first two types of reduction, depending on a more symmetrical pairing of the chromosomes, might be more frequent than the other two types. There would then be four types of eggs-a large number of $\mathrm{X}$ and XY eggs, and a few XX and $\mathrm{Y}$ eggs. Let us suppose that an XXY white female is mated to a red male. The progeny produced by the $\mathrm{X}$ bearing sperm would be:

(1)

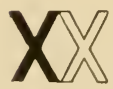

Q red
(2)

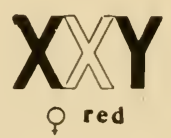

(3)

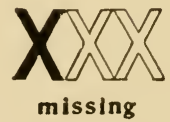

14)

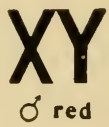


The same series of eggs fertilized by the maleproducing sperm, which carries a $\mathrm{Y}$ chromosome, would give:

(5)

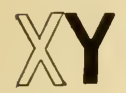

Orwhite
(6)

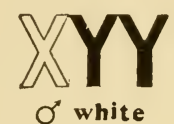

(7)

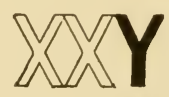

O white
(8)

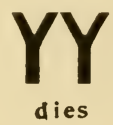

If we consider these eight kinds of progeny we see that the exceptional white females (7) would be expected to repeat the process and be non-disjunctional. This is what actually occurs, for all white females that are the product of such a cross do, in fact, give non-disjunction in the next generation.

The red males (4) are an exceptional class but should not give exceptional results when bred to any normal female, nor should they transmit non-disjunction. This has been shown to be true.

The red females are not alike in composition, half of them (1) should behave like normal females heterozygous for white and the other half (2) should give exceptions. There are in fact found to be these two kinds of red females in equal numbers.

The white males (5) and (6) are not alike; one kind (5) is normal and the other (6) has two $\mathrm{Y}$ chromosomes. The latter should be expected to produce some XY sperm. These sperm would give daughters which would not be exceptions, but such females, with a formula XXY, should produce exceptions. In fact from half of the white males (5 and 6), daughters are produced that give non-disjunction. 
The results bear out to a remarkable degree the hypothesis that they are due to a non-disjunction of the sex chromosomes caused by the presence of a $\mathrm{Y}$ chromosome in the females.

The hypothesis is capable of verification and Bridges has made a study of the chromosomes of the non-disjunctional females. He finds that such

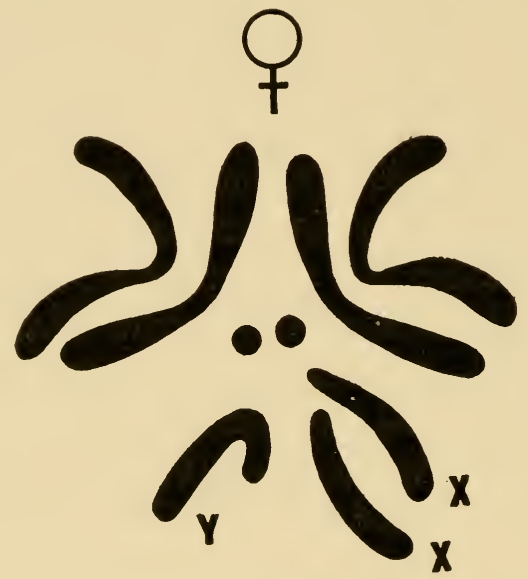

FIG. 49.-Group of chromosomes of an XXY female of a non-disjunctional "line."

females contain an extra chromosome whose size and position show that it is a supernumerary sex chromosome. The normal group of chromosomes of the female of Drosophila ampelophila is shown in Fig. 2, and a group from a non-disjunction female in Fig. 49. They differ by one chromosome, namely, the extra Y.

One additional fact must be mentioned. If an XXY female should be fertilized by an XYY male 
some females would be produced that are XXYY, owing to the union of an XY egg with an XY sperm or an XX egg with a YY sperm. One such female was found-she had two $\mathrm{X}$ and two $\mathrm{Y}$ chromosomes.

Here then is a case that seemed at first to be in direct contradiction to the scheme of sex linked inheritance based on the chromosome hypothesis, which proved, however, on further examination to give a brilliant confirmation of that theory; for not only can the hereditary results be accounted for, but the theory on which they were based was directly confirmed by a microscopical study of the chromosomes themselves.

Cases indicating non-disjunction have also been obtained in Abraxas, by Doncaster. As stated in the chapter on Sex Inheritance, he has found a strain in which the males have 56 chromosomes-the normal number, but the females have only 55 instead of 56 chromosomes. It seems reasonable, then, to suppose that such females arose by the passing of the two sex chromosomes, ZZ, to one pole (spermatocyte) leaving none at the other pole of the cell. The sperm resulting from the no- $Z$ cell fertilizing a $Z$ egg would give a $\mathrm{ZO}$ individual which would be a female with 55 chromosomes. All the daughters of the $\mathrm{ZO}$ female would be $\mathrm{ZO}$ and her sons $\mathrm{ZZ}$ individuals: and the race would continue in this fashion. On the other hand, if the $\mathrm{ZZ}$ sperm produced by nondisjunction fertilized a W egg, a male WZZ, corresponding to the XXY female of Drosophila, would be formed. Such a male would give rise to some sperm 
carrying both $\mathrm{Z}$ and $\mathrm{W}$, and if such a $\mathrm{ZW}$ sperm fertilized a zero egg of the 55 chromosome female, a 56 chromosome female would be produced. Doncaster actually found such a female among offspring from a cross of a female from the 55 chromosome race with wild type male, and he found also the genetic exceptions required on the assumption that this male was a WZZ form. 


\section{CHAPTER VII}

\section{MULTIPLE ALLELOMORPHS}

The meaning of the term multiple allelomorphs may be illustrated by the following example:

1. If a white-eyed male of Drosophila is mated to a red-eyed female, the $\mathrm{F}_{2}$ ratio of 3 reds to 1 white is explained by Mendel's law, on the basis that the factor for red is the allelomorph of the factor for white.

2. If an eosin-eyed male is mated to a red-eyed female, the $\mathrm{F}_{2}$ ratio of 3 reds to 1 eosin is also explained if eosin and red are allelomorphs.

3. If the same white-eyed male is bred to an eosineyed female, the $\mathrm{F}_{2}$ ratio of 3 eosins to 1 white is again explained by making eosin and white allelomorphs.

There are here three factors, any two of which may meet, and whenever they do, they behave as allelomorphs. They form a system of triple allelomorphs.

On the chromosome hypothesis the explanation of this relation is apparent. 'A mutant factor is located at a definite point in a particular chromosome; its normal allelomorph is supposed to occupy a corresponding position (locus) in the homologous chromosome. If another mutation occurs at the same place, 
the new factor must act as an allelomorph to the first mutant; as well as to the "parent" normal allelomorph.

Since these factors have the same location they must all give the same linkage values with other factors. This has been shown to be true. For instance, the factor for white eye color of Drosophila is very closely linked to that for yellow body color. The "distance" between them is 1 unit, which means that crossing over takes place about once in a hundred times. Eosin eye color gives the same crossing over frequency with yellow.

White eye color gives with miniature wings about 33 per cent. crossing over. Eosin gives the same value with miniature.

White gives 44 per cent. of crossing over with bar eye. Eosin has the same value. Similar relations hold for all of the characters of the first group; they all have the same linkage values for eosin that they have for white. This example indicates that the conception of allelomorphs should not be limited to two different factors that occupy identical loci in homologous chromosomes, but that there may be three, as above, or even more different factors that stand in such a relation to each other. Since they lie in identical loci they are mutually exclusive, and therefore no more than two can occur in the same animal at the same time. This is both demonstrated by the facts and postulated by the chromosomal mechanism.

On a priori grounds also it is reasonable to suppose 
that a factor could change in more than one way, and thus give rise to multiple allelomorphs, unless it is supposed that the only change possible in a factor is a complete loss of the factor, as postulated in the presence and absence theory.

There is, however, an alternative theory to that of multiple allelomorphism. This alternative is complete linkage. The numerical result can be equally well explained if, instead of occupying identical loci, the factors are so near together that they never (or very rarely) cross over. For reasons that will be given later we are inclined to think that the explanation of multiple allelomorphism is in most cases the more probable one, but the arguments in favor of this view may be deferred until the facts have been described.

There is a general relation that so far holds for all cases in which multiple allelomorphs have been discovered, namely, that the factor-differences produce similar effects. All of the following examples illustrate this relation.

In rabbits (Fig. 50) the Himalayan pattern has been shown to behave as a recessive to self-color and a dominant to albino. Any two of these three types of pigment formation and distribution give a $3: 1$ ratio in $\mathrm{F}_{2}$ but no two of them, when crossed, ever produce the third genetic type. In other words the factors behave as though allelomorphic, for only two can be gotten into any one individual. A similar relation has been described by Baur in the columbine, where three types of leaves, green, variegated (green 

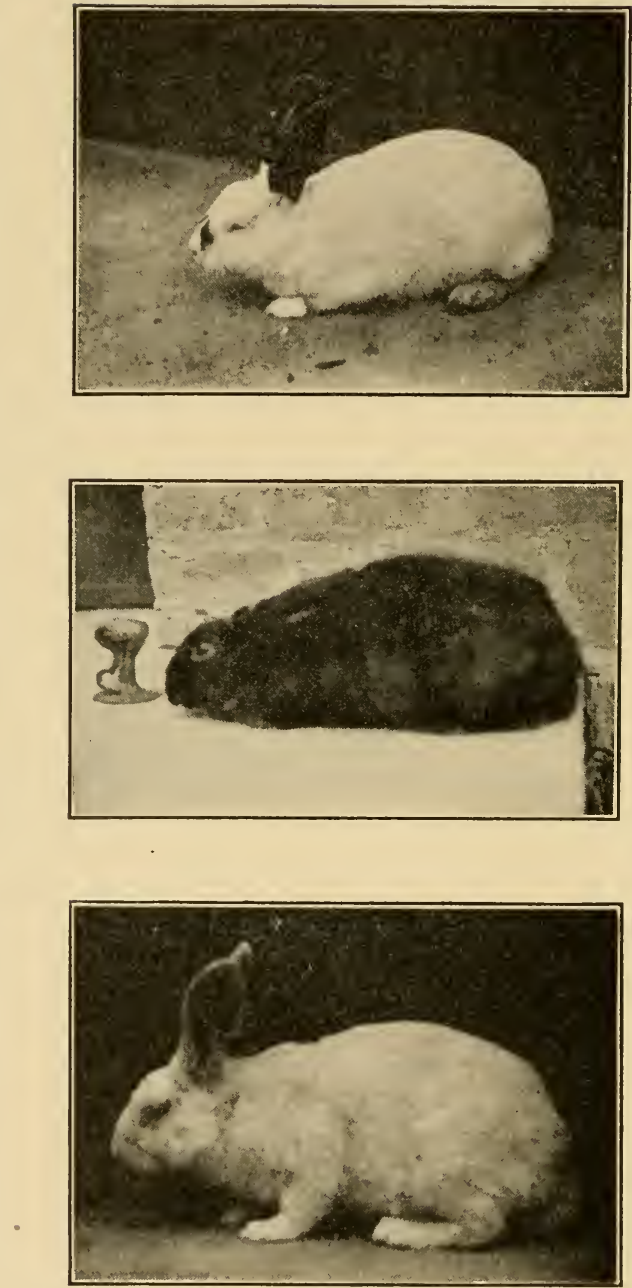

FIG. 50.- Himalayan, black and white rabbits. The factor that stands for each is allelomorphic to the others. 
and yellow), and yellow form a triple system. Emerson's case for pod and leaves in beans-green pods, green leaves; yellow pods, yellow leaves; yellow pods, green leaves-also fulfill the conditions of a triple allelomorph system. Shull has reported a case in Lychnis which he interprets as due to triple allelomorphs for sex-determining factors. Two of them give reversible mutations as have white and eosin in Drosophila.

Cases in which more than three allelomorphs have been found may next be considered. The cases seem to show that here also the same character is affected by each of the mutant factors that form the multiple system. In a few instances the characters have been recognized as due to multiple alleiomorphs, but in most of them no sufficient interpretation has been offered or else the explanation of complete linkage has been advanced.

Tanaka has reported a case in the silkworm moth which seems best interpreted as one of quadruple allelomorphs. The four larval patterns called striped, moricaud, normal, and plain (Fig. 51), are the characters involved. Besides showing the ordinary behavior of multiple allelomorphs when mated together these characters show linkage to another pair of factors (for yellow and white cocoon color). So far as the data go, the strength of this linkage seems to be the same in all combinations tested.

In mice it has been shown (Cuénot, Morgan, Sturtevant, and Little) that yellow, black, gray with gray belly (wild type), and gray with white belly 
(second wild type) are allelomorphs. It will be observed here that the factor in the wild type gray mouse is responsible for the appearance in each hair of the three pigments, chocolate, yellow and
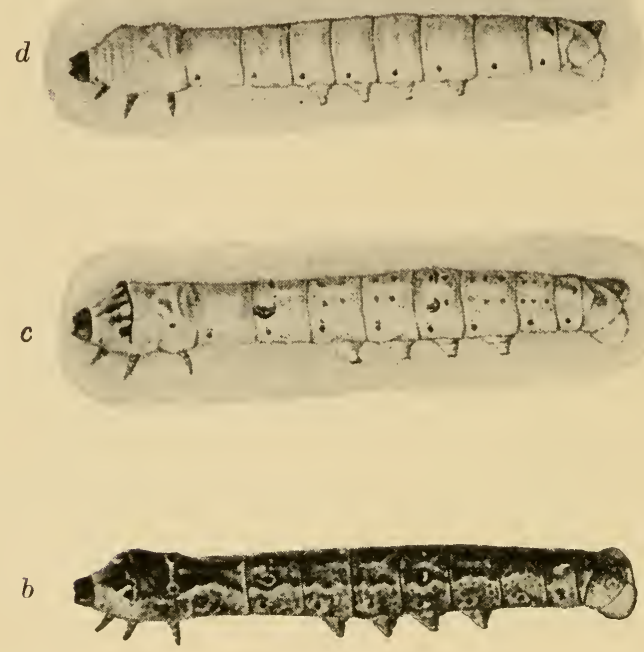

$a$

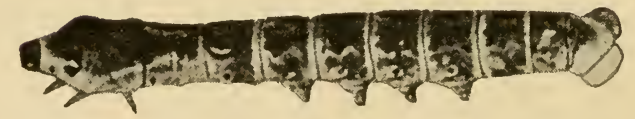

FIG. 51.-Four allelomorphic characters in the silkworm: $a$, Chinese striped yellow; $b$, Chinese moricaud yellow; $c$, Japanese normal yellow; $d$, Chinese plain white.

black. Gray is therefore a mosaic effect, for these colors are stratified in each hair from the base outward in the order above named. The allelomorphic factor for yellow gives rise to only one of these 
colors, although the others may to some extent appear, especially in old mice. The third allelomorph produces only black or at least the chocolate pigment, if present, is obscured by the darker color. Finally, the fourth allelomorph produces gray on the back and sides while the belly is pure white (the under hair is black). This series illustrates how allelomorphs of the same locus may not only determine the color, but also act to determine where a color is to develop. The allelomorphs differ therefore in regard to what part of the body they affect, or the time in ontogeny when they act, as in the banded hair of the gray mouse.

This case serves, therefore, as an excellent introduction to the cases that Emerson has described in corn (maize), in which the red color of the grain (pericarp), cob, silk, and husk furnish a wonderful series of character combinations that can be explained on the multiple allelomorph hypothesis. Emerson adopted the hypothesis of complete linkage, but the same arguments as used in other cases lead us to prefer the alternative of multiple allelomorphs. In some varieties of corn the grain, the cob, the silk, and the husk are all red; in others, all white; in others the grain may be red, the cob, silk, and husk white; in others, the grain may be white and the rest red. Practically all possible combinations are known, and so far as tested the combinations that go in through the two parents come out in $\mathrm{F}_{2}$ according to expectation, i.e., they give no new gametic recombinations. If we assume that there is a system of allelomorphs, 
such that one affects one combination of parts, another a different combination, the results find a simple and consistent explanation. It may seem strange at first that a factor may make the cob red and not color the grain or husk, while another allelomorph may make the grain and husk red but not affect the cob color, but it is no more strange than that one factor determines one distribution of the pigment over the coat and even in each hair of the gray mouse and another one determines another distribution.

Equally striking is the series of forms of the grouse locust (Paratettix) that Nabours has recently studied. Nine true breeding forms that are found in nature were studied. They differ markedly in color pattern (Fig. 52) but each color pattern behaves as a unit in heredity. The hybrid is in a sense intermediate, the color characters of each parent being superimposed. In fact Nabours finds that simple inspection of the hybrid suffices to show which forms were its parents. In the germ cells of the hybrid the two parental color types segregate as units. The resulting $\mathrm{F}_{2}$ types are in the $1: 2: 1$ ratio. It is obvious, since only two of the color types can exist in the same individual, and since they separate in the germ cells, that the condition of multiple allelomorphism is fulfilled.

All Nabour's crosses relating to color pattern (with some possible exceptions) follow the plan just outlined. The case at first sight appears unique in that the color pattern of each type is complex in the sense that different parts of the body are differently affected 
and in that in most cases the hybrid shows at the same time the characters of each parent. Both of these peculiarities occur in other cases, however,
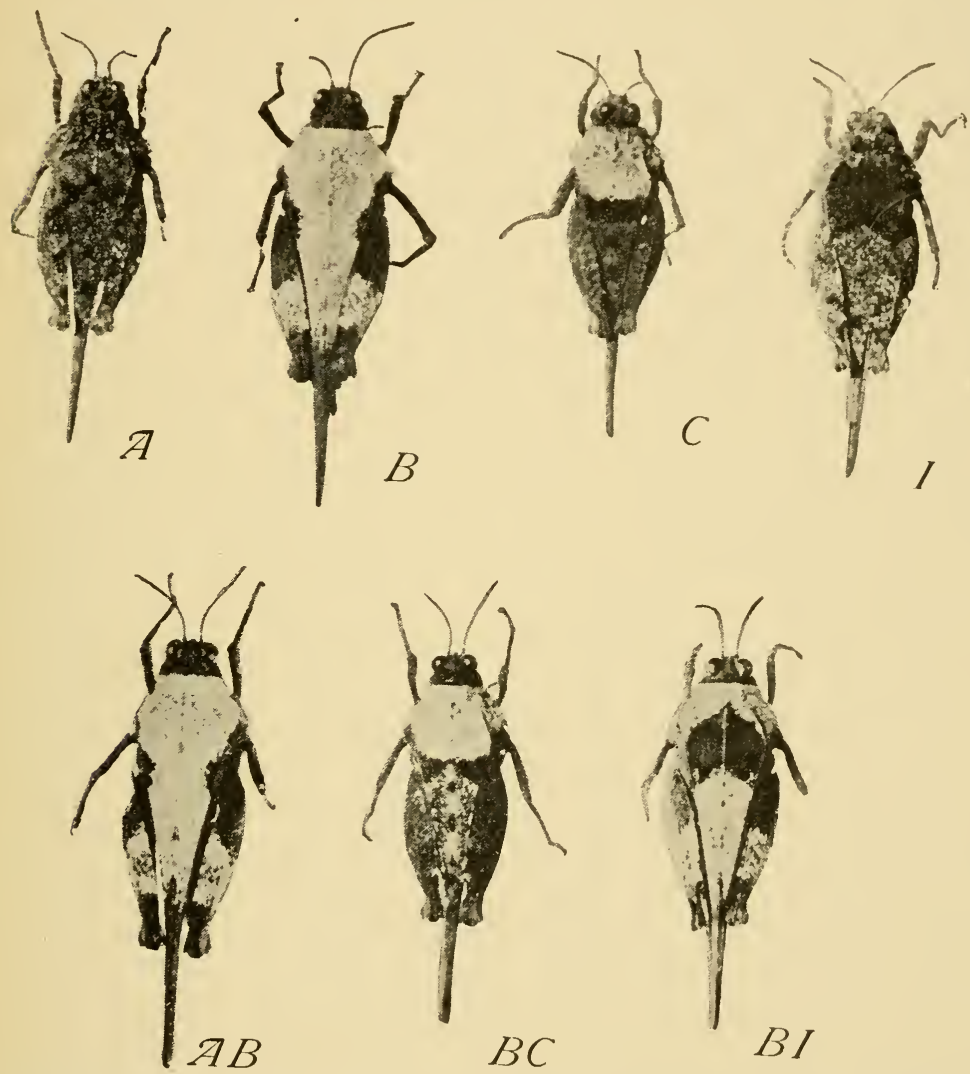

FIG. 52.-Four types, $A, B, C, I$, of Paratettix. Below are hybrids between $A$ and $B, B$ and $C$, and $B$ and $I$. (After Nabours.)

as in Emerson's corn for instance, although nowhere perhaps so strikingly as in Paratettix.

In any attempt to decide between the two alter- 
native views of identical loci and of complete linkage the method of origin of the mutant allelomorph is a matter of prime importance. Emerson has described one type ("variegated" corn) in which a mutation (to red) occurs frequently. This mutation is of such a sort, as Emerson points out, that, on the theory of complete linkage, it must involve the mutation of two factors at the same time. On the theory of multiple allelomorphs only one mutation is necessary each time the change occurs. Fortunately we have complete information concerning the origin of the types of Drosophila that fall into this category. One of these may now be given in detail before attempting to decide between the claims of the rival explanations.

In 1911 a few males with white eyes arose in a culture of red eyed flies. From them the stock of white eyed flies was obtained by the usual procedure. In 1912, in a culture of white eyed flies having also miniature wings and black body color, a male appeared that had eosin eyes. He also had miniature wings and black body color, so that there could be no question of his origin from this particular stock. The eosin stock is descended from this male.

In 1913, in a cross between vermilion eyed flies and wild flies several males appeared in $\mathrm{F}_{2}$ whose eyes were quite different from vermilion. Analysis of the case showed that a mutation had taken place in the stock having vermilion eye color. The new color proved to be a double recessive, for vermilion and for a color called cherry. The new mutation had 
not occurred at the locus of the vermilion factor, however, but at another locus where there had been a normal factor. Subsequent work with the cherry eye color showed that it was allelomorphic to white and to eosin, the three eye colors and their normal allelomorph forming a quadruple system.

To the preceding history must be added cases of the return mutation from eosin to white. Such a mutation occurred in 1914 in a culture of eosin flies with miniature wings. The parents had been treated with alcohol, but there is no evidence to show that the alcohol had any connection with the event. A single white eyed male appeared among many hundred eosin brothers and sisters. The male had miniature wings. When crossed by ordinary white it produced white through two generations. There can be little doubt that it is the same white as the original white. In a pure bred stock, eosin tan vermilion, a few males were found which had a white eye color instead of the cream color of eosin vermilion. These flies mated to white stock gave white offspring for two generations. Here the case was checked by two control characters, for the new white-eyed males showed tan body color and were proved to carry vermilion. In these controlled cases the mutation took place in the reverse direction from the original one. Three other cases of eosin returning to white which are apparently not explainable by contamination are also recorded.

The appearance of eosin in the white-eyed stock 
might be interpreted to mean that a mutation in eye color had appeared in the white-eyed stock in a factor located near the factor for white ("completely linked" with it) and that the effect of this new factor, combined with that of the factor for white, which was already there, gave the color that we call eosin. Eosin from this point of view would be due to two consecutive mutations of completely linked, neighboring loci. This interpretation of two consecutive mutations can not be made in the case of cherry, however, for cherry arose from red by one step, just as did white; yet cherry, like eosin, when mated to white, does not give rise to offspring that are red. It would follow on the complete linkage view that cherry and white differ from red by the same factor, but since they are not alike, that one of them must differ from red by still another factor. Since each arose from red immediately, it would follow that one of them must have arisen by a simultaneous mutation in two factors completely linked and affecting the same character. All these assumptions must be made on the theory of complete linkage, but are avoided on the alternative theory of multiple allelomorphs.

Exactly the same argument applies in the case of two other triple allelomorph systems of Drosophila. The recessive mutants pink and peach colored eyes each arose independently from red eyed flies, yet when crossed do not give red, but a color intermediate between pink and peach. Secondly, sooty body color arose in wild stock, although it was found only 
after the stock had been crossed to ebony, with which it is allelomorphic. Here too the mutant forms though both recessive to normal do not give normal gray color when crossed together, but a color intermediate between sooty and ebony. In both of these cases the complete linkage view would require that one of the mutant types had originated by a mutation in two factors at once. There is still another set

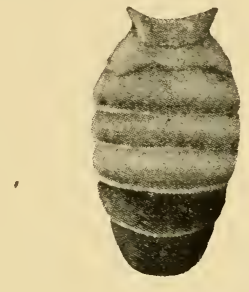

a

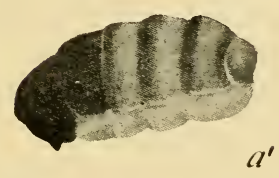

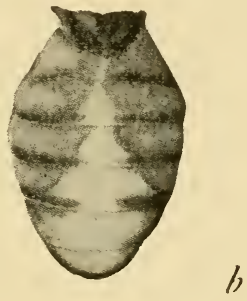

b

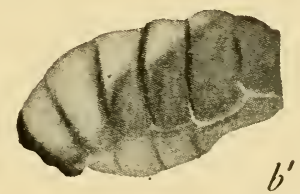

FIG. 53.-The abdomen of normal $a, a$, and spot, $b, b^{\prime}$, males. The other allelomorph is yellow (not shown here).

of triple allelomorphs known in Drosophila, namely, yellow and spot (Fig. 53) and their normal allelomorph. The above argument does not apply to this case, however, for although spot and yellow are both recessive to gray and give yellow when crossed to each other, spot originated in flies containing already the allelomorph for yellow.

The reasons may now be given that incline us to think that the theory of identical loci is much more 
probable for the cases known than is that of complete linkage (in the sense defined). No one of the reasons is in itself conclusive, but taken together they weight the scales heavily on one side.

1. When two mutants that depend on "multiple allelomorphs" are crossed they give in $\mathrm{F}_{1}$ a type that is like one or the other of the two mutants, or an intermediate type. This type is scarcely ever like the original (or wild) type. In this respect they differ from other recessive mutant types which when crossed together give the wild type. We understand why in the latter cases the wild form is recovered. It is because each mutant type contains besides its mutant factor the normal (dominant) allelomorph of the other type. Hence the original type is reconstituted in the cross, as has been already stated. But when two mutant allelomorphs occupying the same locus are brought together neither of them brings in the normal allelomorph of the other; hence the wild type is not reconstituted. If the cases in which these allelomorphic factors arose independently are not cases of identical loci then the explanation involves the occurrence of two mutations at the same time, as explained in the case of cherry.

2. It is a characteristic of "multiple allelomorphs" that the same character is affected. Nearness of factors in the chromosome will not explain this fact unless nearness means the same factorial basis, for in the other mutants that we have obtained, nearness of factors is in no way related to the kind of character 
or part of the body that is affected. It seems therefore more probable that this peculiar fact connected with multiple allelomorphs means that the same portion of the chromosome is changed in one or another direction.

3 . It is true that a very wide range of linkage values has been obtained, that extends from almost free segregation to less than 1 per cent. of crossovers. However, if we should construct a curve showing the number of cases exhibiting the various possible linkage values, the number showing complete linkage or, as we should say, multiple allelomorphism, would be far in excess of the number of these to be expected from the general shape of the rest of the curve. This indicates that multiple allelomorphs are in a class by themselves, not merely extreme cases of the same type as an ordinary linkage case.

4. There is an a priori consideration that may not be out of place in the argument. There is no sufficient reason for supposing that only one sort of mutation can occur in a given locus in the chromosome. If the basis of the chromosome is a chain of chemically complex substances (e.g., proteins), any slight addition or loss or even re-arrangement of the atoms in the molecules of a bead in such a chain might well produce an effect on the organism, and perhaps a more marked effect on that particular character that stands in closest relation to that chemical body. Since we know that mutations and even "reverse" mutations actually occur, it would be indeed strange if only one kind of change were 
possible in a given locus. But if more than one kind of change did take place in a locus, a series of multiple allelomorphs would result.

The ability of the theory of multiple allelomorphs (identical loci) to explain the peculiarities of so many cases in such widely separated fields proves the usefulness of the hypothesis. Although the theory of complete linkage also will cover the numerical results in these cases (and some of the simpler cases cited may prove to fall under this head) there is the very strong first-hand evidence that has just been given that makes the theory of multiple allelomorphs more probable than the former theory. It is important to recognize that there is this strong evidence in favor of multiple allelomorphs, quite aside from special cases of complete linkage, for, as will be shown in the next chapter, there are some far-reaching consequences of the theory of multiple allelomorphs.

A word may not be out of place here concerning the relation of the theory of multiple allelomorphs to the question of the variability of factors. The fact that more than one change may take place in the material at a given locus must not be taken to mean that the material is undergoing continuous fluctuating variability, for such mutations occur rarely and the factors later behave as do others. In fact in only one case (i.e., Emerson's variegated corn) do mutations appear frequently at a given locus. But even in such case the change can not properly be said to be fluctuating, but is of a fixed nature, and when it has once occurred the new factor 
is no more subject to mutation than are other factors, i.e., the factor has lost its unusual instability.

There is no a priori answer possible to the question as to whether a mutation having occurred, a further mutation of the mutated factor is more likely to occur, for it is conceivable that while in one case the new factor might be unstable, in another case it might be even more stable than the original one. In regard to the other question, as to whether a particular locus is more liable to mutate, the work on Drosophila shows that certain loci do mutate more often than do others, and this is shown not only in the recurrence of the same mutation, but also in the occurrence of multiple allelomorphs. 


\section{CHAPTER VIII}

\section{MULTIPLE FACTORS}

The term "multiple factors" has come, in practice, to be applied usually to cases in which two or more factor-differences occur, all of which produce similar effects. The frequency with which such cases are found is not surprising, since, on the factorial interpretation of heredity, it is apparent that many factors must contribute toward the making of every character. For example, the character, eye color, can appear only after the complex series of developmental reactions has taken place, whereby in turn head, eyes, pigment cells, etc., have been formed, and so this character must ultimately depend on all the factors affecting these processes. There must, besides, be many factors that operate in a more direct manner in the production of nearly every character, since on analysis even the simplest character usually proves to be the resultant of many components, both physical and chemical. Thus the color of the eye must depend, among other things, on the size of the pigment granules, on their number and on their color, and the color of the pigment may in turn be dependent on reactions in which many substances take part. It is therefore evident that an apparently simple character, like eye 
color, involving only one organ, is, so far as its mode of inheritance is concerned, in no wise different in kind from a complex character like stature which, as Bateson pointed out in 1902, must depend on all factors affecting length of head, neck, trunk, or legs.

In the case of eye color in Drosophila, more than 25 factor-differences have arisen by mutation. Most of these factor-differences are dissimilar in their effects upon the eye color-thus, one differentiates a purple eyed fly from the red, another differentiates vermilion from red, another white from red, and so on. It so happens, however, that two mutations occurred, one in the sex-linked group, and one in the third, each of which changed the red eye to a pink color. It is to such cases only-where factordifferences produce the same or very similar effects, or effects that differ only in degree-that the term "multiple factors" has come to be specifically applied. It should be recognized that this restriction of the term is arbitrary, but there is a practical advantage in grouping these particular cases together under a common heading, because crosses involving several factor-differences that are similar in effect give peculiar ratios and present certain difficulties to a factorial analysis, not commonly met with elsewhere.

In the above illustration of the sex-linked and third chromosome pinks the two factor-differences were not present in the same cross, and their inheritance was worked out separately. They were shown to be different factors, not by their behavior 
with reference to each other, but by their different linkage values with other factors.

An example of a cross, involving at the same time two factor-differences which have similar effects, is Nilsson-Ehle's cross of dark brown oats having two dominant factors for dark glumes with white-glumed plants having the two recessive allelomorphic factors for light color. The expected $\mathrm{F}_{2}$ ratio is 9 double dominant dark browns $(\mathrm{AB}): 3$ light browns having the first recessive and the second dominant $(\mathrm{aB}): 3$ light browns having the first dominant and the second recessive $(\mathrm{Ab}): 1$ double recessive white $(\mathrm{ab})$. Since the two factor-differences produce similar results, however, the light browns, $\mathrm{aB}$ and $\mathrm{Ab}$, are indistinguishable; counting these two classes together, a $9: 6: 1$ ratio results. The 9 double dominants were distinguishable from the 6 single dominants, the pigment being dark brown in the 9 cases where both factors for dark glumes were present and both factors for light glumes absent, but only light brown in the 6 cases where one light and one dark factor were present. Similarly the 1 double recessive, having both light and no dark factors, was much lighter even than the 6 light browns. This result may be described by saying that the effects of the factors for dark and for light were all cumulative or summative, two darks producing a blacker pigment than one, and two lights a paler color than one.

In many cases, multiple factors do not give results that may, in the above sense, be called cumulative. For example, if a white-flowered sweet pea (ab) 
having two pairs of recessive factors for white is crossed with a colored sweet pea $(\mathrm{AB})$, it is found when the $9 \mathrm{AB}: 3 \mathrm{aB}: 3 \mathrm{Ab}: 1 \mathrm{ab}$ individuals appear in $\mathrm{F}_{2}$ that the $\mathrm{aB}$ and $\mathrm{Ab}$ plants, having only one factor for white and one for red, are just as white as the ab plants. In other words, the ab class can show no cumulative effect of the two white factors. Since the three latter classes all look white, they are added together in the count, and a ratio of 9 reds : 7 whites results.

It is commonly said that this result is due to the occurrence of two factors "for red" (the dominants, $A$ and $B$ ), neither of which alone is sufficient to produce any effect (since $\mathrm{Ab}$ and $\mathrm{aB}$ look no different from $a b$ ), but which, when present together, act as complements to each other and thus produce the red color. Such an interpretation fails, however, to take into consideration the possible effects of the recessive factors "for white" ( $a$ and b). It is therefore unwarranted, unless the "presence and absence" view be accepted, namely, that the dominants are the only real factors, the recessives being mere absences. It would likewise be unwarranted, of course, to ascribe the results purely to the recessive factors, and so to conclude the similarity of $\mathrm{aB}$ and $\mathrm{Ab}$ to $\mathrm{ab}$ was due to the fact that $\mathrm{a}$ and $\mathrm{b}$ were non-cumulative in their effects. Neither of these methods of describing the case should therefore be regarded as more than a shorthand statement of the empirical facts.

In the cross of Bursa which follows, Shull, using the presence and absence scheme, treated the case 
as one of two similar dominant factors producing a non-cumulative result. (Here, then, the $9 \mathrm{AB}$ resemble the $3 \mathrm{aB}$ and $3 \mathrm{Ab}$ individuals and a 15:1 ratio results.) To those who reject the idea that dominance implies presence, recessiveness absence, there is no great distinction between this case and that of

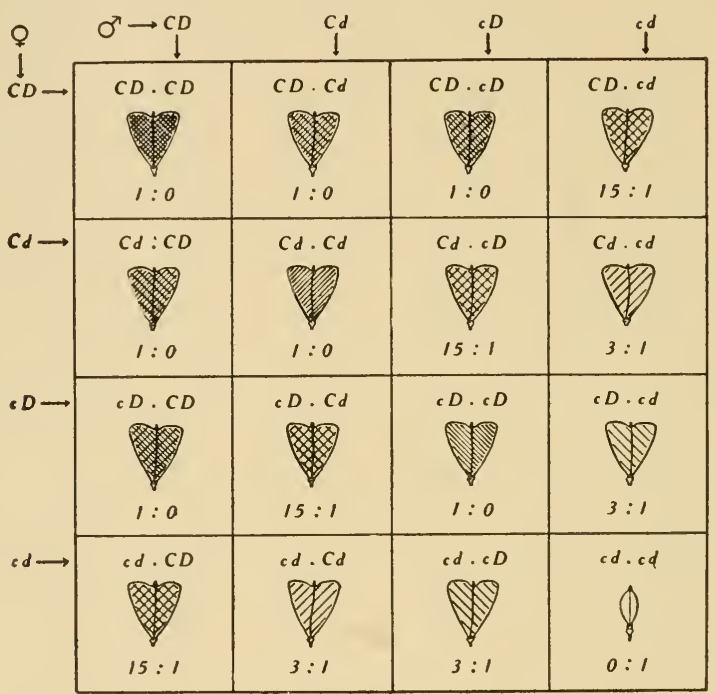

Fig. 54.-Diagram showing the kinds and composition of the $\mathrm{F}_{2}$ capsules of Bursa bursa-pastoris. (After shull.)

the two whites with a $9: 7$ ratio. Shull found that when a plant of Bursa bursa-pastoris with round capsules is crossed to one with triangular capsules, the round is recessive to triangular in $\mathrm{F}_{1}$. In $\mathrm{F}_{2}$ the round reappears only once in sixteen times (Fig. 54). Thus in this cross round may be treated as the resultant of the two recessive factors, either of which by 
itself does not change the triangular type, as shown by the fact that both single recessives are triangular in type and are identical in appearance with the double dominant. Only where the two recessives occur in the same individual does the type change to round.

Six families were bred from the $F_{1}$, and gave the following counts:

$\begin{array}{lccc} & \text { Triangular } & \text { Round } & \text { Ratio } \\ & 507 & 30 & 16.9: 1 \\ & 146 & 4 & 36.5: 1 \\ & 48 & 3 & 16.1: 1 \\ & 179 & 9 & 19.9: 1 \\ & 1743 & 7 & 24.2: 1 \\ \text { Totals } & 159 & 125 & 22.7: 1 \\ \text { Expected } & 2782 & 182 & 22.3: 1 \\ & 2725 & & 15.0: 1\end{array}$

The actual ratios range from $16: 1$ to $36.5: 1$, which exceed the expected ratio of $15: 1$. Nevertheless, the deficiency in the round class is probably due to the lower viability of the round-capsuled type, for in later cultures where the conditions were more favorable the expected 15:1 ratios are more nearly realized. That $15: 1$ is the true ratio is shown by tests that were applied to these $\mathrm{F}_{2}$ plants. In Fig. 54 , the 16 classes $(15: 1)$ of $\mathrm{F}_{2}$ individuals are represented. Within each square is also given the genetic composition of the class. The letter "c" stands for one of the recessive factors, and the letter " $d$ " for the other factor. Both of these recessive factors acting in conjunction produce the round capsules ccdd. Beneath each figure is given the expected ratio for 
the next generation when the plant of that composition is self-fertilized. It will be observed that the

$1: 0$ ratio is expected 7 times.

$3: 1$ ratio is expected 4 times.

$15: 1$ ratio is expected 4 times.

$0: 1$ ratio is expected 1 time.

This test was applied by Shull to his $\mathrm{F}_{2}$ plants of the triangular type. There were seven families that gave a $1: 0$ ratio, four that gave approximately a $3: 1$ ratio, and six that gave a $15: 1$ ratio. These results are in fair accord with the expected numbers given above.

When a further test was carried out by breeding from the six $15: 1$ families of the $\mathrm{F}_{3}$ group above (which should be expected to give the same results as the $\mathrm{F}_{2}$ class, because they have the same composition), the ratios obtained were as follows:

$1: 0$ ratio expected 35 ; realized 39 .

$3: 1$ ratio expected 20 ; realized 12 .

$15: 1$ ratio expected 20 ; realized 26 .

The results agree again fairly well with the expectation.

A second test is found in self-fertilizing plants from families that gave a $3: 1$ ratio. As the diagram shows these contain only the one ("c") or the other ("d") factor, they should give only homogeneous families and $3: 1$ families-never 15:1 families. This result also was obtained.

Nilsson-Ehle found that three recessive factors must combine to produce an effect which, in the 
following case, is the production of a white-seeded wheat. A cross between white-seeded and redseeded wheat gave in $\mathrm{F}_{2}$ one white to sixty-three reds, showing that three independent recessive factors were involved.

Nilsson-Ehle also found that in oats a type without ligules reappeared in $F_{2}$ in such a ratio that four recessive factors must have combined to have produced the type without ligules. East found certain kinds of yellow corn that gave in $\mathrm{F}_{2}$ fifteen yellows to one white. We may here also interpret the white as the double recessive. East has pointed out that in crosses of certain strains of red corn white appears in $\mathrm{F}_{2}$ in such a way as to suggest that three or possibly four recessive factors combine to produce white.

In other cases of multiple factors, the two factordifferences differ in the intensity of their effect, and so in $\mathrm{F}_{2}$ the two classes $\mathrm{aB}$ and $\mathrm{Ab}$ can be distinguished from each other, and a 9:3:3:1 ratio therefore results. In some of these cases, however, the factors are in a sense non-cumulative in that one of the factor-differences produces no effect when a given allelomorph of the other pair of factors is present. Thus, in the ratio $9 \mathrm{AB}: 3 \mathrm{aB}: 3 \mathrm{Ab}: 1 \mathrm{ab}$ if, in the presence of $\mathrm{b}$, a and $A$ produce no different effect there would be a ratio of $9: 3: 4$. This is true in a cross of a black mouse $(A B)$ with a white mouse carrying both the recessive factor (b) for producing an absolutely white color and also the recessive (a) which merely "dilutes" the black to blue. The "diluter" a of course can not have any visible effect 
in a mouse already carrying $b$ and therefore white. There are also reverse cases where, in the presence of $\mathrm{B}$, a and $\mathrm{A}$ produce no different effect and thus a ratio of $12 \mathrm{AB}+\mathrm{aB}: 3 \mathrm{Ab}: 1 \mathrm{ab}$ is obtained.

Departures from the $9: 3: 3: 1$ ratio different from those given above result if one factor for a character is dominant and another recessive. For example, there is a white race of fowls that is dominant and another white race that is recessive. There are two cocoon colors in silkworm moths that have this same relation. A cross of a dominant white to a recessive white gives a ratio of $13: 3$. Here, instead of the recessive classes resembling each other, so that a $9: 6: 1$ or $9: 7$ ratio is produced, both the $9 \mathrm{AB}$ and $3 \mathrm{Ab}$, since they contain the dominant white (A), resemble the one ab containing the recessive white (b), and only the $3 \mathrm{aB}$ appear colored. In this case the effect of the white does not happen to be cumulative, but there is no reason why factors which differ as to dominance should not have a cumulative action; if they did, a $3: 10: 3$ ratio would result.

Cases belonging to any of the types given above show modified ratios if the dominance is incomplete, for then the heterozygous classes are intermediate in character between the others. Consequently, in these cases, the different classes are usually not as easy to distinguish from one another as if dominance were complete, for the character differences now separating the classes are smaller. In such cases, especially if the character is appreciably influenced by environmental conditions, the individuals in any 
one class may vary so much from each other as to overstep the small differences separating the classes. An accurate separation of the individuals into different classes and a count of the number in each class is then impossible, and it becomes so difficult to determine the number of factors involved and the effect of each factor (or, rather, factor-difference) that such cases have at times been used in attempts to disprove the factorial hypothesis. The problem is likewise more difficult if more than two factordifferences occur. This is true especially in those cases where the effects of the different factors are cumulative, for then classes are produced showing characters intermediate in various degrees between the characters of the most extreme classes, just as in cases of incomplete dominance. It will be instructive to consider several instances of crosses of the above types, since, although definite ratios can not be obtained, there are various characteristic effects produced which show that multiple factors are responsible for the peculiarities of the results.

The inheritance of black color in Drosophila has already been described. Black is recessive to the normal ("gray") color, but the heterozygous forms are a little darker than the pure grays. Ebony is another body color, similar in appearance to black, but somewhat darker. It is similarly recessive to gray, but the factor responsible for it is located in a different chromosome (III) from that which carries the factor for black (II). When black and ebony are mated together we should expect gray flies in $F_{1}$. 
Such flies were actually obtained, although they were rather dark in color, since both black and ebony produce some effects on flies heterozygous for them. In $\mathrm{F}_{2}$ the expectation is 9 gray, 3 black, 3 ebony, and 1 black ebony (double recessive). When $\mathrm{F}_{2}$ was actually obtained it was found to be impossible to make an accurate separation of the four classes. There was a practically complete series ranging from the normal gray to individuals darker than either black or ebony. The gradation is obviously due chiefly to the fact that dominance is not complete. There are nine different classes expected, instead of four, if heterozygous forms be counted. These nine classes form groups, each with its own mode, the outlying members of each group overlapping neighboring groups. To add to the difficulty, the colors change considerably with the age of the fly. There are at least seven other mutant factors known in Drosophila that make the flies darker. It will readily be seen that, if one had a population containing a mixture of all these characters, analysis would be well-nigh impossible.

Before making the above cross the inheritance of black and of ebony had been studied separately, and no difficulty in classification is encountered unless they are used in the same cross. This information made it possible for us to interpret the black ebony cross. In the experiments now to be described, we are dealing with factors which had not first been studied separately, so that the interpretation is not so obvious as in the preceding case. 
Two varieties of tobacco, Nicotiana alata grandiflora and $\mathrm{N}$. forgetiana, were crossed by East. They differ mainly in the size and color of the flower. The corolla is three times as long in one as in the other variety, as seen in Fig. 55. In the table, page 185 , the lengths of the corolla in the two varieties,

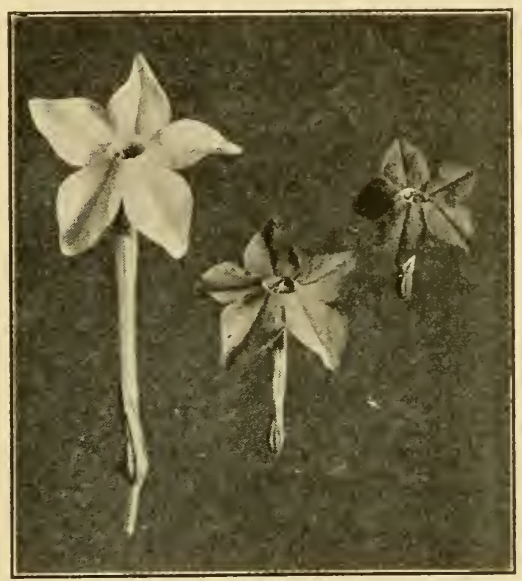

Fig. 55.-At the laft a flower of Nicotiana alata grandiflora; at the right a flower of $\mathrm{N}$. forgetiana; in the middle the $\mathrm{F}_{1}$ hybrid. (After East.)

in the $\mathrm{F}_{1}$, and in the $\mathrm{F}_{2}$ plants are given. The table shows the small variability of the parents. The $\mathrm{F}_{1}$ generation is intermediate in length and also shows little variability, while the $\mathrm{F}_{2}$ generation gives no definite ratios but exhibits great variability (Fig. 56), and overlaps the two grandparental types, although only a few flowers in $\mathrm{F}_{2}$ are identical in size with those of each of the two grandparental types. These results are those expected if the two parent varieties 
differ in several factors that affect their size. If the parent strains were pure the $\mathrm{F}_{1}$ hybrids would all be alike, or rather would show little if any more variability than either parent stock, because all these $\mathrm{F}_{1}$ plants receive the same contributions from the

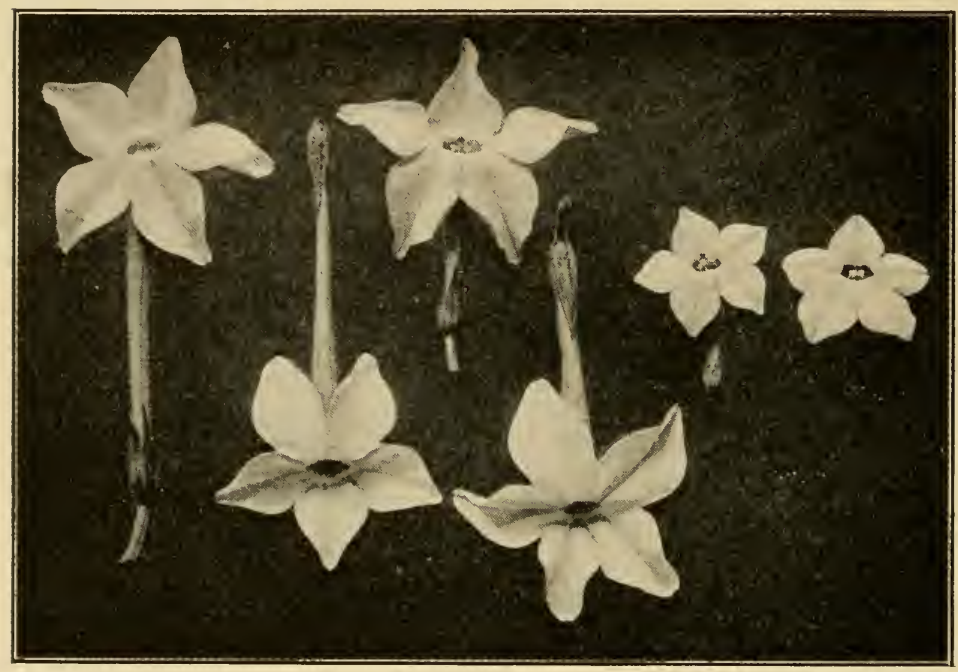

FIG. 56.-At left, a flower of Nicotiana alata grandiflora; at right $\mathrm{N}$. forgetiana; between them are four $F_{2}$ flowers, showing the result of segregation both in the length and the spread of the corolla. (After East.)

parents. But when in the gametogenesis of the $\mathrm{F}_{1}$ plants these factors segregate, many new combinations will be formed, and among them will be a few combinations like those in the original varieties; hence we expect in the $\mathrm{F}_{2}$ a wider variability, with a return to the grandparental types in a certain percentage of the plants. East suggests that four pairs of factors may cover the results in this instance. 
MULTIPLE FACTORS

185

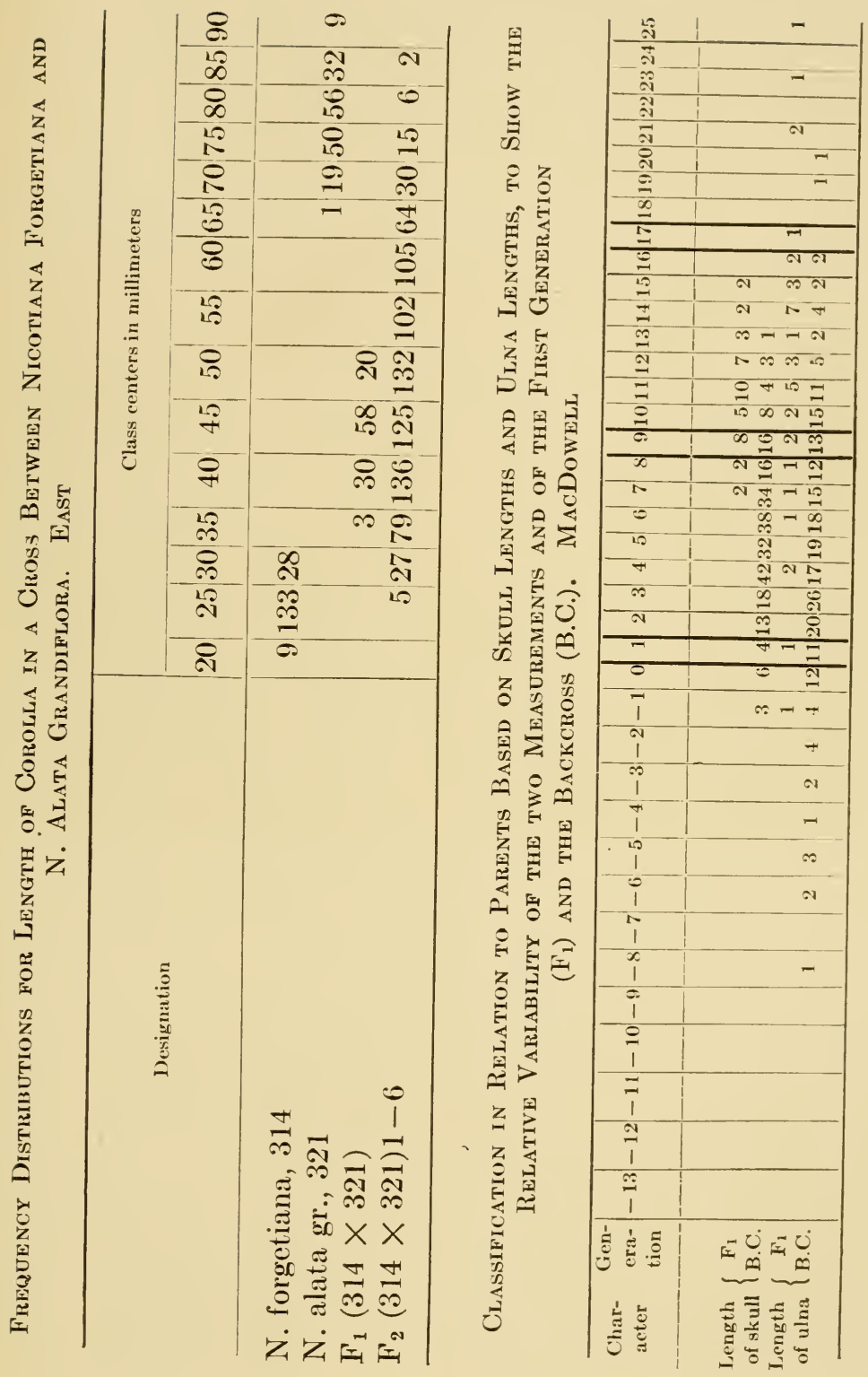


A race of pigeons called fantails differs from other pigeons, and from birds in general, by the large number of feathers in the tail. The ordinary pigeons have
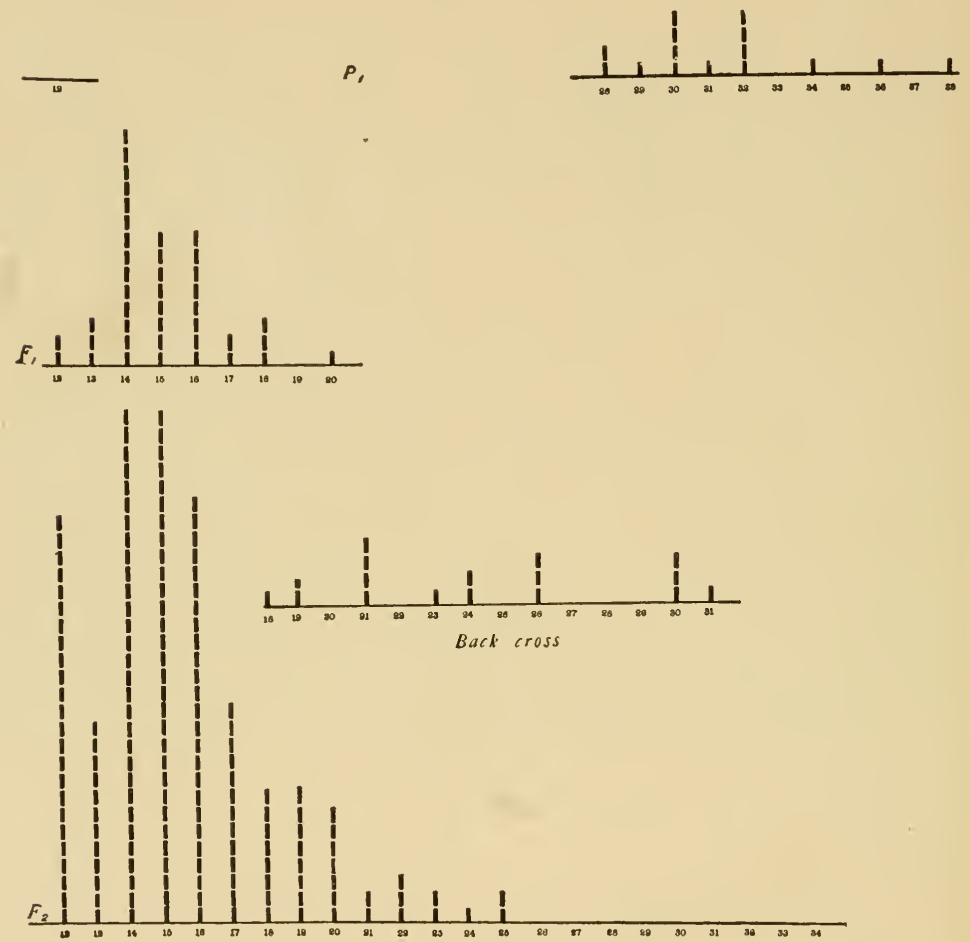

FIG. 57.-lllustrating the results of a cross between pigeons with 12 tail feathers and a race of fantail pigeons with from 28 to 38 tail feathers. The number of feathers in $\mathrm{P}_{1}, \mathrm{~F}_{1}, \mathrm{~F}_{2}$, and the offspring of the backeross ( $F_{1}$ by fantail) is given. In each case the numbers on the base line stand for tail feathers. The vertical columns are the classes.

twelve tail feathers; the fantails used in the cross have from 28 to 38 tail feathers. The $\mathrm{F}_{1}$ hybrids (Fig. 57) have from 12 to 20 tail feathers; the $\mathrm{F}_{2}$ have 12 to 25 as also shown in figure 57 . When the $\mathrm{F}_{1}$ 
birds are backcrossed (Fig. 57) to the fantail the number of feathers varies from 19 to 31 . On the hypothesis that the race of fantails has been built up by the accumulation of several factors these results can be understood.

MacDowell has compared the length of skull and of one of the bones in the leg (ulna) of hybrids between domesticated races of rabbits in the $F_{1}$ generation and in the backcross. As shown in the table, page 185, the variability of the backcross is in both characters greater than that of $F_{1}$. Similar though less convincing evidence was obtained for body weight also.

The inheritance of ear length in rabbits has been studied by Castle in a cross between lop-eared and short-eared races (Fig. 58). He shows that the $\mathrm{F}_{1}$ generation has ears of intermediate length and that the blend is "permanent," i.e., that "no reappearance of the grandparental ear length occurs in generation $\mathrm{F}_{2}$, nor are the individuals of the second generation, as a rule, more variable than those of the first generation of cross breeds." In the light of MacDowell's results for other quantitative characters in rabbits it seems more probable that the number of factors involved is greater for ear length than in the other cases, hence more data will be necessary before we can be certain that no reappearance of the grandparental types will be found in $F_{2}$. If four independent factors were involved either grandparental type would be expected to reappear only once in 256 times, with six factors only once in 4000 
times, etc. It would require a large number of offspring to prove the multiple factor hypothesis if the reappearance of the grandparental types be demanded for such a proof.
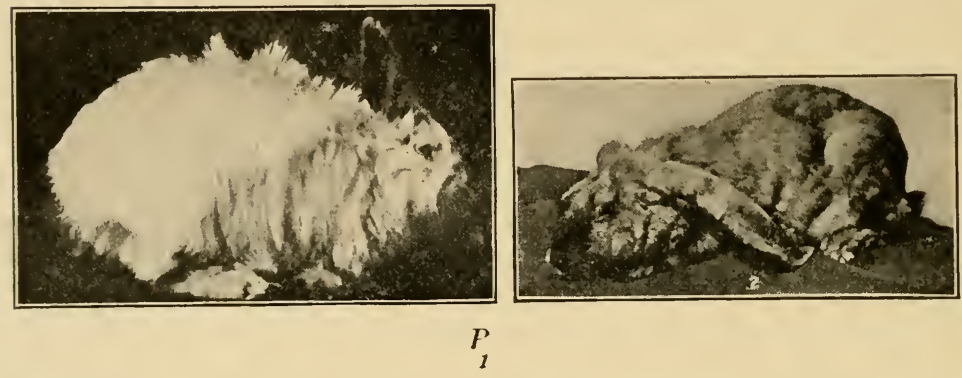

$P$
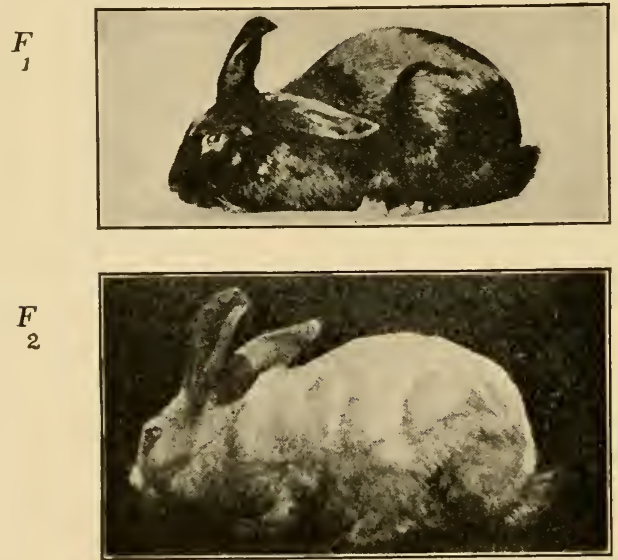

FIG. 5S.- Short-eared by lop-eared rabbit. $F_{1}$, son of last; $F_{2}$, daughter of $\mathrm{F}_{1}$ by his sister. (After Castle.)

Several excellent cases of multiple factors have been worked out with Indian corn. Height of plant (as a concomitant of its vigor), length of ear, and 

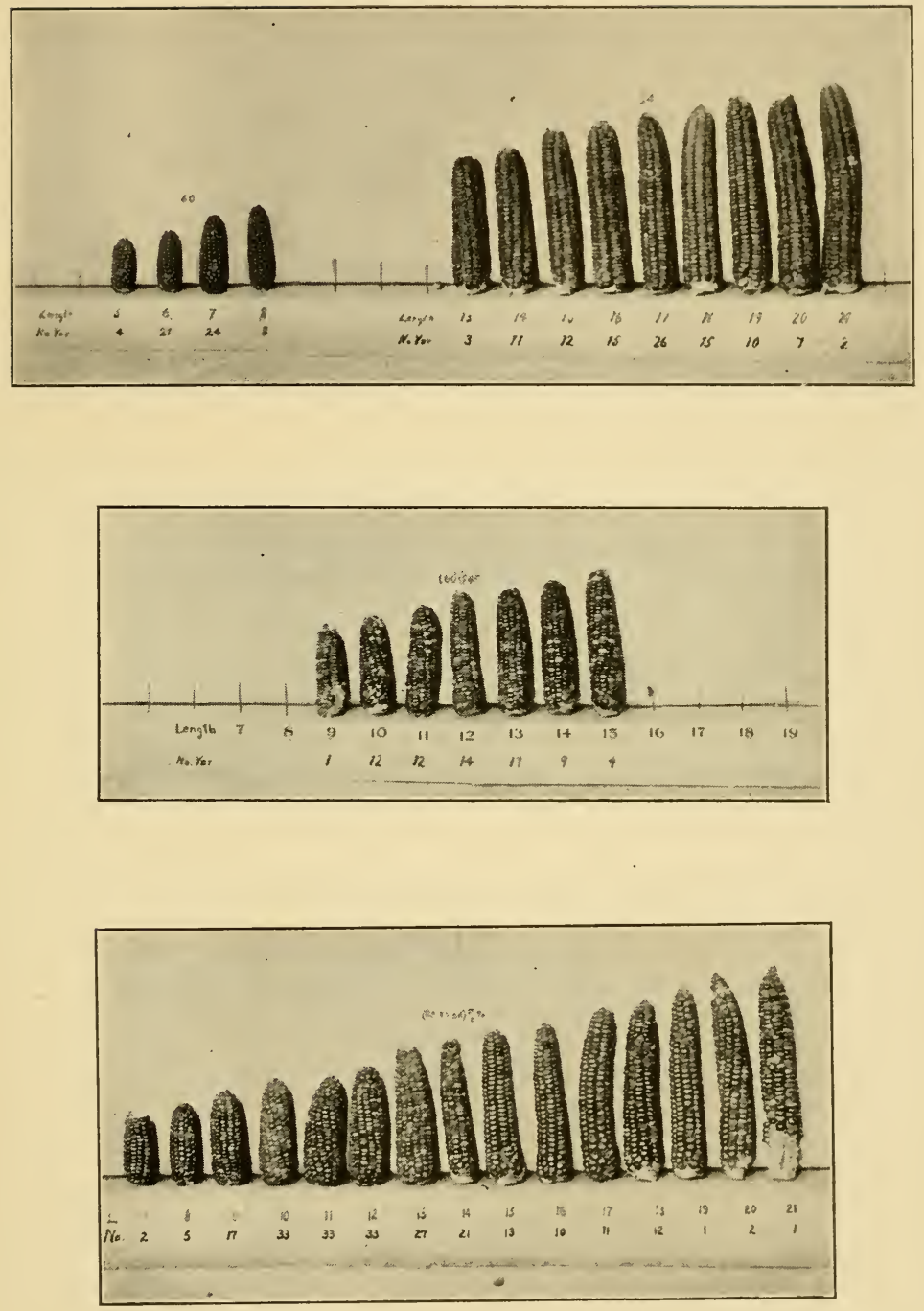

Fig. 59.-Top line; at left, Tom Thumb pop corn; at right, black Mexican sweet corn. Middle row; $F_{1}$ from crossing the above races. Lower line $\mathrm{F}_{2}$ of same cross. (After East.) 
productivity depend on multiple factors. For example, East crossed the strain Tom Thumb (having short ears) to black Mexican sweet (having long ears). The relative length of ear in these two races is shown in the upper line of Fig. 59, to the left and to the right. A sample of the $\mathrm{F}_{1}$ ears is shown in Fig 59, the middle of the figure, while the variability of the $\mathrm{F}_{2}$ ears is shown in the lowest line. It is evident not only that the original types reappear, but that there are all intermediate lengths of ear in $\mathrm{F}_{2}$.

Many cases like this one that show a small variability in $F_{1}$ and a greater variability in $F_{2}$ have been described, for example, in oats (Nilsson-Ehle), beets (Kajanus), turnips (Kajanus), barley (Johannsen), gourd (Emerson), flax (Tammes), tobacco (Hayes and East), evening primrose (Heribert-Nilsson), bean (Emerson, Johannsen), pea (Tschermak), Lyon bean (Belling), wheat (Nilsson-Ehle), corn (East, Emerson, Hayes), duck (Phillips), fowl (Pearl), man (Davenport), rabbit (Castle, MacDowell), mouse (Cuénot), rat (Castle, Hagedoorn). ${ }^{1}$

This partial list will serve to show how often this form of inheritance has been met with, and when it is stated that in a number of these plants or animals several characteristics show this kind of inheritance, its frequency will be apparent. Many but not all of these cases relate to size, and size is obviously a character toward which many separate parts contribute. Moreover size is of ten an important element in domesticated animals and plants, and any differ-

1 This list is an abbreviation of the one compiled by G. H. Shull. 
ences in size that appear might therefore be selected in order to produce new and larger strains.

A more difficult case than those given above is that of truncate (Fig. 18, b) in Drosophila, worked out by E. R. Altenburg and H. J. Muller. The $\mathrm{F}_{2}$ resulting from a cross of a truncate fly to a normal long-winged fly consists of $85-92$ per cent. of long-winged and the rest truncates and flies with wings of various intermediate grades. The extracted truncates do not breed true; by selection it is possible gradually to reduce the longs to about 5 per cent., but even after about 100 generations of selection the proportion of longs could not be reduced any further. These longs produce some truncates, but do not, on the whole, produce nearly as high a percentage of them as do their truncate brothers and sisters. The longs, therefore, differ genetically from the truncates, and the fact that these genetic differences are constantly occurring in this stock, in spite of the long-continued selection, seemed to indicate that here at least there was a case of instability of factors or contamination of allelomorphs.

By means of linkage experiments it was shown that in the production of this character there are involved at least three factors $\left(\mathrm{T}_{1}, \mathrm{~T}_{2}, \mathrm{~T}_{3}\right)$, one in the first, one in the second, and one in the third chromosome. The character cannot make its appearance without the factor in the second chromosome $\left(\mathrm{T}_{2}\right)$, but it may appear without either of the other two factors, which are, therefore, in the nature of intensifiers. Moreover, truncate is influenced by still other fac- 
tors. For instance, bar, a first chromosome factor, acts in much the same way as the ordinary first chromosome intensifier. The sex factor also intensifies truncate, i.e., truncate appears more readily in the females than in the males and may, therefore, be called partially "sex limited." Especially noteworthy is the fact that while recessive in the normal gray it is generally dominant in an individual either homozygous or heterozygous for black.

This latter circumstance made it possible to study truncate as a dominant in heterozygous condition. As will appear later, this simplified the problem greatly, especially in determining whether or not (1) the factors for truncate are stable; (2) whether they are contaminated by their allelomorphs.

A truncate male containing factors for truncate in both its second and third chromosomes was mated to a normal winged female containing in its second chromosomes the factor for black, and in its third chromosomes the factor for pink. The male offspring of this mating will, therefore, have the formula $\frac{\mathrm{T}_{2} \text { gray }}{\text { long black }} \frac{\mathrm{T}_{3} \text { red }}{\text { long pink }}$. They will not contain $\mathrm{T}_{1}$, as males derive all sex-linked factors from their mother. An $F_{1}$ male was then backcrossed to black pink females. Since there is no crossing over in the male, all the gray red offspring of this backcross will be genetically identical, and like their father-unless the factors for truncate are unstable, or contaminated by their normal allelomorphs. The gray reds were not all alike in appearance, however, some being 
truncate, though most were long. Males of these two classes were then mated individually, again to black pink females. From the result of these matings it was clearly shown that the longs and the truncates produced almost exactly the same proportion of truncate, proving that they were alike genetically. Moreover, continuous selection of males of this composition for many generations in an attempt to alter this ratio was without effect. Since such an aiteration did not occur after many generations of outcrossing (heterozygosis) there could not have been any contamination or miscibility of the truncate factors with their allelomorphs, nor any instability of these factors.

It will be recalled that in the truncate stock there is a true genetic difference between the long-winged and the truncate flies, but since it has been shown that the truncate factors themselves do not vary, this genetic variation that is continually occurring in truncate stock must, therefore, be due to the fact that flies homozygous for a large number of the factors favoring the appearance of truncate are either not viable or else infertile, and consequently a pure stock cannot be maintained. ${ }^{1}$ In support of the latter explanation it is found that the greater the percentage of truncate produced by a stock the lower its fertility.

This case is of interest not only because the results indicate that other non-conformable instances might

${ }^{1}$ Nevertheless stock can be maintained by the method of repeated backcrossing to black pink, given above, from which individuals of a definite, known composition can always be obtained. 
be similarly explained, but also because the new methods which have been developed in attacking it are singularly adapted to the solution of such problems. The use of this method has been made possible by the information at hand as to the linkage
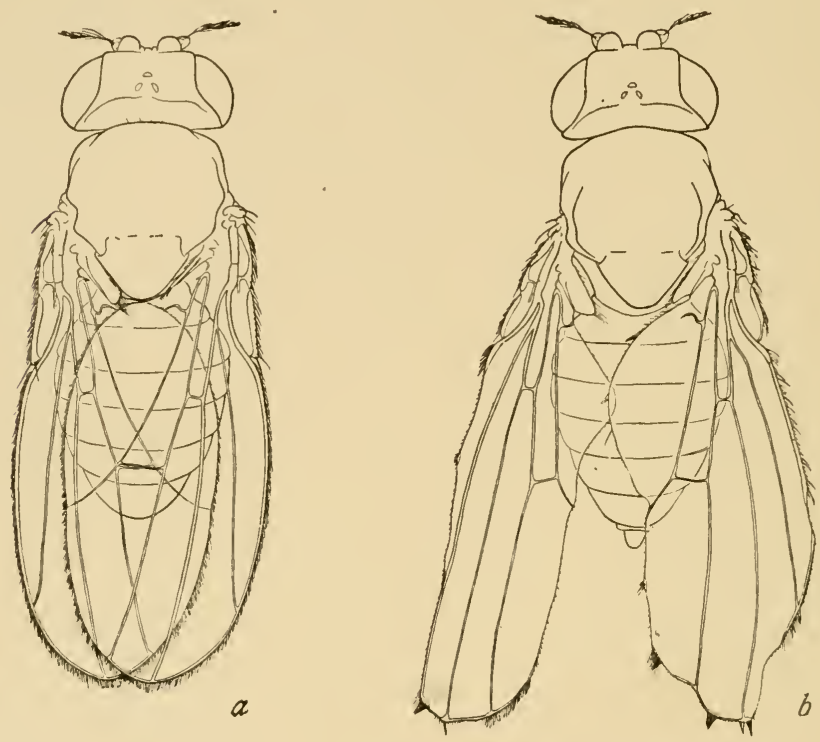

FIG. 60.-Normal wing (to left) and beaded wing (to right) of Drosophila.

groups and as to non-crossing over in the male. Without such knowledge the case would have been practically insoluble.

The same method of attack has also been used by Dexter, in his experiments with the "beaded" wing of Drosophila (Fig. 60). The beaded character is a variable one, some of the beaded individuals being 
very nearly normal in appearance. The degree of abnormality and the proportion of abnormal offspring are both capable of being altered, within limits, by selection or by crossing to normal stock. Dexter crossed beaded flies to flies carrying mutant factors in the different chromosomes and studied the linkage of the beaded character with these other characters. He found that beadedness showed linkage to third chromosome characters, indicating that there is at least one factor for the character located in that chromosome. He also found that sometimes beadedness showed linkage to second chromosome characters, while at other times it failed to do so. This indicates that the beaded stock was impure for a factor located in the second chromosome, which when present increases the amount of beading. Selection would be effective either by eliminating or by preserving this factor.

An extensive selection experiment was carried out by Lutz on Drosophila. He selected for abnormal wing venation-chiefly for extra veins. Abnormalities occur in nature in about 0.3 per cent. of the flies. In two separate experiments Lutz increased this to approximately 100 per cent. abnormals, and in one of the experiments kept it there for eight generations. But, in this same experiment, one pair (brother and sister of the first pair that produced 100 per cent. abnormals) produced no abnormals, and their descendants remained for 40 generations a strain which gave scarcely more abnormals than does a wild strain. Possibly a mutation occurred here, although 
a cross between this "reverted" strain and the selected 100 per cent. abnormal strain failed to give a definite result. From the offspring of this cross, again crossed to the 100 per cent. strain, Lutz selected another abnormal strain, which produced from 95 to 100 per cent. abnormals for eight successive generations. He then selected back again for normals and in six generations he obtained a strain which produced no more abnormals than does a wild strain. Selection for reduced veins was also successful, but was not carried on very extensively.

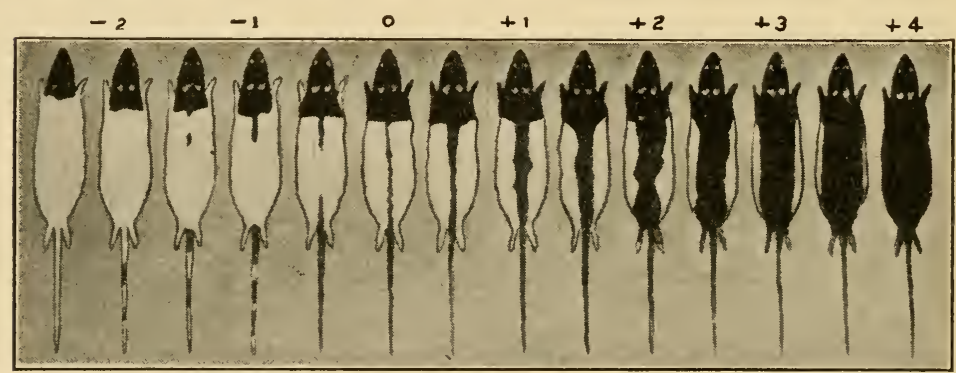

FIG. 61.-Series of arbitrary grades of hooded rats used in classifying results of selection experiment. Above the figures the numbers assigned to the grades are given (see text). (After Castle and Phillips.)

It is not clear what interpretation should be placed upon these experiments of Lutz, but it seems probable that mutations affecting the venation occurred several times, and were selected.

One of the most exhaustively studied cases of the effect of selection on a mixed population is that carried out on hooded rats by Castle and his co-workers, particularly Phillips. The pattern of hooded rats is 
shown in Fig. 61. The dark pigment covers the head and extends as a stripe down the back. The extent of the hood and the breadth of the dorsal band are so variable that in one direction, called plus, the rat is all black, except for a white stripe on the belly, and in the other direction, minus, the only black present is on the head.

Two selections were carried out: one in the plus direction (toward the darker type), the other in the minus direction (toward the lighter type). The steady progress in the plus direction that took place during 13 generations is shown on page 98 , and in the minus direction on page 199 .

This progress in the direction of selection would be expected if the race were not at the start pure for factors that determine the amount of pigmentation, since in all such cases the process of selection in a heterogeneous population sorts out some of the factors from others. Selection in most cases creates nothing that is not already present, but separates existing factors.

There are several ways in which the composition of the rats after their selection can be tested, and some of these tests Castle and Phillips have made. When light-colored rats from the minus series were bred to wild or to Irish rats that had a uniformly (or nearly uniformly) dark coat, all the offspring had practically completely colored coats. When these were inbred they gave 3 uniform to 1 hooded coat. This result shows that there is one chief factor (which is recessive) for hooded coat. However, the $\mathrm{F}_{2}$ hooded 


\begin{tabular}{|c|c|c|c|c|}
\hline 离 & 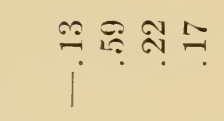 & 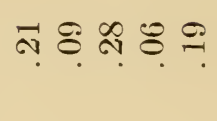 & $\stackrel{20}{0} 0$ & \\
\hline 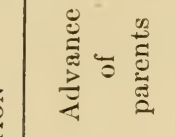 & $\vec{\sigma} \bar{\sim} \stackrel{\sim}{\sim} \overrightarrow{.}$ & 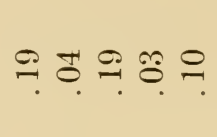 & $\stackrel{ }{=} \stackrel{\leftrightarrow}{\simeq}$ & \\
\hline 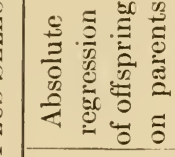 & 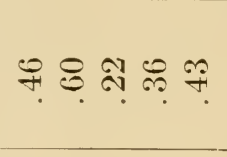 & 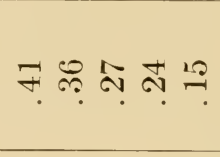 & ลิ & \\
\hline 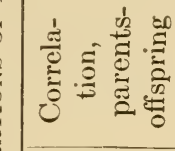 & 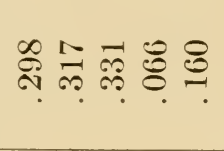 & 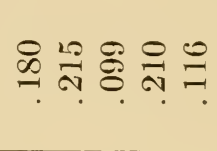 & ๙ิ & \\
\hline 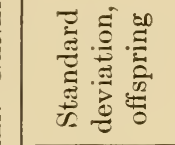 & चे & 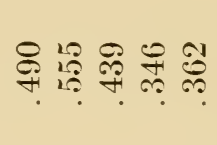 & 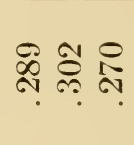 & \\
\hline 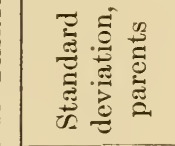 & 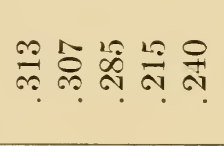 & 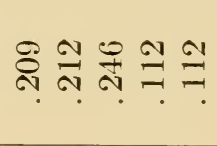 & 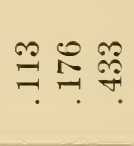 & \\
\hline 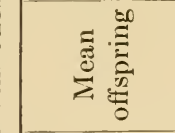 & 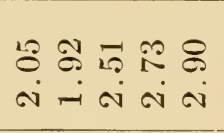 & 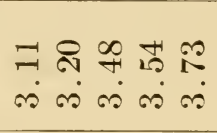 & $\begin{array}{l}\infty \\
1 \\
0\end{array}$ & \\
\hline 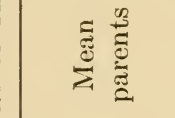 & 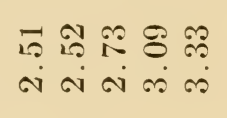 & 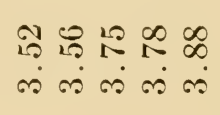 & 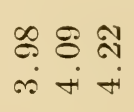 & \\
\hline 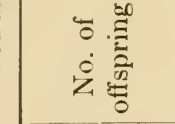 & 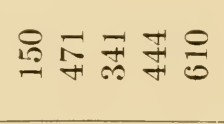 & 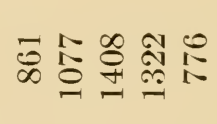 & ఏ్తి & 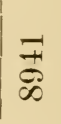 \\
\hline 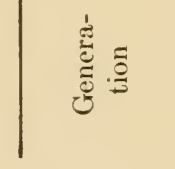 & 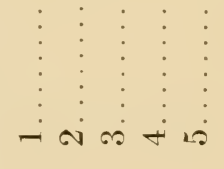 & 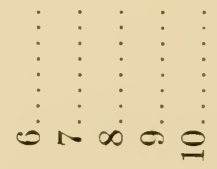 & $\begin{array}{cc}\vdots & \vdots \\
\vdots & \vdots \\
\vdots & \vdots \\
\beth & \vdots\end{array}$ & $\frac{\vdots}{\vdots}$ \\
\hline
\end{tabular}


MULTIPLE FACTORS

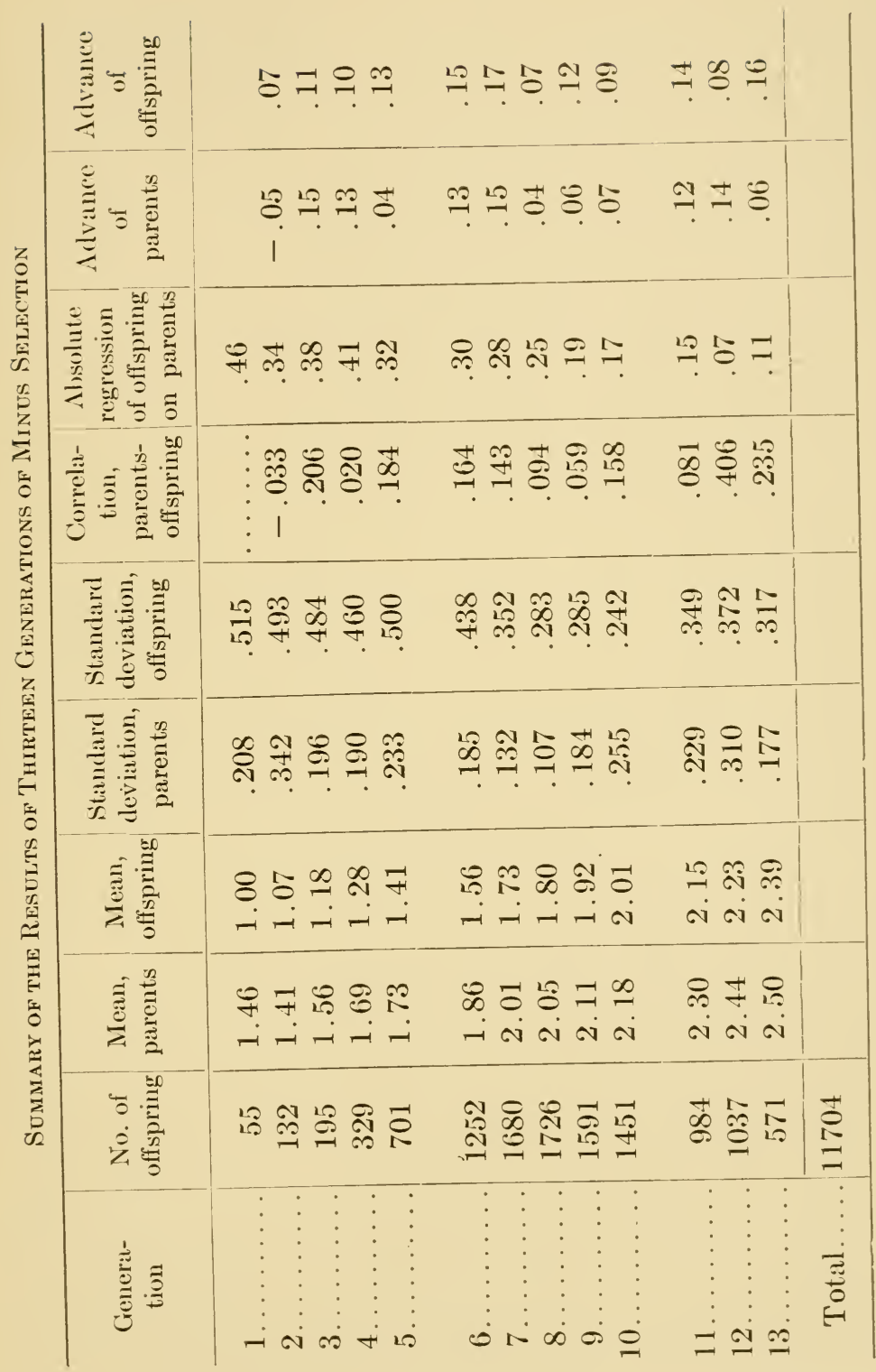


rats differed more among themselves than did those from the grandparental strain of hooded rats, which shows that other factors were involved as well, that modified the extent of pigmentation of the hooded coat, but had little effect on the uniform coat. The range of variation was extended in the direction of the darker coat, showing that modifying factors causing a darker coat had been introduced from the wild strain; and such would be the expectation if selection had eliminated from the domesticated strain some of the factors making for the darker coat that had been present in the original impure population. Conversely the darker hooded rats, plus series, were bred to wild gray rats: the $F_{1}$ were uniform; these inbred gave 3 uniform to 1 hooded in $\mathrm{F}_{2}$. The range of variation of the latter was again greater than that present in the dark hooded rats which had not been outcrossed, but now the range extended rather in the minus direction, i.e., the $\mathrm{F}_{2}$ hooded rats were on the whole lighter than their dark hooded grandparents. The result is what the multiple factor hypothesis calls for, if the wild or Irish rats contain factors that influence the condition of the color pattern. Plus selection had weeded out some of the "minus" factors, but crossing with a race in which no selection had been practised brought them back. When the selected plus and minus races were crossed to each other the variability was somewhat increased in $F_{1}$, and was further increased in $\mathrm{F}_{2}$. The extreme conditions of the grandparents rarely appear in this generation. Again the results are those the theory calls for. 
The test of reversing the direction of selection was tried. The parents belonged to the 6 (and " $6 \frac{1}{2}$ ") generation of the minus selection series, and averaged -1.86 . The average grade of the offspring was -1.56 , a regression of 0.30 , and their range was from 0 to -2.50 . Some of the low-grade offspring ranging from -0.37 to -0.87 were chosen for the return selection. They produced 118 offspring whose average was -1.28 , a regression of 0.68 , which is in the opposite direction from the regression obtained in the former (minus) selection. For six generations the reversed selection went on and carried the race back along its former course, i.e., toward its original condition. The fact that selection in the original direction was still producing some effect when the reversed selection began, means, on the multiple factor hypothesis, that the stock was still heterogeneous, in some factors at least, and, therefore, reversing the process would be expected to give the results that Castle and Phillips obtained.

These important results of Castle and Phillips fulfil so entirely the expectation for multiple factors that they might have been utilized as a good illustration of the effects of selection on a group in which a particular character owed its modifications to multiple factors. Castle has, on a number of occasions, made use of these results to expound a very different interpretation. The experiments were begun, in fact, to see whether selection in a given direction of a varying character that gave a continuous series of types would tend to further variation in the same 
direction. In other words it was intended to discover whether a new genetic type, with a new mode, could be established as a result of selection, so that the original bounds of variability would be transgressed. Castle has interpreted his results to mean that through selection or after selection, a unit character can be changed. He has used at times a word familiar to readers of Darwin, namely "potency." The potency of a factor as well as of a character is supposed to be a somewhat variable element.

It is obvious that it would be exceedingly difficult to establish such an interpretation, because in order to prove that selection can alter a factor it would first be necessary to prove that recombinations of multiple factors were not responsible for the variations of the "unit" character. The results with rats are in harmony with the theory of multiple factors, and hence in harmony with the whole body of Mendelism. There are no a priori grounds for regarding quantitative factors as differing from other Mendelian factors, and many cases are known in which quantitative factors conform in every respect to Mendel's principles.

In support of the view that the particular character of the hooded rat differs from the wild rat by a single factor Castle has pointed out that this is established by the Mendelian ratio, $3: 1$, that obtains when these types are crossed. But the $3: 1$ ratio does not establish this view. The ratio only shows that a recessive factor for hoodedness must be present in order that the rats may be hooded at all. Other factors that 
modify the coat may produce a visible effect only in the presence of this chief factor for hoodedness. The $\mathrm{F}_{2}$ from the crosses to self-color indicate that such modifiers are really present in the rats. The understanding of this point is so important that similar relations of the same sort may be cited. If a chocolate mouse (i.e., one that carries the factors for black and for cinnamon) is mated to a white mouse carrying the factors for gray (instead of those for black and cinnamon) the $F_{1}$ generation will be gray. In the $\mathrm{F}_{2}$ there are three colored mice to one white one, but there are several sorts of colored mice. Color of any kind is dependent on the action of a factor allelomorphic to white, hence the $3: 1$ ratio, but this classification ignores the occurrence of several kinds of colored mice which are due to differences in other factors determining what kind of color will develop.

There is a case in Drosophila that illustrates the same point. Eosin is a light eye color. Another factor called cream produces no effect on other eye colors, but makes eosin still lighter. A male pure for cream and for eosin bred to a red female gives red eye color in $F_{1}$. The $F_{1}$ 's inbred give three reds to one light eye color, but among the lights three different but overlapping kinds may be detected. Here, as in Castle's case, there is a chief factor (eosin) for reduced pigmentation, which must be present if any reduction in the color occurs at all, and another factor (cream) that modifies the amount of pigmentation only when the chief factor is present.

In favor of the view that factors are constant are 
the convincing experiments of Johannsen on the size of the Princess beans. The material is highly favorable for work of this kind, not only because exact measurements may be taken, but because the stocks

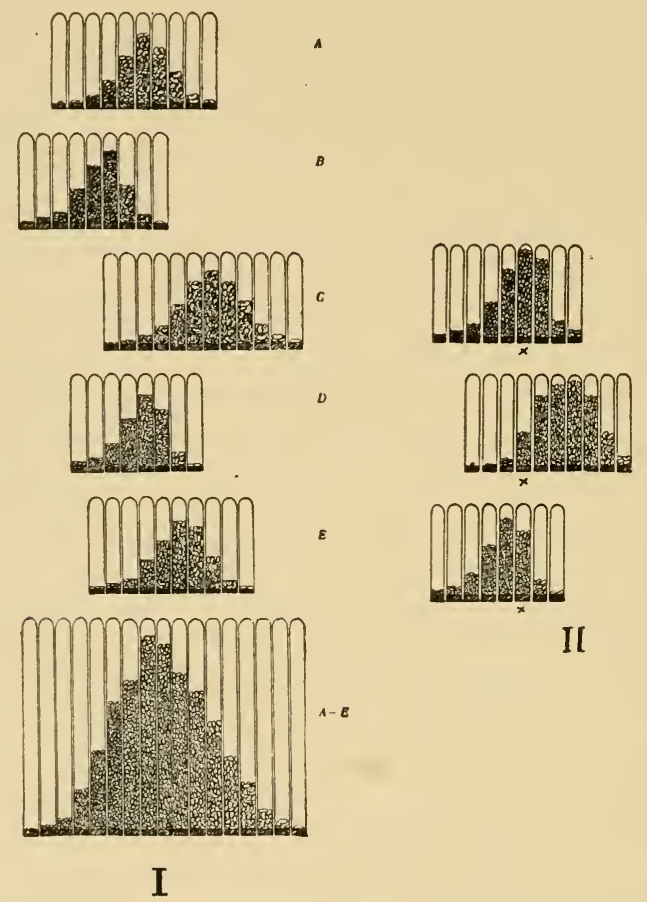

FIG. 62.-I. Five pure lines of beans $(A, B, C, D, E)$, and the population $(\mathrm{A}-\mathrm{E})$ that results when they are mixed. II. The upper figure represents the original biotype, and the two figures below this, the two new biotypes that arose from it. (After Johannsen.)

reproduce by self-fertilization and were found to be homozygous. Johannsen's results (Fig. 62) show that no matter how many factors influence the size of the bean, so long as the bean is homozygous, selection of plus and minus variants produces no effect on 
subsequent generations. Exactly the opposite results are expected when the population is heterogeneous for multiple factors at the beginning.

On several occasions Castle has stated that the practical breeder is especially familiar with the effects of selection because he has obtained most of his results by this method. It is intimated not only that the breeder is in a position to look favorably on the doctrine of potencies, but that his familiarity with work of selection entitles his views to special consideration. But no one has in recent years denied that selection of mixed material will lead to the isolation of definite types and even of new types.

To what has been said one additional consideration must be urged. Mutations may occur at any time and will be quickly observed if they are in the direction in which a selective process is being carried out. It may not be easy to recognize the first appearance of a mutant and, in fact, its presence may be detected only after the selection has gone so far that its origin is lost. The breeder may, if he is not extremely observant, infer that his selection is producing the desired effect on the potency of the character, while in reality he is studying the influence of a new factor on the character under selection. This possibility may be illustrated by two cases. In Castle's experiments two rats appeared that behaved like a new type. In fact he gives them the value of mutants. In Drosophila, Morgan carried out a selection experiment for three years, involving upward of 75 generations. The character selected was a dark "trident" 
on the thorax (Fig. 63). In a few generations a minus stock with no trident was established that bred true. The plus stock went up and down, the selection being not always thorough. A stock that always had the trident present to some degree was obtained

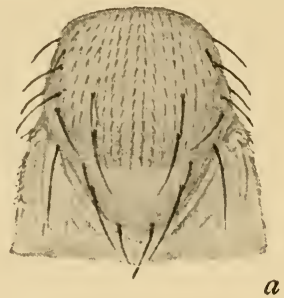

$a$

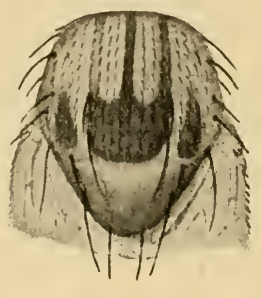

6
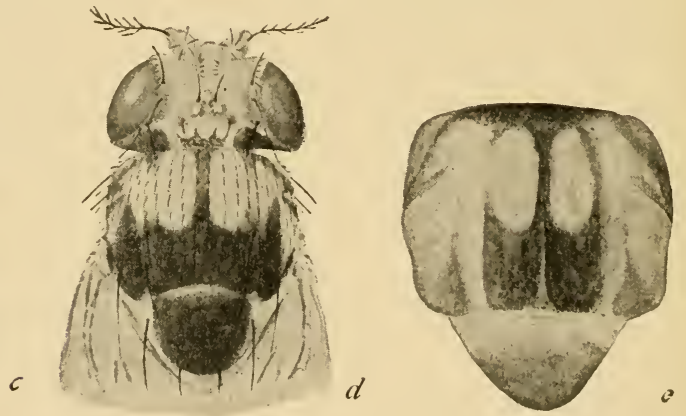

FIG. 63.-Thorax of mutant stocks of Drosophila ampelophila. $a$, race "without" trident; $b$, race "with" trident; $c$, race called streak; $d$, race called trefoil; $e$, race called band.

after a time. Later several other mutations appeared, some of which greatly increased the black on the thorax; some even swamped the trident, making it a broad band. Three such mutant stocks were readily isolated. It might have been concluded that these mutations had occurred in the direction of selection, 
because selection had changed the potency of the trident factor, were it not that during these three years over 100 other mutant characters had appeared in Drosophila, affecting every part of the body. Obviously when such changes are taking place everywhere, one would almost certainly find changes occurring in the parts that were being carefully scrutinized for any changes whatever. 


\section{CHAPTER IX}

\section{THE FACTORIAL HYPOTHESIS}

In Mendelian heredity the word "factor" is used for something which segregates in the germ cells, and which is somehow connected with particular effects on the organism that contains it. For example, if a fly (o) with red eyes is crossed to a fly $\left(\sigma^{7}\right)$ with white eyes, there will be in $\mathrm{F}_{2}$ three reds to one white, and this ratio can be explained by the assumption that in the $F_{1}$ hybrid something for red eyes has separated from something for white eyes.

We may express these factorial relations in another way by saying that a germ cell that produces white eyes differs from a germ cell that produces red eyes by one factor-difference. We think of this difference as having arisen through a factor in the red-eyed wild fly mutating to a factor for white.

Mendelian heredity has taught us that the germ cells must contain many factors that affect the same character. Red eye color in Drosophila, for example, must be due to a large number of factors, for as many as 25 mutations for eye color at different loci have already come to light. Each produced a specific effect on eye color; it is more than probable that in the wild fly all or many of the normal allelomorphs at these loci have something to do with red eye color. 
One can therefore easily imagine that when one of these 25 factors changes, a different end result is produced, such as pink eyes, or vermilion eyes, or white eyes or eosin eyes. Each such color may be the product of 25 factors (probably of many more) and each set of 25 or more differs from the normal in a different factor. It is this one different factor that we regard as the "unit factor" for this particular effect, but obviously it is only one of the 25 unit factors that are producing the effect. However since it is only this one factor and not all 25 which causes the difference between this particular eye color and the normal, we get simple Mendelian segregation in respect to this difference. In this sense we may say that a particular factor (p) is the cause of pink, for we use cause here in the sense in which science always uses this expression, namely, to mean that a particular system differs from another system only in one special factor.

The converse relation is also true, namely, that a single factor may affect more than one character. For example, the factor for rudimentary wings in Drosophila affects not only the wings, but the legs, the number of eggs laid, the viability, etc. Indeed, in his definition of mutation, DeVries supposed that a change in a unit factor involves all parts of the body. The germ cells may be thought of as a mixture of many chemical substances, some of them more closely related to the production of a special character, color, for example, than are others. If any one of the substances undergoes a change, however slight, the end 
product of the activity of the germ cell may be different. All sorts of characters might be affected by the change, but certain parts might be more conspicuously changed than are others. It is these more obvious effects that we seize upon and call unit characters. It is the custom of most writers to speak of the most affected part as a "unit character," and to disregard minor or less obvious changes in other parts. They frequently speak of a unit character as the result of a unit factor, forgetting that the unit character may be only one effect of the factor.

Failure to realize the importance of these two points, namely, that a single factor may have several effects, and that a single character may depend on many factors, has led to much confusion between factors and characters, and at times to the abuse of the term "unit character." It can not, therefore, be too strongly insisted upon that the real unit in heredity is the factor, while the character is the product of a number of genetic factors and of environmental conditions. The character behaves as a unit only when the contrasted individuals differ in regard to a single genetic factor, and only in this case may it be called a unit character. As soon as the individuals differ by two or more genetic factors that affect the same character the latter can be no longer considered a unit. So much misunderstanding has arisen among geneticists themselves through the careless use of the term "unit character" that the term deserves the disrepute into which it is falling. 
In the following sections, several of the more important misconceptions arising from the confusion between factors and characters will be considered in turn:

1. There is a curious objection to the factorial hypothesis that is sometimes brought forward. It originated apparently as an objection to Weismann's idea that a single determinant stands for a single character. Weismann's idea of a sorting out of determinants undoubtedly implies something of this kind. The objection states that the organism is a whole-that the whole determines the nature of the parts. Such a statement, in so far as it has any meaning at all, rests on a confusion of ideas. That the different regions of the developing embryo do sometimes have an immediate influence on each other has been abundantly demonstrated, as well as the fact that in other cases parts have little or no influence on each other. That substances are produced in one place whose principal effects are seen in other places is not likely to be denied. It has even been insisted in the preceding pages that the evidence from heredity indicates with great probability that there are many factors whose combined effect is necessary for the production of each separate character, as in the production of eye color, for example. There is no reason why this interaction should always take place within the separate cells; in other words, why the products of factor $\mathrm{A}$ in one cell should not sometimes affect the products of factor B in another cell. The factorial hypothesis 
does not assume that any one factor produces a particular character directly and by itself, but only that a character in one organism may differ from a character in another because the sets of factors in the two organisms have one difference. This point is not likely to be misunderstood by any one who grasps the meaning of the factorial hypothesis. The "organism-as-a-whole" argument, so long as it is not a vague and mystical sentiment incapable of clear expression, has no terrors for the factorial hypothesis, for this hypothesis disclaims any intention of making one unit character the sole product of one factor of the germ.

2. No one disputes that characters vary, but it has become necessary to explain what we mean by this statement. Many populations have been shown to be mixtures of different genetic types. This means that many of the individuals have different germ plasms. In man, for instance, there are blue-eyed, brown-eyed, black-eyed and pink-eyed individuals, and these variations of eye color have been shown by Hurst, the Davenports, Holmes and others to depend on different factorial constitutions. It has been shown in several cases, notably in corn, by Shull, and by East and Hayes, that populations may contain differences in many factors that have similar effects on the same character. In this case too the different factors that affect a part in the same way are shown to separate and recombine in successive generations. The result is variability, but variability of a sort that is compatible with the 
invariability of the factors involved. When, however, these factors were sorted out so that strains became homozygous, some variability probably due to evironic differences still remained. That is, in addition to the variation due to recombination it has been found that even in pure races "unit characters" vary. Why, then, it may be asked, do not the factors that produce them vary also?

Johannsen's work on material of a kind suitable to give a definite answer to this question and by methods that have not been questioned, has brought out clearly certain facts only vaguely stated before. In a population of beans he found that each bean gave rise by self-fertilization to what he called a pure line. Each of the original beans proved to be homozygous for all of the factors involved. This was probably due to self-fertilization through many generations, a process that automatically produces homozygous lines. The weights of the descendants of any given bean gave a curve of frequency which was different from that of the whole population (Fig. 62). Within the group derived from one bean, however, it was found that any bean, whether heavier or lighter than the others, gave a curve exactly like the curve of the line from which it came. Evidently then the size differences within these pure lines are not inherited. They must be due to the environment of the plant, or to the position of the bean in the pod, etc.; in other words to conditions that are extrinsic to the germ plasm. Here is a demonstration that the factors do not vary, but give identical results in successive 
generations. Of course this demonstration could not have been made with heterozygous individuals.

3. It has also been suggested that one factor may sometimes contaminate its allelomorph, when the two meet in the hybrid. There is no a priori reason why this might not occur so far as we can see. The question is whether there is any evidence to establish or even make probable such a view. The great body of Mendelian evidence points unmistakably to the conclusion that as a rule contamination does not occur. It will require equally clear evidence to show that contamination does sometimes take place. Until this evidence is forthcoming the facts which have been said to support the hypothesis of contamination find a more consistent explanation on the hypothesis of multiple factors.

4. Bateson has recently argued from the visible differences between characters that a process of fractionation of factors takes place. The argument is given in the following quotation:

"Some of my Mendelian colleagues have spoken of genetic factors as permanent and indestructible. Relative permanence in a sense they have, for they commonly come out unchanged after segregation. But I am satisfied that they may occasionally undergo a quantitative disintegration, with the consequence that varieties are produced intermediate between the integral varieties from which they were derived. These disintegrated conditions I have spoken of as subtraction - or reduction - stages. For example, the Picotee sweet pea, with its purple edges, can surely 
be nothing but a condition produced by the factor which ordinarily makes the fully purple flower, quantitatively diminished. The pied animal, such as the Dutch rabbit, must similarly be regarded as the result of partial defect of the chromogen from which the pigment is formed, or conceivably of the factor which effects its oxidation. On such lines I think we may with great confidence interpret all those intergrading forms which breed true and are not produced by factorial interference.

"It is to be inferred that these fractional degradations are the consequences of irregularities in segregation. We constantly see irregularities in the ordinary meristic processes, and in the distribution of somatic differentiation. We are familiar with half segments, with imperfect twinning, with leaves partially petaloid, with petals partially sepaloid. All these are evidences of departures from the normal regularity in the rhythms of repetition, or in those waves of differentiation by which the qualities are sorted out among the parts of the body. Similarly, when in segregation the qualities are sorted out among the germ cells in certain critical cell divisions we can not expect these differentiating divisions to be exempt from the imperfections and irregularities which are found in all the grosser divisions that we can observe."

Bateson has assumed because the character appears to fractionate that we are to infer that some particular factor, that stands for it, fractionates too, but such a conclusion overlooks the fact that a character is produced by many factors in co-operation, 
and that, in consequence, many factor differences may occur which will, in turn, cause the character differences in question. Secondly, Bateson argues that we should expect these irregularities to occur in the segregation of character-factors during germ-cell formation, because we find irregularities in the segregation of factors during development. Apparently Bateson holds the view that differentiation of characters is the result of sorting out of factors in the somatic divisions; in other words, he adopts Weismann's theory of embryonic development. Localization of factors is inferred from localization of characters. Hence his employment of the idea chiefly when patterns are involved. The conclusion to which most modern students of experimental embryology have arrived, a conclusion based on a considerable body of evidence, is that differentiation is not a consequence of sorting out of the hereditary (genetic) materials. This conclusion is not considered or else is ignored by Bateson in this argument.

5 . The confusion of character with factor is nowhere more apparent than in the well-known presence and absence hypothesis, and since this hypothesis has been so widely employed in Mendelian literature it calls for somewhat more extended analysis. The hypothesis was first proposed to explain the inheritance of combs in poultry (Fig. 64). Rose comb by single comb gives in $\mathrm{F}_{2}$ three rose to one single; pea comb to single gives in $\mathrm{F}_{2}$ three pea to one single. When rose is bred to pea a new type of comb, called walnut, appears, and in $\mathrm{F}_{2}$ there are nine walnut: 
three rose: three pea: one single. Since single comb was not present in either of the grandparental strains,
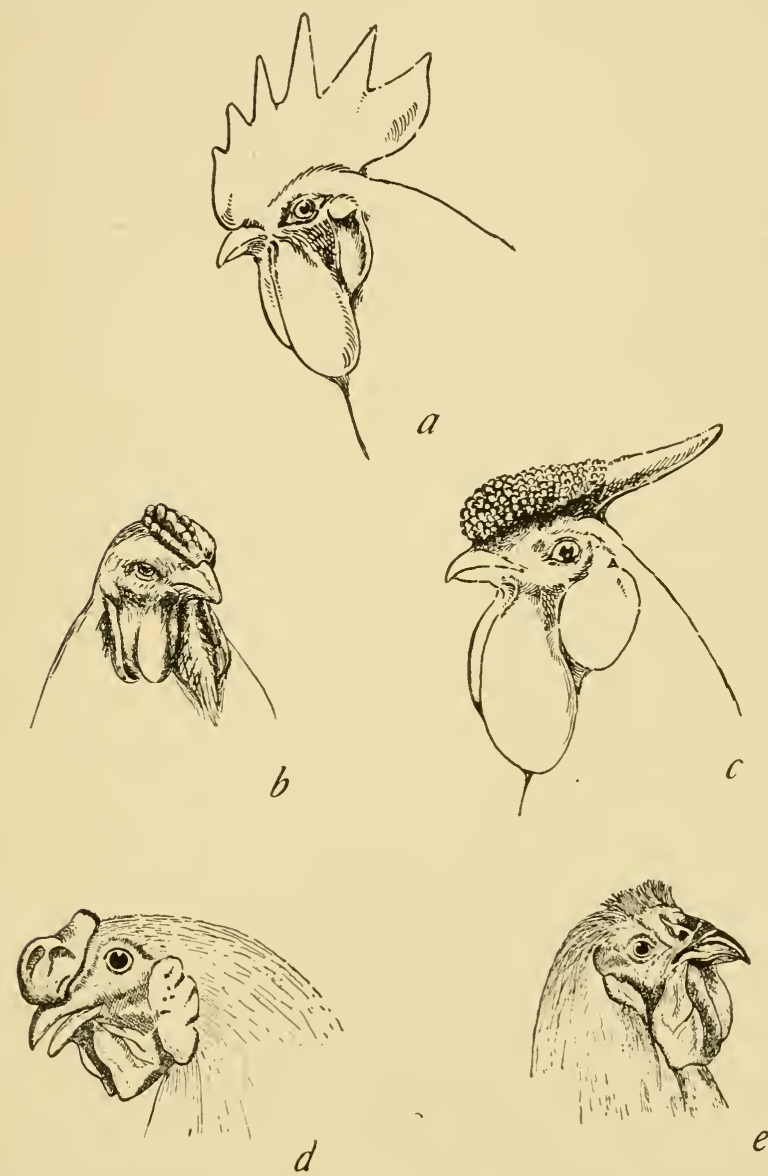

Fig. 64 -Combs of fowls. $a$, Single; $b$, pea; $c$, rose; $d$, walnut; $e$, Breda.

how then can its appearance in this cross be explained? The difficulty was met as follows: The ratio shows 
clearly that two pairs of Mendelian factors are present. Pea comb was assumed to lack a factor for rose, and rose was assumed to lack a factor for pea. By recombination there should result in $\mathrm{F}_{2}$ one individual in sixteen that was no-rose no-pea. This is the single comb. A single letter or symbol $\mathrm{S}$ was inserted in all of the formulæ so that when neither rose nor pea comb was present something would seem to be left to represent the single comb.

The verification of the latter point was supposed to be found in the relation of the single comb to a combless condition found in the Breda race of fowls, which, when crossed to single, gave in $\mathrm{F}_{2}$ three singles to one combless. In other words the combless fowl was supposed to represent a race in which the lowest stage of the series had been reached and the last factor for comb had been lost. The series just described was represented on the presence and absence scheme as follows:

$\begin{array}{ll}\text { Rose } & \text { RpS } \\ \text { Pea } & \text { rPS } \\ \text { Walnut } & \text { RPS } \\ \text { Single } & \text { rpS }\end{array}$

There is, obviously, no necessity to make these characters depend for their expression on losses of something; for the small letters that here stand for absences might just as well stand for actual factors different from those represented by the large letters. The formulæ would then of course work out as well as before. To those accustomed to the presence and 
absence scheme it may, however, be difficult to think of the small letters as anything but absences. It may, therefore, be helpful to represent the same formulæ with other letters.

If the original comb was single, which in fact is the type of comb of the wild bird from which the domesticated races have come, a dominant mutation from $\mathrm{A}$ to $\mathrm{A}^{\prime}$ gave rise to a rose comb; another dominant mutation from the wild type that changed $\mathrm{B}$ to $\mathrm{B}^{\prime}$ gave rise to a pea comb; a third but recessive mutation that changed $\mathrm{C}$ to $\mathrm{C}^{\prime}$ gave rise to a "combless" comb. The normal allelomorphs would be represented by the same letters without the primes. The formulæ (in simplex) for the combs would then be as follows:

$\begin{array}{ll}\text { Wild type (single) } & \text { A B C } \\ \text { Rose } & \mathrm{A}^{\prime} \mathrm{B} \mathrm{C} \\ \text { Pea } & \text { A B C } \\ \text { Combless } & \text { A B C }\end{array}$

The walnut comb that appears when pea is bred to rose is, of course, the double dominant form $\mathrm{A}^{\prime} \mathrm{B}^{\prime} \mathrm{C}$.

If it seems desirable to use letters that give a clue to the name of the factor for which they stand, either of the next alternatives would cover the case under discussion. In the second of these the small letters are not absences, but only the recessive allelomorphs.

$\begin{array}{ll}\text { Wild type (single) } & \mathrm{P} R \mathrm{C} \text { or } \mathrm{p}^{\prime} \mathrm{r}^{\prime} \mathrm{C} \\ \text { Rose } & \mathrm{P} \mathrm{R}^{\prime} \mathrm{C} \text { or } \mathrm{p}^{\prime} \mathrm{R}^{\prime} \mathrm{C} \\ \text { Pea } & \mathrm{P}^{\prime} \mathrm{R} \text { or } \mathrm{P}^{\prime} \mathrm{r}^{\prime} \mathrm{C} \\ \text { Combless } & \mathrm{P} R \mathrm{C}^{\prime} \text { or } \mathrm{p}^{\prime} \mathrm{r}^{\prime} \mathrm{c}\end{array}$


It is a matter of little theoretical importance what system of symbols is adopted, unless that system proves to be impracticable, or unless it implies relations that are unnecessary or unjustifiable. (See Appendix.)

We do not wish to appear to base our objection to the presence and absence hypothesis on the impracticability of its nomenclature in a new field, but rather on the grounds that the conception of presence and absence assumes that we do know something about the relation between character and factor that we can not possibly know. To assume the absence of a factor from the absence of a character is, in a sense, as naive as it was to assume that an animal moved toward light because it liked the light.

It need not be denied that losses of factors may occur, and it may even be probable that a loss in the germ plasm might lead to a loss in some part or parts of the body, but there still remains no justification for the assumption in any given case that we can infer from the lack of a character in an animal or plant a loss of factors. Such an assumption is entirely gratuitous; and gives a totally false impression concerning the factorial hypothesis of Mendelian heredity. Moreover, if taken literally it may lead to unwarranted conclusions in other fields.

It is similarly naive to assume the absence of a factor from the recessiveness of the character, yet the literature abounds with instances where the recessiveness of the character is taken as a criterion for 
assuming the absence of the factor, the dominant character being considered as a "presence." Dominance, however, is often found to be incomplete if exact quantitative studies are made. In fact, characters are known to show all degrees of dominance and recessiveness over their alternative allelomorphs. Which character is to be considered dominant and which recessive when each allelomorph has an equal effect, as in the case of the red and the white Mirabilis, is entirely a matter of choice. Hence, no matter whether red or white is presence, the present factor is not truly dominant. It seems reasonable, then, to suppose that if presence and absence is true a hybrid (with one presence) might approach more nearly the type with two absences than to the type with two presences. In such a case the present factor would actually be the recessive. Such a case is in fact known. In the cross of horned by hornless sheep, the horned condition dominates in one sex and the hornless in the other. Here no matter which is considered as a presence it must be conceded that in one sex or the other it is recessive. The view that dominance of a factor proves its presence and recessiveness its absence should therefore be abandoned.

A further argument against the theory of presence and absence is found in the evidence, already given, which indicates the possibility of multiple allelomorphs. On the presence and absence system, only two kinds of allelomorphs, the presence and the absence, are possible, and no character differences 
can be due to different kinds of factors, all of them "presences."

A word here may not be out of place concerning inhibitors. As pointed out, the adherents of presence and absence generally interpret the absence of a character to mean the absence of a factor; they also interpret recessiveness to mean the absence of a factor. When cases come up in which a character is absent, as horns in cattle, but the absence of the character is dominant, an attempt is made to reconcile fact and theory by assuming that the factor for the absent character is not really absent, but that an inhibitor is present whose activity prevents the appearance of the character.

Those who do not accept the presence and absence hypothesis need make no such assumption here of course. To them there is no reason why a factor for hornless should not dominate a factor for horns. Moreover, the facts do not even require one to assume that the hornless race differs from the horned because of the lack or inhibition of certain reactions, for it is possible in such cases that the reaction merely takes a different course, or may even proceed beyond the usual point.

These statements are not, however, intended to mean that factors may not at times act as inhibitors, but rather that we do not know, and in most cases can not know, in a single case enough about the nature of the reaction to demonstrate the existence of a factorial inhibitor. 
Weismann's Praformation Hypothesis and the Factorial Theory

Weismann's theory of development postulates particles in the germ plasm that are sorted out in proper sequence to appropriate parts of the body as the embryonic cells divide. What determines the order of the sorting out of the factors was not explained. Weismann's speculation differed from other præformation theories mainly in that he made use of the chromosomal mechanism not only to carry the hereditary materials, but also to bring about the sorting out of the materials in order to reach their final destination in the body. His theory as applied to embryonic development failed, both because the facts concerning the behavior of the chromosomes during segmentation of the egg gave no support to his assumption of sorting out of the materials of the chromosomes, and also because the data from experimental embryology and regeneration indicated very clearly that no such sorting process takes place. On the other hand, Weismann's ideas of heredity concerning the segregation in the reduction divisions of the egg and sperm of inherited materials present in the chromosomes, furnish the basis of our present attempt to explain heredity in terms of the cell.

In common with Weismann's theory, the factorial theory of heredity rests on the assumption that the germ plasm contains a host of elements, that are independent of each other in the sense that one allelomorph may be substituted for another one without 
alteration of either, and that these allelomorphs will now perpetuate themselves unchanged although in company with different factors. Today this assumption is no longer an a priori deduction, but a conclusion from experimental data.

The second real and important point of agreement between the factorial theory and Weismann's theory is that both maintain that at one period in the history of the germ cells, the factors derived from the mother separate from those derived from the father, each pair by itself. The precise way in which this is supposed to take place may differ slightly on the two views, but the essential point is the same. We owe to Weismann more than to any other biologist the conception of segregation at the reduction division of the egg and sperm-a conception of fundamental importance in the application of the chromosome theory to Mendelian heredity. The factorial hypothesis postulates only three things about the factors with which it works, viz.: (1) that they are constant, (2) that they are usually in duplicate in each cell of the body, and (3) that they usually segregate in the maturing germ cells. But the biologist is not likely to stop here, for, to him the problem involves cells about whose history and processes he has come to know certain facts. Weismann, following Roux, was the first to point out that these facts give a mechanism showing how separation of factors might take place. The specific application of the behavior of the chromosomes to heredity, then, is the third important contribution which modern genetics owes 
to Weismann. Today, however, we have advanced beyond Weismann in this respect, and may more specifically interpret our numerical results of independent segregation, linkage, and even crossing over on the basis of a chromosome mechanism. Moreover, the new facts have given us ideas very different from those of Weismann regarding the arrangement of the factors in the chromosomes and the way in which the characters of an individual are determined by the chromosomal factors.

In the last edition of his Vortræge ueber Descendenztheorie (3d edition, 1913) Weismann modifies his earlier views in regard to the factorial nature of the chromosomes so that his conception of the germ plasm is brought into harmony with the Mendelian theory of heredity. Formerly he had supposed that the chromosomes are all alike, or nearly alike, in so far as each one carries a full assortment of "ids." Each id, in itself, represented the full complement of all the factors that go to make up the organism. But since the results of Mendelian heredity show that all sorts of characters, however trivial, may be segregated independently (which would not be the case, if, as Weismann formerly supposed, all the hereditary characters are carried by each chromosome), it follows that the chromosomes must be bearers of part ids (Theil Ids).

Weismann still adheres nevertheless to his mosaic theory of development, but as before stated the modern work on development does not support this interpretation of development. His view assumes 
disintegration of the germ plasm when the body cells are produced in order to account for the localization of characters; the other view, following the experimental results and microscopical observations, assumes, so far as the chromosomal materials are concerned, that all of the hereditary factors are present in every cell in the body. This view is essentially that proposed by DeVries in his book on Intracellular Pangenesis. The cause of the differentiation of the cells of the embryo is not explained on the factorial hypothesis of heredity. On the factorial hypothesis the factors are conceived as chemical materials in the egg, which, like all chemical bodies, have definite composition. The characters of the organism are far removed, in all likelihood, from these materials. Between the two lies the whole world of embryonic development in which many and varied reactions take place before the end result, the character, emerges. Obviously, however, if every cell in the body of one individual has one complex, and every cell in the body of another individual has another complex that differs from the former by one difference, we can treat the two systems as two complexes quite irrespective of what development does so long as development is orderly.

It is sometimes said that our theories of heredity must remain superficial until we know something of the reactions that transform the egg into the adult. There can be no question of the paramount importance of finding out what takes place during development. The efforts of all students of experimental 
embryology have been directed for several years toward this goal. It may even be true that this information, when gained, may help us to a better understanding of the factorial theory-we can not tell; for a knowledge of the chemistry of all of the pigments in an animal or plant might still be very far removed from an understanding of the chemical constitution of the hereditary factors by whose activity the pigments are ultimately produced. However this may be, the far-reaching significance of Mendel's principles remains, and gives us a numerical basis for the study of heredity. Although Mendel's law does not explain the phenomena of development, and does not pretend to explain them, it stands as a scientific explanation of heredity, because it fulfils all the requirements of any causal explanation. 


\section{APPENDIX}

\section{Methods of Breeding Drosophila}

Drosophila ampelophila has shown itself to be so generally useful for class work in genetics and is being so widely employed for this purpose that it may not be out of place here to give a few directions concerning apparatus, methods and material.

Culture Bottles.-Large-mouthed bottles of about 500 c.c. capacity should be used. Pint milk bottles can be purchased at reasonable rates from wholesale dealers, and serve admirably as culture bottles. Stoppers of raw cotton are used, which should be tight but not packed in the mouth of the bottle.

Temperature.-The optimum is about $25^{\circ} \mathrm{C}$. Extreme summer heat kills the flies in culture bottles unless special precautions are taken. Cold retards the development of the larvæ indefinitely, but the flies themselves can withstand almost a freezing temperature. Ordinary room temperature suffices, as a rule, but a controlled temperature of about $25^{\circ} \mathrm{C}$. is better.

Food.-Ripe fermented banana is the best food. If raw bananas with intact skin are peeled and put into old juice contamination is not likely to occur, but for ordinary purposes the bananas should be 
peeled, broken up into pieces, covered with water, and slowly brought to nearly the boiling point, or else steamed. The pieces are then put into the old juice. This juice is made in the first instance by adding a little yeast to the water that covers the bananas (after they have cooled). The juice can then be used over and over again if it is occasionally greatly diluted with water to keep it from becoming too acid. The food is at its best from one to two days after being in the juice, although it may be used for a week or more. Keep food in glass-stoppered large-mouthed jars. Scrupulously avoid leaving the margin of the jar wet after removing food.

Feeding.-When a culture is to be made up the most approved way is to put about a teaspoonful of food on the bottom of the bottle and over it a folded piece of absorbent paper. The flies, while still under ether, may be dropped into a cornucopia of paper which is placed in the bottle. Often, however, the flies are brushed into a dry bottle and the cotton plug put in. An hour or more later, when the flies have recovered, the food, wrapped up in paper, is added. Toweling paper is cheap and serves excellently the purpose of wrapping the food, etc.

By putting in at first more food than recommended above it is possible to carry a culture to the end without further feeding. But more flies and greater accuracy result if a small amount of food is first added, then as much more at the end of six or seven days. When the parent flies are taken out at about the tenth day, food may be added for a third time. New 
food should not be allowed to cover the old food and thereby drown the pupæ.

Precautions.-In most cases a single female with one, or in some cases more males should be put into a bottle, except for stock breeding, when more flies should usually be used. Under favorable conditions 200 to 300 flies should be obtained within the first ten days after hatching has commenced. The parents should be removed about ten days after the beginning to avoid overlapping of generations. If desirable they may then be transferred to a second, or even to a third culture bottle. In summer the parents should not remain over eight days in the old bottle; in winter they may be left more than ten days with safety. To obtain virgin females for mating, the bottles should be thoroughly emptiedit may be necessary to remove the old paper, etc., in order to make certain that all of the old flies are removed-and females obtained not later than six hours after the bottle was emptied. Females obtained twelve hours after the bottle was emptied are not certainly virgin. If the old males have not been removed females so young as to have their wings not yet unfolded may in rare cases have already undergone copulation.

Examination.- - The flies go toward the light. Therefore, if the bottle is held with its mouth away from the light, the flies are not likely to escape. The plug may then be removed and another smaller bottle, with a mouth that fits the larger one, placed mouth to mouth against the larger bottle. The com- 
bination is then turned around, and the flies fly into the smaller bottle- or the smaller bottle may be held firmly underneath the other and the flies shaken into it by jarring. The small bottle can then be plugged, and a bit of cotton with four or five drops of ether put into it. In a minute or two the flies are under the influence of the ether and may be emptied out on to a piece of white paper, or a white glass plate. Some workers prefer to have the small bottle already saturated with ether before the flies are shaken into it; in this case they become etherized almost immediately. They can then be examined with a hand lens or with a binocular microscope. Some of the characters require for study the latter or an ordinary microscope.

With a camel's hair brush the flies are pushed out into a row and then sorted out, from right to left, into an upper and a lower row, each of which may again be subdivided. If overetherized, the wings stand out above and at right angles to the body. If insufficiently etherized, so that they recover before they can be examined, they may be etherized again.

The pure stock is kept in pint bottles and new cultures made up each week. Descriptions of the mutants as far as published will be found in the following journals:

BAr.- "A New Sex-linked Character in Drosophila." Biol. Bull., XXVI. 1914.

BEADED.- "The Analysis of a Case of Continuous Variation, Etc." Amer. Nat., XLIII. 1914.

Bext.- "A Gene for the Fourth Chromosome of Drosophila." Jour. Exper. Zoöl., XVII. 1914. 
Black.-"Heredity of Body Color in Drosophila." Jour. Exper. Zoöl., XIII. 1912.

Cherry.- “A New Eye Color Mutation in Drosophila, Etc." Biol. Bull., XXV. 1913.

Eвony.- "A Third Group of Linked Genes in Drosophila." Science, XXXVII. 1913.

Eosin.- "Dilution Effects and Bicolorism, Etc." Jour. Exper. Zoöl., XV. 1913.

Eyeless.- "Another Gene in the Fourth Chromosome of Drosophila." Amer. Nat., XLIX. 1915.

Lethal.- "Two Sex-linked Lethal Factors in Drosophila, Etc." Jour. Exper. Zoöl., XVII. 1914.

Miniature.- "A Modification of the Sex Ratio, Etc." Zeits. f. ind. Abst.- u. Vererb.-Lehre., VII. 1912.

Prnk.- "Dilution Effects and Bicolorism, Etc." Jour. Exper. Zoöl., XV. 1913.

Rudimentary.- "A Modification of the Sex Ratio, Etc." Zeits. $f$. ind. Abst.- u. Vererb.-Lehre., VII. 1912.

Sрот.- "Another Case of Multiple Allelomorphs in Drosophila." Biol. Bull., XXVI. 1914.

Vermilion.--"Dilution Effects and Bicolorism, Etc." Jour. Exper. Zoöl., XV, 1913.

Vestigial.- "No Crossing Over in the Male of Drosophila, etc." Biol. Bull., XXVI. 1914.

White.- "Sex Limited Inheritance in Drosophila." Science, XXXII. 1910.

Yellow.- "Heredity of Body Color in Drosophila." Jour. Exper. Zoöl., XIII. 1912.

\section{Formul}

Baur's plan of using non-significant letters has no doubt certain advantages, but in practice significant letters are too useful to be given up. We have followed a plan which avoids the objections of the presence and absence scheme, and has the advantage of significant letters. In this plan a small letter is used for the mutant factor if recessive, and a large 
letter if dominant. With a little practice we have found, from our own experience, there is no real difficulty in making the transition from the presence and absence notation to this one. For example:
Simplex Duplex
Pink eye
$\mathrm{pVW} \rightarrow \frac{\mathrm{pVW}}{\mathrm{pVW}}$
Vermilion eye $\mathrm{PvW} \rightarrow \frac{\mathrm{PvW}}{\mathrm{PvW}}$
White eye $\quad \mathrm{PVw} \rightarrow \frac{\mathrm{PVw}}{\mathrm{PVw}}$
Red eye

$$
\mathrm{PVW} \rightarrow \frac{\mathrm{PVW}}{\mathrm{PVW}}
$$

A further simplification would consist in using the letters for the mutant factors alone, as Castle has done, and omitting the normal factors. But in writing out formulæ for heterozygous forms, it is often convenient to represent both members of a pair of allelomorphs. In matters relating to linkage it is essential to indicate, in some way, both allelomorphs.

If in any formula it is desirable to distinguish between dominant and recessive mutant factors, it may be convenient to prime both allelomorphs of a pair in which the factor is named from the dominant character.

In addition to the more important objections to the presence and absence representation that have been dealt with in the text, there are certain technical drawbacks to the presence and absence scheme of nomenclature that should not pass unnoticed. 
When to a familiar or to an established system it becomes necessary to add new recessive types difficulties arise. This may be illustrated in the case of combs of fowls, the main facts concerning whose inheritance have been discussed on page 216 . On the presence and absence scheme a factor gets its name from the effect that that factor produces in the absence of other factors affecting the character. The factor for pea, for instance, got its name from the effect produced when a factor for rose was supposed to be absent; and the formula for single comb, rpS, means that a factor S, for single, produced its particular effect when the two other factors were absent. When a new condition, combless, was met with and added to the series it was represented as due to the loss of the factor (S) for single. The formula for combless became rpsB (B standing for the vestige of a comb, called Breda, that remained). What now is the factor for rose comb? Originally this factor got its name from its effect in the absence of pea but in the presence of $\mathrm{S}(\mathrm{RpS})$; now the factor for rose, $\mathrm{R}$, should be re-named from its effect in the absence of both factors $\mathrm{P}$ and $\mathrm{S}$. The series must then be re-constructed on a new basis and the same process must be gone through with whenever a new factor is brought into relation with an established system.

\section{ACKNowledgments}

We wish to express our indebtedness to Miss E. M. Wallace for her skill in making many of the illustrations, and also to Miss M. L. Hedge who has 
helped us likewise. The text has been gone over in parts by Dr. F. N. Duncan, Mr. Alexander Weinstein, Mr. E. Altenburg and Mr. D. B. Young; we wish to express our appreciation for the help they have given. Four well-known geneticists have looked through the last three chapters and have made valuable suggestions. They are not named here lest we appear to commit them to opinions with which they may not agree in all details, but on the whole we know that they do in general agree with the interpretation of the factorial hypothesis that we have followed. We express to them individually our appreciation of their advice and criticism. 


\section{BIBLIOGRAPHY}

Agar, IW. E., 1914. Parthenogenetic and Sexual Reproduction in Simocephalus vetulus and other Cladocera. Jour. Genet., III. Bailey, P. G., 1914. Primary and Secondary Reduplication Series. Jour. Gen., III.

Baltzer, F., 1910. Über die Beziehung zwischen dem Chromatin und der Entwicklung und Vererbungsrichtung bei Echinodermenbastarden. Arch.f. Zellf., V.

Baltzer, F., 1913. Über die Herkunft der Idiochromosomen bei Seeigeln. Sitz. Phys.-Med. Gesell. Wïrzburg, 1913.

Baltzer, F., 1914. Die Bestimmung des Geschlechts nebst einer Analyse des Geschlechts-dimorphismus bei Bonellia. Mitteil.

Zoöl. Station Neapel, XXII.

Baltzer, F., 1914. Die Bestimmung und der Dimorphismus des

Geschlechts bei Bonellia. Sitz. Phys.-Med. Ges. Würzburg, 1914. Bateson, W., 1909. Mendel's Principles of Heredity. Cambridge. Bateson, W., 1913. Mendel's Principles of Heredity. 3d impression. Cambridge.

Bateson, W., and R. C. Punnett, 1905. Rep. Evol. Comm., II. Bateson, W., and R. C. Punnett, 1908. The Heredity of Sex. Science, XXVII.

Bateson, IW., and R. C. Punnett, 1911. On the Interrelations of Genetic Factors. Proc. Roy. Soc., LXXXIV.

Bateson, W., and R. C. Punnett, 1911. The Inheritance of the Peculiar Pigmentation of the Silky Fowl. Jour. Gen., I.

Bateson, W., and R. C. Punnett, 1911. On Gametic Series Involving Reduplication of Certain Terms. Jour. Gen., I.

Bateson, W., 1914. Address. British Assoc. Adv. Sci., Part I, Ref. 1; Part II, Ref. 66.

Baur, E., 1910. Propfbastarde. Biol. Centr., XXX.

Baur, E., 1911. Ein Fall von Faktorenkoppelung bei Antirrhinum majus. Verh. naturf. Ver. Brünn, XLIX.

BAur, E., 1912. Vererbungs- und Bastardierungsversuche mit Antirrhinum-II. Faktorenkoppelung. Zeits. Abst. u. Vererb., VI. 
BAUR, E., 1912. Ein Fall von geschlechtsbegrenzter Vererbung bei Melandrium album. Zeits. Abst. u. Vererb., VIII.

BAUR, E., 1914. Einführung in die experimentelle Vererbungslehre. BeARD, J., 1902. The Determination of Sex in Animal Development. Zoöl. Jahrb. Abt. Anat., XVI.

Belling, John, 1914. The Mode of Inheritance of Semi-sterility in the Offspring of Certain Hybrid Plants. Zeits. Abst. Vererb., XII.

Boring, A. M., 1909. A Small Chromosome in Ascaris megalocephala. Arch.f. Zellf., IV.

Boring, Alice M., and Raymond Pearl, 1914. The Odd Chromosome in the Spermatogenesis of the Domestic Chicken. Jour. Exp. Zoöl., XVI.

Boveri, Th., 1907. Zellen Studien. Die Entwicklung dispermer Seeigel-Eier, etc. Jena.

Boveri, Тн., 1908. Über die Beziehung des Chromatins zur Geschlechtbestimmung. Sitz. Phys.-1led. Gesell. Würzburg, Dez., 1908.

Boveri, Тн., 1909. Die Blastomerenkerne von Ascaris megalocephala und die Theorie der Chromosomen-Individualität. Arch. Zellf., III.

Boveri, TH., 1909. Über "Geschlechtschromosomen" bei Nematoden. Arch. Zellf., IV.

Boveri, TH., 1911. Über das Verhalten der Geschlechtschromosomen bei Hermaphroditismus. Verh. Phys.-.Yed. Gessell. Würzburg, XLI.

BoverI, Th., 1914. Über die Charaktere von Echiniden-Bastardlarven bei verschiedenen Mengenverhältnis mütterlicher und väterlicher Substanzen. Verh. Phys.-Iled. Gesell. Wïrzburg, XLIII.

Brauer, A., 1893. Zur Kenntniss der Spermatogenese von Ascaris megalocephala. Arch. mikr. Anat., XLII.

Bridges, C. B.; 1913. Partial Sex Linkage in the Pigeon. Science, XXXVII.

Bridges, C. B., 1913. Non-disjunction of the Sex Chromosomes of Drosophila. Jour. Exp. Zoöl., XV.

Bridges, C. B., 1914. The Chromosome Hypothesis of Linkage Applied to Cases in Sweet Peas and Primula. Am. Nat., XLVIII. Bridges, C. B., 1914. Direct Proof through Non-disjunction that 
the Sex-linked Genes of Drosophila are Borne by the X-chromosome. Scicnce, XL.

Bridges, C. B., and A. H. Sturtevant, 1914. A New Gene in the Second Chromosome of Drosophila and some Considerations on Differential Viability. Biol. Bull., XXVI.

Calkins, G. N., and C. C. Lieb, 1902. Studies on the Life History of Protozoa, II. Arch. Protist., 1902.

Calkins, G. N., 1902. Studies on the Life History of Protozoa. III. Biol. Bull., III.

Calkins, G. N., 1904. Studies on the Life History of Protozoa. IV. Jour. Exp. Zoöl., I.

Calkins, G. N., 1911. Protozoön Germ Plasm. Pop. Sci. Monthly. Calkins, G. N., 1913. Further Light on the Conjugation of Paramecium. Proc. Soc. Exp. Biol. Med., X.

Carothers, E. E., 1913. The Mendelian Ratio in Relation to Certain Orthopteran Chromosomes. Jour. Morph., XXIV.

Castle, W. E., F. W. Carpenter, A. H. Clark, S. O. Mast, and W. M. Barrows, 1906. The Effects of Inbreeding. Crossbreeding, and Selection upon the Fertility and Variability of Drosophila. Proc. Am. Acad. Arts and Sci., XLI.

Castle, W. E., H. E. Walter, R. C. Mullenix, and S. Cobb, 1909. Studies of Inheritance in Rabbits. Carnegie Inst. Wash., pub. 114.

Castle, W. E., and John C. Phillips, 1913. Further Experiments on Ovarian Transplantation in Guinea-pigs. Science, XXXVIII. Castle, W. E. and John C. Phillips, 1914. Piebald Rats and Selection. Carnegie Inst. Wash., pub. 195.

Castle, W. E., 1913. Reversion in Guinea-pigs and its Explanation. Carnegie Inst. Wash., pub. 179.

Castle, W. E., 1914. Bateson on Problems of Genetics, Weismann's Vorträge über Deszendenztheorie and Bateson's Principles of Heredity. Science, XL.

Castle, W. E., 1914. Some New Varieties of Rats and Guinea-pigs and Their Relation to Problems of Color Inheritance. Am. Nat., XLVIII.

Castle, W. E., 1914. Size Inheritance and the Pure Line Theory. Zeits. Abst. Vererb., XII.

Castle, W. E., 1914. Yellow Varieties of Rats. Am. Nat., XLVIII. 
Castle, W. E., 1914. Pure Lines and Selection. Jour. Heredity, V. Castle, W. E., 1914. Variation and Selection; a Reply. Zeits. Abst. Vererb., XII.

Castle, W. E., 1914. Multiple Factors in Heredity. Science, XXXIX.

Castle, W. E., 1914. An Apple Chimera. Jour. Heredity, V.

Castle, W. E., 1914. Nabour's Grasshoppers, Multiple Allelomorphism, Linkage and Misleading Terminologies in Genetics. Am. Nat., XLVIII.

Castle, W. E., 1914. Mr. Muller on the Constancy of Mendelian Factors. Am. Nat., XLIX.

Castle, W. E. and Philip B. Hadley, 1915. The English Rabbit and the Question of Mendelian Unit-character Constancy. Am. Nat., XLIX.

Castle, W. E., 1915. Bateson's Address, Mendelism and Mutation.

Cole, L. J., 1912. A Case of Sex-linked Inheritance in the Domestic Pigeon. Science, XXXVI.

Correxs, C., 1902. Über den Modus und den Zeitpunkt der Spaltung, etc. Bot. Ziet., LX.

Correns, C., 1909. Zur Kenntniss der Rolle von Kern und Plasma bei der Vererbung. Zeit. Abst. Vererb., II.

Cúnsot, L., 1903. L'hérédité de la pigmentation chez les souris

(2), I. Hérédité de la pigmentation ches les souris noires. Arch. Zoöl. Exp. et Gén., I.

Cúñot, L., 1904. L'hérédité de la pigmentation chez les souris

(3), I. Les formules héréditaires. Arch. Zoöl. Exp. et Gén., II. Cuéxot, L., 1905. Les races pures et leurs combinaisons chez les souris (4). Arch. Zoöl. Exp. et Gén., III.

Cú́xoт, L., 1907. L'hérédité de la pigmentation chez les souris

(5). Arch. Zoöl. Exp. et Gén., VI.

Cú́xot, L., 1908. Sur quelques anomalies apparentes des proportions mendéliennes (6). Arch. Zoöl. Exp. et. Gén., IX.

Cuénot, L., 1911. Les determinants de la couleur chez les souris étude comparative (7). Arch. Zoöl. Exp. et Gén., VIII.

Cú́xót, L., 1911. L'hérédité chez les souris. Verh. naturf. Tereines in Brünn, XLIX.

Cú́xoт, L., 1909. Recherches sur l'hybridation. Proc. VII Inter.

Zoöl. Congress. 
Davenport, C. B., 1906. Inheritance in Poultry. Carnegie Inst. Wash., pub. 53.

Davenport, C. B., 1909. Inheritance of Characteristics in Domestic Fowl. Carnegie Inst. Wash., pub. 121.

Davenport, C. B., 1911. Heredity in Relation to Eugenics. New York.

Davenport, C. B., 1912. Sex-limited Inheritance in Poultry. Jour. Exp. Zoöl., XIII.

Davenport, G. C., and C. B., 1909. Heredity of Hair Color in Man. Am. Nat., XLIII.

Dederer, P. H., 1907. Spermatogenesis in Philosamia cynthia. Biol. Bull., XIII.

Delcourt, A., and E. Gurénot, 1911. Génétique et milieu. Bull. Scient. France Belg., XLV.

Dexter, J. S., 1912. On Coupling of Certain Sex-linked Characters in Drosophila. Biol. Bull., XXIII.

Dexter, J. S., 1914. The Analysis of a Case of Continuous Variation in Drosophila by a Study of Its Linkage Relations. Am. Nat., XLVIII.

Dexter, J. S., 1914. Nabours' Breeding Experiments with Grasshoppers. Am. Nat., XLVIII.

Doncaster, L., 1907. Inheritance and Sex in Abraxas grossulariata. Nature, LXXVI.

Doncaster, L., 1907. Gametogenesis and Fertilization in Nematus ribesii. Q.J. M.S., LI.

Doncaster, L., 1908. On Sex Inheritance in the Moth, Abraxas grossulariata and its var. lacticolor. 4th Rep. Evol. Comm., R. Soc. Lond

Doncaster, L., 1910. Gametogenesis of the Gall-fly, Neuroterus lenticularis (Spathegaster baccarum). Part I. Proc. Roy. Soc., B, LXXXII.

Doncaster, L., 1911. Gametogenesis of the Gall-fly, Neuroterus lenticularis. Part II. Proc. Roy. Soc., LXXXIII.

Doncaster, L., 1911. Note on the Inheritance of Characters in which Dominance Appears to be Influenced by Sex. Jour. Genet., I.

Doxcaster, L., 1911. Some Stages in the Spermatogenesis of Abraxas grossulariata and its var. lacticolor. Jour. Genet., I.

Doncaster, L., 1912. The Chromosomes in the Oögenesis and 
Spermatogenesis of Pieris brassicæ, and in the Oögenesis of Abraxas grossulariata. Jour. Genet., II.

Doncaster, L., 1912. Note on the Chromosomes in Oögenesis and

Spermatogenesis of the White Butterfly, Pieris brassicæ. Proc.

Camb. Phil. Soc., XVI.

Doncaster, L., and G. H. Raynor, 1906. Breeding Experiments with Lepidoptera. Proc. Zoöl. Soc. Lond.

Doncaster, L., and G. Gray, 1911. Cytological Observations on

Cross-fertilized Echinoderm Eggs. Proc. Camb. Phil. Soc., XVI.

Doncaster, L., and F. H. A. Marshall, 1910. The Effects of One-sided Ovariotomy on the Sex of the Offspring. Jour. Genet., I.

Doncaster, L., 1914. On the Relations between Chromosomes, Sex-limited Transmission and Sex Determination in Abraxas grossulariata. Jour. Genet., IV.

Doncaster, L., 1914. Chromosomes, Heredity, and Sex. Quart. Jour. Micr. Sc., No. 236.

Dorsey, M. J., 1914. Pollen Development in the Grape with Special Reference to Sterility. Univ. Minn. Agric. Exp. Station, Bull. 144.

Durham, F. M., 1911. Further Experiments on Coat Color in Mice. Jour. Genet., I.

Durham, F. M., and D. E. C. Marryat, 1908. Note on the Inheritance of Sex in Canaries. 4th Rep. Evol. Comm., Roy. Soc. Lond.

East, E. M., 1910. Notes on an Experiment concerning the Nature of Unit Characters. Science, XXXII.

EAst, E. M., 1911. The Genotype Hypothesis and Hybridization. Am. Nat., XLV.

East, E. M., 1912. A Study of Hybrids between Nicotiana bigelovii and N. quadrivalvis. Bot. Gaz., LIII.

East, E. M., and H. K. Hayes, 1911. Inheritance in Maize. Conn. Exp. Sta. Bull., 167.

EAst, E. M., and H. K. HAYES, 1912. Heterozygosis in Evolution and in Plant Breeding. U. S. Dept. Agric., Bureau Plant Ind. Bull., 243.

EAst, E. M., 1913. Inheritance of Flower Size in Crosses between Species of Nicotiana. Bot. Gaz., LV. 
EAst, E. M., and H. K. Hayes, 1914. A Genetic Analysis of the Changes produced by Selection in Experiments with Tobacco. Am. Nat., XLVIII.

Emerson, R. A., 1909. Inheritance of Color in the Seeds of the Common Bean, Phaseolus vulgaris. Ann. Rep. Nebr. Agr. Exp. Sta., XXII.

Emerson, R. A., 1910. The Inheritance of Sizes and Shapes in Plants. Ann. Nat., XLIV.

Emerson, R. A., 1911. Genetic Correlation and Spurious Allelomorphism in Maize. Ann. Rep. Nebr. Agr. Exp. Sta., XXIV.

Euerson, R. A., 1912. The Inheritance of Certain Forms of Chlorophyll Reduction in Corn Leaves. Ann. Rep. Nebr. Agr. Exp. Sta., XXV.

Emerson, R. A., 1912. The Inheritance of the Ligule and Auricles of Corn Leaves. Ann. Rep. Nebr. Agr. Exp. Sta., XXV.

Emerson, R. A., 1912. The Unexpected Occurrence of Aleurone Colors in $\mathrm{F}_{2}$ of a Cross between Non-colored Varieties of Maize. Am. Nat., XLVI.

Emerson, R. A. and E. M. EAst, 1913. The Inheritance of Quantitative Characters in Maize. Un. Neb. Agric. Exp. Station Bull., 2.

Euerson, R. A., 1914. The Inheritance of a Recurring Somatic Variation in Variegated Ears of Maize. Am. Nat., XLVIII.

Federley, H., 1913. Das Verhalten der Chromosomen bei der Spermatogenese der Schmetterlinge, etc. Zeit. Abst. Vererb., IX.

Foot, K., and E. C. Strobell, 1913. Preliminary Note on the Results of Crossing Two Hemipterous Species, etc. Biol. Bull., XXIV.

Foot, Katherine, and E. C. Strobell, 1914. Results of Crossing Euschistus variolarius and Euschistus servus with Reference to the Inheritance of an Exclusively Male Character. Linn. Soc. Jour., XXXII.

Gates, R. R., and N. Thomas, 1914. A Cytological Study of Enothera mut. lata and CE. mut. semilata in Relation to Mutation. Quart. Jour. Micr. Sc., No. 236.

Gerould, J. H., 1911. The Inheritance of Polymorphism and Sex in Colias philodice. Am. Nat., XLV.

Goldschmidt, R., 1911. Einführung in die Vererbungswissenschaft. Leipzig. 
Goldschmidt, R., 1912. Erblichkeitsstudien an Schmetterlingen. I, 1. Zeits. Abst. Vererb., VII.

Goldschmid, R., 1912. Bemerkungen zur Vererbung des Geschlechtspolymorphismus. Zeits. Abst. Vererb., VIII.

Goodale, H. D., 1910. Some Results of Castration in Ducks. Biol. Bull., XX.

Goodale, H. D., 1911. Studies on Hybrid Ducks. Jour. Exp. Zoöl., X.

Goodale, H. D., 1911. Sex-limited Inheritance and Sexual Dimorphism in Poultry. Science, XXXIII.

Goodale, H. D., 1913. Castration in Relation to the Secondary Sexual Characters of Brown Leghorns. Am. Nat., XLVII.

Gregory, R. P., 1911. Experiments with Primula sinensis. Jour. Genet., I.

Gregory, R. P., 1911. On Gametic Coupling and Repulsion in Primula sinensis. Proc. Roy. Soc., LXXXIV.

Gregory, R. P., 1914. On the Genetics of Tetraploid Plants in Primula sinensis. Proc. Royal Soc., 1914.

Gulick, A., 1911. Über die Geschlechtschromosomen bei einigen Nematoden. Arch.f. Zellf., VI.

Guyer, M. F., 1902. Hybridism and the Germ Cell. Univ. of Cincinnati Bull., No. 21.

Guyer, M. F., 1903. The Germ Cell and the Results of Mendel. Cincinnati Lancet-Clinic.

Guyer, M. F., 1909. The Spermatogenesis of the Domestic Chicken. Anat. Anz., XXXIV.

Guyer, M. F., 1910. Accessory Chromosomes in Man. Biol. Bull., XIX.

Guyer, M. F., 1911. Nucleus and Cytoplasm in Heredity. Am. Nat., XLV.

Hagedoors, A. L., 1912. The Genetic Factors in the Development of the House Mouse, etc. Zeits. Abst. Vererb., VI.

Harrison, J. W. H., and L. Doncasier, 1914. On Hybrids between Moths of the Geometrid Sub-family Bistoninæ, with an account of the Behavior of the Chromosomes in Gametogenesis in Lycia (Biston) hirtaria, Ithysia (Nyssia) zonaria and in their Hybrids. Jour. Genet., III.

Heape, W., 1908. The Proportions of the Sexes produced by Whites 
and Colored Peoples in Cuba. Phil. Trans. Roy. Soc. Lond., Series B, Vol. CC.

Henking, H., 1891. Untersuchungen über die ersten Entwicklungsvorgänge in den Eiern der Insekten. Zeits. f. uiss. Zoöl., LI.

Hoge, M. A., 1915. The Influence of Temperature on the Development of a Mendelian Character. Jour. Exp. Zoöl., XVIII.

Hoge, M. A., 1915. Another Gene in the Fourth Chromosome of Drosophila. Am. Nat., XLIX.

Hyde, R. R., 1914. Fertility and Sterility in Drosophila ampelophila. I-IV. Jour. Exp. Zoöl., XVII.

Janssens, F. A., 1901. La spermatogénèse chez les tritons. La Cellule, XIX.

Janssens, F. A., 1905. Evolution des auxocytes mâles du Batracoseps attenuatus. La Cellule, XXII.

Janssens, F. A., 1909. La théorie de la chiasmatypie. Nouvelle interprétation des cinèses de maturation. La Cellule, XXV.

Janssens, F. A., and R. Dumez, 1903. L'élément nucléinien pendant les cinèses de maturation des spermatocytes chez Batracoseps attenuatus et Plethedon cinereus. La Cellule, XX.

Jennings, H. S., 1911. Assortative Mating, Variability and Inheritance of Size in the Conjugation of Paramecium. Jour. Exp. Zoöl., XI.

Jennings, H. S., 1911. Pure Lines in the Study of Genetics in Lower Organisms. Amer. Nat., XLV.

Jennings, H. S., 1913. The Effect of Conjugation in Paramecium. Jour. Exp. Zoöl., XIV.

Jennings, H. S., and G. T. Hargitt, 1910. Characteristics of the Diverse Races of Paramecium. Jour. Morph., XXI.

Jennings, H. S., and K. S. Lashley, 1913. Biparental Inheritance and the Question of Sexuality in Paramecium. Jour. Exp. Zoöl., XIV.

Johannsen, W., 1909. Elemente der exakten Erblichkeitslehre. Jena.

Johannsen, W., 1911. The Genotype Conception of Heredity. Am. Nat., XLV.

Jones, W. N., 1912. Species Hybrids of Digitalis. Jour. Genet., II. 
Keeble, F., and C. Pellew, 1910. The Mode of Inheritance of Stature and of Time of Flowering in Peas (Pisum sativum). Jour. Genet., I.

Kellogg, Vernon L., 1908. Inheritance in Silkworms, I. Stan. Un. Pub., 1.

KING, H. D., 1910. Temperature as a Factor in the Determination of Sex in Amphibians. Biol. Bull., XVIII.

King, H. D., 1911. The Sex Ratio in Hybrid Rats. Biol. Bull., XXI.

KING, H. D., 1912. Dimorphism in the Spermatozoa of Necturus maculosus. Anat. Rec., VI.

KING, H. D., 1912. Studies on Sex Determination in Amphibians, V. Jour. Exp. Zoöl., XII.

LANG, A., 1912. Vererbungswissenschaftliche Miszellen. Zeits. Abst. Vererb., VIII.

Liff, Joseph, 1915. Data on a Peculiar Mendelian Ratio in Drosophila ampelophila. Am. Nat., XLIX.

Little, C. C., 1912. Preliminary Note on the Occurrence of a Sexlimited Character in Cats. Science, XXXV.

Little, C. C., 1913. Experimental Studies of the Inheritance of Color in Mice. Carnegie Inst. Wash., pub. 179.

Loes, J., 1912. Heredity in Heterogeneous Hybrids. Jour. Morph., XXIII.

Loeb, J., and F. W. Bancroft, 1911. Some Experiments on the Production of Mutants in Drosophila. Science, XXXIII.

Loeb, JAcques, and F. W. Bancroft, 1913. Further Observations on Artificial Parthenogenesis in Frogs. Jour. Exp. Zoöl., XV.

Lutz, A. M., 1912. Triploid Mutants in Enothera. Biol. Centr., XXXII.

Lutz, F. E., 1911. Experiments with Drosophila ampelophila concerning Evolution. Carnegie Inst. Wash., pub. 143.

Lutz, F. E., 1913. Experiments concerning the Sexual Difference in the Wing Length of Drosophila ampelophila. Jour. Exp. Zoöl., XIV.

MacCurdy, Hansford, and W. E. Castle, 1907. Selection and Cross-breeding in Relation to the Inheritance of Coat Pigments and Coat Patterns in Rats and Guinea-pigs. Carnegie Inst. Wash., pub. 70. 
MacDowell, E. C., 1914. Multiple Factors in Mendelian Inheritance. Jour. Exp. Zoöl., XVI.

Maréchal, J., 1906. Sur l'Ovogénèse des Sélaciens et de quelques autres Chordates. La Cellule, XXIV.

McClendon, J. F., 1910. On the Effect of External Conditions on the Reproduction of Daphnia. Am. Nat., XLIV.

McClung, C. E., 1902. The Accessory Chromosome-Sex Determinant? Biol. Bull., III.

McClung, C. E., 1902. Notes on the Accessory Chromosome. Anat. Anz., XX.

McClung, C. E., 1905. The Chromosome Complex of Orthopteran Spermatocytes. Biol. Bull., IX.

MCClung, C. E., 1914. A Comparative Study of the Chromosomes in Orthopteran Spermatogenesis. Jour. Morph., XXV.

de Meijere, J. C. H., 1910. Über Jacobsons Züchtungsversuche bezüglich des Polymorphismus von Papilio Memnon. Zeits. Abst. Vererb., III.

de Meijere, J. C. H., 1910. Über getrennte Vererbung der Geschlechter. Biol. Centr., XXX.

de Meijere, J. C. H., 1911. Über getrennte Vererbung der Geschlechter. Arch. Rass. Gesell., VIII.

Meisenheiner, J., 1908. Über den Zusammenhang von Geschlechtsdrüsen und sekundären Geschlechtsmerkmalen bei den Arthropoden. Verh. d. deutsch. Zoöl. Gesell., 1908.

Meisenheiner, J., 1909. Experimentelle Studien zur Soma- und Geschlechtsdifferenzierung, I. Jena, 1909.

Meisenhenmer, J., 1912. Experimentelle Studien zur Soma- und Geschlechtsdifferenzierung. Fests. zum 60 Geburtstage ron Dr. J. W. Spengel, III.

Mendel, G., 1865. Versuche über Pflanzen-hybriden. Verh. d. Naturf. Vereins in Brünn, IV.

Metz, C. W., 1914. An Apterous Drosophila and its Genetic Behavior. Am. Nat., XLVIH.

Metz, C. W., 1914. Chromosome Studies in the Diptera., I. Jour. Exp. Zoöl., XVII.

Mitchell, C. W., and J. H. Powers, 191!. Transmission through the Resting Egg of Experimentally Induced Characters in Asplanchna amphora. Jour. Exp. Zoöl., XVI. 
Moenkhaus, W. J., 1910. Cross Fertilization among Fishes. Proc. Ind. Acad. Sci.

Moenkhaus, W. J., 1911. Effects of Inbreeding, etc., in Drosophila ampelophila. Jour. Morph., XXII.

Montgomery, T. H., 1912. Human Spermatogenesis. Jour. Acad. Nat. Sci. Phila., XV.

Morgan, T. H., 1903. Recent Theories in Regard to the Determination of Sex. Pop. Sci. Mon., 1903.

Morgan, T. H., 1905. An Alternative Interpretation of the Origin of Gynandromorphous Insects. Science, XXI.

Morgan, T. H., 1906. The Male and Female Eggs of Phylloxerans of the Hickories. Biol. Bull., X.

Morgan, T. H., 1907. Experimental Zoölogy. New York.

Morgan, T. H., 1907. The Cause of Gynandromorphism in Insects. Am. Nat., XLI.

Morgan, T. H., 1908. The Production of two kinds of Spermatozoa in Phylloxerans. Proc. Soc. Exp. Biol. and Med., V.

Morgan, T. H., 1909. Sex Determination and Parthenogenesis in Phylloxerans and Aphids. Science, XXIX.

Morgan, T. H., 1909. Hybridology and Gynandromorphism. Am. Nat., XLIII.

Morgan, T. H., 1909. A Biological and Cytological Study of Sex Determination in Phylloxerans and Aphids. Jour. Exp. Zoöl., VII.

Morgan, T. H., 1910. Sex-limited Inheritance in Drosophila. Science, XXXII.

Morgan, T. H., 1910. The Chromosomes in the Parthenogenetic and Sexual Eggs of Phylloxerans and Aphids. Proc. Soc. Exp. Biol. and Med., VII.

Morgan, T. H., 1910. Chromosomes and Heredity. Am. Nat., XLIV.

Morgan, T. H., 1910. The Method of Inheritance of two Sexlimited Characters in the Same Animal. Proc. Soc. Exp. Biol. Med., VIII.

Morgan, T. H., 1911. An Attempt to analyze the Constitution of the Chromosomes on the Basis of Sex-limited Inheritance in Drosophila. Jour. Exp. Zoöl., XI.

Morgan, T. H., 1912. Heredity of Body Color in Drosophila. Jour Exp. Zoöl., XIII. 
Morgan, T. H., 1912. A Modification of the Sex Ratio and of other Ratios in Drosophila through Linkage. Zeits. Abst. Vererb., VII.

Morgan, T. H., 1913. Factors and Unit Characters in Mendelian Heredity. Am. Nat., XLVII.

Morgan, T. H., 1914. Mosaics and Gynandromorphs in Drosophila. Proc. Soc. Exp. Biol. Med., XI.

Morgan, T. H., 1914. The Failure of Ether to Produce Mutations in Drosophila. Am. Nat., XLVIII.

Morgan, T. H., 1914. Sex-limited and Sex-linked Inheritance. Am. Nat., XLVIII.

Morgan, T. H., 1914. Two Sex-linked Lethal Factors in Drosophila and their Influence on the Sex Ratio. Jour. Exp. Zoöl., XVII.

Morgan, T. H., 1914. A Third Sex-linked Lethal Factor in Drosophila. Jour. Exp. Zoöl., XVII.

Morgan, T. H., and C. B. Bridges, 1913. Dilution effects and Bicolorism in Certain Eye Colors of Drosophila. Jour. Exp. Zoöl., XV.

Morgan, T. H., and E. Cattell, 1912. Data for the Study of Sexlinked Inheritance in Drosophila. Jour. Exp. Zoöl., XIII.

Morgan, T. H., and E. Cattell, 1913. Additional Data for the Study of Sex-linked Inheritance in Drosophila. Jour. Exp. Zoöl., XIV.

Morgan, T. H., and H. D. Goodale, 1912. Sex-linked Inheritance in Poultry. Ann. N. Y. Acad. Sci., XXII:

Morgan, T. H., and C. J. Lynch, 1912. The Linkage of Two Factors in Drosophila that are not Sex-linked. Biol. Bull., XXIII.

Morgan, T. H., F. Payne, and E. N. Browne, 1910. A Method to test the Hypothesis of Selective Fertilization. Biol. Bull., XVIII.

Morrill, C. V., 1909. Preliminary note on the Chromosomes in the Oögenesis, Fertilization and Cleavage of certain Hemiptera. Science, XXX.

Morrill, C. V., 1910. The Chromosomes in the Oögenesis, Fertilization and Cleavage of Coreid Hemiptera. Biol. Bull., XIX.

Morris, Margaret, 1914. The Behavior of the Chromatin in Hybrids between ${ }^{-}$Fundulus and Ctenolabrus. Jour. Exp. Zoöl., XVI. 
Monse, M., 1910. Sterility. Am. Nat., XLIV.

Muller, H. J., 1914. The Bearing of the Selection Experiments of Castle and Phillips on the Variability of Genes. Am. Nat., XLVIII.

Muller, H. J., 1914. A New Mode of Segregation in Gregory's Tetraploid Primulas. Am. Nat., XLVIII.

Muller, H. J., 1914. A Gene for the Fourth Chromosome of Drosophila. Jour. of Exp. Zoöl., XVII.

Mulsow, K., 1912. Der Chromosomencyclus bei Ancyracanthus cystidicola Rud. Arch.f. Zellf., IX. 1.

Nabours, R. K., 1914. Studies of Inheritance and Evolution in Orthoptera I. Jour. Genet., III.

Nachtsheim, H., 1912. Parthenogenese, Eireifung und Geschlechtsbestimmung bei der Honigbiene. Sitzungsber. Gesell. Morph. u. Phys. München.

Newman, H. H., 1907. Spawning Behavior and Sexual Dimorphism in Fundulus heteroclitus and Allied Fish. Biol. Bull., XII.

Newman, H. H., 1908. A Significant Case of Hermaphroditism in Fish. Biol. Bull., XV.

Newman, H. H., and J. T. Patterson, 1909. A Case of Normal Identical Quadruplets in the Nine-banded Armadillo. Biol. Bull., XVII.

Newman, H. H., and J. T. Patterson, 1910. The Development of the Nine-banded Armadillo, etc. Jour. Morph., XXI.

Newman, H. H., and J. T. Patterson, 1911. The Limits of Hereditary Control in Armadillo Quadruplets. Jour. Morph., XXII.

Newana, H. H., 1914. Modes of Inheritance in Teleost Hybrids. Jour. Exp. Zoöl., XVI.

Nilsson-Ehle, H., 1908. Einige Ergebnisse von Kreuzungen bei Hafer und Weizen. Botaniska Notiser.

Payne, F., 1912. A Further Study of the Chromosomes of the

Reduviidæ, etc. Jour. Morph., XXXIII.

Payne, F., 1912. The Chromosomes of Gryllotalpa borealis. Arch.f. Zellf., IX.

J'E.ARL, M. and R., 1908. On the Relation of Race Crossing to the Sex Ratio. Biol. Bull., XV.

Pearl, R., 1912. The Mode of Inheritance of Fecundity in the Domestic Fowl. Jour. Exp. Zoöl., XIII. 
Pearl, R., and H. M. Parshley, 1913. Data on Sex Determination in Cattle. Biol. Bull., XXIV.

Plate, L., 1913. Vererbungslehre. Leipzig.

Phillips, J. C., 1914. A Further Study of the Size Inheritance in Ducks with Observations on the Sex Ratio of Hybrid Birds. Jour. Exp. Zoöl., XVI.

Punnett, R. C., 1903. On Nutrition and Sex Determination in Man. Proc. Cambr. Phil. Soc., XII.

Punnett, R. C., 1906. Sex Determination in Hydatina, with some

Remarks on Parthenogenesis. Proc. Roy. Soc., LXXVIII.

Punnett, R. C., 1909 On the Alleged Influence of Lecithin upon the Determination of Sex in Rabbits. Proc. Camb. Phil. Soc., XV.

Punnett, R. C., 1910. "Mimicry" in Ceylon Butterflies, etc. Spol. Zeyl., VII.

Punnett, R. C., 1911. Mendelism.

Punnett, R. C., 1912. Inheritance of Coat Color in Rabbits. Jour. Genet., II.

RAWLs, E., 1913. Sex Ratios in Drosophila ampelophila. Biol. Bull., XXIV.

Richardson, C. IV., 1914. A Preliminary Note on the Genetics of Fragaria. Jour. Genet., III.

Riddle, O., 1912. Preliminary Chemical Studies on Male and Female Producing Eggs of Pigeons. Science, XXXV.

SAfir, S. R., 1913. A New Eye Color Mutation in Drosophila and its Mode of Inheritance. Biol. Bull., XXV.

Saunders, E. R., 1911. Further Experiments on the Inheritance of

"Doubleness" and Other Characters in Stocks. Jour. Genet., I. Saunders, E. R., 1911. Studies in the Inheritance of Doubleness in Flowers. I. Petunia. Jour. Genet., I.

Seiler, J., 1913. Das Verhaltung der Geschlectschromosomen bei Lepidopteren. Zoül Anz., XLI.

Shearer, C., 1912. The Problem of Sex Determination in Dinophilus gyrociliatus. Q.J.M.S., LVII.

Shearer, C., IT. de Morgan, and H. M. Fuchs, 1912. On Paternal Characters in Echinoid Hybrids. Q. J. M. S., LVIII.

Shull, A. F., 1910. Studies in the Life Cycle of Hydatina senta. Jour. Exp. Zoöl., VIII.

Shull, A. F., 191j. Inheritance in Hydatina senta, II. Characters 
of the Females and their Parthenogenetic Eggs. Jour. Exp. Zoöl., XVIII.

Shull, G. H., 1908. The Composition of a Field of Maize. Am. Breeders' Assoc., IV.

Shull, G. H., 1909. The "Presence and Absence" Hypothesis. Am. Nat., XLIII.

Shull, G. H., 1909. A Pure Line Method in Corn Breeding. Am. Breed. Ass., V.

Shull, G. H., 1910. Hybridization Methods in Corn Breeding. Am. Breeder's Mag., I.

Shull, G. H., 1910. Inheritance of Sex in Lychnis. Bot. Gaz., XLIX.

Shull, G. H., 1911. Reversible Sex-mutants in Lychnis dioica. Bot. Gaz., LII.

Shull, G. H., 1912. "Genotypes," "Biotypes," "Pure Lines," and "Clones." Science, XXXV.

Shull, G. H., 1912. Hermaphrodite Females in Lychnis dioica. Science, XXXVI.

Shull, G. H., 1914. Duplicate Genes for Capsule Form in Bursa bursa-pastoris. Zeits. Abst. Vererb., XII.

Surth, G., 1910. Studies in the Experimental Analysis of Sex. Parts 1 and 2. Q.J.M. S., LIV.

Sirith, G., 1910. Studies in the Experimental Analysis of Sex. Parts 3 and 4. Q. J. M. S., LV.

Suith, G., 1911. Studies in the Experimental Analysis of Sex. Part 5. Q. J. M. S., LVI.

Smith, G., 1911. Studies in the Experimental Analysis of Sex. Part 6. Q. J. M. S., LVII.

Sirth, G., 1911. Studies in the Experimental Analysis of Sex. Part 7. Q. J. M. S., LVII.

Spenaxx, H., 1895. Zur Entwicklung des Strongylus paradoxus. Zoöl. Jahrb., Anat. Abt., VIII.

Spillian, W. J., 1908. Spurious Allelomorphism. Results of Recent Investigations. Am. Nat., XLII.

Spillmax, W. J., 1909. Barring in Barred Plymouth Rocks. Poultry, V.

Standfuss, M., 1896. Handbuch der paläarktischen Grosschmetterlinge. Jena. 
Standfuss, M., 1910. Chaerocampa elpenor und einige Mitteilungen über Aglia tau. Iris, XXIV.

Staples-Browx, R., 1912. Second Report on the Inheritance of Color in Pigeons, with Special Reference to Sex-limited Inheritance.

Stevens, N. M., 1905. Studies in Spermatogenesis with Especial Reference to the "Accessory Chromosome." Carnegie Inst., Wash., pub. 36.

Stevens, N. M., 1908. A Study of the Germ Cells of Certain Diptera. Jour. Exp. Zoöl., V.

Stevens, N. M., 1911. Heterochromosomes in the Guinea-pig. Biol. Bull., XXI.

Sturtevant, A. H., 1912a. An Experiment Dealing with Sex Linkage in fowls. Jour. Exp. Zoöl., XII.

Sturtevant, A. H., 1912b. Is there Association between the Yellow and Agouti Factors in Mice? Am. Nat., XLVI.

Sturtevant, A. H., 1913a. The Linear Arrangement of Six Sexlinked Factors in Drosophila, etc. Jour. Exp. Zoöl., XIV.

Sturtevant, A. H., 1913b: The Himalayan Rabbit Case, with Some

Considerations on Multiple Allelomorphs. Am. Nat., XLVII.

Sturtevant, A. H., 1913c: A Third Group of Linked Genes in

Drosophila ampelophila. Science, XXXVII.

Sturtevant, A. H., 1914. Linkage in the Silkworm Moth. Am. Nat., XLVIII.

Sturtevant, A. H., 1915. No Crossing over in the Female of the Silkworm Moth. Am. Nat., XLIX.

Sturtevant, A. H., 1915. The Behavior of the Chromosomes as Studied through Linkage. Zeits Abst. Vererb., XIII.

TaxakA, Y., 1913. A Study of Mendelian Factors in the Silkworm, Bombyx mori. Jour. Coll. Agr., Tohoku Imp. Uni., Sapporo, Japan, V.

TANaka Y., 1913. Gametic Coupling and Repulsion in Silkworms. Jour. Coll. Agr., Sapporo, Japan, V.

Taxaka, Y., 1914. Sexual Dimorphism of Gemetic Series in the Reduplication. Trans. Sapporo Nat. His. Soc., V.

TANakA, Y., 1914. Further Data on the Re-duplication in Silkworms. Jour. Coll. Agr., Sapporo, Japan, VI.

Thousen, E., 1911. Die Differenzierung des Geschlechts und das 
Verhältnis der Geschlechter beim Hühnchen. Arch. Entw.mech. der Org., XXXI.

Tennent, D. H., 1911. A Heterochromosome of Male Origin in Echinoids. Biol. Bull., XXI.

Tennent, D. H., 1912. Studies in Cytology, I and II. Jour. Exp. Zoöl., XII.

Tower, W. L., 1906. An Investigation of Evolution in Chrysomelid Beetles of the Genus Leptinotarsa. Carnegie Inst. Wash., pub. 48.

Tower, W. L., 1910. The Determination of Dominance and the Modification of Behavior in Alternative (Mendelian) Inheritance, by Conditions Surrounding or Incident upon the Germ Cells at Fertilization. Biol. Bull., XVIII, also XX.

Toyama, K., 1906. On the Hybridology of the Silkworm. Report Sericultural Assoc., Japan, May, 1906.

Toyama, K., 1906. Studies on the Hybridology of Insects, I. On Some Silkworm Crosses, with Special Reference to Mendel's Law of Heredity. Bull. Coll. Agr., Tokyo Imp. Uni., VII.

Toyama, K., 1912. On Certain Characteristics of the Silkworm apparently Non-mendelian. Biol. Cent., XXXII.

Trow, A. H., 1913. On the Inheritance of Certain Characters in the Common Groundsel-Senecio vulgaris-and its Segregates. Jour. Genet., II.

Trow, A. H., 1913. Forms of Reduplication-Primary and Secondary. Jour. Genet., II.

v. Tschermak, A., 1910. Über den Einfluss der Bastardierung auf Form, Farbe und Zeichnung von Kanarieneiern. Biol. Centr., XXX.

v. Tschermak, A., 1912. Über Veränderung der Form, Farbe und Zeichnung von Kanarieneiern durch Bastardierung. Arch. $f$. Gesell. Phys., CXLVIII.

v. Tschermak, E., 1908. Der moderne Stand des Vererbungsproblems. Arch. Rass. und Gesell., V.

de Vilmorin, P., and W. Bateson, 1911. A Case of Gametic Coupling in Pisum. Proc. Roy. Soc., B, LXXXIV.

de Vries, H., 1901. Die Mutationstheorie. Leipzig.

DE Vries, H., 1908. Über die Zwillingsbastarde von Enothera nanella. Ber. deutsch. Bot. Gesell., XXVI a. 
DE VRies, H., 1908. Bastarde von Enothera gigas. Ber. deutsch. Bot. Gesell., XXVI $a$.

de Vries, Hugo, 1909. On Triple Hybrids. Bot. Gaz., XLIX.

DE VRIES, H., 1911. Über doppeltreziproke Bastarde von CEnothera biennis und O. muricata. Biol. Centr., XXXI.

Weisman, August, 1913. Vorträge über Deszendenztheorie. Jena, 1913.

Wheeler, W. M., 1903. The Origin of Female and Worker Ants from the Eggs of Parthenogenetic Workers. Science, XVIII.

Wheeler, W. M., 1910. The Effects of Parasitic and Other Kinds of Castration in Insects. Jour. Exp. Zoöl., VIII.

Wheeler, W. M., 1910. A Gynandromorphous Mutillid. Psyche, XVII.

Wheeler, W. M., 1914. Gynandromorphous Ants, Described during the Decade, 1903-1913. Am. Nat., XLVIII.

Whitney, D. D., 1912. Reinvigoration Produced by Cross Fertilization in Hydatina senta. Jour. Exp. Zoöl., XII.

Whitney, D. D., 1914. The influence of Food in Controlling Sex in Hydatina senta. Jour. Exp. Zoöl., XVII.

Wilson, E. B., 1899. The Cell in Development and Inheritance. New York.

Wilson, E. B., 1905. Studies on Chromosomes, I and II. Jour. Exp. Zoöl., II.

Wilson, E. B., 1906. Studies on Chromosomes, III. Jour. Exp. Zoöl., III.

Wilson, E. B., 1909. Studies on Chromosomes, IV and V. Jour. Exp. Zoöl., VI.

Wilson, E. B., 1909. Recent Researches on the Determination and Inheritance of Sex. Science, XXIX.

Wilson, E. B., 1909. Secondary Chromosome Couplings and the Sexual Relations in Abraxas. Science, XXIX.

Wilson, E. B., 1910. Note on the Chromosomes of Nezara. Science, XXXI.

Wilson, E. B., 1910. The Chromosomes in Relation to the Determination of Sex. Sci. Progr., XVI.

Wilson, E. B., 1910. Studies on Chromosomes, VI. Jour. Exp. Zoöl., IX.

Wilson, E. B., 1911. Studies on Chromosomes, VII. Jour. Morph., XXII. 
Wilson, E. B., 1911. The Sex Chromosomes. Arch. Mikr. Anat., LXXYll.

Wilson, E. B., 1912. Studies on Chromosomes, VIII. Jour. Exp. Zoöl., XIII.

Wilsox, E. B., 1912. Some Aspects of Cytology in Relation to the Study of Genetics. Am. Nat., XLVI.

Wilson, E. B., 1914. Croonian Lecture: The Bearing of Cytological Research on Heredity. Proc. Roy. Soc., LXXXVIII.

Woltereck, R., 1911. Über Veränderung der Sexualität bei Daphniden. Leipzig, 1911.

Woodruff, L. L., 1905. An Experimental Study of the Life History of Hypotrichous Infusoria. Jour. Exp. Zoöl., II.

Woodruff, L. L., 1908. The Life Cycle of Paramæcium when Subjected to a Varied Environment. Am. Nat., XLII.

Woodruff, L. L., 1914. On So-called Conjugating and Non-conjugating Races of Paramæcium. Jour. Exp. Zoöl., XVI.

Woodruff, L. L., and Rhoda Erdmann, 1914. A Normal Periodic Reorganization Process without Cell Fusion in Paramæcium. Jour. Exp. Zoöl., XVII.

Wright, Sewall, 1914. Duplicate Genes. Am. Nat., XLVIII. 
INDEX 



\section{INDEX}

A

Abnormal abdomen, 39-41, 47

Abnormal venation, 195-196

Abraxas, 70, 78-79, 83-88, 153-154

Age, 42

Altenburg, 191

Amitosis, 118

Andalusian fowl, 28-29

Antirrhinum, 69, 138

Aphids, 97

Arc wings, 37

Ascaris, 79, 119, 129-131

B

Back cross, 50

Baltzer, 96-97, 114-117, 121

Band, 206

Bar eye, 29-30, 58-59, 62-64, 232

Bateson, 5, 74-76, 173, 214-216

Batracoseps, 123-125, 132

Baur, 38, 138-139, 157, 233

Beaded wing, 194-195, 232

Beans, 159, 204-205, 213

Belling, 190

van Beneden, 129

Bierens de Haans, 110

Bifid wings, 64

Biston, 144-145

Black color, 37, 42, 48-53, 181-182, 233

Bonellia, 96-97

Boveri, 110-113, 119

Bow wings, 37

Brauer, 129
Bryonia, 79

Bursa, 175-178

C

Canaries, 70, 79

Carothers, 140

Castle, 187-188, 190, 196-202, 205

Cat, 70, 79, 83

Cattle, 222

Cherry eyes, 164-166, 233

Chiasmatype, 132-134

Chickens (see Fowls).

Chlorophyll grains, 137-139

Chromosomes, 2, 7-8

Club, 32-34

Color blindness, 83

Columbine, 157

Corn, 26, 161-164, 179, 188-190

Correns, 137-138

Cotton, 26 .

Coupling, 5

Cream color, 203

Crossing over, 48-71, 131-135

Ctenolabrus, 121

Cuénot, 159, 190

Cumulative factors, 174

D

Davenport, 190, 212

Dederer, 90

Dexter, 194-195

Differentiation, 43-45

Dominance, 31-32 
Doncaster, 83-88, 90, 121, 144-145, 153-154

Driesch, 113

Drosophila, 5-26, 29-35, 37-43, 45-70, 78-83, 90-92, 105, $132,134,148-153,154-$ $157, \quad 164-167, \quad 173-174$, 181-182, 191-196, 203,

Ducks, 79 205-209, 229-234

Dunaliella, 97

\section{E}

East, 179, 183-185, 189-190

Ebony color, 13, 21-25, 37, 167, 181-182, 233

Emerson, 159, 161, 164, 170, 190

Environment, 38-42

Eosin eyes, 155-156, 165-166, 233

Evening primrose (see Enothera).

Eye color, 208-209

Eyeless, 13-14, 25, 233

F

Facet, 38

Factors, 3

Fantails, 186-187

Faust, 106

Federley, 121, 141-144

Formulæ, 233-235

Four o'clock, 26, 27-28, 137-138

Fowls, 28-29, 36, 70-73, 79, 90, 179, 216-219

Fractionation, 214-216

Fringed wings, 37

Fundulus, 121

G

Gates, 146

Gregory, 147-148

Hæmophilia, 83

Hagedoorn, 190

Hayes, 190

Helix, 26

Herbst, 110, 116-117, 121

Heribert-Nilsson, 190

Hertwig, G., 121

Hertwig, O., 129

Hertwig, P., 121

Hipponoë, 116

Hoge, 41

Holmes, 212

Hurst, 212

Hybrids, 120-121, 141-146

Hydatina, 97-99

\section{I}

Ids, 225

Inhibitors, 222

Interference, 64

J

Janssens, 123-125, 132-134

Jaunty wings, 37

Johannsen, 190, 204-205, 213

K

Kajanus, 190

L

Leptinotarsa, 26, 43-44

Lethal factor, 105, 233

Linkage, 5

Lock, 5

Lutz, A. M.,146

Lutz, F. E., 195-196 
Lychnis, 7, 79, 138, 159

Lymantria, 70

\section{MI}

MacDowell, 185, 187, 190

Man, 26, 79, 83, 212

Maréchal, 125-127

Maturation, 59-60, 122-131

Melandrium (see Lychnis).

Mendel, 1, 30, 227

Menidia, 121

Metapodius, 120, 140

Miniature wings, 30, 58, 62-63, 233

Mirabilis (see Four o'clock).

Moenkhaus, 120

Morris, 121

Mouse, 26, 45, 159, 161, 179-180, 190

Mutations, 35, 205-207

N

Nabour, 162-163

Nicotiansa, 26, 183-185, 190 (see Tobacco).

Nightshade, 26

Nilsson-Ehle, 174, 178-179, 190

Non-disjunction, 7, 80, 149-154

$\mathrm{O}$

Oats, 179,190

Enothera, 26, 146-147

\section{$\mathrm{P}$}

Paratettix, 162-163

Pea, 1, 26, 69

Peach eyes, 166

Pearl, 190

Pelargonium, 138-139
Phillips, 190, 196-197, 201

Phragmatobia, 88-90

Phylloxera, 99-105

Pigeons, 70, 186-187

Pink eyes, 37, 42, 45, 47, 166, 173, 233

Potato beetle (see Leptinotarsa).

Præformation, 223

Presence and absence, 216-222

Primrose (see Primula).

Primula, 38, 69, 147-148

Pristiurus, 125-127

Punnett, 5, 76

Pure line, 213

Purple eyes, 42, 45

Pygæra, 141-144

R

Rabbits, 157-158, 185-188, 190

Rats, 196-202

Reduplicated legs, 41-42

Reduplication, 74-77

Rosenberg, 121

Rough, 38

Roux, 77, 224

Ruby eyes, 37

Rudimentary wings, 34-35, 38, 209, 233

\section{S}

Sable color, 37, 63-64

Sea urchins, 110-118

Segregation, 3

Seiler, 86, 88-90

Sex chromosomes, 14-16, 78-90

Sex limited, 94-95

Shull: A. F., 97

Shull, G. H., 159, 175-17S, 190

Silkworm, 37, 69, 136-137, 159-160

Snapdragon (see Antirrhinum). 
Sooty color, 166-167

Sphærechinus, 114-116

Spiders, 79

Spot, 167, 233

Spread wings, 37

Stature, 173

Stevens, 90

Stocks, 69

Streak, 207

Strongylocentrotus, 114-116

Sutton, 4

Sweet peas, $5,36,69,174-175$

\section{$\mathrm{T}$}

Tammes, 190

Tanaka, 69, 159

Tennent, 116, 121

Tetrad, 128

Thomas, 146

Tobacco (see Nicotiana).

Tomato, 26

Tower, 43-44

Toxopneustes, 116

Trefoil, 206

Trident, 205-207

Trow, 75

Truncate wings, 34, 38, 191-194

Tschermak, 190
Unit character, 210

V

Vermilion eyes, 45, 63-64, 233

Vestigial wings, 8-12, 21-25, 48-53, 233

de Vries, 226

\section{IV}

Weismann, 77, 211, 223-225

Wheat, 26, 179, 190

White eyes, 16-20, 31, 45, 47, 54$59,62-64,82$, 149-151, 155-156, 164-166, 208, 233

- Whitney, 97

IVilson, 120, 140

\section{Y}

Yellow color, 54-58, 64, 156, 167, 233

Z

Zeleny, 106 


1 

